\title{
Numerical and Experimental Investigation of Ribbon Floating Bridges
}

by

Daniel Van-Johnson

A Thesis submitted to the Faculty of Graduate and Postdoctoral Affairs in partial fulfillment of the requirements for the degree of Master of Applied Science

in

Civil Engineering

Carleton University

Ottawa, Ontario

(C) 2018, Daniel Van-Johnson 


\begin{abstract}
Floating bridges are temporary or permanent structures that utilize the buoyancy of water to resist loads imposed by traversing vehicles and can be used for emergency water crossings or during war. Due to the advent of heavier and faster vehicles, coupled with the dearth of analysis and design information on ribbon floating bridges, it is important to investigate the behaviour of these bridges under various vehicle crossing conditions.
\end{abstract}

This study examines the dynamic behaviour and potential to increase the vehicle-crossing capacity of a hinge-connected ribbon floating bridge. A finite element program was developed to simulate the vertical displacement response of the floating bridge when subjected to single or multiple vehicles of varying weight, speed, and inter-vehicle spacing. A 1/25-scale experimental model was constructed to physically investigate bridge behaviour and to validate the developed finite element program for further parametric analyses.

For two-vehicle crossings, the experimental and numerical results showed that the magnitude of the first peak vertical midpoint displacement of the ribbon floating bridge primarily depended on vehicle speed, with the displacement value equal to that caused by a single vehicle if the inter-vehicle spacing was greater than one-half the bridge length. The second peak depended on both vehicle speed and spacing and was influenced by the free vibration of the bridge after passage of the first vehicle.

To study the relationship between maximum midpoint displacement and vehicle weight, a Speed Ratio was defined which relates the frequency of vehicle induced loads to the natural frequency of vibration of the floating bridge. The maximum midpoint 
displacement was found to be linearly proportional to vehicle weight, the rate of increase being dependent on the weight and Speed Ratio of the traversing vehicle. An analytical equation based on the Speed Ratio was proposed to calculate the maximum displacement that would occur with vehicle weight increase.

The overall bridge capacity in a state of dynamic equilibrium was finally investigated by subjecting the bridge to ten consecutive vehicles. For optimum bridge capacity, ideal inter-vehicle spacings were proposed for each specified vehicle speed to minimize vertical bridge displacements. 


\section{Acknowledgements}

Completing a research thesis is not an easy undertaking, so I would like to take this opportunity to thank all those who contributed to this endeavor.

First, I would like to thank the almighty God for giving me the strength to see it through. My deepest gratitude goes to my supervisors Professor Abass Braimah and Professor A. O. Abd El Halim for their essential guidance throughout this research work.

My sincere thanks go to my parents and siblings Bridgette and Sylvester Van-Johnson for enduring my isolation during this period. My deep gratitude goes to my late mentor and friend Ing. Anthony Mensah Bonsu for his fatherly advice and wholistic insight. May his soul rest in perfect peace.

I also want to thank all my friends and colleagues especially Theophilus Tettey, Conrad Kyei, Mr and Mrs Kwaffo, Eddie Ameh, Ryan Brault, Brandon Robinson, Igboke Chinecherem, and all others who have contributed in one way or another to this undertaking.

Finally, special recognition goes to Alexander Mensah Bonsu and Paul Honyenuga for their brotherly support, Professor John Gales of the Department of Civil Engineering for his empathy which is second to none, and Tanisha Williams who was instrumental in inspiring the conclusion to this work. 


\section{Table of Contents}

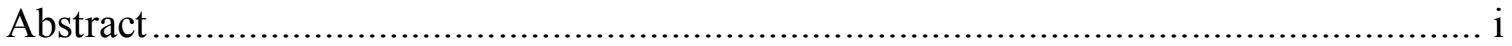

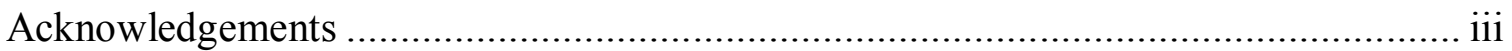

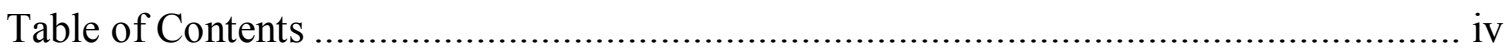

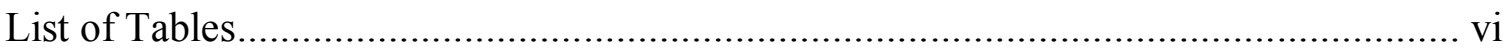

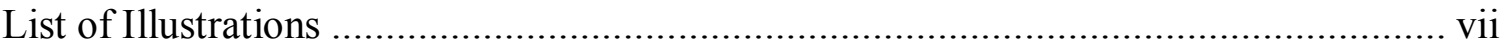

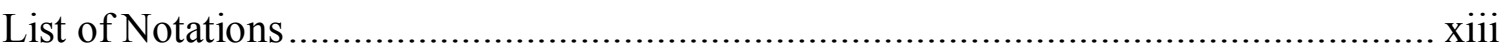

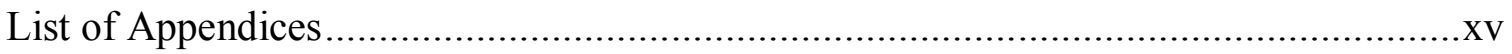

1 Chapter: Introduction ........................................................................................ 1

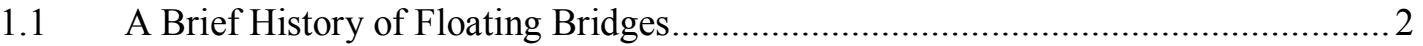

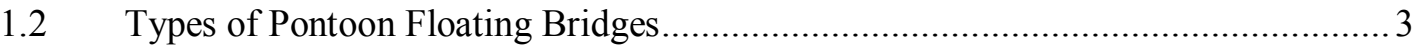

$1.3 \quad$ Main Loads Acting on Floating Bridges .......................................................... 8

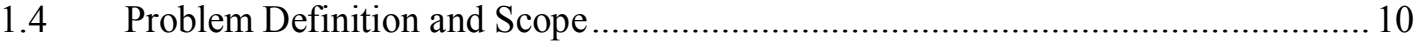

1.5 Previous Work and Scope of Current Study …………….................................... 13

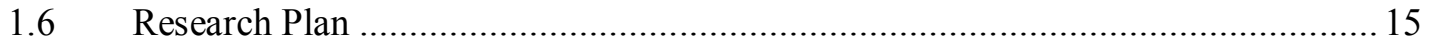

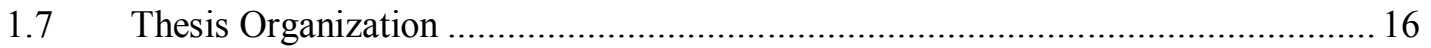

2 Chapter: Literature Review ………………………............................................ 18

2.1 Floating Bridge Analysis Models ………………….................................... 19

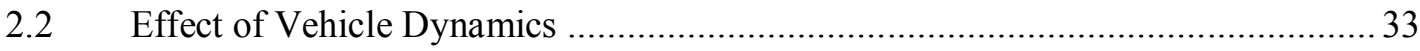

2.3 Main Findings from the Literature Review …………………………………........ 35

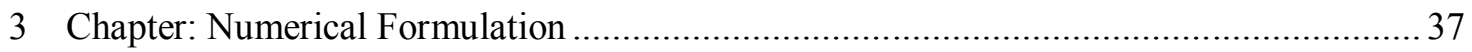

3.1 Structural Response of Ribbon Floating Bridges..................................................... 38

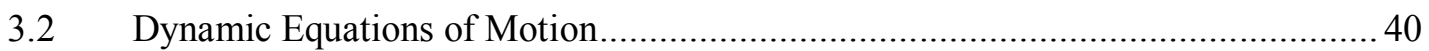

3.3 Beam Element in Finite Element Analysis .......................................................... 41

3.4 Finite Element Analysis of Floating Bridges....................................................... 42 


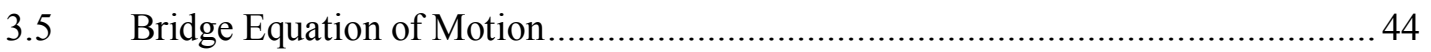

3.6 Dynamic Equation of Motion for Bridge Subjected to Double-axle Vehicle.......... 50

3.7 Dynamic Equation of Motion for Bridge Subjected to Two or More Successive

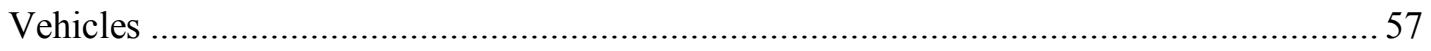

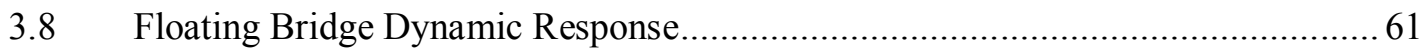

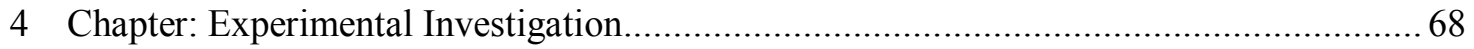

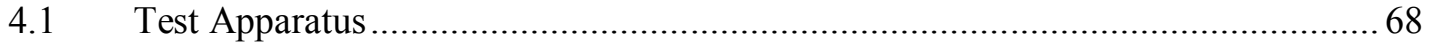

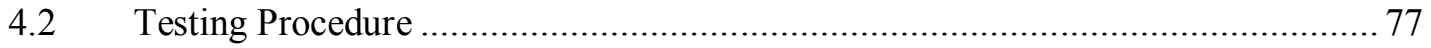

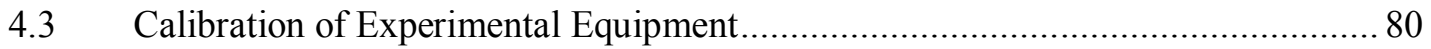

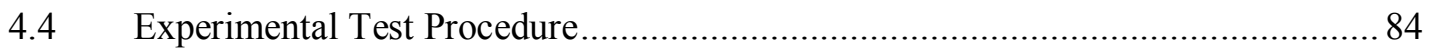

5 Chapter: Results and Discussion of Experimental and Numerical Study....................... 87

5.1 Results and Discussion of Experimental Test Program and Validation of Finite

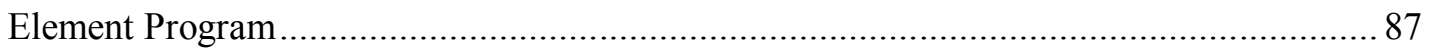

5.2 Numerical Parametric Studies for the Dynamic Response of a Hinge-Connected

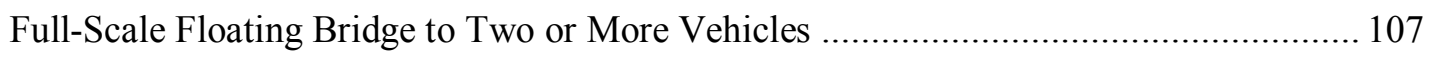

6 Chapter: Conclusions and Recommendations for Future Work ............................... 124

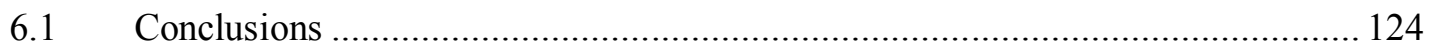

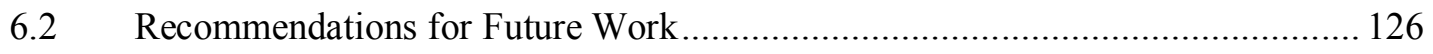

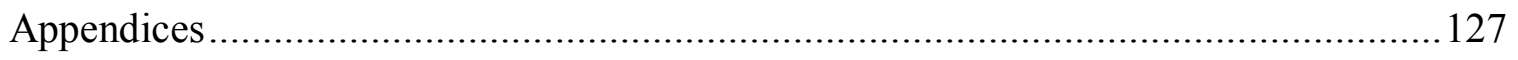

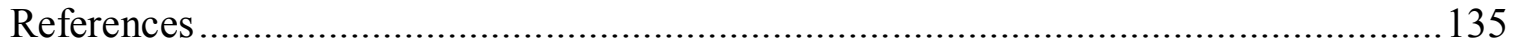




\section{List of Tables}

Table 1-1: Vehicle Design Crossing Speeds (Hornbeck et al., 2005) 13

Table 4-1: Vehicle Test Weights 76

Table 4-2: Vehicle Test Speeds

Table 4-3: Inter-vehicle Spacing $\quad 80$

Table 4-4: Final Velocity-Voltage Calibration Factors for different Test Weights 83

Table 5-1: Model Ribbon Pontoon Bridge Properties 87

Table 5-2: Maximum Midpoint Displacements for 2.56-kg Vehicles spaced at $1.6 \mathrm{~m} \quad 92$

Table 5-3: Maximum Midpoint Displacements for 2.56-kg Vehicles spaced at $1.4 \mathrm{~m} \quad 92$

Table 5-4: Maximum Midpoint Displacements for 2.56-kg Vehicles spaced at $1.4 \mathrm{~m} \quad 93$

Table 5-5: Maximum Midpoint Displacements for 2.56-kg Vehicles spaced at $1.0 \mathrm{~m} \quad 93$

Table 5-6: Maximum Midpoint Displacements for 2.56-kg Vehicles spaced at $0.8 \mathrm{~m} \quad 93$

Table 5-7: Maximum Midpoint Displacements for 2.56-kg Vehicles spaced at $0.6 \mathrm{~m} \quad 94$

Table 5-8: Maximum Midpoint Displacements for 2.56-kg Vehicles spaced at $0.4 \mathrm{~m} \quad 94$

Table 5-9: Maximum Single Vehicle Displacements $(2.56 \mathrm{~kg})$

Table 5-10: Numerical vs Experimental Results for $2.56 \mathrm{~kg} \quad 105$

Table 5-11: Input Properties of Ribbon Floating Bridge for Full Scale Parametric Study

Table 5-12: Floating Bridge Vibration Frequencies 109

Table 5-13: Maximum Displacement to Weight Gradient at various Speed Ratios 113

Table 5-14: Optimum Inter-Vehicle Spacing $\quad 120$ 


\section{List of Illustrations}

Figure 1-1: Folding Boat Equipment, Mk. III (United States War Department, 1942) ......3

Figure 1-2: Streamlined Discrete Pontoons - West India Quay Floating Bridge, London, England (structurae.com) …………….................................................................

Figure 1-3: Bergsoysund Floating Bridge, Norway (bridgeinfo.net) ….............................5

Figure 1-4: Lace V. Murrow Bridge, Washington, USA

(https://www.jinlisting.com/listing/lacey-v-murrow-memorial-bridge/) .........................6

Figure 1-5: Interior and Ramp Modules of a Ribbon Floating Bridge (http://www.army-

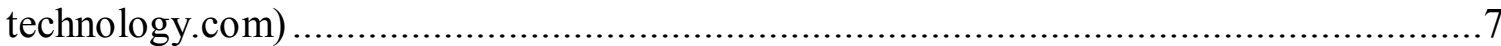

Figure 1-6: Maximum Midpoint Displacements due to Single and Double Axle Vehicle

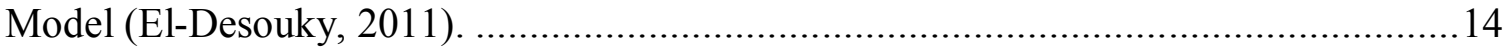

Figure 2-1: Variation of Dynamic Amplification Factor $(\phi D)$ with Moving Load Speed for varying dimensionless Foundation Stiffness (kf) (Thambiratnam \& Zhuge, 1996)....20 Figure 2-2: Separated pontoon bridge computational model (Seif \& Inoue, 1998)..........20 Figure 2-3: Influence of moving load speed on (a) Maximum heave displacement and (b) Maximum pitch displacement for different moving load speeds (Wu \& Sheu, 1996)......22 Figure 2-4: Illustration of the nonlinear connector (Fu \& Cui, 2012) .............................24 Figure 2-5: Numerical vs Experimental results for midpoint displacement at $3 \mathrm{~m} / \mathrm{s}, 6 \mathrm{~m} / \mathrm{s}$

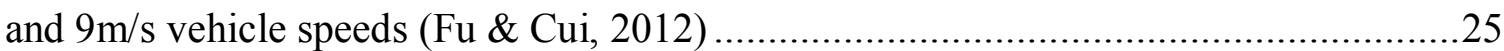

Figure 2-6: Vehicle-structure system: (a) schematic illustration and (b) free body diagram (Neves et al., 2012)

Figure 2-7: Simply supported beam subjected to moving sprung mass (Neves et al., 2012) 
Figure 2-8: Vertical displacement of first sprung mass (Neves et al., 2012).....

Figure 2-9: Dimensionless Basic Natural Vibration Frequency vs Depth to Length Ratio of Continuous Floating Bridge (Fleischer \& Park 2004).........................................28

Figure 2-10: Bridge midpoint displacement versus vehicle position at $10 \mathrm{~m} / \mathrm{s}$ for $6-\mathrm{m}, 9-$

$\mathrm{m}$ and 12-m water depths

Figure 2-11: Half-bonded contact element with a) three, b) two, c) one lift-off point

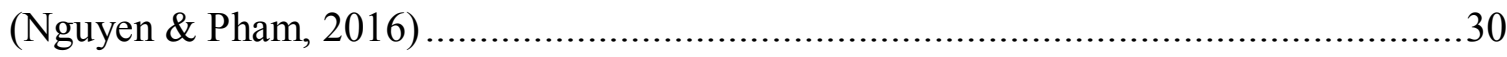

Figure 2-12: Dynamic Modification Factors for different Foundation Stiffness Parameters

(a) $K_{0}=10$, (b) $K_{0}=20$, (c) $K_{0}=30$, (d) $K_{0}=40$. (Nguyen \& Pham, 2016)..................31

Figure 2-13: Comparative Vehicle Model (Zhang et al,, 2010)................................32

Figure 3-1: Pontoon Hinged and Rigid Connection details .......................................39

Figure 3-2: Rigid Connected Bridge Bending Moments (Harre, 2002) .........................40

Figure 3-3: The Beam Element (Logan et al., 2007) .............................................41

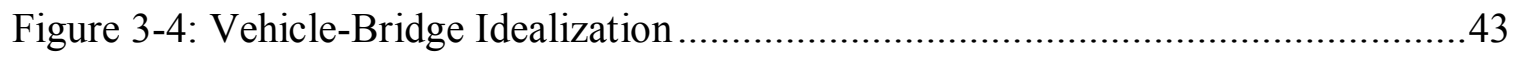

Figure 3-5: Free Body Diagram of vehicle-bridge dynamic forces ..............................52

Figure 3-6: Free Body Diagram of floating bridge traversed by single axle (after Humar

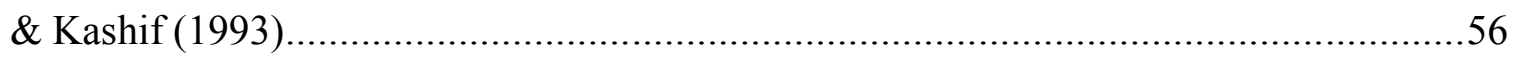

Figure 3-7: Flowchart of MatLab Finite Element Program .......................................67

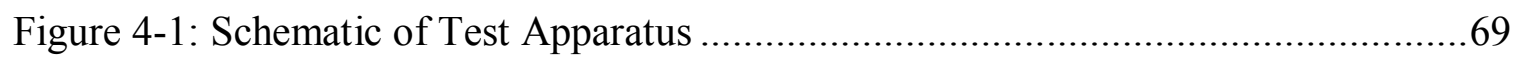

Figure 4-2: Experimental Test Bench........................................................ 70

Figure 4-3: Schematic Layout of the Interior Bay of a Ribbon Floating Bridge

(http://www.army-technology.com) ........................................................ 71

Figure 4-4: Model Pontoon Cross Section (G. Viecili et al., 2014) .............................71 
Figure 4-5: Interlocking grid within pontoons (G. Viecili et al., 2014) ........................72

Figure 4-6: Pontoon hinge connectors (G. Viecili et al., 2014) .................................74

Figure 4-7: Slider and Socket Bridge Supports.................................................... 74

Figure 4-8: Vehicle Polystyrene Guide and LVDTs ........................................... 75

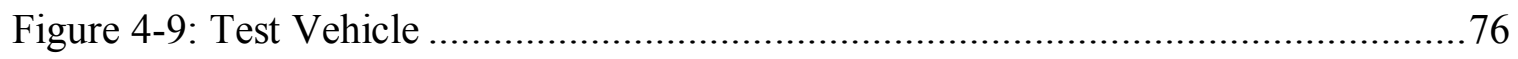

Figure 4-10: Inter-vehicle Connection and Light Gate Trigger ..................................77

Figure 4-11: Rear End of Test Apparatus........................................................... 78

Figure 4-12: Schematic of Floating Bridge Test Apparatus .....................................79

Figure 4-13: Bridge Cross-Section Showing Hinge Connection .................................79

Figure 4-14: LVDT Recording Stations on Model Bridge ...................................... 80

Figure 4-15: Turnkey Potentiometer Calibration Graph ...................................... 81

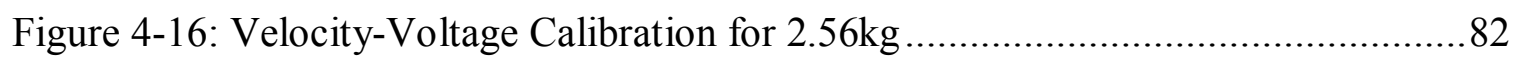

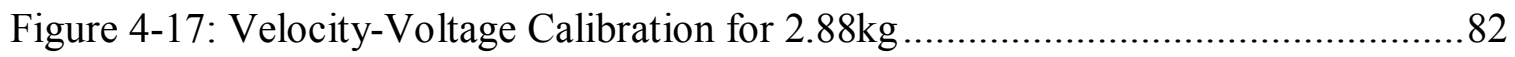

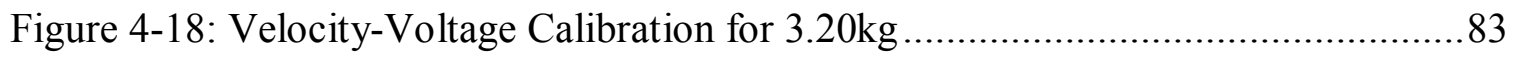

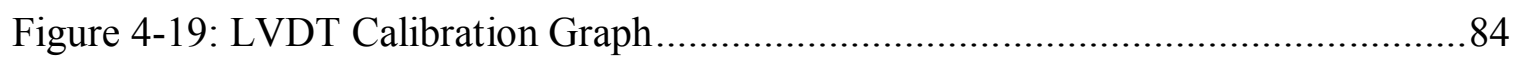

Figure 4-20: Agilent Power Supplies for 30V Ametek Motor (Top) and LVDTs (Bottom)

Figure 5-1: Analysis Model Two Vehicles on Hinge-Connected Bridge.........................88

Figure 5-2: Midpoint displacements of model floating bridge under two 2.56-kg vehicles

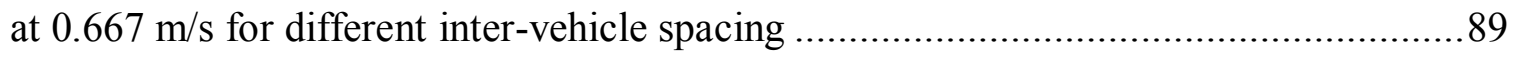

Figure 5-3: Experimental Midpoint Displacements Profiles under Single Vehicle

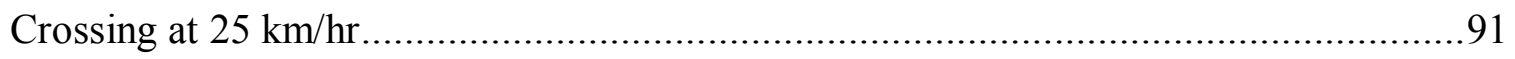


Figure 5-4: Effect of Vehicle Weight on Experimental Maximum Midpoint Displacement

Figure 5-5: Peak 1 Displacement vs Inter-Vehicle Spacing $(2.56 \mathrm{~kg})$.........................96

Figure 5-6: Convergence of Peak 1 Displacement to Single Vehicle Equivalent.............97

Figure 5-7: Midpoint Displacements for single 2.56- $\mathrm{kg}$ vehicle at $0.278 \mathrm{~m} / \mathrm{s} \ldots \ldots \ldots \ldots \ldots . . .98$

Figure 5-8: Influence of Leading Vehicle-Induced Displacements on Peak $2(0.278 \mathrm{~m} / \mathrm{s})$

Figure 5-9: Influence of Leading Vehicle- Induced Displacements on Peak $2(0.333 \mathrm{~m} / \mathrm{s})$

Figure 5-10: Influence of Leading Vehicle- Induced Displacements on Peak $2(0.389 \mathrm{~m} / \mathrm{s})$ 100

Figure 5-11: Influence of Leading Vehicle- Induced Displacements on Peak $2(0.444 \mathrm{~m} / \mathrm{s})$ .100

Figure 5-12: Influence of Leading Vehicle- Induced Displacements on Peak $2(0.500 \mathrm{~m} / \mathrm{s})$ .101

Figure 5-13: Influence of Leading Vehicle- Induced Displacements on Peak $2(0.556 \mathrm{~m} / \mathrm{s})$ .101

Figure 5-14: Influence of Leading Vehicle- Induced Displacements on Peak $2(0.611 \mathrm{~m} / \mathrm{s})$ 102

Figure 5-15: Influence of Leading Vehicle- Induced Displacements on Peak $2(0.667 \mathrm{~m} / \mathrm{s})$ .102

Figure 5-16: Numerical vs Experimental Results for $0.278 \mathrm{~m} / \mathrm{s}$ and $0.333 \mathrm{~m} / \mathrm{s}$ .103 
Figure 5-17: Numerical vs Experimental Midpoint Displacement for $0.389 \mathrm{~m} / \mathrm{s}$ and 0.444

$\mathrm{m} / \mathrm{s}$ 104

Figure 5-18: Numerical vs Experimental Midpoint Displacement for $0.500 \mathrm{~m} / \mathrm{s}$ and 0.556 $\mathrm{m} / \mathrm{s}$ 104

Figure 5-19: Numerical vs Experimental Midpoint Displacement for $0.611 \mathrm{~m} / \mathrm{s}$ and 0.667 $\mathrm{m} / \mathrm{s}$ 105

Figure 5-20: First Three Flexural Mode Shapes of Floating Bridge .109

Figure 5-21: Speed Ratio vs Maximum Midpoint Displacement for a Single Vehicle...111 Figure 5-22: Effect of Vehicle Weight on Maximum Midpoint Displacement for Different Speed Ratios....... .112

Figure 5-23: Comparison of Numerical Results and Sine Function 113

Figure 5-24: Influence of Inter-Vehicle Spacing on Peak 1 Displacements for different Speeds 115

Figure 5-25: Peak 1 and Peak 2 Displacements for different Inter-Vehicle Spacings at $16 \mathrm{~km} / \mathrm{hr}$ and $25 \mathrm{~km} / \mathrm{hr}$ 116

Figure 5-26: Peak 2 Optimum Inter-Vehicle Spacing vs Vehicle Speed 117

Figure 5-27: Superposition of Midpoint Displacements for 50ton Vehicle at 16km/hr..118 Figure 5-28: Bridge Midpoint displacement for 10 consecutive 50-ton vehicles at 16 $\mathrm{km} / \mathrm{hr}$ spaced at $12.9 \mathrm{~m}$. 120

Figure 5-29: Bridge Midpoint displacement for 10 consecutive 50-ton vehicles at 20 $\mathrm{km} / \mathrm{hr}$ spaced at $13.6 \mathrm{~m}$. 121

Figure 5-30: Bridge Midpoint displacement for 10 consecutive 50-ton vehicles at 25 $\mathrm{km} / \mathrm{hr}$ spaced at $16.0 \mathrm{~m}$ 121 
Figure 5-31: Bridge Midpoint displacement for 10 consecutive 50-ton vehicles at 30 $\mathrm{km} / \mathrm{hr}$ spaced at $18.6 \mathrm{~m}$.

Figure 5-32: Bridge Midpoint displacement for 10 consecutive 50-ton vehicles at 35 $\mathrm{km} / \mathrm{hr}$ spaced at $21.1 \mathrm{~m}$. 122

Figure 5-33: Bridge Midpoint displacement for 10 consecutive 50-ton vehicles at 40 $\mathrm{km} / \mathrm{hr}$ spaced at $24.5 \mathrm{~m}$. 123

Figure 5-34: Bridge Midpoint displacement for 10 consecutive 50-ton vehicles at 45 $\mathrm{km} / \mathrm{hr}$ spaced at $27.2 \mathrm{~m}$. 123 


\section{List of Notations}

Below are the main symbols used in the text. All symbols are defined at the time of first use. Matrices are written with square brackets and vectors represented with curly brackets. An overdot represents differential with respect to time and a subscript of comma followed by the spatial coordinate $x$ represents differentiation with respect to $x$.

\begin{tabular}{|c|c|}
\hline$a_{1}$ & $\begin{array}{l}\text { ratio of rear axle distance from vehicle centre of mass to } \\
\text { vehicle inter-axle spacing }\end{array}$ \\
\hline$a_{2}$ & $\begin{array}{l}\text { ratio of front axle distance from vehicle centre of mass to } \\
\text { vehicle inter-axle spacing }\end{array}$ \\
\hline$c_{f}$ & vehicle front axle viscous damping coefficient \\
\hline$c_{r}$ & vehicle rear axle viscous damping coefficient \\
\hline$\{\ddot{D}\},\{\dot{D}\},\{D\}$ & $\begin{array}{l}\text { global acceleration, velocity and displacement vectors of } \\
\text { bridge }\end{array}$ \\
\hline$E$ & elastic modulus \\
\hline$f(\chi)$ & $\begin{array}{l}\text { maximum bridge displacement in metres as a function of } \\
\text { speed ratio for } 75 \text {-ton vehicle }\end{array}$ \\
\hline$F_{c r}, F_{k r}$ and $F_{c f}, F_{k f}$ & rear and front axle dynamic damping and stiffness forces \\
\hline$g$ & acceleration due to gravity \\
\hline$h$ & numerical time-step \\
\hline I & flexural moment of inertia \\
\hline$I_{v}$ & vehicle mass moment of inertia \\
\hline$k_{w}$ & buoyancy force per unit length \\
\hline$k_{f}$ & vehicle front axle stiffness constant \\
\hline$k_{r}$ & vehicle rear axle stiffness constant \\
\hline$L$ & length of beam element \\
\hline $\bar{m}_{a}$ & water added mass per unit length \\
\hline$\left[m^{*}\right],\left[c^{*}\right],\left[k^{*}\right]$ & mass, damping and stiffness interaction coefficient matrices \\
\hline$m_{-} t f$ & vehicle front axle unsprung mass \\
\hline$m_{-} t r$ & vehicle rear axle unsprung mass \\
\hline$m_{-} v$ & vehicle sprung mass \\
\hline$\{N\}$ & $\begin{array}{l}\text { beam shape function vector; beam shape function vector } \\
\text { evaluated at position of vehicle front axle }\end{array}$ \\
\hline$\{N\}_{i}$ & $\begin{array}{l}\text { beam shape function vector evaluated at position of } i^{\text {th }} \\
\text { vehicle front axle }\end{array}$ \\
\hline$\{N\}_{i r}$ & $\begin{array}{l}\text { beam shape function vector evaluated at position of } i^{\wedge} \text { th } \\
\text { vehicle rear axle }\end{array}$ \\
\hline
\end{tabular}




\begin{tabular}{|c|c|}
\hline$\{N\}_{r}$ & $\begin{array}{l}\text { beam shape function evaluated at position of vehicle rear } \\
\text { axle }\end{array}$ \\
\hline$\{P\}$ & bridge global force vector \\
\hline$[k]$ & beam element stiffness matrix \\
\hline$\left[k_{e}\right]$ & bridge local effective stiffness matrix \\
\hline$\left[k_{w}\right]$ & local water buoyancy stiffness matrix \\
\hline$[\mathrm{m}]$ & beam consistent mass matrix \\
\hline$[M],[C],[K]$ & $\begin{array}{l}\text { global mass, damping and stiffness matrices of bridge with } \\
\text { water }\end{array}$ \\
\hline$\left[m_{a}\right]$ & local water added mass matrix \\
\hline$\left[m_{e}\right]$ & local bridge effective mass matrix \\
\hline$\left[M_{G}\right],\left[C_{G}\right],\left[K_{G}\right]$ & $\begin{array}{l}\text { global mass, damping and stiffness matrices of bridge } \\
\text { without water }\end{array}$ \\
\hline$\left[p^{*}\right]$ & vehicle-induced force in bridge local degrees of freedom \\
\hline Peak 1 & $\begin{array}{l}\text { maximum bridge midpoint displacement due to the first of } \\
\text { two vehicles }\end{array}$ \\
\hline Peak 2 & $\begin{array}{l}\text { maximum bridge midpoint displacement due to the second } \\
\text { of two vehicles }\end{array}$ \\
\hline$S$ & vehicle inter-axle spacing \\
\hline$S_{v}$ & inter-vehicle spacing \\
\hline$t$ & elapsed time \\
\hline$T$ & undamped natural period \\
\hline$u(x, t)$ & beam element transverse displacement \\
\hline$v$ & vehicle speed \\
\hline W & vehicle weight \\
\hline$x$ & position along beam element or bridge \\
\hline$\alpha$ & stiffness-proportional damping coefficient \\
\hline$\beta$ & mass proportional damping coefficient \\
\hline$\Delta_{1}, \theta_{1}$ and $\Delta_{2}, \theta_{2}$ & $\begin{array}{l}\text { vertical displacement and counter clockwise rotation at } \\
\text { nodes } 1 \text { and } 2 \text {, respectively }\end{array}$ \\
\hline$\eta$ & vertical bridge displacement under vehicle front axle \\
\hline$\eta_{r}$ & vertical bridge displacement under vehicle rear axle \\
\hline$\xi$ & bridge damping coefficient \\
\hline$\chi$ & vehicle-bridge speed ratio parameter \\
\hline$\psi_{1}, \psi_{2}, \psi_{3}, \psi_{4}$ & $\begin{array}{l}\text { beam element shape functions in degrees of freedom 1,2, } 3 \text {, } \\
\text { and } 4\end{array}$ \\
\hline$\omega$ & undamped natural frequency \\
\hline
\end{tabular}




\section{List of Appendices}

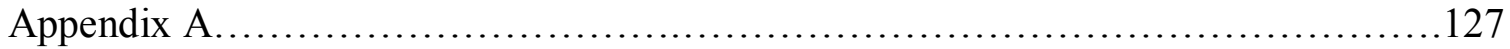

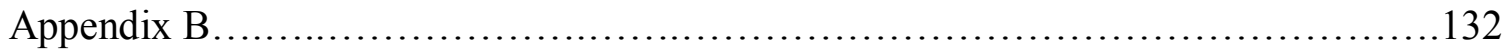

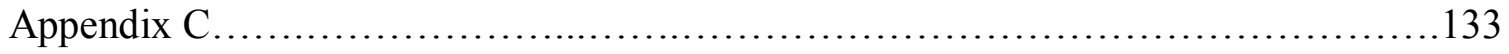




\section{Chapter: Introduction}

Conventional bridges employ different structural forms that best suit the specific situation and site for vehicle crossing. For example arch bridges are used to take advantage of a solid foundation, suspension bridges are usually the most economical solution for extremely long spans $(300 \mathrm{~m}-2000 \mathrm{~m})$, while girder bridges are typically used to cross relatively short spans (Barker \& Puckett, 2013).

Essentially however, all conventional bridge types consist of three main structural components, namely the superstructure which directly receives traffic load, the substructure which transfers load from the superstructure to the third component- the foundation. It is crucial that the bridge foundation be supported on a foundation capable of resisting the applied loading.

There are cases where conventional foundations including pile foundations cannot be used, as in the case of soft lake/river bed material or where the body of water to be bridged is too deep as to make the construction of piers uneconomical, or not feasible (Seif \& Koulaei, 2005). In such a case, a floating pontoon bridge which employs the buoyancy force of displaced water as its foundation may be the most economical or viable solution. Apart from using a floating bridge as a permanent alternative to a conventional bridge, temporary floating bridges are also important in times of emergency where existing bridges maybe damaged beyond use, or simply not available, as in the case of floods. Floating bridges may also be employed in times of war to enable troops to cross a body of water quickly and efficiently. 


\subsection{A Brief History of Floating Bridges}

Floating bridges have been in existence as far back as the $8^{\text {th }}$ century BC in Ancient China. (Needham, 1994). During the Song Dynasty (960-1279), Chinese statesman Cao Cheng wrote about the invention of the floating bridge in the $58^{\text {th }}$ year of Zhou King Nan (257 BC) during the Qin Dynasty. Subsequently, King Yen is said to have "joined boats and made of them a bridge" over the River Wei. The boats were arranged in a row with flat boards laid transversely across them to form the bridge deck, and was used to cross rivers whenever the need arose (Needham, 1994).

In $480 \mathrm{BC}$ during the Greco-Roman era, King Xerxes had two floating bridges constructed across the Hellespont to transport his armies into Europe (Study Group of World Cities, 1998). One of the bridges consisted of 360 galleys and triremes which were anchored to the bottom of the strait. Strong cables were then stretched tight from shore to shore to hold the ships together and accommodate the wooden deck (Bailkey \& Richard, 1992).

Towards the end of the Middle Ages and for most of the modern period, pontoon bridges were mostly used for military purposes, with design efforts in the Early Modern Period focusing on optimizing the shape of the pontoon for maximum buoyancy and stability. A notable example was the development of the Palsey Pontoon in 1817 which featured a split design.

During World War I, trestles were developed to connect the pontoon bridge to river banks. The Folding Boat Equipment III (FBE Mk III), which utilized the trestle design (Figure 1-1), was widely used by the British and American Armies. The folding 
mechanism of military floating bridges was developed in 1928 to enable the efficient transportation of pontoons. During World War II, American Engineers built three main types of pontoon bridges namely the M1938 infantry footbridges, M1938 pontoon bridges, and M1940 treadway bridges, designed to carry troops and vehicles of varying weight (Anderson, 2000).

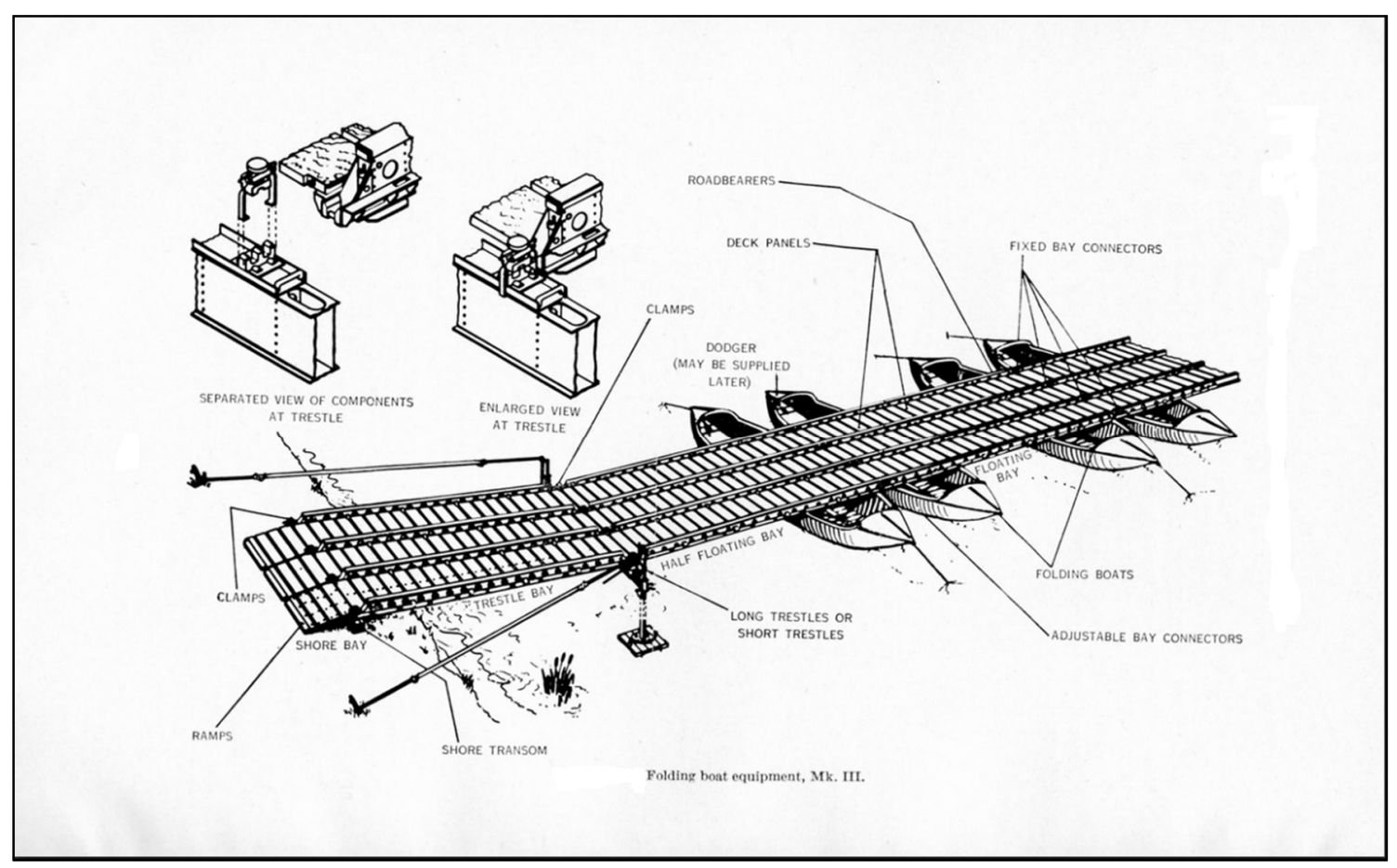

Figure 1-1: Folding Boat Equipment, Mk. III (United States War Department, 1942)

\subsection{Types of Pontoon Floating Bridges}

Pontoon floating bridges can be classified into two general categories based on the configuration of supporting pontoons - separated pontoon floating bridges and continuous pontoon floating bridges (Watanabe \& Utsunomiya, 2003). 


\subsubsection{Separated Pontoon Floating Bridges}

Separated pontoon floating bridges are supported by pontoons spaced at intervals. They are mainly used where gaps are required between bridge supports to accommodate the passage of water borne vessels as in the case of the West India Quay Floating Bridge in London, England (Figure 1-2). In the separated pontoon floating bridge, pontoons are discrete units which have adequate buoyancy to support the bridge under design static and dynamic loads. The pontoons are hollow components made of lightweight reinforced or prestressed concrete, steel, aluminum, or other lightweight composite material. Some pontoons have a streamlined design to minimize drag forces.

Apart from carrying traffic loads, the superstructure of a pontoon bridge is designed to withstand a tolerable amount of differential movement (or displacement) of the pontoon supports. Other examples of Separated Pontoon Floating Bridges are Bergsoysund Bridge at Bergsoyfjord near Kristiansund, Norway (Figure 1-3) and Nordhordland Bridge at Salhus near Bergen, Norway. 


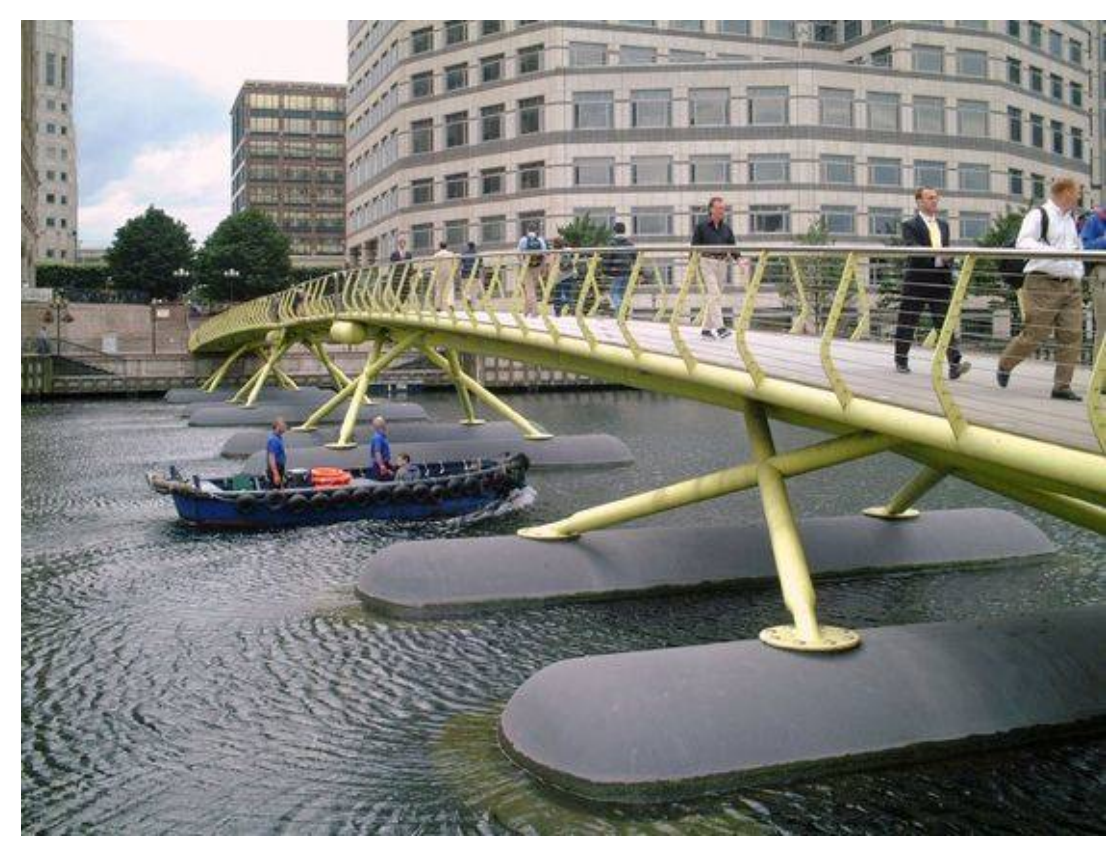

Figure 1-2: Streamlined Discrete Pontoons - West India Quay Floating Bridge, London, England (structurae.com)

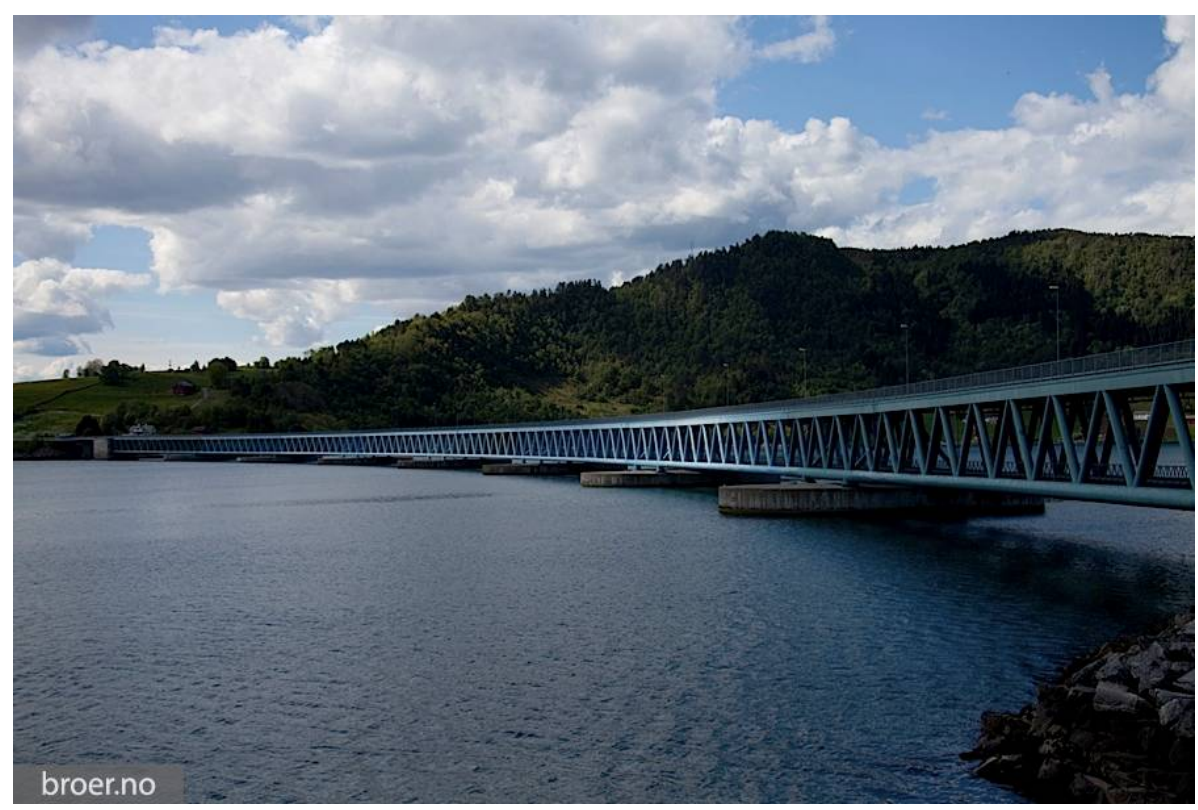

Figure 1-3: Bergsoysund Floating Bridge, Norway (bridgeinfo.net) 


\subsubsection{Continuous Pontoon Floating Bridges}

Continuous pontoon floating bridges consist of pontoons which make unbroken contact with the water surface. The road surface may consist of a separate superstructure, or the top of the pontoons may serve to carry traffic loads directly. Most continuous pontoon floating bridges are constructed with elevated sections near the supports to enable waterborne vessel crossings. An example a continuous pontoon bridge with elevated end sections is the Lace V. Murrow Bridge on Lake Washington, USA (Figure 1-4).

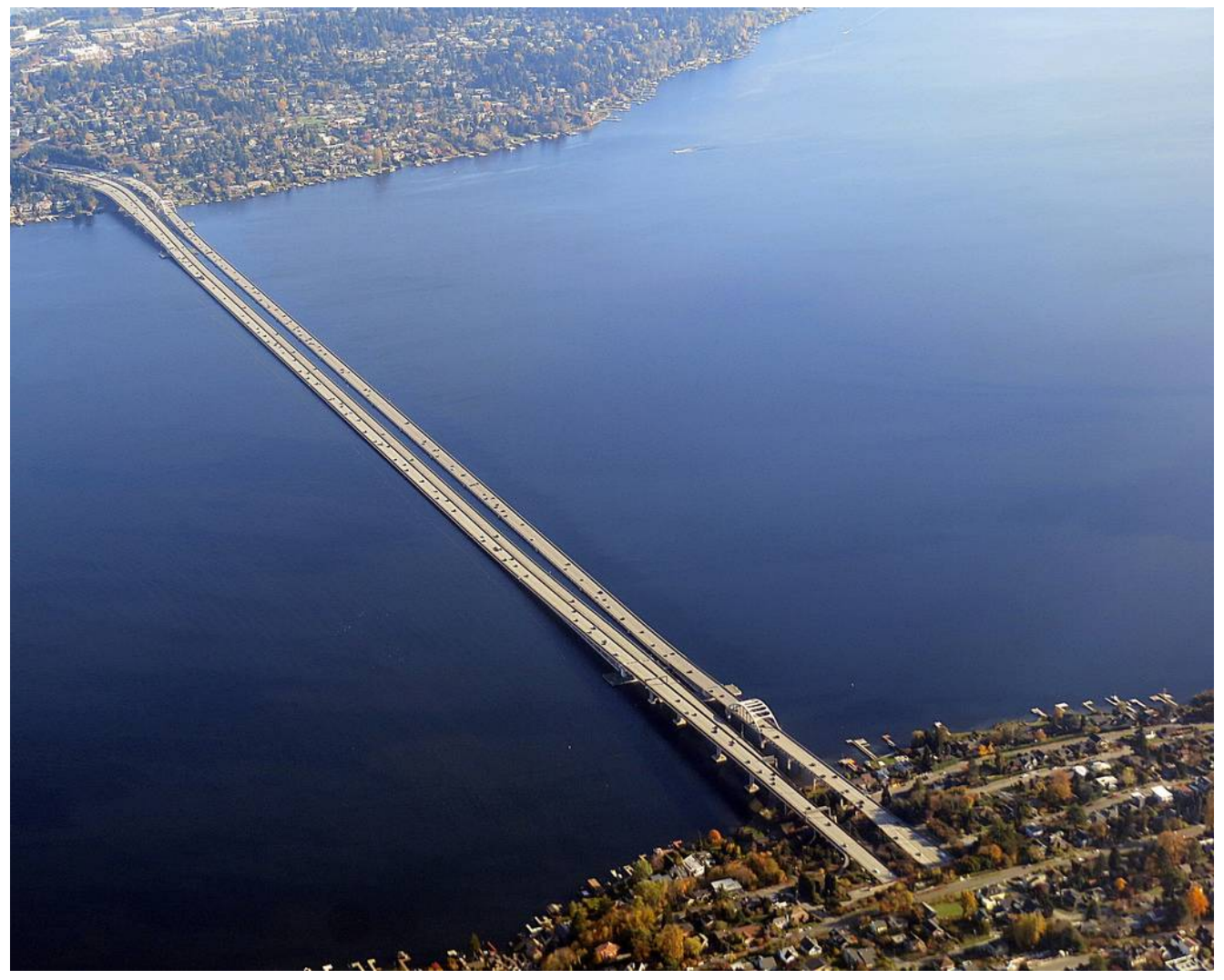

Figure 1-4: Lace V. Murrow Bridge, Washington, USA (https://www.jinlisting.com/listing/lacey-v-murrow-memorial-bridge/)

Alternatively, a movable section may be incorporated into the bridge design at midspan to allow for the crossing of larger vessels. Continuous pontoon floating bridges 
experience a larger water drag force due to the increased surface area exposed to stream currents. However, they have the advantage of maximizing the buoyant force mobilized by the pontoons. Other examples of continuous pontoon floating bridges are the William R. Bennett Bridge, British Columbia, Canada and the Evergreen Point Floating Bridge in Seattle, Washington, USA.

\subsubsection{Ribbon Floating Bridges}

Ribbon floating bridges are a special type of continuous pontoon bridges. They consist of interior and ramp pontoons (Figure 1-5) of modular design that can be joined with rigid or hinged connections. Designed for quick assembly and deployment, ribbon floating bridges are also referred to as rapid deployment bridges and are primarily used in emergency and military applications, making it imperative to minimize the time it takes to assemble the bridge for use and to maximize their vehicle crossing capacity.

Interior bay

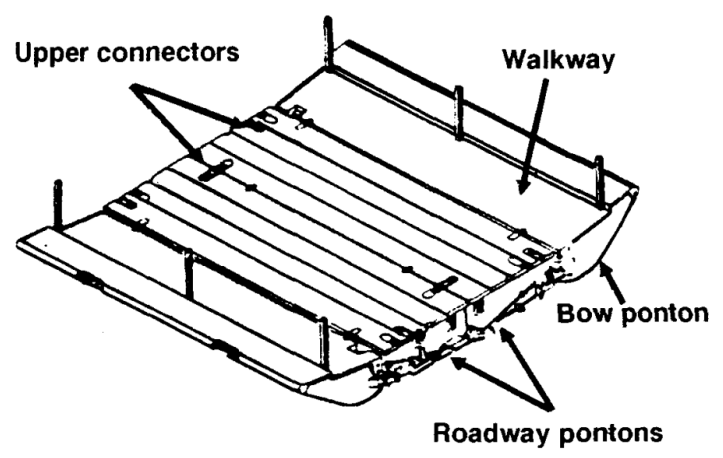

Ramp bay

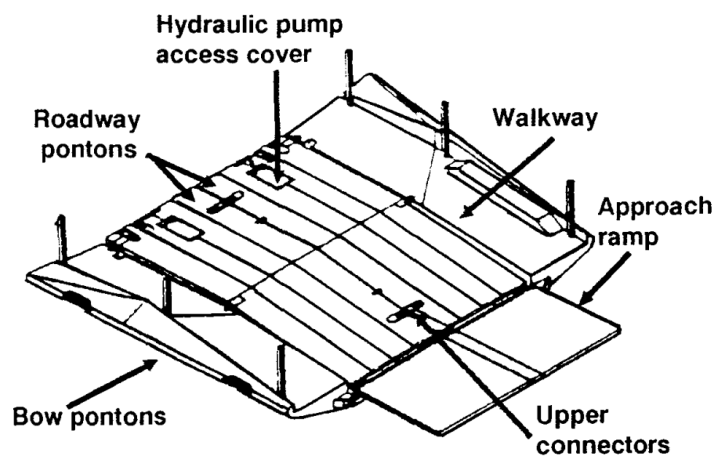

Figure 1-5: Interior and Ramp Modules of a Ribbon Floating Bridge (http:/www.armytechnology.com) 


\subsection{Main Loads Acting on Floating Bridges}

Apart from the loads from traversing vehicles on floating bridges, there are various environmental loads that act on floating bridges that are taken into account during design. This section presents the most important loads acting on a floating bridge (El-Desouky, 2011).

\subsubsection{Self-Weight and Buoyancy Force}

The self-weight load arises from the action of gravity on the mass of bridge components and is counter-balanced by the upward-acting buoyancy force which is equal to the weight of water displaced by the submerged hull of the pontoons of the floating bridge. When at rest, the floating bridge must displace enough water to allow for adequate freeboard above the water line such to accommodate vehicle loads without exceeding the design displacement limit.

If zero bridge downward displacement is assumed at the depth of floatation at rest, bridge self-weight need not be considered in analysis unless the floating bridge undergoes excessive upward displacement whereby the pontoon underside lifts off the water surface in which case the buoyancy force is no longer available.

\subsubsection{Traffic Loads}

The traffic loads are the dynamic loads imposed under the axles of a traversing vehicle and is mainly dependent on the vehicle velocity, its suspension system, as well as the surface roughness of the bridge deck (Green et al., 1995). Vehicle eccentricity about the longitudinal centerline of the bridge also introduces torsional loads into the bridge (El- 
Desouky, 2011). For multiple vehicles, the inter-vehicle spacing is an additional determinant of traffic loading and is an important consideration in analyzing the dynamic load effects on the bridge.

\subsubsection{Water Current Loads}

Water current forces act on the submerged portion of a floating bridge and influence the out of plane response of the floating bridge. These forces are an important consideration for continuous pontoon floating bridges which have a greater area exposed to the water current as compared to discrete/discontinuous pontoon floating bridges. Mooring cables can be employed to resist lateral displacement caused by water current on permanent floating bridges.

For temporary floating bridges such as ribbon bridges, motorized boats may be used to secure the bridge and thus counteract the effect of the water current on the response of the bridge. The effect of water current is outside the scope of the present investigation.

\subsubsection{Wave Loads}

Wave loads constitute a main consideration for floating structures located in the ocean. For inland bodies of water such as lakes and rivers, and other narrow water channels, the average height of waves that impinge on a floating bridge is not of major concern (ElDesouky, 2011). 


\subsubsection{Wind Loads}

Wind loads acting on a floating bridge are generally small in magnitude due to the fact that the exposed depth of the bridge above the waterline which is exposed to wind is small. Based on the local wind conditions of the floating bridge site, wind loads may be neglected. Additionally, wind loading on traversing vehicles can cause torsional loads on the bridge structure. For the purpose of the present study, it is assumed that the effect of wind loads on the ribbon floating bridge can be ignored.

\subsubsection{Earthquake Loads}

Earthquake events do not directly affect a floating bridge due to the absence of piers founded in the earth. Earthquakes may however cause significant waves on inland water bodies and large waves or tsunamis in the case of floating structures in open seas. Earthquakes may also result in floating bridge anchorage slippage, causing stresses in a floating bridge.

\subsection{Problem Definition and Scope}

Rapid deployment (ribbon pontoon) floating bridges are a crucial asset in many circumstances such as emergencies, during flooding disasters, or military operations. The modular components are stock-piled by the military and disaster management outfits and deployed in times of need. Currently, limits are imposed on the loading levels of floating bridges; mainly in terms of the vehicle weight and crossing speed. The spacing of successive vehicles crossing the bridge is also limited to a lower bound to minimize the 
dynamic effects of closely spaced vehicles. To achieve higher traffic flow on ribbon floating bridges, more investigation is required.

In the design of conventional bridges, influence lines based on gravity loads are the primary consideration with vehicle dynamic considered in the form of impact factors (Barker \& Puckett, 2013). Though influence lines are also used in the preliminary estimation of the stresses of a floating bridge, Dynamic Amplification Factors (DAFs) play a major role in determining the critical loads due to traversing vehicles. At present, there is little guidance on the appropriate DAF values for use with ribbon pontoon floating bridges (Watanabe \& Utsunomiya, 2003). It is thus important to investigate the behaviour of the bridges under various crossing conditions to facilitate the determination of appropriate DAFs for use in design.

The dynamic characteristics of a crossing affect bridge displacements, which in turn affect the vehicle displacements. The vehicle, bridge and underlying water are ideally considered as a coupled dynamic system making for a complicated analysis. Multiple vehicles add to the complexity of the system. These require further study to establish the dominant factors that affect bridge response.

Military vehicles are classified according to a standard system which assigns a weight class to bridging equipment and vehicles. A bridge Military Load Classification of 70 (MLC70) means that it can carry vehicles with a gross weight up to 70 ton, with specified limits on vehicle speed, acceleration/deceleration and longitudinal eccentricity during a bridge crossing. Specifically, vehicles are required to cross the bridge one at a time. With the advent of heavier and faster military vehicles, it is important to study the behavior of 
ribbon pontoon bridges under higher loads to optimize their capacity in terms of the allowable vehicle weight, vehicle speed, and inter-vehicle spacing for multi-vehicle crossing.

There are severe limitations on the crossing of ribbon floating bridges. According to the Trilateral Design and Testing Code for Military Bridging (2005), the maximum speed for vehicle classes of MLC 30 and above is $25 \mathrm{~km} / \mathrm{hr}$ (Table 1-1). Also, minimum intervehicle spacing, i.e. distance between successive vehicle axles is $30.5 \mathrm{~m}$, which is most likely to ensure that only one vehicle crosses the bridge at a time, or to reduce dynamic interactions between vehicles to a minimum. With further study, a lower conservative limit can be established for vehicle weights, speed and spacing to increase the capacity of existing and future rapid deployment bridges. 
Table 1-1: Vehicle Design Crossing Speeds (Hornbeck et al., 2005)

\begin{tabular}{|c|c|c|}
\hline Vehicle Design Speed & Up to MLC 30 & Above MLC 30 \\
\hline Essential* & $25 \mathrm{~km} / \mathrm{h}(15 \mathrm{mi} / \mathrm{h})$ & $16 \mathrm{~km} / \mathrm{h}(10 \mathrm{mi} / \mathrm{h})$ \\
\hline Desirable & $40 \mathrm{~km} / \mathrm{h}(25 \mathrm{mi} / \mathrm{h})$ & $25 \mathrm{~km} / \mathrm{h}(15 \mathrm{mi} / \mathrm{h})$ \\
\hline
\end{tabular}

* Essential speeds are the maximum speeds under normal field conditions and the speeds to which the bridge must be tested

\subsection{Previous Work and Scope of Current Study}

El-Desouky (2011) developed a numerical finite element-based program to simulate the dynamic behavior of rigid and hinge-connected floating bridges traversed by vehicles represented as single- or double-axles. The author investigated the effect of single and two vehicle crossings on the vertical displacement response of rigid- and hinge-connected floating bridges. The single was represented as a lone axle, while the two successive vehicles were represented as two single axles separated by the equivalent inter-vehicle spacing. Parametric studies using vehicles with varying vehicle weight and speed were conducted with the finite element program.

El-Desouky (2011) reported that the single-axle model representation of the vehicle was less accurate than the double-axle representation. The former model produced higher bridge displacement in comparison with the double-axle model. The author also reported that the single-axle vehicle model provided good results for small inter-axle spacing but not for large inter-axle spacing. Figure 1-6 shows a comparison of results obtained from the single and double axle models. Also, the author's finite element program tests a maximum of two vehicles (represented as single axles) which cannot be used to directly examine the floating bridge capacity under multiple vehicles. 


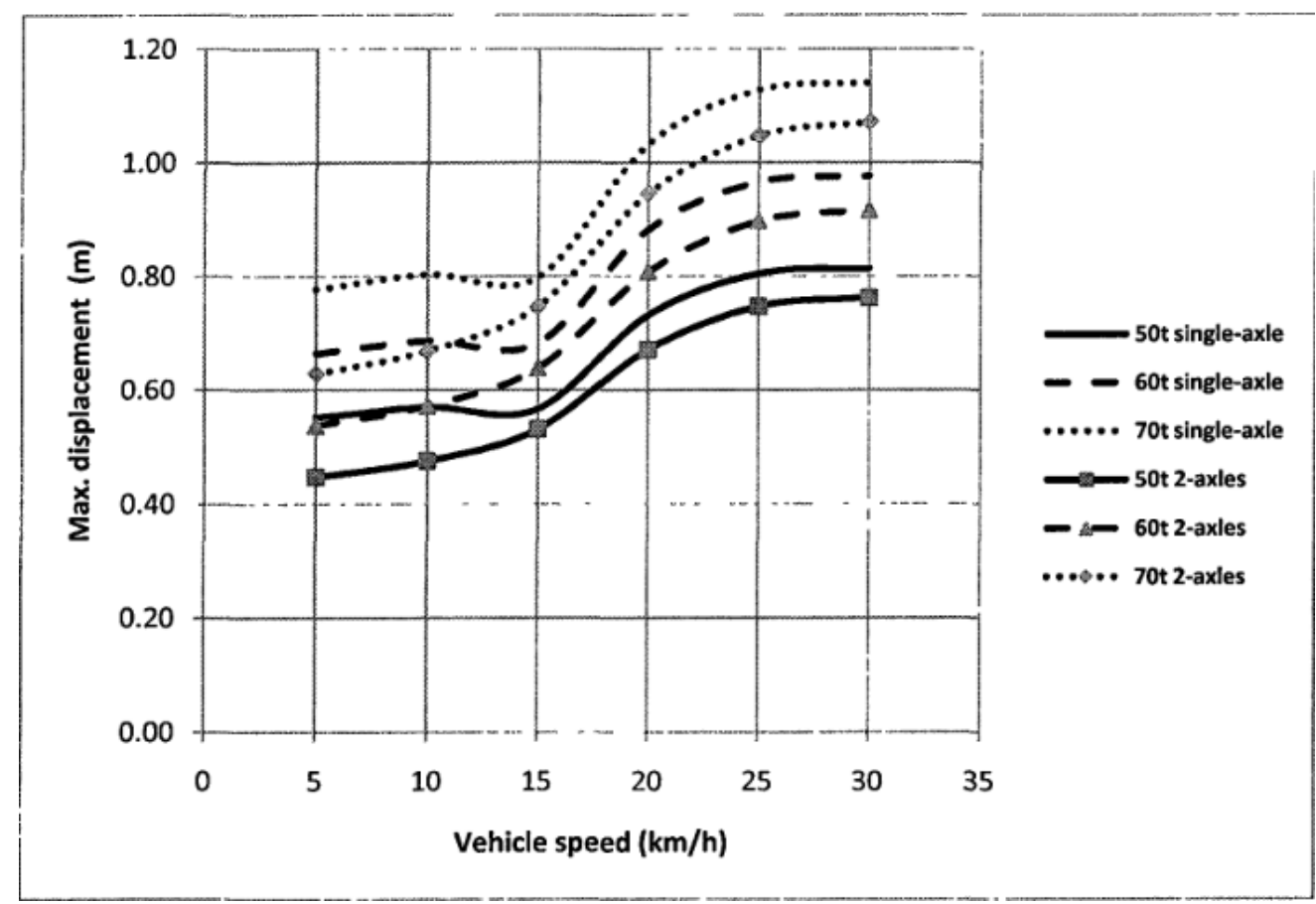

Figure 1-6: Maximum Midpoint Displacements due to Single and Double Axle Vehicle Model (El-Desouky, 2011).

El-Desouky's (2011) study was numerical in nature and it was necessary to validate the results of the finite element model with laboratory testing. Accordingly, Viecili et al. (2014) designed and constructed a 1/25 - scale experimental model of a hinge-connected floating bridge to determine the effect of vehicle speeds and weights of a 2-axle model vehicle on the response of the bridge. The experimental results were used to validate ElDesouky's, (2011) finite element model with satisfactory results.

The experimental setup designed by Viecili et al., (2014) was not capable of testing two or more vehicle crossings. In the present study, the previous experimental setup was modified to accommodate two vehicles at varying inter-vehicle spacing. The new experimental scale-model tests in conjunction with the enhanced numerical model is 
capable of providing invaluable information for the design and operation of ribbon floating bridges in lieu of field testing which is significantly more expensive.

The experimental testing involving two vehicles and the numerical results will provide valuable insight into factors that affect the capacity of the bridge when subjected to multiple vehicles with varying weight, inter-vehicle spacing and speed. The experimental results for two vehicles will also be used to validate the results from a modified finite element program based on the works of El-Desouky (2011)which is capable of modelling multiple double-axle vehicle crossing of the ribbon pontoon floating bridge.

The main goals of the current research are defined as follows:

- To further develop the existing finite element program to accommodate two or more double-axle vehicles crossing the hinge-connected ribbon pontoon floating bridge,

- To investigate numerically and experimentally the effect of two or more vehicles of varying weight, inter-vehicle spacing, and speed on the response of the hingeconnected ribbon pontoon floating bridge, and

- To develop appropriate guidelines to optimize the vehicle crossing capacity of a hinge-connected ribbon pontoon floating bridge in terms of vehicle weight, intervehicle spacing and speed.

\subsection{Research Plan}

The research plan to achieve the above stated objectives is divided into five stages. In Stage 1 a comprehensive review of the literature on floating bridges in general and ribbon pontoon floating bridges in particular was carried out. The works of El-Desouky and 
Viecili et al. ( 2013,2014$)$ were reviewed to gain an understanding of the research already completed at Carleton University. Furthermore, open source literature was reviewed to understand the response of floating bridges under vehicle loading and to establish the fundamental parameters affecting the efficiency and vehicle crossing capacity of floating bridges.

The Second stage of the research plan involved further development and modification of the finite element numerical program developed by El-Desouky (2011). The program was modified to include the capability of modelling the passage of two or more double-axle vehicles across the ribbon pontoon floating bridges. Stage 3 involved the modification of the experimental test setup developed by Viecili $(2013,2014)$ to include entry and exit ramps capable of accommodating two successive vehicles. In stage 3, experimental testing using the two successive model vehicles was carried out to facilitate validation of the new finite element program. The experimental testing coupled with the numerical modelling was used to study and identify the parameters controlling vehicle crossing capacity of the ribbon pontoon floating bridge.

In Stage 4, a full-scale ribbon pontoon floating bridge was numerically modelled, and the results analysed to further identify the critical parameters that control the bridge vehicle crossing capacity. In Stage 5, critical parameters affecting the vehicle crossing capacity in of the ribbon pontoon floating bridge were optimized and guidelines proposed.

\subsection{Thesis Organization}

This thesis is divided into seven chapters. Chapter 1 provides an introduction to floating bridges in general. A brief history of floating bridges, types of floating bridges and main 
loads acting on floating bridges are discussed. Problem definition, previous work done on the ribbon pontoon floating bridges, and the scope of the present study are given.

Chapter 2 provides a comprehensive literature review of work previously done by other researchers including floating bridge analyses and modelling under the effects of vehicle loading. Also, the effects of dynamics and characteristics on bridges was reviewed. The main findings from the literature review are presented.

In chapter 3 , the equations of motion for two or more vehicle crossings were developed. The Newmark Average Acceleration method is also discussed as a viable technique to solve the equations of motion and a flowchart of the finite element program is presented.

Chapter 4 discusses the experimental setup used to test two model vehicles of varying weights, speed and inter-vehicle spacing. Chapter 5 discusses a preliminary experimental investigation of the factors that affect maximum displacements in the model floating bridge and undertakes a full-scale numerical study of an 84-m long hinge-connected bridge.

Chapter 5 provides parametric studies of the full-scale 4-pontoon hinge-connected ribbon pontoon floating bridge. Optimum spacing resulting in minimum displacements in the floating bridge are identified for each vehicle speed tested. The bridge was also subjected to multiple vehicles at optimum inter-vehicle spacing. Results showed that bridge displacements diminished with each consecutive vehicle. Corresponding bridge capacities in terms of vehicles per hour are provided. The research findings are summarized in Chapter 6 followed by conclusions based on the research findings. Suggestions for future work are also provided. 


\section{Chapter: Literature Review}

Floating bridges are mostly used in place of conventional bridges due to technical, practical and economic reasons. Conventional bridges make up a crucial component of any transportation system. Without bridges, the construction of highways and railway across valleys and water bodies would not be possible.

However, there are instances where the depth to firm foundation may present a major limitation to the construction and economic viability of the bridge. In such cases the limitation can be overcome by constructing bridges that use the buoyancy of the water to resist applied loads. Some other general physical constraints or scenarios which may warrant the use of a floating bridge instead of a conventional one are presented below (Watanabe \& Utsunomiya, 2003).

- At locations with large water depths where the construction of piers for a conventional bridge is either uneconomical or impossible.

- On rivers with very soft foundation material that cannot support the loads from conventional bridge piers.

- For temporary applications i.e. for fast crossings in times of war or in emergencies where conventional bridges are damaged, destroyed or non-existent.

- Floating bridges by their nature are isolated from severe shaking during earthquakes and are thus appropriate in earthquake-prone areas

- In areas where it is undesirable to disturb aquatic wildlife during bridge construction 
This chapter presents a comprehensive review and summary of research work with respect to the response of bridges to traffic loading with an emphasis on the response of ribbon pontoon floating bridges to vehicle loads.

\subsection{Floating Bridge Analysis Models}

The structural system of a floating bridge is typically represented by an Euler Bernoulli beam supported on elastic foundations represented as springs. Depending on the bridge, the elastic foundation may be modelled as continuous springs (Georgiadis, 1985) to represent continuous pontoon bridges, or discrete springs (M. Seif \& Inoue, 1998) to represent separated pontoon floating bridges. The floating bridge may also be represented by a hydroelastic model (Fleischer \& Park, 2004) where the underlying water is explicitly modelled.

Thambiratnam \& Zhuge (1996) studied the vertical displacement of a beam on elastic foundation subjected to moving point loads using the finite element approach. The foundation was modelled as uniformly distributed elastic springs and the beam was subjected to moving loads at various speeds. The effect of various foundation (elastic spring) stiffnesses on bridge displacement was investigated. It was determined that the dynamic amplification factor (denoted $\phi_{D}$ ), defined as the ratio of the maximum dynamic to static midpoint displacements, increased as the vehicle speed increased (Figure 2-1). Also, the DAF increased more significantly with respect to higher load speeds for softer foundations than for stiffer foundations. Since the authors dealt with soils, which have higher stiffness values compared to water, it is expected that DAFs for floating bridges would, in general, increase at high vehicle velocities. It should however be noted that the 
study involved a non-segmented beam unlike the floating bridges investigated in this thesis which are discontinuous and hinge-connected bridge.

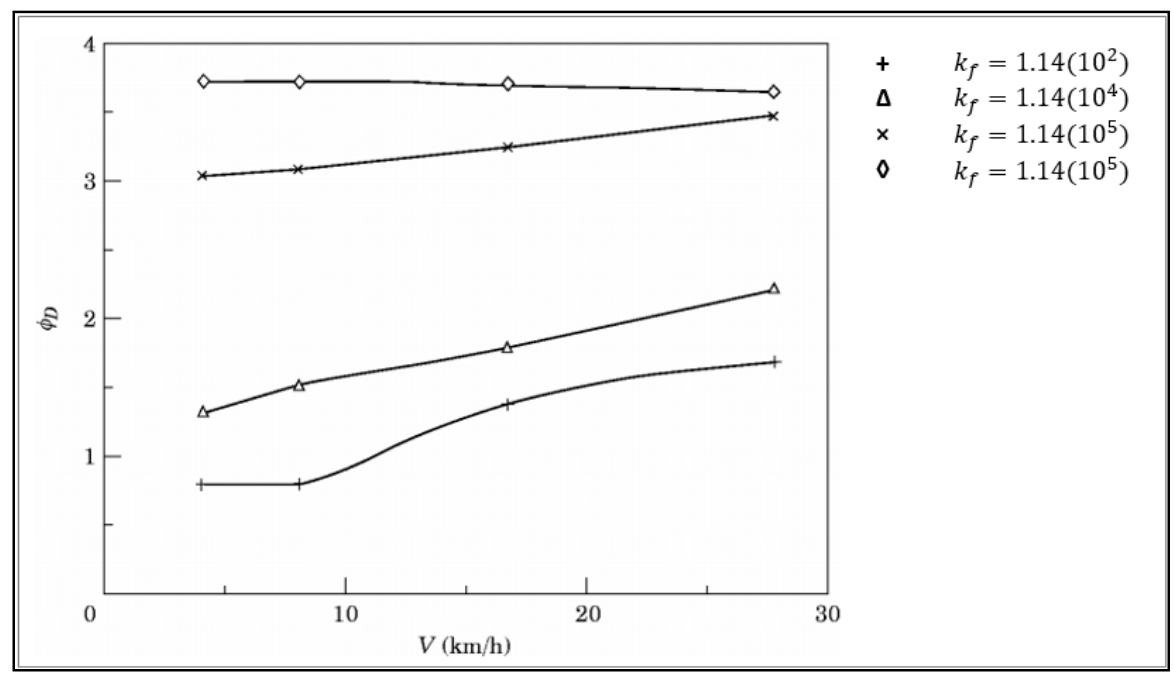

Figure 2-1: Variation of Dynamic Amplification Factor $\left(\phi_{D}\right)$ with Moving Load Speed for varying dimensionless Foundation Stiffness $\left(k_{f}\right)$ (Thambiratnam \& Zhuge, 1996)

Seif \& Inoue (1998) studied the analysis of discrete pontoon floating bridges subjected primarily to wave loading with varying parameters. The model, shown in Figure 2-2, consists of a continuous beam supported by multiple discrete floating pontoons.

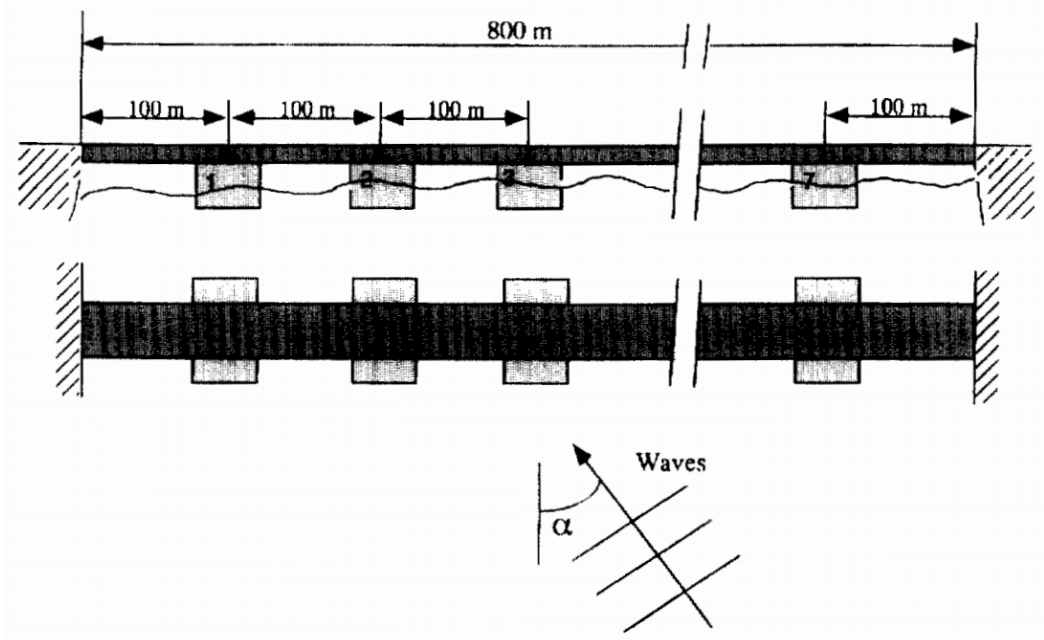

Figure 2-2: Separated pontoon bridge computational model (Seif \& Inoue, 1998) 
The model was subjected to a 30-ton moving force at varying speeds to investigate the effects of traffic loads on the bridge. It was discovered that at high speeds, the moving load induced high vertical oscillations in the pontoons in comparison to forces traveling at lower speeds. At lower force speeds the oscillations were damped out. This was because the forces moving at faster speeds tended to excite the fundamental vibration frequency of the bridge as compared to low speed forces.

Wu \& Sheu (1996) studied the coupled heave and pitch motions of a ship hull subjected to a moving load. The ship, representative of an aircraft carrier, a car ferry or a floating bridge, was modelled as a rigid beam on elastic foundations. The elastic foundation was modelled as distributed springs and dampers. The effect of induced waves was considered in terms of additional damping. The water added mass, which represents the mass of water accelerated during oscillations, was not considered by Wu \& Sheu (1996). Closed form analytical solution for the response of the ship hull was obtained using mode superposition and the Duhamel integral. The analytical results were compared with those obtained numerically using Newmark's iteration procedure with good correlation. The numerical results for heave and pitch were also compared at different moving load speeds. It was established that the heave response remained constant with increasing load velocity over most of the investigated range while pitch response varied considerably (Figure 2-3). The authors reported that the period of vibration for both heave and pitch motions of the model remained near the natural period of vibration, irrespective of the moving load speed.

Wu \& Sheu (1996) explained that the reason for relatively higher frequencies of the numerical model as compared to the experimental model was because of the 
overestimation the water stiffness by the elastic spring model. Fleischer \& Park (2004) however observed that the resulting higher frequencies of the elastic spring model as compared to the hydrodynamic model occurred when the added mass of water was ignored in the elastic spring model. It is therefore important to accurately estimate the added mass of water accelerated during bridge vibrations.

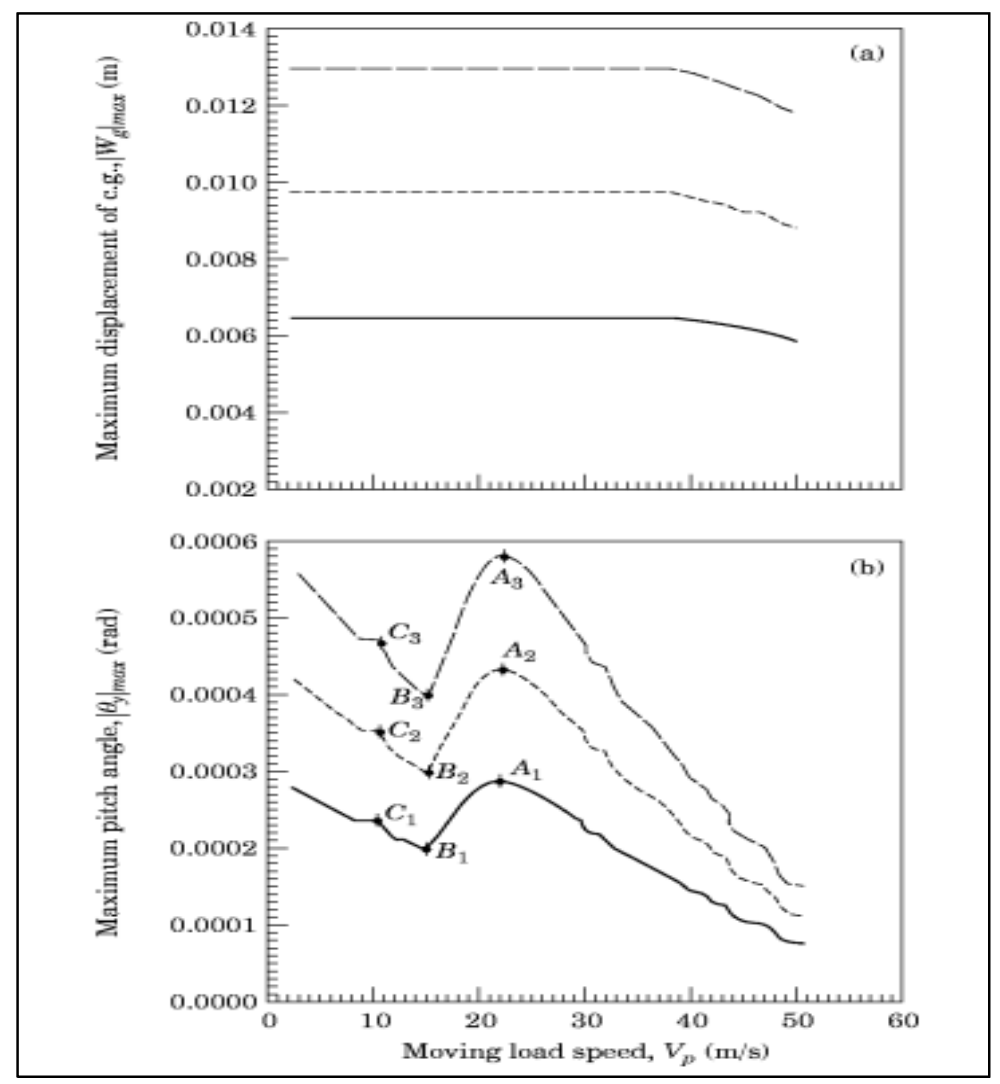

Figure 2-3: Influence of moving load speed on (a) Maximum heave displacement and (b) Maximum pitch displacement for different moving load speeds (Wu \& Sheu, 1996)

Wu \& Shih (1998) studied the vertical and torsion response of a moored rigid- and hinged-connected floating bridge in still water subjected to a moving load using the finite element approach. The bridge, which was modelled as a series of beam elements on elastic foundations was subjected to an axial pre-tensioned force. Water inertial forces 
were included as a constant added mass. The mooring cables were modelled as discrete elastic springs at the points of attachment to the bridge. Hinge connections were modelled by standard finite element procedure involving a beam element with nodal hinges.

Results for the hinge-connected model showed that the differences in frequencies of the first few modes of vertical vibration were small. Also, the dynamic displacement response of the bridge was dominated by the rigid modes of vibration

Fu \& Cui (2012) undertook an experimental and numerical study on the moving loadinduced response of ribbon floating bridges in an experimental ocean basin. Emphasis was placed on modelling the nonlinear properties of the pontoon connectors. The response of the nonlinear connector under load is presented in Figure 2-4. The nonlinear dynamic equation of the entire bridge was formulated as in Equation (2-1.

$$
[M]\{\ddot{D}\}+[C]\{\dot{D}\}+\left\{R^{\text {int }}\right\}=\left\{R^{\text {ext }}\right\}
$$

where $\left\{R^{i n t}\right\}$ is the internal force vector representing the bridge internal forces i.e. internal bridge elastic forces and nonlinear connection forces. $\left\{R^{e x t}\right\}$ is the external force vector representing all external surface forces acting on the bridge including water elastic forces, inertial forces due to water added mass, and forces due to the external moving load. $[\mathrm{C}]$ is the Rayleigh damping matrix while $[\mathrm{M}]$ is the mass matrix. $\{\ddot{D}\},\{\dot{D}\}$, and $\{D\}$ are the nodal acceleration, velocity and displacement vectors of the bridge. The NewtonRaphson method was used to solve Equation (2-1 after static condensation of the degrees of freedom (dofs) of elements that would not be in direct contact with the moving vehicle wheels. 


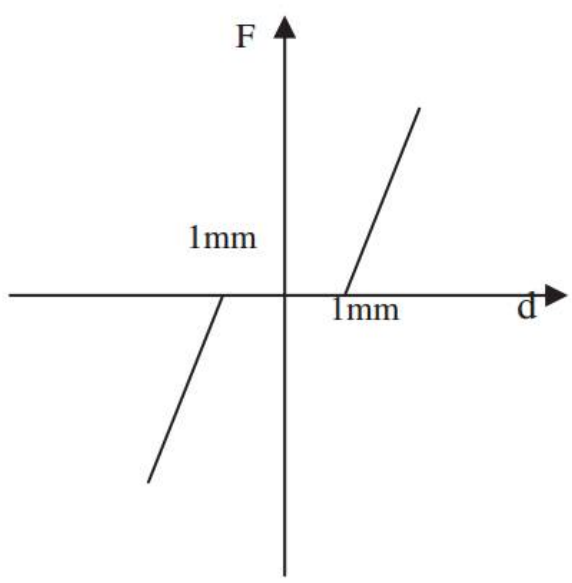

Figure 2-4: Illustration of the nonlinear connector (Fu \& Cui, 2012)

The numerical and experimental results showed good agreement in terms of maximum displacement (Figure 2-5). The upward displacements for both numerical and experimental models were more sensitive to vehicle speed than downward displacements. Also, the experimental maximum upward displacement was higher than the numerical maximum upward displacement. The dynamic properties of the vehicle were not considered in this study, which could have a significant impact on the bridge response. 

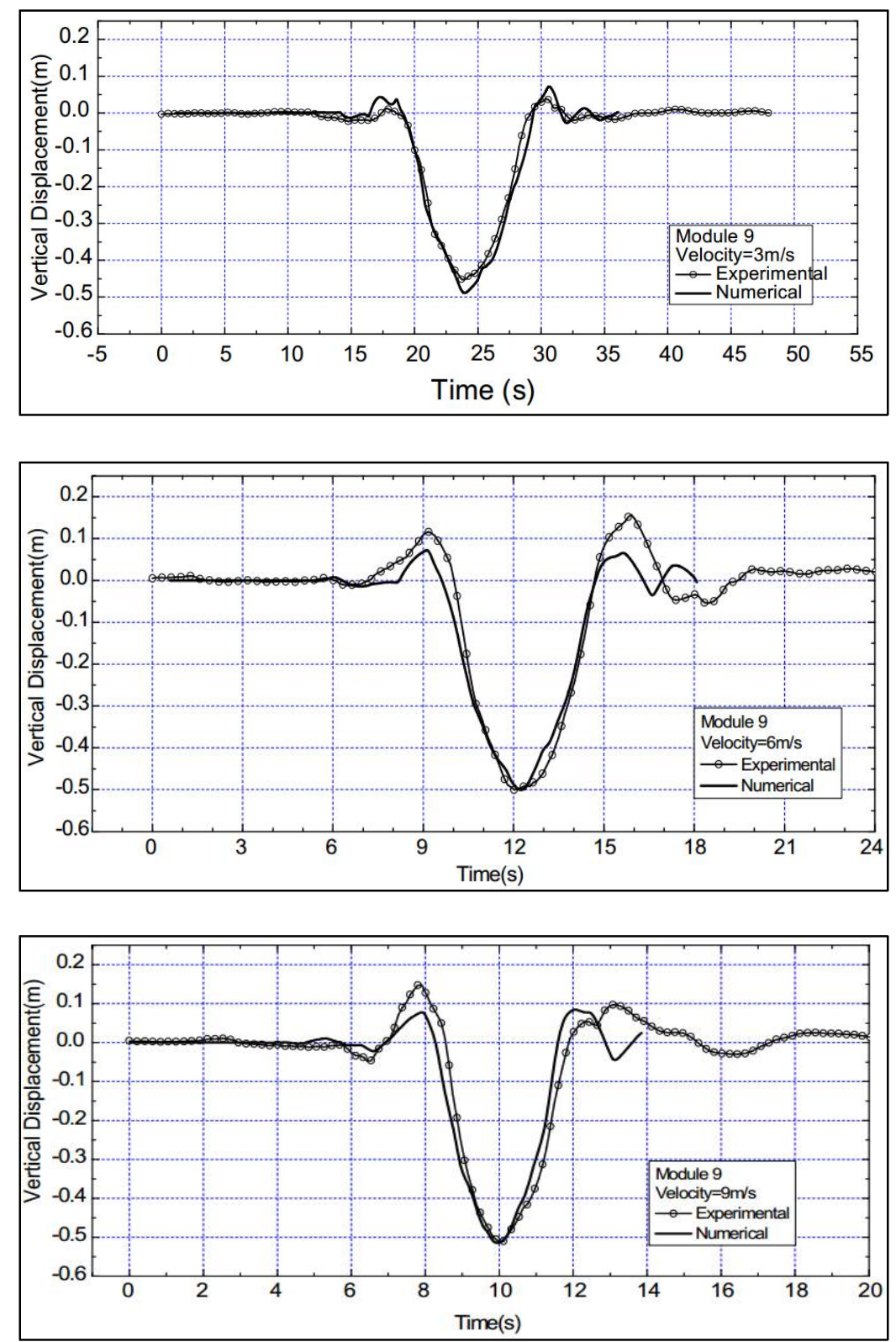

Figure 2-5: Numerical vs Experimental results for midpoint displacement at $3 \mathrm{~m} / \mathrm{s}, 6 \mathrm{~m} / \mathrm{s}$ and $9 \mathrm{~m} / \mathrm{s}$ vehicle speeds (Fu \& Cui, 2012)

Neves (2012) proposed a direct stepwise integration method of incorporating bridge deck irregularities (Figure 2-6) into the analysis of vehicle-bridge interactions, as opposed to the iterative procedure used by other authors to satisfy displacement compatibility between the bridge surface and a traversing sprung mass. 


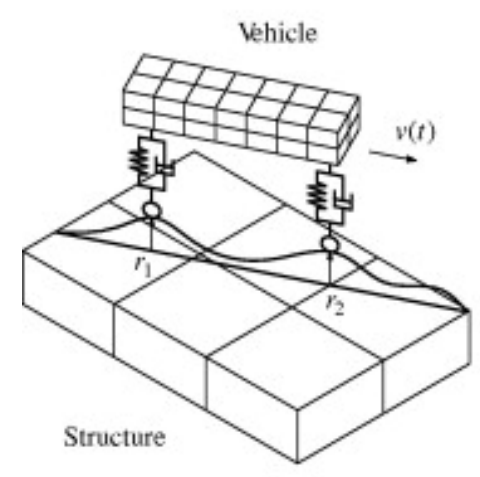

(a)

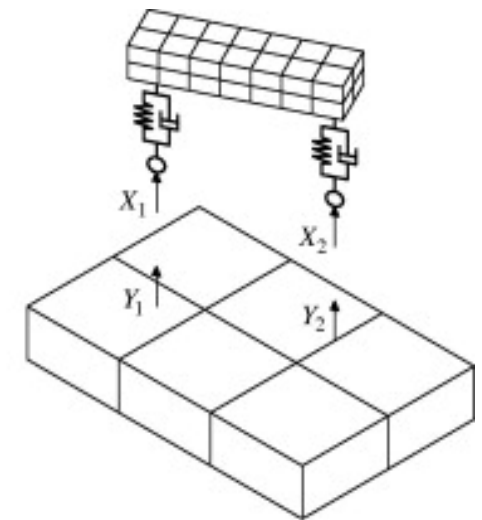

(b)

Figure 2-6: Vehicle-structure system: (a) schematic illustration and (b) free body diagram (Neves et al., 2012)

Employing the Newmark iterative procedure, compatibility between the vehicle nodes and the deck surface was achieved by ensuring that the vertical difference between the position of vehicle-bridge contact and bridge displacement was always equal to the height of irregularity. The stepwise direct integration procedure was compared with the semianalytical/ iterative method by comparing the response of the first of 50 sprung masses traversing the bridge with irregularities defined as sine functions. Figure 2-7 shows the beam analysis model with a single sprung mass, and the vertical displacement by the direct and semi-analytical methods of the leading sprung mass are comparatively shown in Figure 2-8. The results showed good agreement.

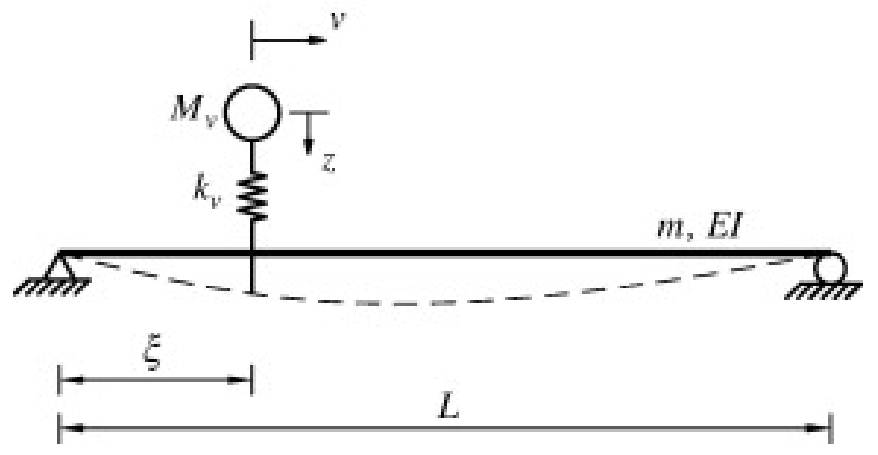

Figure 2-7: Simply supported beam subjected to moving sprung mass (Neves et al., 2012) 


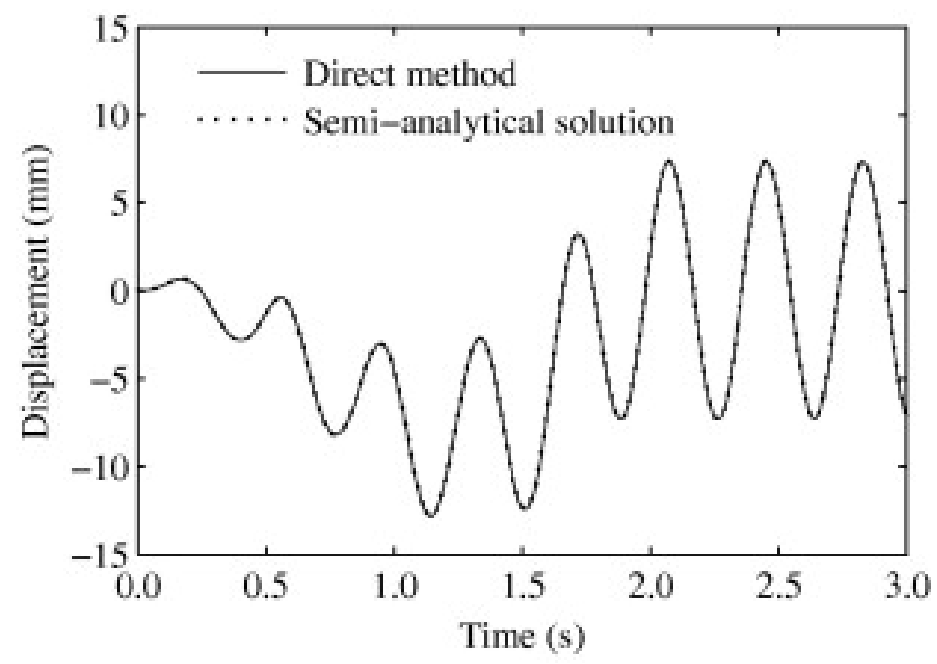

Figure 2-8: Vertical displacement of first sprung mass (Neves et al., 2012)

Fleischer \& Park (2004) investigated the dynamic response of a rectangular cross-section beam resting on water confined in a prismatic bowl of finite depth. The vibration mode shapes were determined for a hydroelastic analytical model and an equivalent elastic spring foundation model. The hydroelastic mode shapes were evaluated such that the volume of water underlying the bridge remained constant during beam vibrations. The authors pointed out that representing a floating bridge purely as a beam on elastic foundation yielded higher natural frequencies as compared to a hydroelastic model if the water added-mass is neglected in the former. For the hydroelastic model, the natural circular frequency was found to be upper bound as the depth to length ratio of the water bowl increased. The bridge natural frequency of vibration was constant for depth to length ratios greater than 0.5 (Figure 2-9). 


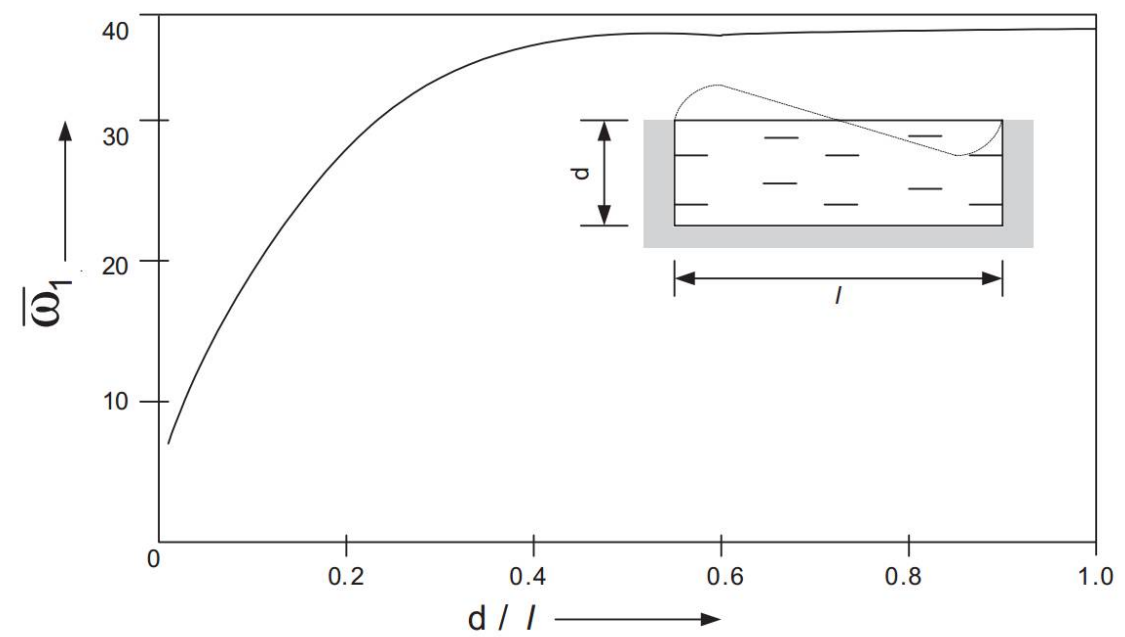

Figure 2-9: Dimensionless Basic Natural Vibration Frequency vs Depth to Length Ratio of Continuous Floating Bridge (Fleischer \& Park 2004)

Zhang et al. (2008) studied the effect of water depth on the displacement response of a continuous and discrete pontoon floating bridges subjected to a moving load. The EulerBernoulli Beam Theory and Potential Theory were used to formulate the analytical problem. The continuous pontoon bridge was modelled as a simply-supported beam on distributed elastic springs while the separated pontoon bridge model was supported on discrete elastic springs. The problem was solved using the Garlekin Method of Weighted Residuals. The authors concluded that water depth had negligible effect on the bridge displacement of both the continuous and discrete pontoon bridges and could therefore be ignored in the analysis. Figure 2-10 shows a comparison of pontoon midpoint displacements for different water depths of $6 \mathrm{~m}, 9 \mathrm{~m}$ and $12 \mathrm{~m}$. The results show that the variation in bridge displacements was negligible for all three tested water depths. This study agrees with that undertaken by Fleischer \& Park (2004) which showed the natural frequency of vibration of a continuous floating bridge converging to a constant value with increasing depth. 


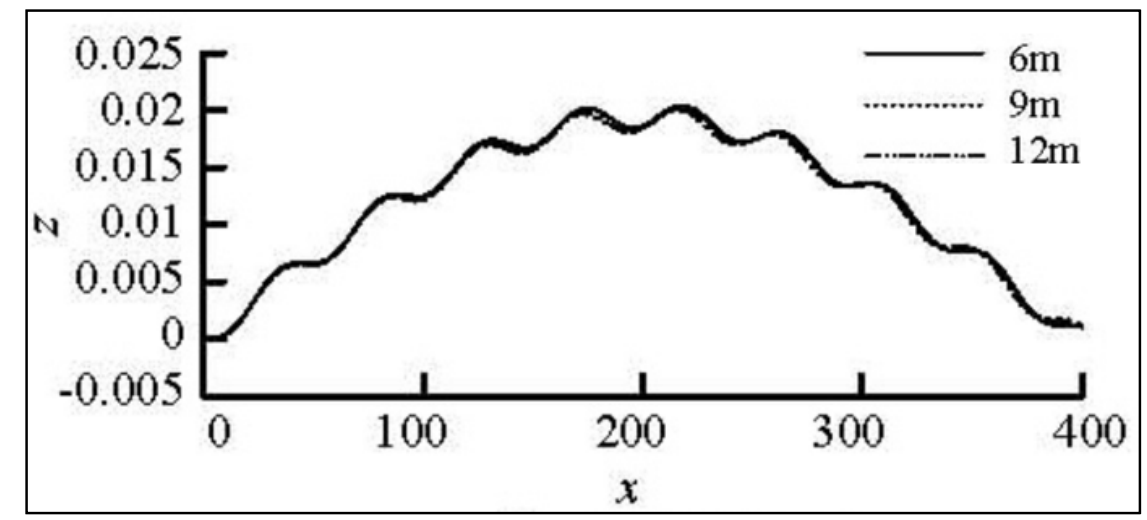

Figure 2-10: Bridge midpoint displacement versus vehicle position at $10 \mathrm{~m} / \mathrm{s}$ for $6-\mathrm{m}$, 9$\mathrm{m}$ and 12-m water depths

Nguyen \& Pham (2016) investigated the effect of beam separation from an elastic foundation, on vertical beam vertical displacement when traversed by a moving oscillator. A contact element which allowed for beam-foundation separation was compared with the ordinary beam-on-elastic-foundation element which assumed the beam to be in continuous contact with the foundation. The contact element can simulate three conditions beam-foundation contact; full-bonded, full-unbonded and half-bonded (Figure 2-11).

The elastic contact force between beam and foundation is represented by varying distributed loads, converted to equivalent UDLs on the regions of contact. The equivalent nodal forces were then obtained by finding the resulting fixed end forces. The contact element can have a maximum of three lift-off points according to the maximum degree of the beam element shape function polynomials. A dimensionless parameter of the elastic foundation was defined as $K_{0}=k_{w} L^{4} / E I$, where $k_{w}, L, E$, and $I$ are the elastic stiffness per unit length of foundation, length, Young's modulus and moment of inertia of the beam respectively. 
No contact
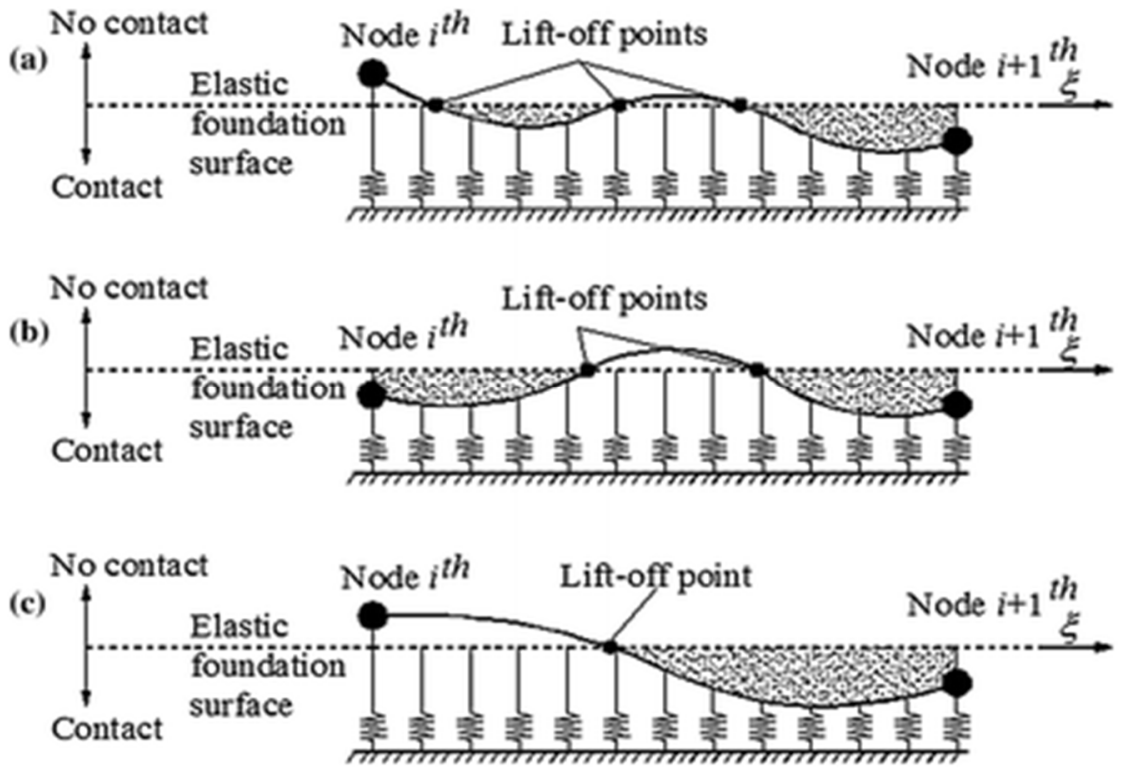

Figure 2-11: Half-bonded contact element with a) three, b) two, c) one lift-off point (Nguyen \& Pham, 2016)

The dynamic midpoint displacement of the beam, accounting for discontinuous contact, was compared with that using ordinary elements with continuous contact. It was determined that the contact element models (DC) produced displacements that were significantly different from those of the ordinary element (CC) which assumed continuous contact between beam and foundation, the difference becoming more pronounced with decreasing foundation stiffness. DC and CC results also differed appreciably for different 'sprung mass' to 'beam mass' ratios.

The beam was subjected to a single axle having a sprung and unsprung mass. The Dynamic Magnification Factors (DMF), which was defined as the ratio of maximum dynamic deflection to maximum static deflection, for different values of foundation stiffness $\left(k_{\mathrm{w}}\right)$ were compared at increasing vehicle velocities. For all four values of $\mathrm{k}_{\mathrm{w}}$, the CC model produced higher DMFs than the DC model in almost all test cases. Results for different values of $K_{0}$ are shown in Figure 2-12. 

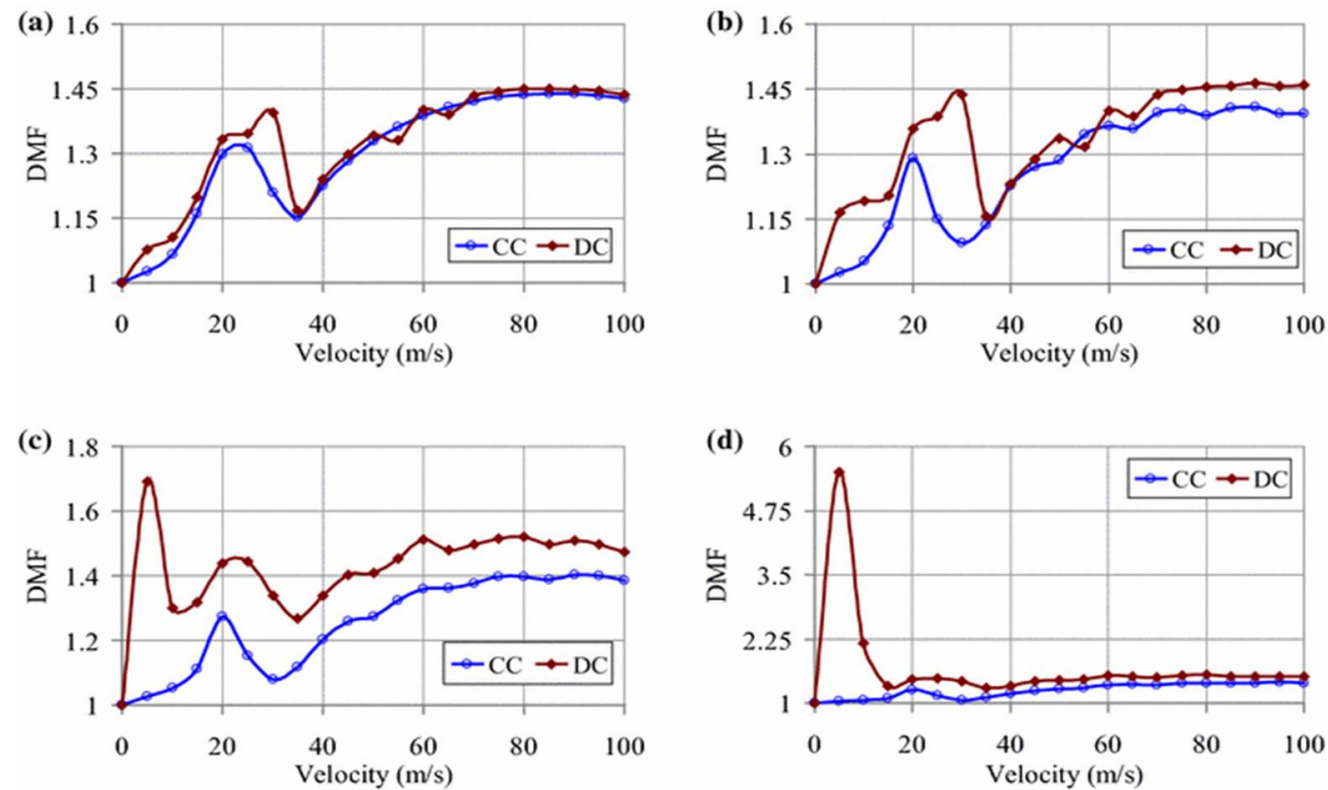

Figure 2-12: Dynamic Modification Factors for different Foundation Stiffness Parameters (a) $K_{0}=10$, (b) $K_{0}=20$, (c) $K_{0}=30$, (d) $K_{0}=40$. (Nguyen \& Pham, 2016) Raftoyiannis et al. (2014) studied the dynamic response of a floating bridge represented by non-deformable hinged-connected floating pontoons subjected to a moving load. Dynamic equations of equilibrium were formulated with respect to the pontoon joints and solved by the numerical Runge-Kutta procedure for different velocities of the moving load. Water elastic forces, damping, inertia and wave forces were considered in the problem formulation. A five-pontoon bridge numerical example was used to test the analytical formulation and a modal analysis conducted to determine the eigenmodes and frequencies. It was determined that vehicle velocities less than $18 \mathrm{~km} / \mathrm{hr}$ produced relatively smaller bridge displacements. Bridge displacements increased significantly in an intermediate range of 36 to $72 \mathrm{~km} / \mathrm{hr}$ and returned to lower values for vehicle velocities above $72 \mathrm{~km} / \mathrm{hr}$. An equivalent finite element model consisting of beam elements on elastic foundation represented as linear distributed springs was employed 
which resulted in $98.5 \%$ and $95 \%$ agreement in terms of eigenfrequencies and displacements respectively. It was concluded that above a certain moving load speed, bridge displacements reduced in magnitude due to the increase in difference between the frequency of the vehicle loading on the bridge, and the natural vibration frequency of the bridge.

Zhang et al. (2010) undertook the comparative study of moving load versus moving vehicle on a discrete pontoon floating bridge. The bridge was modelled as an elastic beam of uniform cross section and the pontoon supports as discrete mass-spring-damper systems.

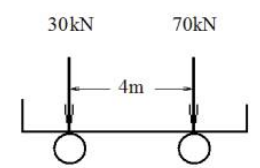

(a) The vehicle load of $100 \mathrm{kN}$

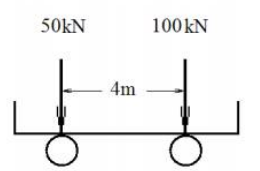

(b) The vehicle load of $150 \mathrm{kN}$

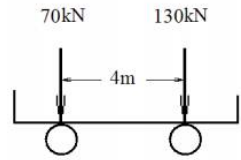

(c) The vehicle load of $200 \mathrm{kN}$

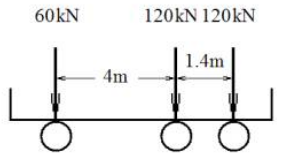

(d) The vehicle load of $300 \mathrm{kN}$

Figure 2-13: Comparative Vehicle Model (Zhang et al,, 2010)

The analytical problem was formulated using the Elastic Beam Theory and a 400-m span discrete floating bridge example was analyzed. Results showed that vehicle loads could be replaced by single point loads with little change in bridge response. However, the vehicle model used in this study (Figure 2-13) consisted of equivalent vertical forces representing the vehicle axle loads and does not account for the dynamic characteristics of the moving vehicles.

All studies discussed so far consider the bridge-traversing vehicle(s) as a series of point forces in which case a modal analysis is applicable for the dynamic analysis of the 
vehicle-bridge problem, because the dynamic characteristics of the system are localized in the bridge.

The previous simplifying assumption however ignores the mass of the vehicle which forms an integral part of the dynamic system, especially in the case of ribbon hingedconnected pontoon bridges. Thus, if the vehicle mass is considered, the mass matrix of the system is no longer static, but rather 'Pseudo-Static". In such a case, the bridge has a different set of mode shapes at each time step that the moving vehicle mass remains on the bridge.

\subsection{Effect of Vehicle Dynamics}

The characteristics of vehicle suspension have a significant bearing on the dynamic displacement of a bridge. In a study by Green et al. (1995) comparing the dynamic response of bridges traversed by an air sprung and leaf sprung vehicle, the effect of the vehicle suspension on bridge response was primarily determined by the difference in natural frequency of vibration between the vehicle and bridge. Because the dynamic wheel loads of the vehicle were dependent on the bridge response which is in turn dependent on the wheel loads, an iterative procedure was used to determine the dynamic wheel loads with appropriate allowance for the effect of bridge dynamics. This load was then applied to the bridge to determine its response. The effect of vehicle speed on bridge response was however inconclusive.

Though a lot of studies have been conducted on the effect of vehicle dynamic characteristics and speed on the response of conventional bridges, few have addressed their effect on floating bridges. 
Humar \& Kashif (1993) studied the dynamic response of bridges under moving loads. A speed ratio, given by Equation 2-2 was defined to study the effect of various parameters on the response of bridges.

$$
\alpha=\frac{v T_{b}}{2 L}
$$

$v$ is the velocity of moving load, $T_{b}$ is the bridge natural period of vibration and $L$ is the length of the bridge. The speed ratio relates the speed of the vehicle to the natural frequency of vibration of the bridge. This is a very important parameter as it indicates how close the bounce frequency of the vehicle-induced loads is to the natural frequency of vibration of the bridge. The closer the speed parameter is to unity, the closer the bridge vibration approaches resonance.

The moving mass-bridge interaction problem is one of kinematic coupling such that the force exerted by the vehicle on the bridge is a function of the vehicle motion, which in turn depends on the motion of the bridge (Yener \& Chompooming, 1994). In addition, for multiple vehicles crossing a bridge, the vehicle induced axle loads are indirectly affected by other vehicle axles through bridge vibrations. The force exerted by the vehicle on the bridge is a function of the bridge displacement under the vehicle wheel, and its first and second time derivatives.

There are a number of ways to treat such vehicle-bridge interaction problems. An iterative procedure can be used to first determine the wheel loads exerted by the vehicle on the bridge (Green et al., 1995) based on factors such as the vehicle suspension system and bridge deck irregularities. After the appropriate axle loads are determined, they can be applied externally to determine the response of the bridge. 
The above procedure is sufficiently efficient for general studies and for single-vehicle analysis cases to determine the effect of leaf sprung and air sprung vehicles on highway bridges (Green et al. 1995). It is however not suitable as a versatile tool to study the effect of multiple parameters such as vehicle spacing, weight and velocity on floating bridges, as it requires several iterations to establish vehicle loads.

The second procedure commonly used to solve kinematic-coupling problems is to consider the bridge and vehicle as one dynamic coupled system, the solution of which is more efficient and less prone to divergence (Neves et al.; 2012).

\subsection{Main Findings from the Literature Review}

Though there are a number of studies on the dynamic effect of vehicles on the response of conventional, pier-supported bridges, few studies deal with the response of floating bridges. Also, most of the studies dealing with the response of floating bridges to vehicle loads employ point forces to represent vehicle loads, thus ignoring the effects of mass and other dynamic properties of the vehicles on the floating bridge response.

It has been established by several researchers that bridge displacements tend to increase with increasing vehicle weight and speed, though it has also been observed that above a threshold speed, vehicle induced bridge displacements tended to reduce. It is, thus, necessary to further explore this phenomenon and to potentially increase floating bridge capacity in terms of vehicle passage.

Most studies focused on rigid-connected floating bridges, with little attention to hingeconnected floating bridges. Although rigid-connected floating bridges produce less 
displacement for the same loading, the induced moments are higher in rigid-connected bridges compared with hinge-connected floating bridges. Moreover, the vehicular loads are resisted by both the buoyancy and internal moment. Comparatively, vehicular loads in hinge-connected bridges are resisted predominantly by water buoyancy, with negligible internal moments developed in the pontoons. Hinge-connected pontoon bridges will be the focus of the current study. 


\section{Chapter: Numerical Formulation}

Field testing of the dynamic response of floating bridges is expensive. The usefulness of information obtained from such tests is also limited because floating bridge systems differ widely from one location to another in terms of water current forces, width of water channel. In addition, the properties of the crossing vehicles such as vehicle weight, velocity, and inter-vehicle spacing can affect the response of the hinge-connected ribbon pontoon floating bridges. A versatile and validated numerical tool can however be used to investigate the effect of various parameters on the design and response of floating bridges.

A numerical tool is necessary to test the various load types that the floating bridge can be subjected to. Also, since current bridge design codes do address design of floating bridges, a reliable numerical tool is of vital importance to test all the possible load combinations that can impact the response of floating bridges, and to optimize its vehicle passage capacity. This chapter discusses the analytical formulation of such a tool for ribbon pontoon floating bridges. The following assumptions are made in the numerical modelling of the bridge:

1. The test vehicle is a wheeled Humvee with an inter-axle spacing of $6 \mathrm{~m}$. This is widely used by the United States Military to transport troops and equipment.

2. Vehicles travelling on the bridge move in a straight line at constant speed. Thus no eccentric moments are introduced about the longitudinal centre-line of the bridge. 
3. The bridge can be idealised as a prismatic beam of constant rectangular cross section.

4. The underside of the pontoon bridge is assumed to be in contact with the water at all times during bridge vibration.

5. It is assumed that the maximum height of water waves is small and can be ignored in determining bridge displacements.

\subsection{Structural Response of Ribbon Floating Bridges}

The structural response of a ribbon pontoon floating bridge, among other factors, primarily depends on the type of pontoon connections. Two main types of connections are used in ribbon pontoon floating bridges: hinge and rigid connections.

The hinge-connection consists of two flat plates, with circular holes, welded to opposite pontoon faces. The flat plates overlap with the circular holes aligned when the pontoons are assembled. A circular shaft is inserted through the holes and bolted to complete the connection. With the rigid-connections, the sets of flat plates are welded near the bottom of the pontoon to resist relative rotation of two successive pontoons. The rigidconnections enable the ribbon pontoon structure to resist a moment couple. Figure 3-1 shows the plan and elevation views of the hinged and rigid connections. The hinged connection is investigated in the current study. 


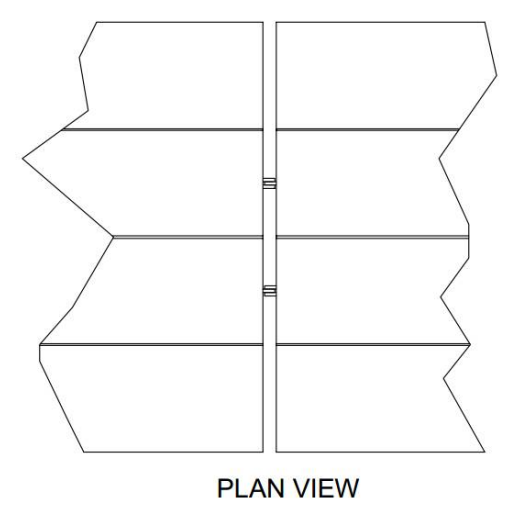

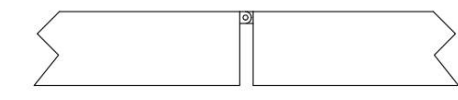

HINGED CONNECTION ELEVATION VIEW

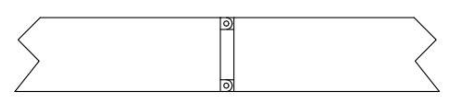

RIGID CONNECTION ELEVATION VIEW

Figure 3-1: Pontoon Hinged and Rigid Connection details

\subsubsection{Comparison of Hinged and Rigid Pontoon Bridges}

In the rigid-connected bridge, the pontoon joints are designed to resist moments induced by dynamic vehicle loads. The entire rigid-connected pontoon bridge therefore acts as a cantilever with the support at the position of maximum downward displacement, having arms in both directions towards the bridge supports. Figure 3-2 shows the bending moment diagram and deflected shape of a rigid-connected bridge. It is important to design pontoon connections to resist the bending moments they would be subjected to. $\mathrm{M}_{1}$ and $\mathrm{M}_{2}$, in the Figure 3-2, represent the moments at the left and right of the middle pontoon, respectively.

Because of their higher rigidity as compared to hinge-connected floating bridges, displacements in rigid-connected floating bridges are lower compared to hinge-connected ribbon pontoon bridges subjected to same loads. Moments in the hinge-connected ribbon 
pontoon bridges are not transferred from one pontoon to the next, thus limiting the demand on hinge connections.

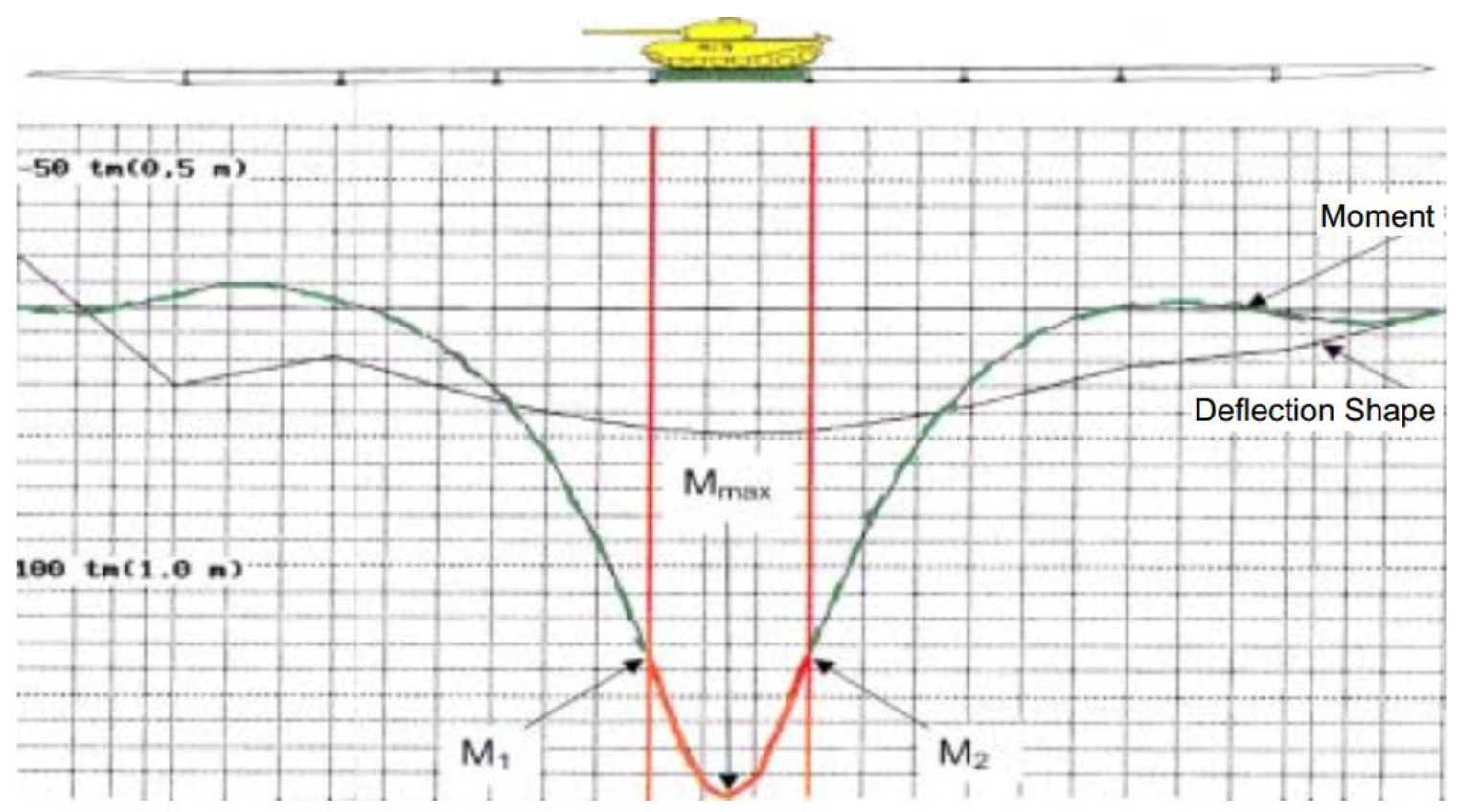

Figure 3-2: Rigid Connected Bridge Bending Moments (Harre, 2002)

\subsection{Dynamic Equations of Motion}

The general equation of motion of any dynamic system can be expressed by an equilibrium equation of all forces involved at any point in time (Equation 3-1).

$$
\left\{f_{I}\right\}+\left\{f_{D}\right\}+\left\{f_{S}\right\}=\{p(t)\}
$$

where:

- $\left\{f_{I}\right\}$ is the inertial force, opposite to and proportional to the acceleration of the vehicle-bridge system

- $\left\{f_{D}\right\}$ is the damping force made up of internal damping and external water frictional resistance and is proportional to velocity of the vehicle-bridge system 
- $\left\{f_{s}\right\}$ represents the elastic spring forces, both internal and external to the bridge, which is proportional to displacement from the equilibrium position

- $\{p(t)\}$ represents the time varying force applied externally to the system; including the vehicle loading

\subsection{Beam Element in Finite Element Analysis}

The beam element (Figure 3-3) is well suited for studying the vertical bridge displacements due to moving vehicle loads is because it is well documented in literature to yield satisfactory results. A beam element in this context is defined as "a long, slender structural member generally subject to transverse loading that produces significant bending effects as opposed to twisting or axial effects." (Logan et al., 2007).

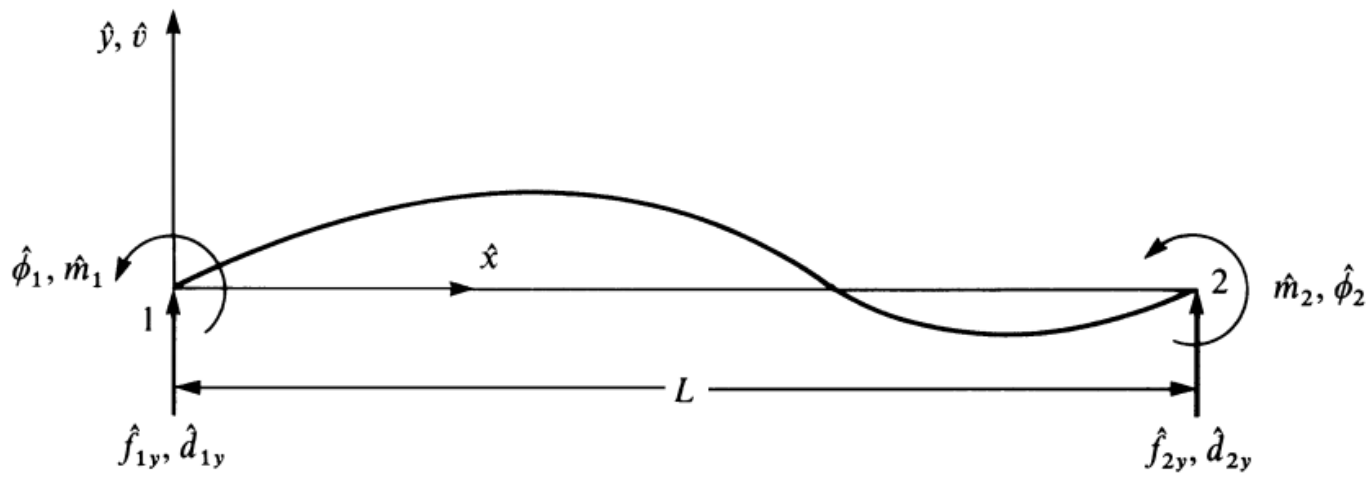

Figure 3-3: The Beam Element (Logan et al., 2007)

The beam element, in two-dimensional analyses, has two degrees of freedom at each node; one transverse and one rotational degree of freedom. Loading and axial deformation are negligible and are thus ignored. Each degree of freedom has a corresponding shape function which defines the shape of the beam when that degree of freedom is given a unit displacement with all others restrained. 


\subsection{Finite Element Analysis of Floating Bridges}

For relatively simple dynamic systems of a beam traversed by moving loads, analytical solutions of the time varying transverse displacements along the beam can be found. For a more complex dynamic problem like that considered in the current thesis, which involves multiple vehicles with separate dynamic systems, a closed form solution would be difficult if not impossible to determine. This problem is more amenable to a numerical solution. The finite element method is most appropriate for ribbon pontoon floating bridges and has been used by many authors.

The hinge-connected ribbon pontoon floating bridge consists of hinged-connected sections, each of which can be discretized into beam elements each of length $L$, elastic modulus $E$, moment of inertia $I$, and flexural rigidity $E I$. The hinge-connected bridge is simply-supported at both ends with a total span of $L_{b}$ and rests on water represented by springs of uniformly distributed stiffness, $k_{w}$. The vehicle (Figure 3-4) is idealized by two unsprung masses each of mass $m_{t r}$ and $m_{t f}$, representing the rear and front unsprung masses respectively; a sprung mass $m_{v}$ with mass moment of inertia $I_{v}$; and rear and front suspensions having spring stiffness and damping coefficient $k_{r}, c_{r}$ and $k_{f}, c_{f}$ respectively. This vehicle model is simple yet captures the vehicle dynamic characteristics, and has been used by many authors including Humar \& Kashif(1993), Fu \& Cui (2012), Nguyen \& Pham (2016) and Ertekin et al. (2001). 


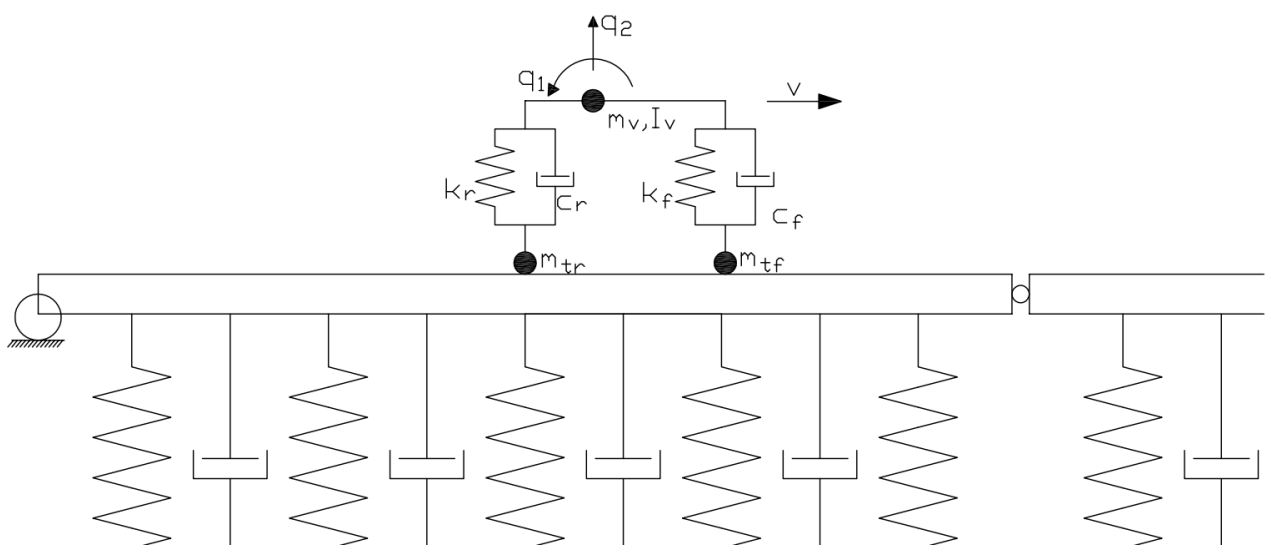

Figure 3-4: Vehicle-Bridge Idealization

The shape function of the beam element corresponding to the four degrees of freedom are presented in Equation (3-2).

$$
\begin{aligned}
& \psi_{1}=1-3 \frac{x^{2}}{L^{2}}+2 \frac{x^{3}}{L^{3}} \\
& \psi_{2}=x-2 \frac{x^{2}}{L}+\frac{x^{3}}{L^{2}} \\
& \psi_{3}=3 \frac{x^{2}}{L^{2}}-2 \frac{x^{3}}{L^{3}} \\
& \psi_{4}=-\frac{x^{2}}{L}+\frac{x^{3}}{L^{2}}
\end{aligned}
$$

Where $\psi_{1}, \psi_{2}, \psi_{3}, \psi_{4}$ represent the beam element shape functions associated with unit vertical displacement at node 1 , unit counter-clockwise rotation at node 1 , unit vertical displacement at node 2 , and unit counter clockwise rotation at node 2 , respectively. The displacement along the beam element can be determined as the superposition of each shape function multiplied by the displacement in its 
associated generalized degree of freedom (dof). The beam shape function vector can be represented as:

$$
N=\left\{\psi_{1}(x) \quad \psi_{2}(x) \quad \psi_{3}(x) \quad \psi_{4}(x)\right\}
$$

The transverse displacement as a function of time, $t$, and space, $x$, is written as:

$$
u(x, t)=\Delta_{1}(t) \psi_{1}(x)+\theta_{1}(t) \psi_{2}(x)+\Delta_{2}(t) \psi_{3}(x)+\theta_{2} \psi_{4}(x)
$$

where $\Delta_{1}, \theta_{1}$ and $\Delta_{2}, \theta_{2}$ are the vertical displacement and counter clockwise rotation at nodes 1 and 2 respectively.

\subsection{Bridge Equation of Motion}

The general dynamic equation of motion (Equation (3.1) can be expanded and rewritten in terms of mass, damping and stiffness terms as:

$$
\left[M_{G}\right]\{\ddot{D}\}+\left[C_{G}\right]\{\dot{D}\}+\left[K_{G}\right]\{D\}=\{P\}
$$

where

$\{D\}$ is the global displacement vector of the bridge.

$\{\dot{D}\}$ is the global velocity vector of the bridge.

$\{\ddot{D}\}$ is the global acceleration vector of the bridge

$\left[M_{G}\right]$ is the global mass matrix of the bridge.

$\left[C_{G}\right]$ is the global damping matrix of the bridge. 
$\left[K_{G}\right]$ is the global stiffness matrix of the bridge.

$\{P\}$ is the external global load vector acting on the bridge.

\subsubsection{Local Stiffness Matrix}

The hinge-connected bridge is modelled as a beam with a number of internal hinges representing the hinge connection. After discretization, the bridge is composed of regular beam elements with continuous ends and beam elements with one end hinged. The regular beam element, which is considered to have vertical displacement and flexural bending in the longitudinal vertical plane has stiffness matrix given as:

$$
[k]=\frac{E I}{L^{3}}\left[\begin{array}{cccc}
12 & 6 L & -12 & 6 L \\
6 L & 4 L^{2} & -6 L & 2 L^{2} \\
-12 & -6 L & 12 & -6 L \\
6 L & 2 L^{2} & -6 L & 4 L^{2}
\end{array}\right]
$$

Since the bending moment at internal hinges is equal to zero, the stiffness matrix for the beam with nodal hinge on the right is formed by condensing the rotational degree of freedom at the right side of the beam element (Logan et al., 2007). The condensed stiffness matrix is given as:

$$
[k]=\frac{E I}{L^{3}}\left[\begin{array}{cccc}
3 & 3 L & -3 & 0 \\
3 L & 12 L^{2} & -3 L & 0 \\
-3 & -3 L & 3 & 0 \\
0 & 0 & 0 & 0
\end{array}\right]
$$

To model the hinge-connected bridge, the beam element directly adjacent to the hinge connection is assumed to have a nodal hinge on the right. 


\subsubsection{Water Buoyancy Stiffness}

The main feature of a floating bridge is the utilization of water buoyancy to support the bridge self-weight and external vehicle loads. Thus, the shape of the pontoon hull is designed to take maximum advantage of the buoyant foundation. The buoyancy force acting on the bridge per metre is equal to the weight of water displaced per metre. The volume of water displaced is dependent on the depth of pontoon submersion, and the width of pontoons.

The depth of submersion changes along the pontoon with respect to time as the bridge pontoons oscillate in response to traversing vehicle loads, which requires that the water buoyancy forces be treated as dynamic loads. In this regard, the floating bridge can be idealized as a beam resting on a uniformly distributed elastic foundation of stiffness per unit length $\bar{k}_{w}$. The element bending stiffness due to underlying water is given as follows:

$$
\left[k_{i j}\right]=\int_{0}^{L} \bar{k}_{w} \psi_{i}(x) \psi_{j}(x) d x
$$

Assuming a rectangular bridge cross section and linear water stiffness, the buoyancy force per unit length along the bridge $\bar{k}_{w}$ is given as:

$$
\bar{k}_{w}=\rho_{w} b g
$$

where $\rho_{w}$ is the density of water, $b$ is the width of bridge cross section and $g$ is the acceleration due to gravity. The resulting stiffness matrix due to water buoyancy is given as: 


$$
k_{w}=\left[\begin{array}{cccc}
\frac{13 \bar{k}_{w} L}{35} & \frac{11 \bar{k}_{w} L^{2}}{210} & \frac{9 \bar{k}_{w} L}{70} & -\frac{13 \bar{k}_{w} L^{2}}{420} \\
\frac{11 \bar{k}_{w} L^{2}}{210} & \frac{\bar{k}_{w} L^{3}}{105} & \frac{13 \bar{k}_{w} L^{2}}{420} & -\frac{\bar{k}_{w} L^{3}}{140} \\
\frac{9 \bar{k}_{w} L}{70} & \frac{13 \bar{k}_{w} L^{2}}{420} & \frac{13 \bar{k}_{w} L}{35} & -\frac{11 \bar{k}_{w} L^{2}}{210} \\
-\frac{13 \bar{k}_{w} L^{2}}{420} & -\frac{\bar{k}_{w} L^{3}}{140} & -\frac{11 \bar{k}_{w} L^{2}}{210} & \frac{\bar{k}_{w} L^{3}}{105}
\end{array}\right]
$$

\subsubsection{Element Effective Stiffness Matrix}

The regular or hinged element effective stiffness matrix $\left[k_{e}\right]$ and $\left[k_{e, h i}\right]$ are equal to the sum of regular beam stiffness matrix $[k]$ or hinged beam stiffness matrix $\left[k_{h i}\right]$, and the buoyant stiffness matrix $k_{w}$, respectively.

$$
\begin{aligned}
& k_{e}=[k]+\left[k_{w}\right] \\
& k_{e, h i}=\left[k_{h i}\right]+\left[k_{w}\right]
\end{aligned}
$$

\subsubsection{Bridge Global Stiffness Matrix}

The global stiffness matrix $\left[K_{G}\right]$ of the floating bridge is obtained by the standard finite element assembly technique, which involves combining the element stiffness matrix at shared degrees of freedom.

\subsubsection{Element Mass Matrix}

The Principle of Virtual Work can be used to derive the consistent mass matrix of the Euler-Bernoulli beam as: 


$$
[m]=\frac{1}{420}\left[\begin{array}{cccc}
156 \bar{m} L & 22 \bar{m} L^{2} & 54 \bar{m} L & -13 \bar{m} L^{2} \\
22 \bar{m} L^{2} & 4 \bar{m} L^{3} & 13 \bar{m} L^{2} & -3 \bar{m} L^{3} \\
54 \bar{m} L & 13 \bar{m} L^{2} & 156 \bar{m} L & -22 \bar{m} L^{2} \\
-13 \bar{m} L^{2} & -3 \bar{m} L^{3} & -22 \bar{m} L^{2} & 4 \bar{m} L^{3}
\end{array}\right]
$$

\subsubsection{Element Water Added Mass Matrix}

A body that moves through a fluid accelerates a mass of fluid that was originally occupying the displaced volume. Thus, the floating bridge pontoon hull accelerates a certain mass of water during bridge vibrations. For the sake of analysis, the accelerated mass of water may be assumed to be rigidly attached to the pontoon hull (Chen \& Chung, 1976). The added water mass per unit length along the bridge is then calculated as:

$$
\bar{m}_{a}=c_{m} \pi \rho_{w}\left(\frac{b}{2}\right)^{2}
$$

where $b$ is the pontoon width, $\rho_{w}$ is the density of water and $c_{m}$ is the heave hydrodynamic coefficient which is a function of the pontoon horizontal section. The corresponding mass coefficients in the direction of heave motion can be approximated as:

$$
m_{a_{11}}=m_{a_{33}}=c_{m} \pi \rho_{w}\left(\frac{b}{2}\right)^{2} \frac{L}{2}=\frac{1}{8} c_{m} \pi \rho_{w} b^{2} L
$$

The added mass matrix of an element is then given as:

$$
\left[m_{a}\right]=\left[\begin{array}{cccc}
\frac{1}{8} c_{m} \pi \rho_{w} b^{2} L & 0 & 0 & 0 \\
0 & 0 & 0 & 0 \\
0 & 0 & \frac{1}{8} c_{m} \pi \rho_{w} b^{2} L & 0 \\
0 & 0 & 0 & 0
\end{array}\right]
$$




\subsubsection{Element Effective Mass Matrix}

The effective element mass matrix of the beam element is given as the sum of the element consistent mass matrix and the element added mass matrix (Equation 3-17).

$$
\left[m_{e}\right]=[m]+\left[m_{a}\right]
$$

\subsubsection{Bridge Global Mass Matrix}

The bridge global mass matrix $[M]$ is formed by standard finite element assemblage of the effective local mass matrix $\left[m_{e}\right]$. It represents the mass coefficients contributed by mass of the bridge and the mass of water accelerated during bridge vibrations.

\subsubsection{Bridge Global Damping Matrix}

The damping in the floating bridge is contributed by the internal friction within the bridge itself, and external friction due to the viscosity of water. The damping force vector can be expressed as:

$$
\left\{F_{D}\right\}=\left[C_{G}\right]\{\dot{D}\}
$$

where $\left[C_{G}\right]$ is the bridge global damping matrix.

The damping coefficient $(\xi)$ of the experimental bridge model was determined to be 0.5 by logarithmic decrement of the amplitudes of free vibration of the bridge. In the numerical model, linear viscous damping was assumed and the Rayleigh proportional damping used to form the damping matrix of the bridge as a linear combination of the global stiffness and mass matrices (Humar, 2002): 


$$
\left[C_{G}\right]=\alpha\left[K_{G}\right]+\beta\left[M_{G}\right]
$$

where $\alpha$ and $\beta$ are the stiffness and mass proportional damping constants respectively, given as:

$$
\xi=0.5\left(\alpha \omega+\frac{\beta}{\omega}\right)
$$

For two vibration frequencies $\omega_{1}, \omega_{2}$ with known damping $\xi_{1}, \xi_{2}$,

$$
\begin{aligned}
& \xi_{1}=0.5\left(\alpha \omega_{1}+\frac{\beta}{\omega_{1}}\right) \\
& \xi_{2}=0.5\left(\alpha \omega_{2}+\frac{\beta}{\omega_{2}}\right)
\end{aligned}
$$

In the current study, a damping coefficient of $\xi=0.5$ is assumed at the first and second modes of vibration. Equation 3-23 and Equation 3-24(3-20) are then solved simultaneously to obtain $\alpha$ and $\beta$ :

$$
\begin{aligned}
& \alpha=\frac{2\left(\xi_{2} \omega_{2}-\xi_{1} \omega_{1}\right)}{\left(\omega_{2}^{2}-\omega_{1}^{2}\right)} \\
& \beta=\frac{2 \omega_{1} \omega_{2}\left(\xi_{1} \omega_{2}-\xi_{2} \omega_{1}\right)}{\left(\omega_{2}^{2}-\omega_{1}^{2}\right)}
\end{aligned}
$$

\subsection{Dynamic Equation of Motion for Bridge Subjected to Double-axle Vehicle}

The equation of the vertical displacement at the point of contact between the vehicle front axle and the bridge deck, denoted as the distance $x$ from the left node of the beam element, is given as: 


$$
\eta=\{N(x)\}\{D(t)\}
$$

where $\{N(x)\}$ is the value of the shape function evaluated at the position of the front axle along the beam element and $\{D(t)\}$ is the beam element nodal displacement vector.

$$
\begin{aligned}
& N(x)=\left\{\begin{array}{llll}
\psi_{1}(x) & \psi_{2}(x) & \psi_{3}(x) & \psi_{4}(x)
\end{array}\right\} \\
& D(t)=\left\{\begin{array}{llll}
\Delta_{1}(t) & \theta_{1}(t) & \Delta_{2}(t) & \left.\theta_{2}(t)\right\}^{T}
\end{array}\right.
\end{aligned}
$$

The front axle location is a function of vehicle velocity $v$ and time $t$ :

$x=v t$.

For the vehicle rear axle, $x,\{N\}, \eta$ are replaced by $x_{r},\left\{N_{r}\right\}, \eta_{r}$, the latter being the rear axle position, shape function evaluated at the location of the rear axle, and the vertical displacement of the bridge under the rear axle, respectively.

The vertical velocity and acceleration of the front and rear axles are the first and second derivatives of $\eta$ and $\eta_{r}$ respectively, given as:

$$
\begin{aligned}
& \dot{\eta}=v\left\{N_{x}\right\}\{D\}+\{N\}\{\dot{D}\} \\
& \dot{\eta_{r}}=v\left\{N_{r, x}\right\}\{D\}+\left\{N_{r}\{\dot{D}\}\right. \\
& \ddot{\eta}=v^{2}\left\{N_{x x}\right\}\{D\}+2 v\left\{N_{x}\right\}\{\dot{D}\}+\{N\}\{\ddot{D}\} \\
& \ddot{\eta_{r}}=v^{2}\left\{N_{r, x x}\right\}\{D\}+2 v\left\{N_{r, x}\right\}\{\dot{D}\}+\left\{N_{r}\right\}\{\ddot{D}\}
\end{aligned}
$$


where $\{N\}_{x},\{N\}_{x x}$ and $\left\{N_{r}\right\}_{, x},\left\{N_{r}\right\}_{, x x}$ are the first and second derivatives of the shape function evaluated at the location of the front and rear axles, respectively.

The Free Body Diagram (FBD) showing the dynamic and static forces on the vehicle sprung and unsprung masses is shown in Figure 3-5. To obtain the coupled matrix equation of the vehicle-bridge system, displacements $d_{1}, d_{2}$, velocities $\dot{d}_{1}, \dot{d}_{2}$ and accelerations $\ddot{d}_{1}$, $\ddot{d}_{2}$ are applied to the bounce and roll degrees of freedom 1 and 2 of the vehicle. The first row of the matrix equation of motion is obtained by summing vertical forces on the vehicle FBD. The second row is obtained by summing moments about the vehicle center of mass.
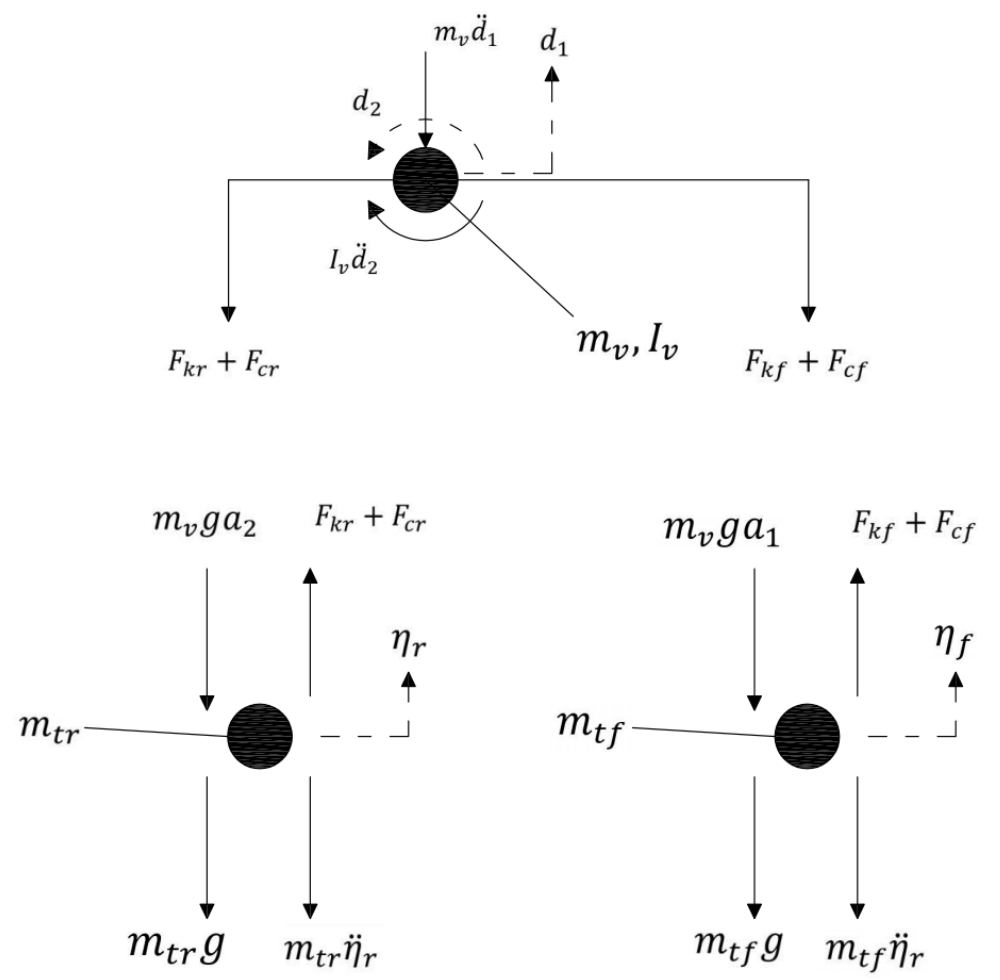

Figure 3-5: Free Body Diagram of vehicle-bridge dynamic forces

Since the vehicle and bridge act as a coupled dynamic system, it is important to consider the interaction coefficient matrices of mass $\left(\left[\mathrm{m}^{*}\right]\right)$, damping $\left(\left[c^{*}\right]\right)$ stiffness $\left(\left[k^{*}\right]\right)$, and 
force $\left(p^{*}\right)$ which the vehicle produces in the bridge degrees of freedom. These are obtained by pre-multiplying the resultant forces on the rear and front unsprung masses in the vehicle FBD (Figure 3-5) by $\{N\}^{T}$ and $\left\{N_{r}\right\}^{T}$ respectively for normalization in the bridge local degrees of freedom. The results are then equated to zero since no external force acts on the vehicle outside the vehicle-bridge dynamic system. With reference to Figure 3-5,

$$
\begin{aligned}
\left\{N_{r}\right\}^{T}\left(m_{t r} \ddot{\eta}_{r}\right. & \left.-\left(F_{c r}+F_{k r}\right)+\left(m_{t r} g+m_{v} g a_{2}\right)\right) \\
& +\{N\}^{T}\left(m_{t f} \ddot{\eta}-\left(F_{c f}+F_{k f}\right)+\left(m_{t f} g+m_{v} g a_{1}\right)\right) \\
& =\{0\}
\end{aligned}
$$

With $a_{1}$ as the ratio of rear axle distance from vehicle centre of mass to the vehicle interaxle spacing and $a_{2}$ as the ratio of front axle distance from vehicle centre of mass to the vehicle inter-axle spacing, the rear and front spring and damper forces (Figure 3-5) are given as follows:

$$
\begin{aligned}
& F_{c r}=c_{r}\left(\dot{d}_{1}-\dot{d}_{2} a_{1} S-\dot{\eta}_{r}\right) \\
& F_{k r}=k_{r}\left(d_{1}-d_{2} a_{1} S-\eta_{r}\right) \\
& F_{c f}=c_{f}\left(\dot{d}_{1}+\dot{d}_{2} a_{2} S-\dot{\eta}_{f}\right) \\
& F_{k f}=k_{f}\left(d_{1}+d_{2} a_{2} S-\eta_{f}\right)
\end{aligned}
$$


The complete double-axle vehicle-bridge coupled matrix dynamic system equation is given as:

where:

$\left[\begin{array}{ccc}m_{v} & 0 & \{0\} \\ 0 & \frac{I_{v}}{S^{2}} & \{0\} \\ \{0\} & \{0\} & {[M]+\left[m^{*}\right]}\end{array}\right]\left\{\begin{array}{c}\ddot{d}_{1} \\ \ddot{d}_{2} \\ \{\ddot{D}\}\end{array}\right\}+\left[\begin{array}{ccc}c_{r}+c_{f} & -a_{1} c_{r}+a_{2} c_{f} & \left\{c_{h 1}\right\} \\ -a_{1} c_{r}+a_{2} c_{f} & a_{1}^{2} c_{r}+a_{2}^{2} c_{f} & \left\{c_{h 2}\right\} \\ \left\{c_{v 1}\right\} & \left\{c_{v 2}\right\} & {[C]+\left[c^{*}\right]}\end{array}\right]\left\{\begin{array}{c}\dot{d}_{1} \\ \dot{d}_{2} \\ \{\dot{D}\}\end{array}\right\}+$

$$
\left[\begin{array}{ccc}
k_{r}+k_{f} & -a_{1} k_{r}+a_{2} k_{f} & \left\{k_{h 1}\right\} \\
-a_{1} k_{r}+a_{2} k_{f} & a_{1}^{2} k_{r}+a_{2}^{2} k_{f} & \left\{k_{h 2}\right\} \\
\left\{k_{v 1}\right\} & \left\{k_{v 2}\right\} & {[K]+\left[k^{*}\right]}
\end{array}\right]\left\{\begin{array}{c}
d_{1} \\
d_{2} \\
\{D\}
\end{array}\right\}=\left\{\begin{array}{c}
0 \\
0 \\
\left\{p^{*}\right\}
\end{array}\right\}
$$

$\left[m^{*}\right]=m_{t r}\left\{N_{r}\right\}^{T}\left\{N_{r}\right\}+m_{t f}\{N\}^{T}\{N\}$

$\left.\left[c^{*}\right]=2 m_{t r} v\left\{N_{r}\right\}^{T}\left\{N_{r}\right\}_{, x}\right\}+2 m_{t f} v\{N\}^{T}\{N\}_{, x}+c_{r}\left\{N_{r}\right\}^{T}\left\{N_{r}\right\}$

$\left[k^{*}\right]=m_{t r} v^{2}\left\{N_{r}\right\}^{T}\left\{N_{r}\right\}_{, x x}+m_{t f} v^{2}\{N\}^{T}\{N\}_{, x x}+c_{r} v\left\{N_{r}\right\}^{T}\left\{N_{r}\right\}_{, x}+c_{f} v\{N\}^{T}\{N\}_{, x}+k_{r}\left\{N_{r}\right\}^{T}\left\{N_{r}\right\}+k_{f}\{N\}^{T}\{N\}$

$\left\{p^{*}\right\}=-\left(a_{2} m_{v}+m_{t r}\right) g\left\{N_{r}\right\}^{T}-\left(a_{1} m_{v}+m_{t f}\right) g\{N\}^{T}$ 


$$
\begin{aligned}
& \left\{c_{h 1}\right\}=-c_{r}\left\{N_{r}\right\}-c_{f}\{N\} \\
& \left\{c_{h 2}\right\}=a_{1} c_{r}\left\{N_{r}\right\}-a_{2} c_{f}\{N\} \\
& \left\{c_{v 1}\right\}=-c_{r}\left\{N_{r}\right\}^{T}-c_{f}\{N\}^{T} \\
& \left\{c_{v 2}\right\}=a_{1} c_{r}\left\{N_{r}\right\}^{T}-a_{2} c_{f}\{N\}^{T} \\
& \left\{k_{h 1}\right\}=-c_{r} v\left\{N_{r}\right\}_{, x}-c_{f} v\{N\}_{, x}-k_{r}\left\{N_{r}\right\}-k_{f}\{N\} \\
& \left\{k_{h 2}\right\}=a_{1} c_{r} v\left\{N_{r}\right\}_{, x}-a_{2} c_{f} v\{N\}_{, x}+a_{1} k_{r}\left\{N_{r}\right\}-a_{2} k_{f}\{N\} \\
& \left\{k_{v 1}\right\}=-k_{r}\left\{N_{r}\right\}^{T}-k_{f}\{N\}^{T} \\
& \left\{k_{v 1}\right\}=-k_{r}\left\{N_{r}\right\}^{T}-k_{f}\{N\}^{T} \\
& \left\{k_{v 2}\right\}=a_{1} k_{r}\left\{N_{r}\right\}^{T}-a_{2} k_{f}\{N\}^{T}
\end{aligned}
$$

$\left\{N_{r}\right\}=\left\{\psi_{1}(x-S) \quad \psi_{2}(x-S) \quad \psi_{3}(x-S) \quad \psi_{4}(x-S)\right\}$

$\left\{N_{r}\right\}_{, x}=\left\{\psi_{1}^{\prime}(x-S) \quad \psi_{2}^{\prime}(x-S) \quad \psi_{3}^{\prime}(x-S) \quad \psi_{4}^{\prime}(x-S)\right\}$

$\left\{N_{r}\right\}_{, x x}=\left\{\psi_{1}^{\prime \prime}(x-S) \quad \psi_{2}^{\prime \prime}(x-S) \quad \psi_{3}^{\prime \prime}(x-S) \quad \psi_{4}^{\prime \prime}(x-S)\right\}$

For Equations (3-41) to (3-49), the subscripts 1 and 2 represent the bounce and roll degrees of freedom of the vehicle respectively. 
Figure 3-6 shows the Free Body Diagram of a single axle with sprung and unsprung mass traversing a beam on elastic foundation. This represents a simpler model of a single vehicle on a floating bridge. This model is relatively more accurate the smaller the vehicle inter-axle spacing. The equation of motion of a single axle is simpler to derive and is given in Equation (3-50).

Details of the derivation can be found in El-Desouky (2011).

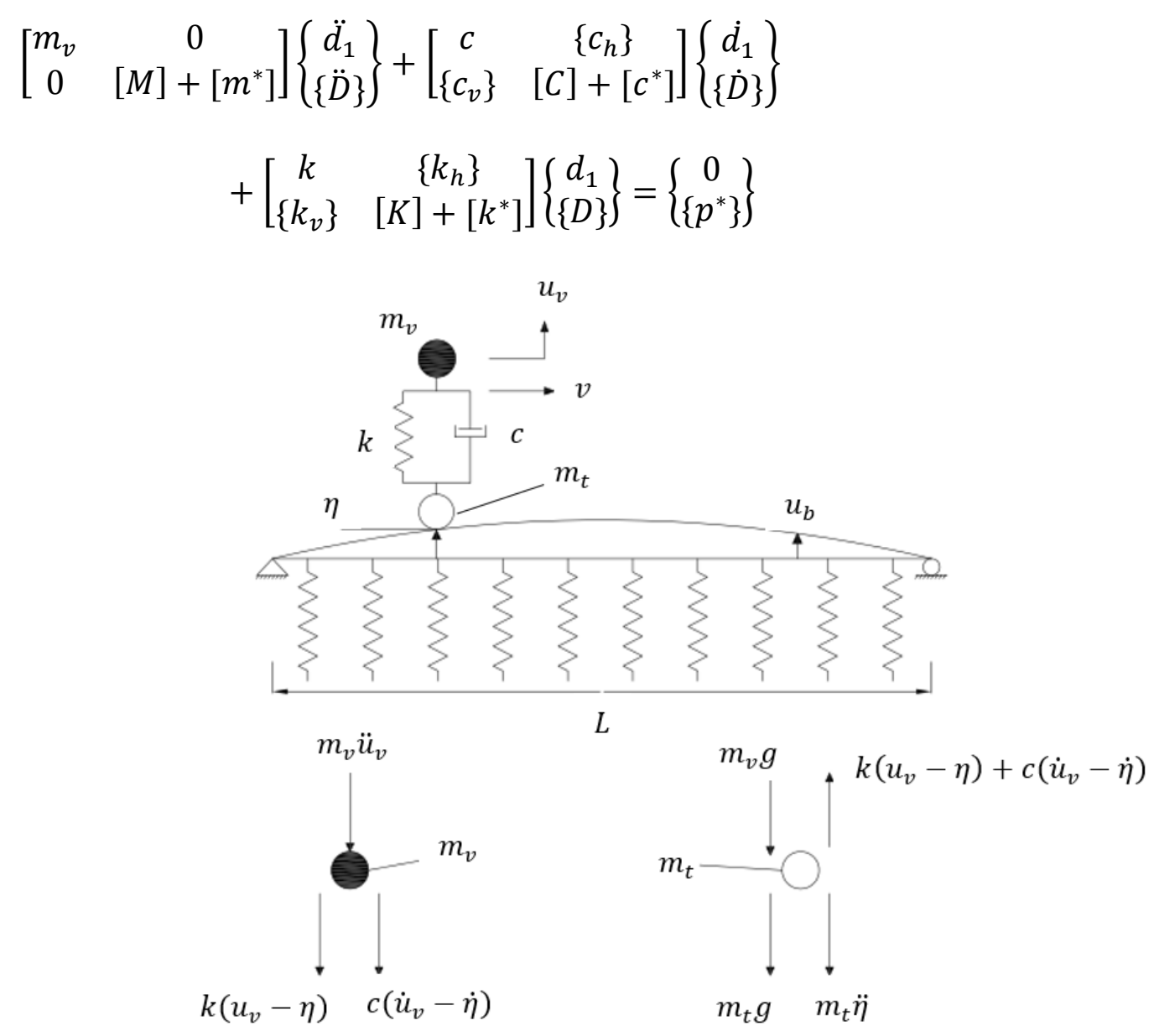

Figure 3-6: Free Body Diagram of floating bridge traversed by single axle (after Humar \& Kashif (1993) 


\subsection{Dynamic Equation of Motion for Bridge Subjected to Two or More Successive Vehicles}

The dynamic equation of motion for a floating bridge subjected to two successive vehicles is obtained by combing the matrix equation of motion of both vehicles with that of the bridge, according to Equation (3-36) to obtain:

$$
\left[\begin{array}{ccccc}
m_{v} & 0 & 0 & 0 & \{0\} \\
0 & \frac{I_{v}}{S^{2}} & 0 & 0 & \{0\} \\
0 & 0 & m_{v} & 0 & \{0\} \\
0 & 0 & 0 & \frac{I_{v}}{S^{2}} & \{0\} \\
\{0\} & \{0\} & \{0\} & \{0\} & {[M]+\left[m^{*}\right]_{2}}
\end{array}\right]\left\{\begin{array}{c}
\ddot{d}_{1} \\
\ddot{d}_{2} \\
\ddot{d}_{3} \\
\ddot{d}_{4} \\
\{\ddot{D}\}
\end{array}\right\}
$$$$
+\left[\begin{array}{ccccc}
c_{r}+c_{f} & -a_{1} c_{r}+a_{2} c_{f} & 0 & 0 & \left\{c_{h 1}\right\} \\
-a_{1} c_{r}+a_{2} c_{f} & a_{1}^{2} c_{r}+a_{2}^{2} c_{f} & 0 & 0 & \left\{c_{h 1 r}\right\} \\
0 & 0 & c_{r}+c_{f} & -a_{1} c_{r}+a_{2} c_{f} & \left\{c_{h 2}\right\} \\
0 & 0 & -a_{1} c_{r}+a_{2} c_{f} & a_{1}^{2} c_{r}+a_{2}^{2} c_{f} & \left\{c_{h 2 r}\right\} \\
\left\{c_{v 1}\right\} & \left\{c_{v 1 r}\right\} & \left\{c_{v 2}\right\} & \left\{c_{v 2 r}\right\} & {[C]+\left[c^{*}\right]_{2}}
\end{array}\right]\left\{\begin{array}{c}
\dot{d}_{1} \\
\dot{d}_{2} \\
\dot{d}_{3} \\
\dot{d}_{4} \\
\{\dot{D}\}
\end{array}\right\}
$$

$$
+\left[\begin{array}{ccccc}
k_{r}+k_{f} & -a_{1} k_{r}+a_{2} k_{f} & 0 & 0 & \left\{k_{h 1}\right\} \\
-a_{1} k_{r}+a_{2} k_{f} & a_{1}^{2} k_{r}+a_{2}^{2} k_{f} & 0 & 0 & \left\{k_{h 1 r}\right\} \\
0 & 0 & k_{r}+k_{f} & -a_{1} k_{r}+a_{2} k_{f} & \left\{k_{h 2}\right\} \\
0 & 0 & -a_{1} k_{r}+a_{2} k_{f} & a_{1}^{2} k_{r}+a_{2}^{2} k_{f} & \left\{k_{h 2 r}\right\} \\
\left\{k_{v 1}\right\} & \left\{k_{v 1 r}\right\} & \left\{k_{v 2}\right\} & \left\{k_{v 2 r}\right\} & {[K]+\left[k^{*}\right]_{2}}
\end{array}\right]\left\{\begin{array}{c}
d_{1} \\
d_{2} \\
d_{3} \\
d_{4} \\
\{D\}
\end{array}\right\}=\left\{\begin{array}{c}
0 \\
0 \\
0 \\
0 \\
\left\{p^{*}\right\}_{2}
\end{array}\right\}
$$


where:

$$
\begin{aligned}
& {\left[m^{*}\right]_{2}=m_{t r} }\left\{N_{r}\right\}^{T}\left\{N_{r}\right\}+m_{t f}\{N\}^{T}\{N\}+m_{t r}\left\{N_{2 r}\right\}^{T}\left\{N_{2 r}\right\}+m_{t f}\left\{N_{2}\right\}^{T}\left\{N_{2}\right\} \\
& c_{2}^{*}=2 m_{t r} v\left\{N_{r}\right\}^{T}\left\{N_{r}\right\}_{, x}+2 m_{t f} v\{N\}^{T}\{N\}_{, x}+c_{r}\left\{N_{r}\right\}^{T}\left\{N_{r}\right\}+c_{f}\{N\}^{T}\{N\} \\
&+2 m_{t r} v\left\{N_{2 r}\right\}^{T}\left\{N_{2 r}\right\}_{, x}+2 m_{t f} v\left\{N_{2}\right\}^{T}\left\{N_{2}\right\}_{, x}+c_{r}\left\{N_{2 r}\right\}^{T}\left\{N_{2 r}\right\} \\
&+c_{f}\left\{N_{2}\right\}^{T}\left\{N_{2}\right\} \\
& k_{2}^{*}=m_{t r} v^{2}\left\{N_{r}\right\}^{T}\left\{N_{r}\right\}_{, x x}+m_{t f} v^{2}\{N\}^{T}\{N\}_{, x x}+c_{r} v\left\{N_{r}\right\}^{T}\left\{N_{r}\right\}_{, x}+c_{f} v\{N\}^{T}\{N\}_{, x} \\
&+k_{r}\left\{N_{r}\right\}^{T}\left\{N_{r}\right\}+k_{f}\{N\}^{T}\{N\}+m_{t r} v^{2}\left\{N_{2 r}\right\}^{T}\left\{N_{2 r}\right\}_{, x x} \\
&+m_{t f} v^{2}\left\{N_{2}\right\}^{T}\left\{N_{2}\right\}_{, x x}+c_{r} v\left\{N_{2 r}\right\}^{T}\left\{N_{2 r}\right\}_{, x}+c_{f} v\left\{N_{2}\right\}^{T}\left\{N_{2}\right\}_{, x} \\
&+ k_{r}\left\{N_{2 r}\right\}^{T}\left\{N_{2 r}\right\}+k_{f}\left\{N_{2}\right\}^{T}\left\{N_{2}\right\} \\
& p_{2}^{*}=-\left(a_{2} m_{v}\right.\left.+m_{t r}\right) g\left\{N_{r}\right\}^{T}-\left(a_{1} m_{v}+m_{t f}\right)\{N\}^{T}-\left(a_{2} m_{v}+m_{t r}\right) g\left\{N_{2 r}\right\}^{T} \\
&-\left(a_{1} m_{v}+m_{t f}\right)\left\{N_{2}\right\}^{T}
\end{aligned}
$$$$
\left\{c_{h 1}\right\}=-c_{r}\left\{N_{r}\right\}-c_{f}\{N\}
$$$$
\left\{c_{h 1 r}\right\}=a_{1} c_{r}\left\{N_{r}\right\}-a_{2} c_{f}\{N\}
$$$$
\left\{c_{h 2}\right\}=-c_{r}\left\{N_{2 r}\right\}-c_{f}\left\{N_{2}\right\}
$$$$
\left\{c_{h 2 r}\right\}=a_{1} c_{r}\left\{N_{2 r}\right\}-a_{2} c_{f}\left\{N_{2}\right\}
$$$$
\left\{c_{v 1}\right\}=-c_{r}\left\{N_{r}\right\}^{T}-c_{f}\{N\}^{T}
$$$$
\left\{c_{v 1 r}\right\}=a_{1} c_{r}\left\{N_{r}\right\}^{T}-a_{2} c_{f}\{N\}^{T}
$$ 


$$
\begin{aligned}
& \left\{c_{v 2}\right\}=-c_{r}\left\{N_{2 r}\right\}^{T}-c_{f}\left\{N_{2}\right\}^{T} \\
& \left\{c_{v 2 r}\right\}=a_{1} c_{r}\left\{N_{2 r}\right\}^{T}-a_{2} c_{f}\left\{N_{2}\right\}^{T} \\
& \left\{k_{h 1}\right\}=-c_{r} v\left\{N_{r}\right\}_{, x}-c_{f} v\{N\}_{, x}-k_{r}\left\{N_{r}\right\}-k_{f}\{N\} \\
& \left\{k_{h 1 r}\right\}=a_{1} c_{r} v\left\{N_{r}\right\}_{, x}-a_{2} c_{f} v\{N\}_{, x}+a_{1} k_{r}\left\{N_{r}\right\}-a_{2} k_{f}\{N\} \\
& \left\{k_{h 2}\right\}=-c_{r} v\left\{N_{2 r}\right\}_{, x}-c_{f} v\left\{N_{2}\right\}_{, x}-k_{r}\left\{N_{2 r}\right\}-k_{f}\left\{N_{2}\right\} \\
& \left\{k_{h 2 r}\right\}=a_{1} c_{r} v\left\{N_{2 r}\right\}_{, x}-a_{2} c_{f} v\left\{N_{2}\right\}_{, x}+a_{1} k_{r}\left\{N_{2 r}\right\}-a_{2} k_{f}\left\{N_{2}\right\} \\
& \left\{k_{v 1}\right\}=-k_{r}\left\{N_{r}\right\}^{T}-k_{f}\{N\}^{T} \\
& \left\{k_{v 1 r}\right\}=a_{1} k_{r}\left\{N_{r}\right\}^{T}-a_{2} k_{f}\{N\}^{T} \\
& \left\{k_{v 2}\right\}=-k_{r}\left\{N_{2 r}\right\}^{T}-k_{f}\left\{N_{2}\right\}^{T} \\
& \left\{k_{v 2 r}\right\}=a_{1} k_{r}\left\{N_{2 r}\right\}^{T}-a_{2} k_{f}\left\{N_{2}\right\}^{T} \\
& \{N\}_{2}=\left\{\psi_{1}\left(x-S-S_{v}\right) \quad \psi_{2}\left(x-S-S_{v}\right) \quad \psi_{3}\left(x-S-S_{v}\right) \quad \psi_{4}\left(x-S-S_{v}\right)\right\} \\
& \{N\}_{2 r}=\left[\begin{array}{llll}
\psi_{1}\left(x-2 S-S_{v}\right) & \psi_{2}\left(x-2 S-S_{v}\right) & \psi_{3}\left(x-2 S-S_{v}\right) & \psi_{4}\left(x-2 S-S_{v}\right)
\end{array}\right]
\end{aligned}
$$

where $x$ is the position of the leading vehicle front axle and $\left\{N_{2}\right\},\left\{N_{2 r}\right\}$ are the is the value of the beam shape function evaluated at the rear vehicle front axle and rear axle respectively. $S_{v}$ is the inter-vehicle spacing defined as the distance between the leading vehicle rear axle and rear vehicle front axle. 
For $n$ vehicles, the equation of motion becomes:

$$
\left[\begin{array}{cccccc}
m_{v} & 0 & 0 & 0 & 0 & \{0\} \\
0 & \frac{I_{v}}{S^{2}} & 0 & 0 & 0 & \{0\} \\
0 & 0 & \ddots & \vdots & \vdots & \vdots \\
0 & 0 & \cdots & m_{v} & 0 & \{0\} \\
0 & 0 & \cdots & 0 & \frac{I_{v}}{S^{2}} & \{0\} \\
\{0\} & \{0\} & \cdots & \{0\} & \{0\} & {[M]+\left[m^{*}\right]_{n}}
\end{array}\right]\left\{\begin{array}{c}
\ddot{d}_{1} \\
\ddot{d}_{2} \\
\vdots \\
\ddot{d}_{2 n-1} \\
\ddot{d}_{2 n} \\
\{\ddot{D}\}
\end{array}\right\}
$$

$$
+\left[\begin{array}{cccccc}
c_{r}+c_{f} & -a_{1} c_{r}+a_{2} c_{f} & 0 & 0 & 0 & \left\{c_{h 1}\right\} \\
-a_{1} c_{r}+a_{2} c_{f} & a_{1}^{2} c_{r}+a_{2}^{2} c_{f} & 0 & 0 & 0 & \left\{c_{h 1 r}\right\} \\
0 & 0 & \ddots & \vdots & \vdots & \vdots \\
0 & 0 & \cdots & c_{r}+c_{f} & -a_{1} c_{r}+a_{2} c_{f} & \left\{c_{h n}\right\} \\
0 & 0 & \cdots & -a_{1} c_{r}+a_{2} c_{f} & a_{1}^{2} c_{r}+a_{2}^{2} c_{f} & \left\{c_{h n r}\right\} \\
\left\{c_{v 1}\right\} & \left\{c_{v 1 r}\right\} & \cdots & \left\{c_{v n}\right\} & \left\{c_{v n r}\right\} & {[C]+\left[c^{*}\right]_{n}}
\end{array}\right]\left\{\begin{array}{c}
\dot{d}_{1} \\
\dot{d}_{2} \\
\vdots \\
\dot{d}_{2 n-1} \\
\dot{d}_{2 n} \\
\dot{D}\}
\end{array}\right\}
$$

$$
+\left[\begin{array}{cccccc}
k_{r}+k_{f} & -a_{1} k_{r}+a_{2} k_{f} & 0 & 0 & 0 & \left\{k_{h 1}\right\} \\
-a_{1} k_{r}+a_{2} k_{f} & a_{1}^{2} k_{r}+a_{2}^{2} k_{f} & 0 & 0 & 0 & \left\{k_{h 1 r}\right\} \\
0 & 0 & \ddots & \vdots & \vdots & \vdots \\
0 & 0 & \cdots & k_{r}+k_{f} & -a_{1} k_{r}+a_{2} k_{f} & \left\{k_{h n}\right\} \\
0 & 0 & \cdots & -a_{1} c_{r}+a_{2} c_{f} & a_{1}^{2} k_{r}+a_{2}^{2} k_{f} & \left\{k_{h n r}\right\} \\
\left\{k_{v 1}\right\} & \left\{k_{v 1 r}\right\} & \cdots & \left\{k_{v n}\right\} & \left\{k_{v n r}\right\} & {[K]+\left[k^{*}\right]_{n}}
\end{array}\right]\left\{\begin{array}{c}
d_{1} \\
d_{2} \\
\vdots \\
d_{2 n-1} \\
d_{2 n} \\
\{D\}
\end{array}\right\}=\left\{\begin{array}{c}
0 \\
0 \\
\vdots \\
0 \\
0 \\
\left\{p^{*}\right\}_{n}
\end{array}\right\}
$$




\subsubsection{Previous Formulation for Floating Bridge Traversed by Two Vehicles}

For the case of two vehicles moving on the floating bridge El-Desouky (2011)represented each vehicle as a separate single axle (Figure 3-6), which is less accurate than considering two double-axle vehicle models, as given in Equation 3-46. Also, bridge response to multiple double-axle vehicles was not in the study by El-Desouky (2011.

\subsection{Floating Bridge Dynamic Response}

The matrix Equation (3-52) of the vehicle-bridge dynamic system has mass, damping and stiffness matrices which can be termed as pseudostatic, as they change based on the vehicle location along the bridge deck. An analytical closed-form solution of the bridge response is difficult, if not impossible, to determine.

Thus, to solve the dynamic equation of motion, a numerical time-stepping Newmark's average acceleration procedure, which is unconditionally stable, was employed. A timestep was however chosen to be smaller than one-tenth of the fundamental natural period of the bridge. The Newmark average acceleration equations for a multiple degree of freedom system are given as follows (Humar, 2002):

$$
\begin{aligned}
& \begin{aligned}
\left(\frac{4[M]}{h^{2}}+\frac{2[C]}{h}\right. & +[K])\{u\}_{n+1} \\
& =\{p\}_{n+1}+[M]\left(\frac{4}{h^{2}}\{u\}_{n}+\frac{4}{h}\{\dot{u}\}_{n}+\{\ddot{u}\}_{n}\right) \\
& +[C]\left(\frac{2}{h}\{u\}_{n}+\{\dot{u}\}_{n}\right)
\end{aligned} \\
& \{\dot{u}\}_{n+1}=-\left\{\dot{u}_{n}\right\}+\frac{2}{h}\left(\{u\}_{n+1}-\{u\}_{n}\right)
\end{aligned}
$$




$$
\{\ddot{u}\}_{n+1}=\frac{4}{h^{2}}\left(\{u\}_{n+1}-\{u\}_{n}-h\{\dot{u}\}_{n}\right)-\{\ddot{u}\}_{n}
$$

where $[M],[C],[K]$ are the mass stiffness and damping matrices of the dynamic system, which in the current application, vary at each time step $h$.

A finite element based Matlab program was developed by El-Desouky (2011) to assemble the element matrices into the global bridge matrix and to evaluate the Newmark equations at specified time-steps. A full account of the determination of floating bridge response to single- and double-axle vehicles is provided in (El-Desouky, 2011). In the present study, the finite element program developed by El-Desouky was expanded to simulate the bridge response to multiple double-axle vehicles. The dynamic characteristics of the vehicles and their impact on the floating bridge response was also implemented.

The following are some assumptions made in evaluating the floating bridge response to moving vehicle loads:

- The vehicle(s) is assumed to travel at constant speed across the bridge. This is a practical requirement for ribbon pontoon floating bridges

- The vehicle(s) is assumed to travel on the longitudinal centre line of the bridge with minimal transverse eccentricity 
The following (Figure 3-7) is a flowchart of the Matlab program developed to determine the floating bridge response for multiple vehicles. The program requires as input the vehicle mass (ton), vehicle strut stiffness ( $N / m)$, inter-vehicle spacing $(m)$, vehicle speed $(\mathrm{km} / \mathrm{hr})$, number of vehicles. The outputs the program are dofs $\times$ Nstep matrix of the system response where dofs is the number of global degrees of freedom of the vehiclebridge system, and Nstep is the number of analytical timesteps at which the system response is calculated.

A time lapse video of the bridge response is also generated by successively plotting the bridge displacements at each timestep. The main Matlab program has a separate input file which is loaded during program execution. 


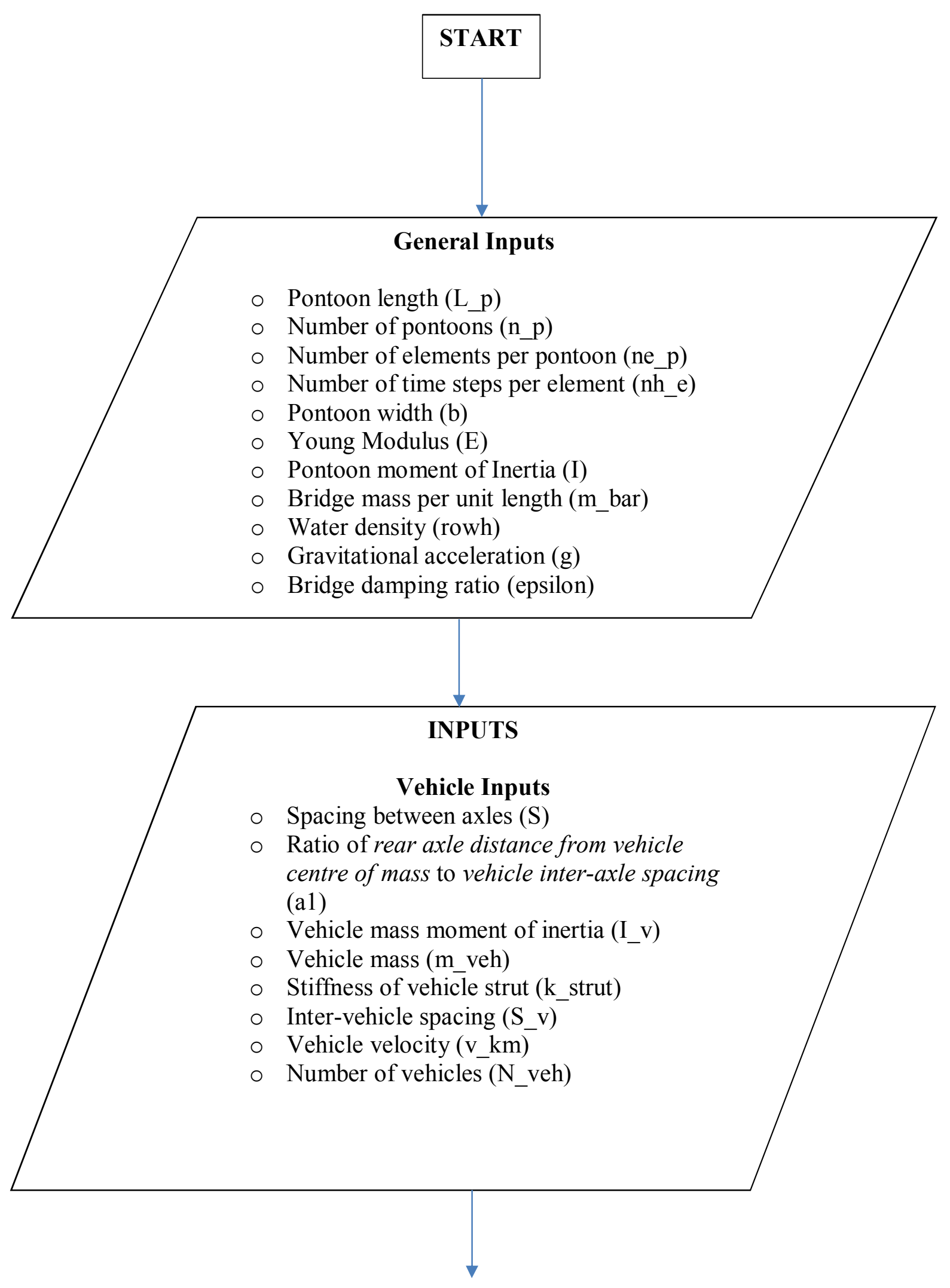




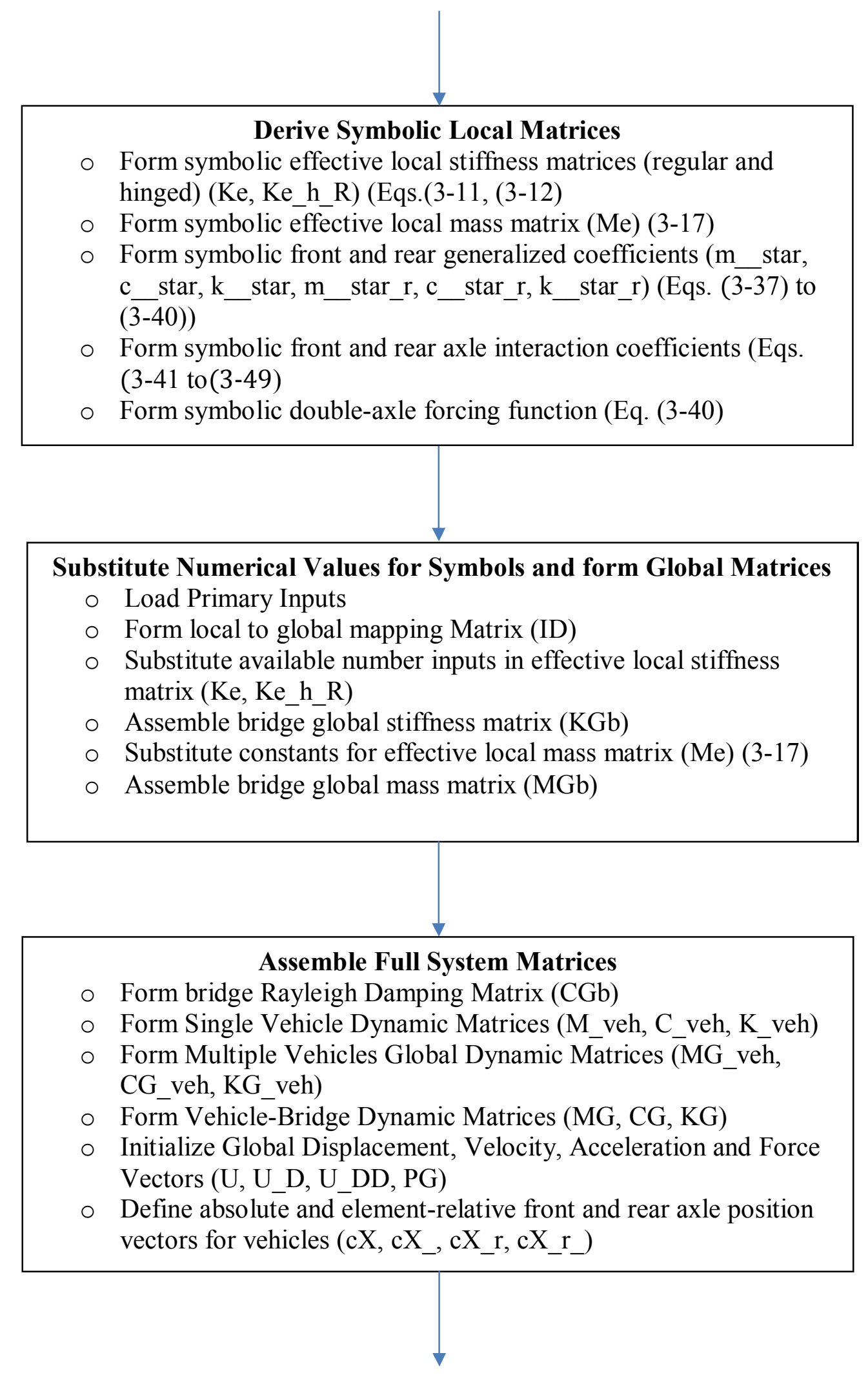




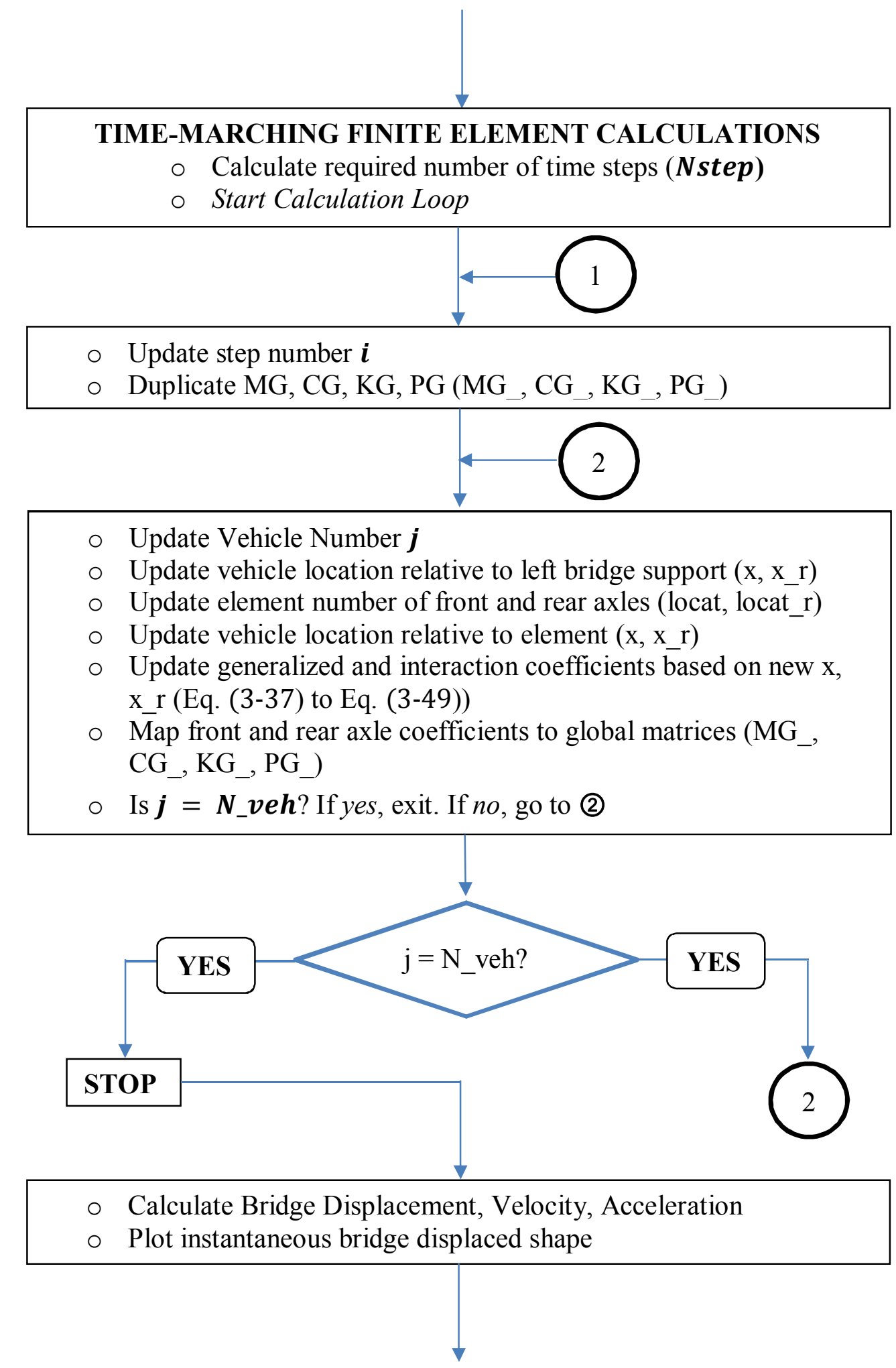




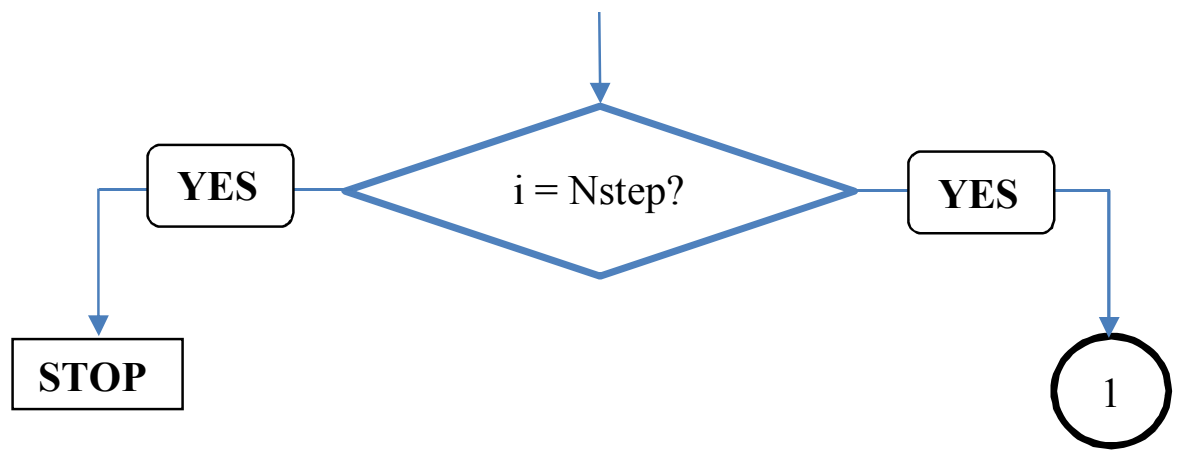

Figure 3-7: Flowchart of MatLab Finite Element Program 


\section{Chapter: Experimental Investigation}

A 1:25 scaled model of a pontoon floating bridge was constructed and used to simulate the effect of two successive vehicles on the displacement of the hinge-connected ribbon pontoon floating bridge. The weight of vehicles, speed and inter-vehicle spacing were varied to determine their effect on the vertical displacement of the floating bridge.

In addition to studying the effects of vehicle crossings at a scaled down level, the experimental setup was also used to validate the numerical finite element program developed in Matlab to investigate vehicle crossings using a wider range of bridge design parameters.

\subsection{Test Apparatus}

The setup for testing the model floating bridge is represented in Figure 4-1 in the form of a flowchart. The experimental setup consists of the following components:

1. Test bench

2. Turnkey potentiometer

3. Two 1:25 scale model vehicles with weight ballasts

4. Vehicle spacers of various lengths

5. 5 Linear Variable Displacement Transducers (LVDTs)

6. Spiderwire $\AA$

7. Spiral spring

8. National Instruments Data Acquisition System

9. Ametek 30V DC Motor

10. HP System Power Supply (2 No.) 
A 30V DC motor, powered by an HP System Power Supply Unit was used to drive the model vehicles across the bridge. Another power supply was used to power the Turnkey Potentiometer and LVDTs. The Turnkey Potentiometer was used to measure the vehicle velocity while the LVDTs were used to measure the vertical displacements of the bridge at predetermined locations.

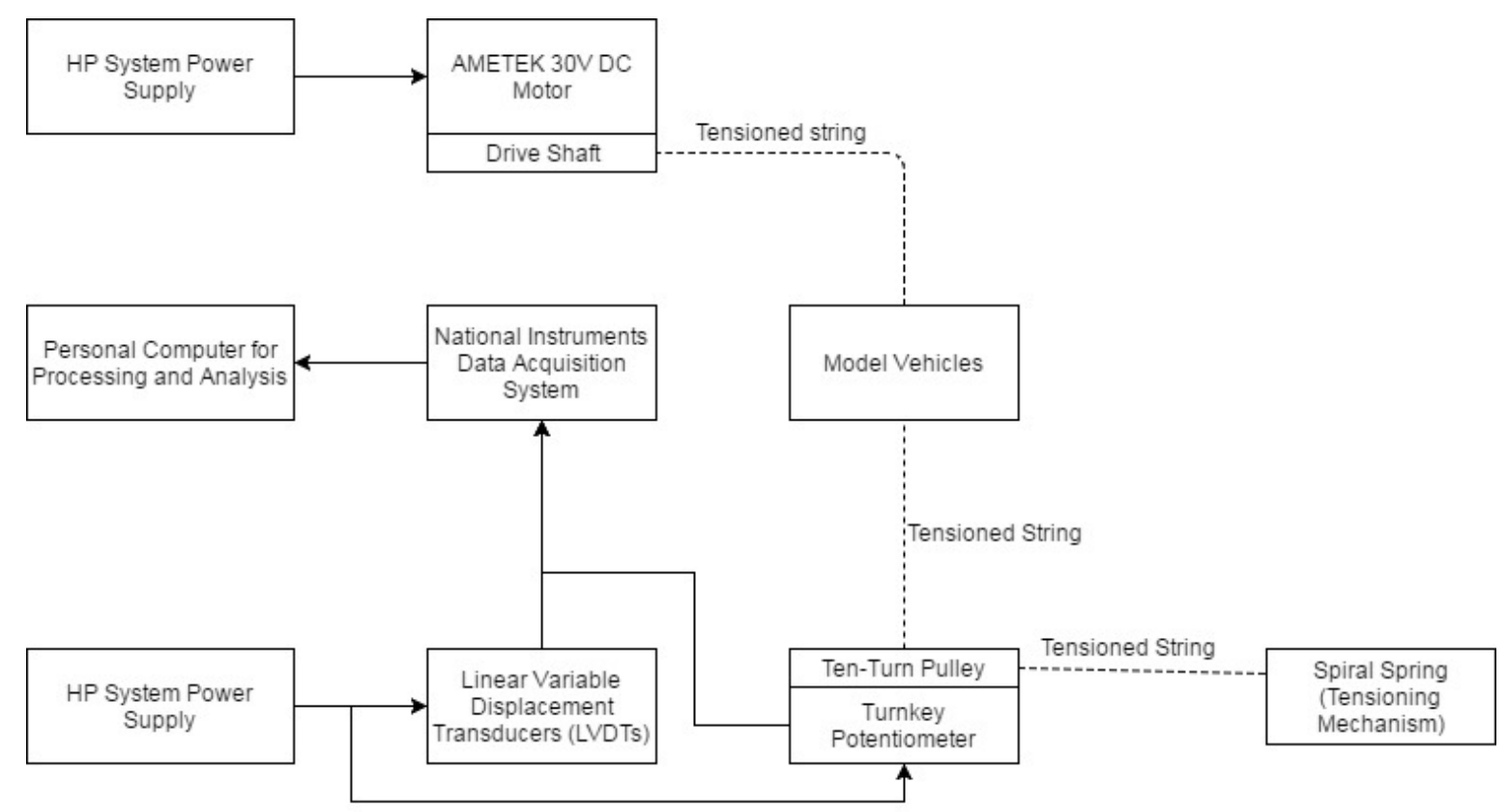

Figure 4-1: Schematic of Test Apparatus

The National Instruments ${ }^{\circledR}$ Data Acquisition System (DAQ) was used to log the voltage data from the Turnkey Potentiometer and LVDT channels for processing on a Personal Computer. DAQ sampling rate was set to $100 \mathrm{~Hz}$ for both the turnkey potentiometer and LVDTs.

\subsubsection{Test Bench}

A test bench made of lumber and plywood (Figure 4-2) was constructed to primarily accommodate the water obstacle (pontoon floating bridge) and approach and exit ramps 
as well as LVDTs used to measure the bridge displacements along its length. The entry and exit ramps (platforms) were extended from a bench previously used for single vehicle tests (G. Viecili et al., 2014) so as to accommodate two successive vehicles at a maximum spacing of $1.60 \mathrm{~m}$.

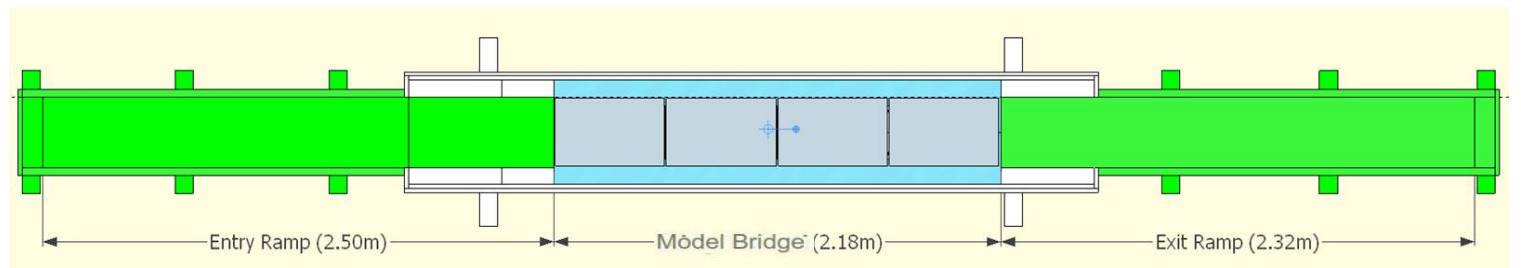

Figure 4-2: Experimental Test Bench

A polystyrene guide was constructed on the entry ramp, model bridge, and exit ramp to keep the vehicle in a straight line during crossings.

The middle portion of the test bench is a tank to contain the pontoon bridge water obstacle. The tank is $2,438 \mathrm{~mm}$ long, $508 \mathrm{~mm}$ wide and $184 \mathrm{~mm}$ deep, holding a total water volume of 228 litres, and sealed to prevent water leakages.

\subsubsection{Pontoon Design}

The 1/25-scale model of a 4-pontoon prototype floating bridge was constructed to simulate the response of a prototype ribbon floating bridge. In assembling a ribbon hingeconnected floating bridge, it is common in the field to rigidly connect two pontoons (Figure 4-3) to form a single unit of $540 \mathrm{~mm}$ length The experimental hinge-connected bridge tested is made up of 4 such units and scaled down by a length factor of 25 The tested bridge model has a width of $340 \mathrm{~mm}$ and a depth of $47.3 \mathrm{~mm}$. The cross-section dimensions of a model pontoon are shown in Figure 4-4. 


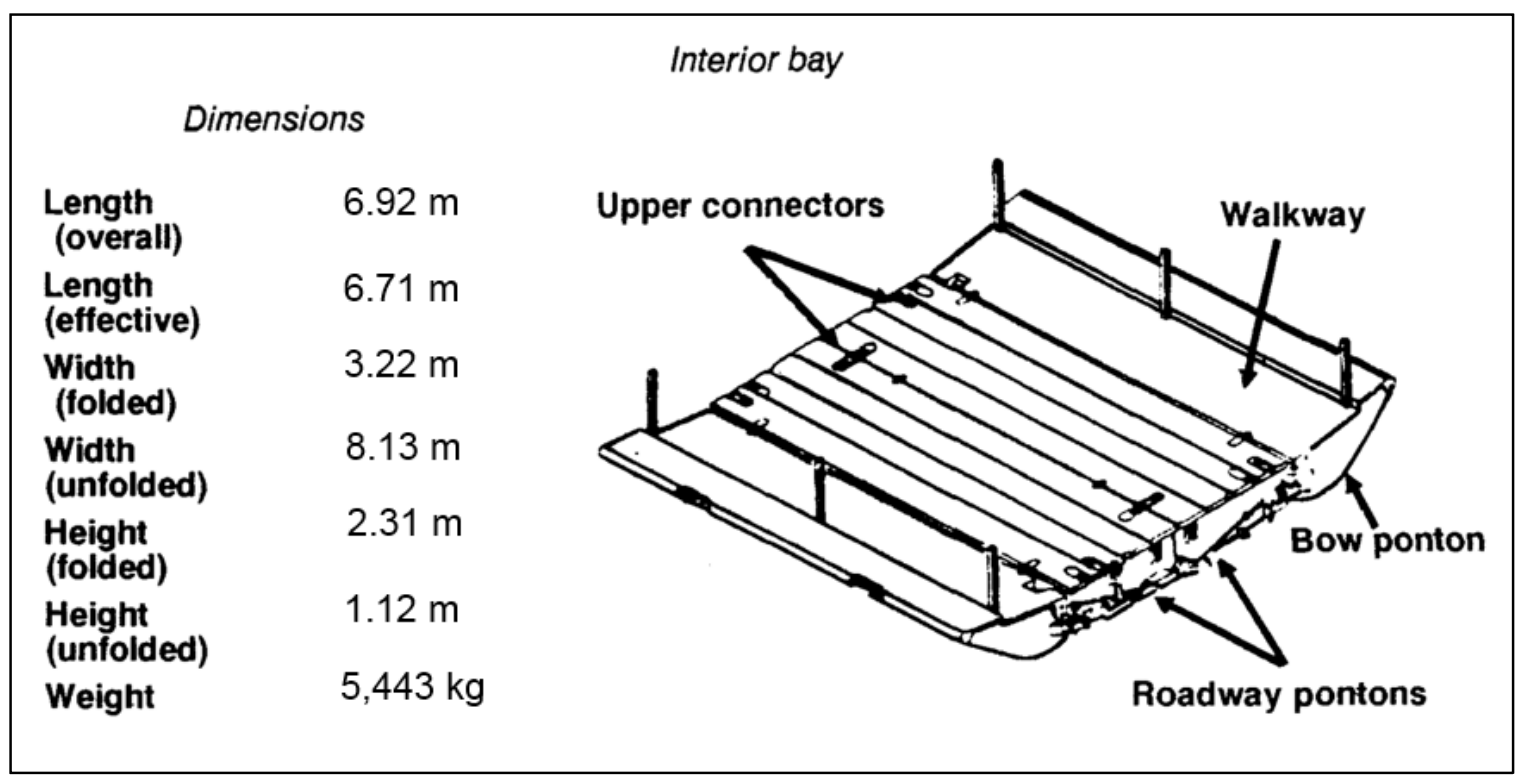

Figure 4-3: Schematic Layout of the Interior Bay of a Ribbon Floating Bridge (http://www.army-technology.com)

The interior of the model pontoon contains an interlocking grid of plates (Figure 4-5) to maintain the structural integrity of the pontoon deck under vehicle loading. In practice, the interlocking grid is made of concrete or steel into watertight compartments which serve to localize interior flooding in the event of rupture of the outer shell of the pontoon.

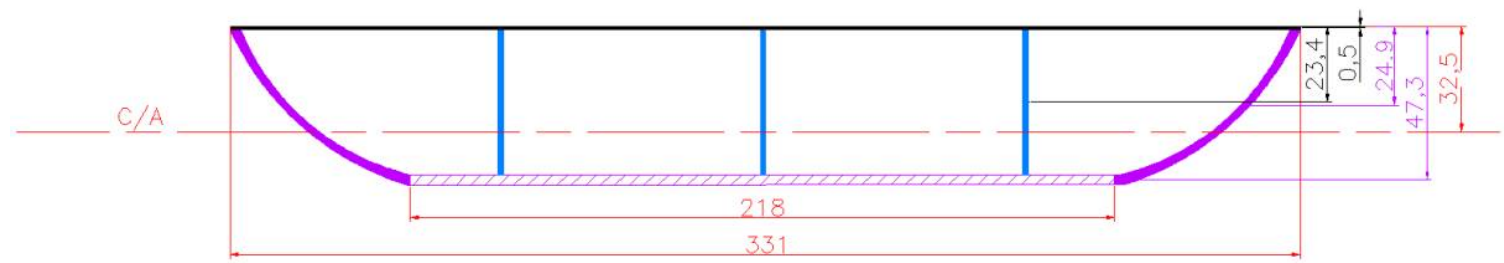

Figure 4-4: Model Pontoon Cross Section (G. Viecili et al., 2014) 


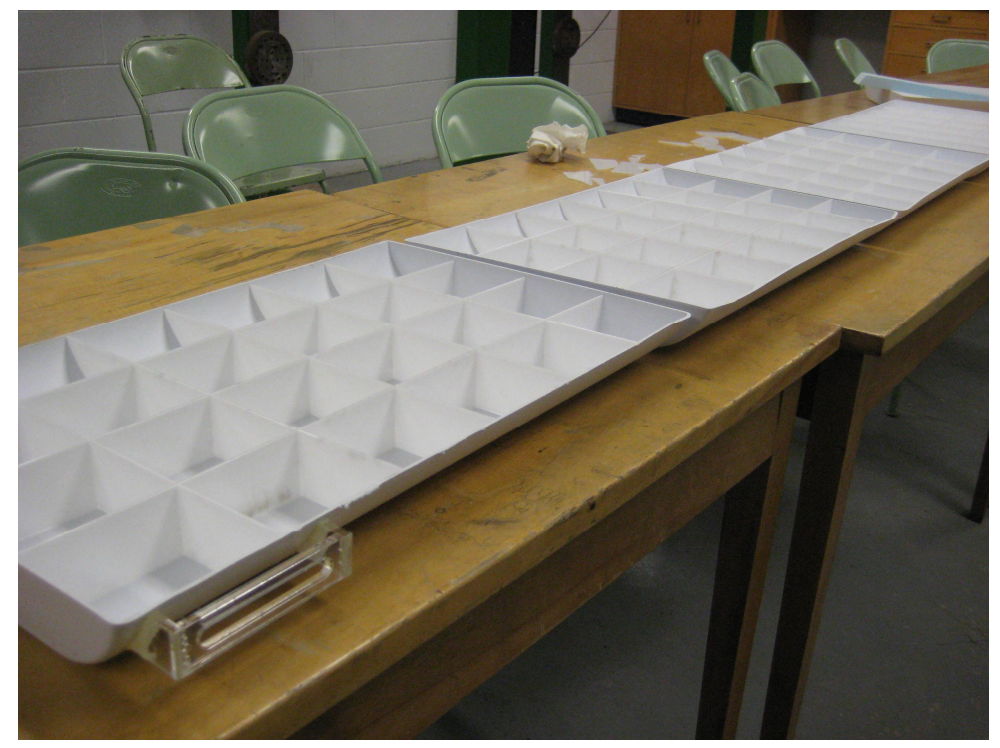

Figure 4-5: Interlocking grid within pontoons (G. Viecili et al., 2014)

The equivalent volumetric scale for a linear scale of 25 is equal to $25^{3}$. And thus

$V_{\text {model }}=\frac{V_{\text {prototype }}}{25^{3}}$

Assuming the prototype and model have the same average density, the model pontoon mass is given by

$M_{\text {model }}=\frac{M_{\text {prototype }}}{25^{3}}$

where $V$ and $M$ represent volume and mass respectively.

The model bridge is made up of four $540 \mathrm{~mm}$ long pontoons connected by hinged joints. The total length of the ribbon pontoon floating bridge model is $2.18 \mathrm{~m}$. 


\subsubsection{Hinge Connection Design}

Connections are very important in determining the displacement response of ribbon pontoon floating bridges and may be either rigid- or hinge-connected. The specific connection type determines the response characteristics of the bridge such as natural frequency of vibration as well as the amplitude of vibration (Fu \& Cui, 2012).

The rigid-connected bridge results in less bridge displacement but imposes higher stresses on the connections. The hinge connection of the pontoons consists of two ear lug connectors as shown in Figure 4-6, and a pin. This type of connection design allows for the free relative rotation of adjacent pontoons to simulate a hinge-connected bridge.

The hinge connection is used because it eliminates bending moment in the floating bridge and at connections and ensures that maximum water buoyancy is mobilized by the pontoons to support vehicle loads. In terms of resonance of vehicle induced loads with the floating bridge, the hinge-connected bridge results in lower natural frequency of vibration of the bridge, and a wider range of safe inter-vehicle spacing at various travelling speeds. 


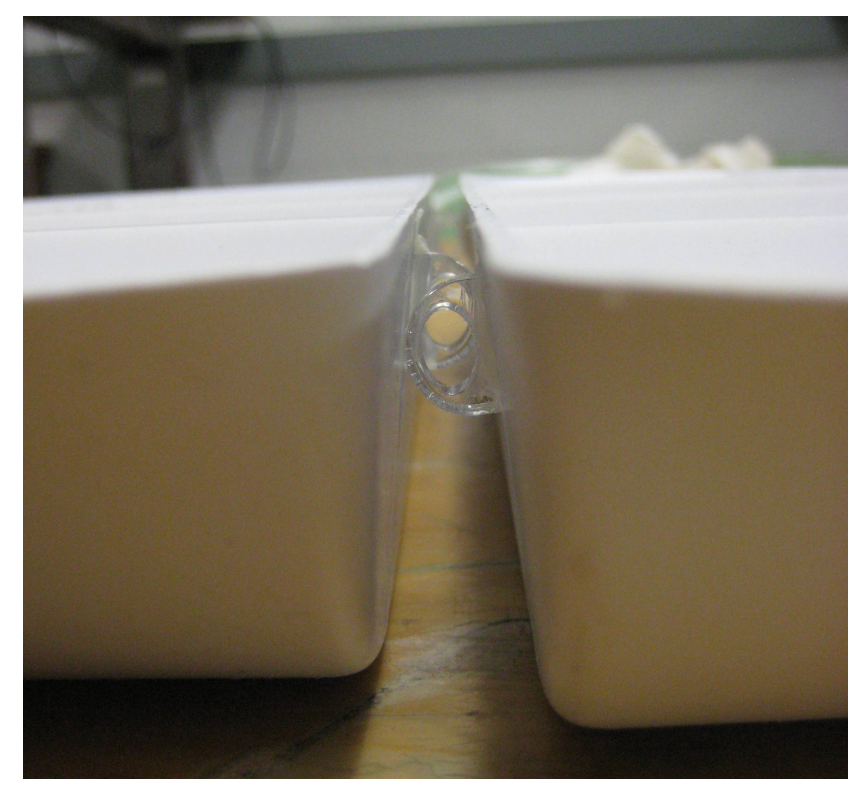

Figure 4-6: Pontoon hinge connectors (G. Viecili et al., 2014)

Bridge supports were modelled in the form of a socket and a slider to simulate pin and roller supports respectively (Figure 4-7). A polystyrene track (Figure 4-8) collinear with the center of the pontoons on the approach and exit ramps as well as on the model bridge deck ensures that the vehicle remains in the middle of the bridge during crossing.

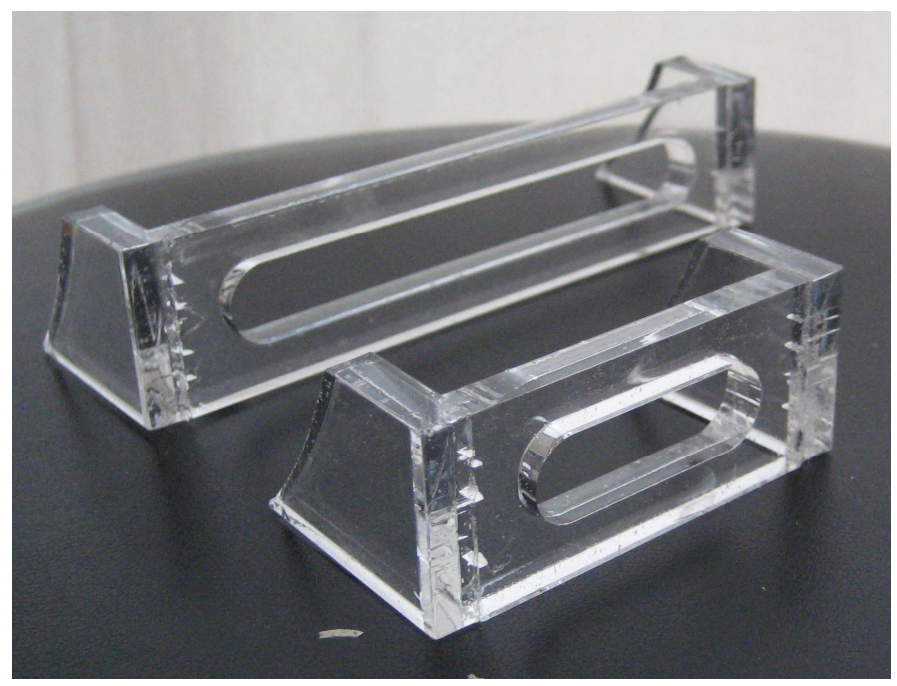

Figure 4-7: Slider and Socket Bridge Supports 


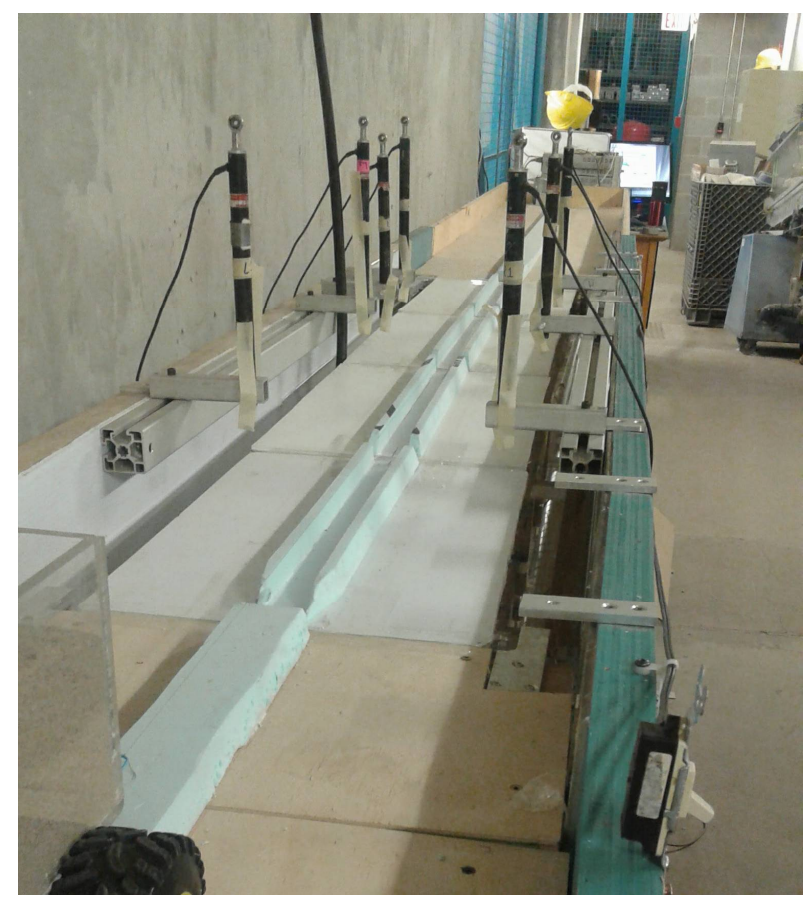

Figure 4-8: Vehicle Polystyrene Guide and LVDTs

\subsubsection{Vehicle Design}

The vehicle weights tested were based on the Military Load Classification System which assigns a class to a vehicle based on its gross weight in tons. The model cars used are based on a hypothetical prototype weight of 40 tons, 45 tons and 50 tons, which, according to a scale of $1 / 25^{3}$ correspond to model vehicle weights of $2.56 \mathrm{~kg}, 2.88 \mathrm{~kg}$ and $3.20 \mathrm{~kg}$ respectively.

A specified weight of sand was deposited into the vehicle to achieve the desired model vehicle weight (Figure 4-9). Table 4-1 shows the prototype vehicle weights and corresponding weights for the laboratory tests. 


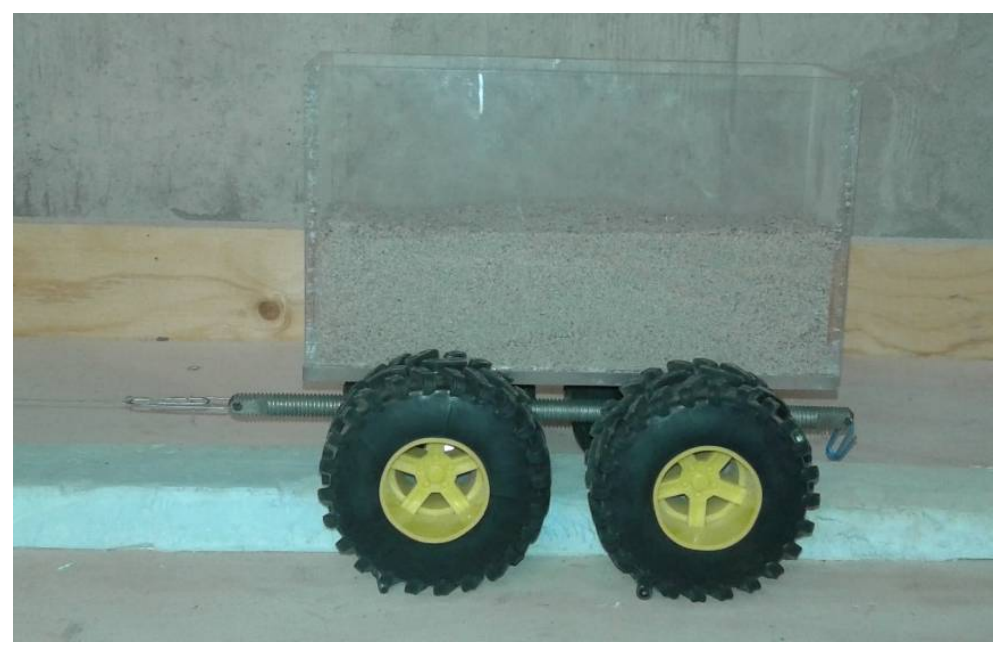

Figure 4-9: Test Vehicle

Table 4-1: Vehicle Test Weights

\begin{tabular}{|l|l|l|}
\hline Prototype Mass (tons) & Prototype Mass (kg) & Model Car Mass (kg) \\
\hline 40 & 40,000 & 2.56 \\
\hline 45 & 45,000 & 2.88 \\
\hline 50 & 50,000 & 3.20 \\
\hline
\end{tabular}

A model vehicle with $0.11 \mathrm{~m}$ inter-axle spacing was designed to apply dynamic vertical wheel loads on the floating bridge. The vehicle model allows for varying the vehicle weight by adding specific weights of sand. Inter-vehicle spacers (Figure 4-10) were used to provide specified and consistent spacing between the two vehicles ranging from $0.4 \mathrm{~m}$ to $1.6 \mathrm{~m}$. 


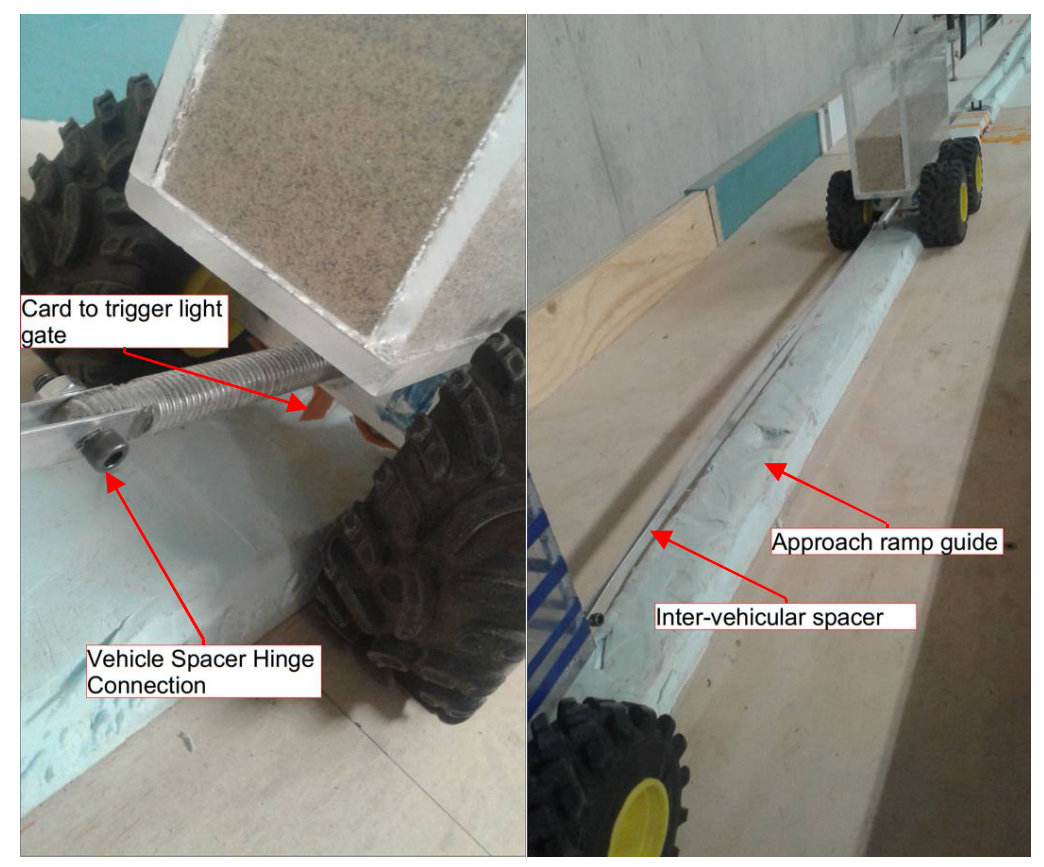

Figure 4-10: Inter-vehicle Connection and Light Gate Trigger

The inter-vehicle spacers are hinged to each model vehicle such that no moment is transferred between vehicle shafts due to difference in vehicle elevations while crossing the bridge. The vehicle speeds tested are shown in Table 4-2.

Table 4-2: Vehicle Test Speeds

\begin{tabular}{|l|l|l|}
\hline $\begin{array}{l}\text { Prototype Speed } \\
\mathbf{( k m} / \mathbf{h r})\end{array}$ & $\begin{array}{l}\text { Prototype Speed } \\
\mathbf{( m / s )}\end{array}$ & Model Vehicle Speed (m/s) \\
\hline 25 & 6.944 & 0.278 \\
\hline 40 & 11.111 & 0.444 \\
\hline 60 & 16.667 & 0.667 \\
\hline
\end{tabular}

\subsection{Testing Procedure}

A 30V DC Ametek motor was used to provide the driving force to advance the model vehicles across the bridge at the design velocities. The vehicle was pulled along by a taut 
Spiderwire ${ }^{\circledR}$ string across the bridge along its centerline and was wound around the rotating shaft of the drive motor. The motor reels in the string at different speeds based on the motor input voltage.

To determine the travelling speed of the model car, another string was attached behind the vehicle or rear vehicle in the case of two vehicles and passed round the pulley wheel of a turnkey potentiometer, (Figure 4-11) and finally fed into a spiral spring tensioning unit. Tautening the string ensures that it does not slip around the pulley when the vehicle(s) advanced across the bridge.

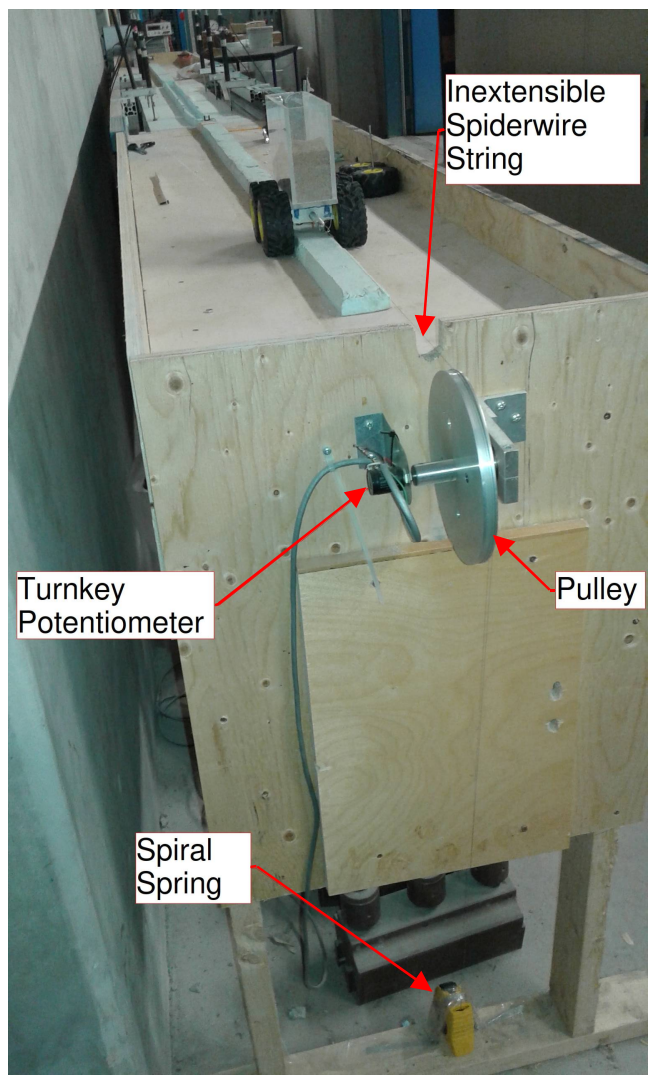

Figure 4-11: Rear End of Test Apparatus

As the vehicles advance and the pulley rotates, the travelling speed of the vehicles could be determined based on the rate of variation of the turnkey potentiometer voltage. Figure 
4-12 and Figure 4-13 show the elevation view and cross-section of the test apparatus respectively.

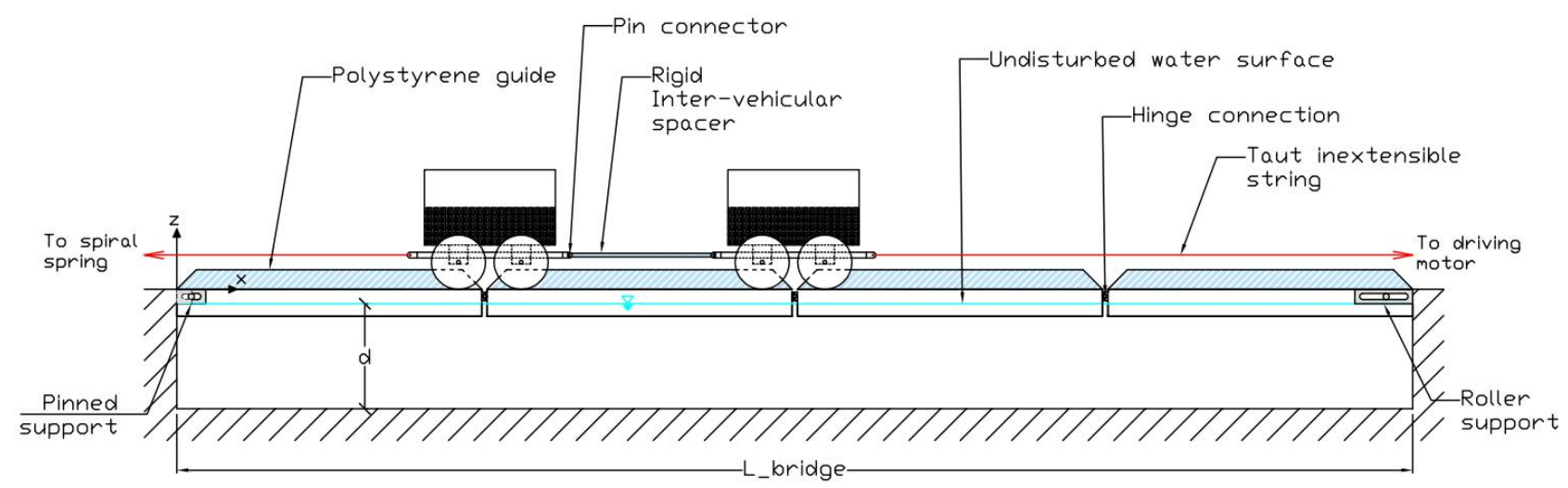

Figure 4-12: Schematic of Floating Bridge Test Apparatus

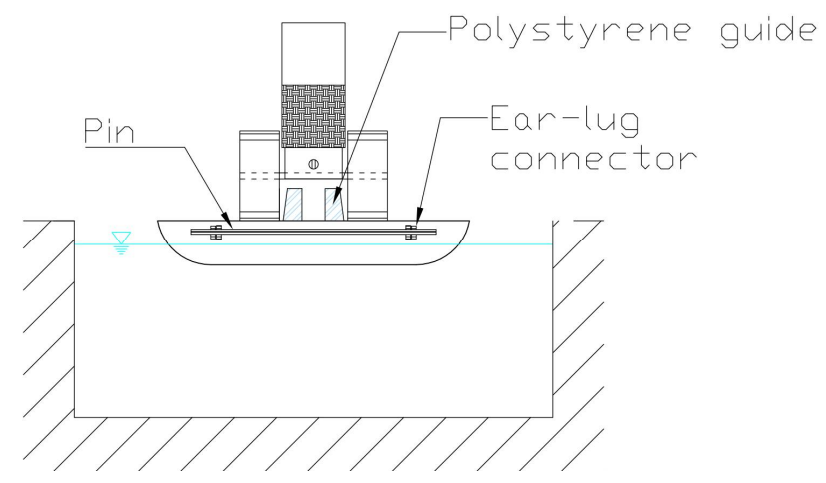

Figure 4-13: Bridge Cross-Section Showing Hinge Connection

The vertical displacements of the pontoon joints were measured using six LVDTs positioned along the model bridge as shown in Figure 4-14. LVDTs were positioned on adjacent pontoons about each hinge-connected end to enable measurement of differential displacements on opposite sides of a pontoon joint. 


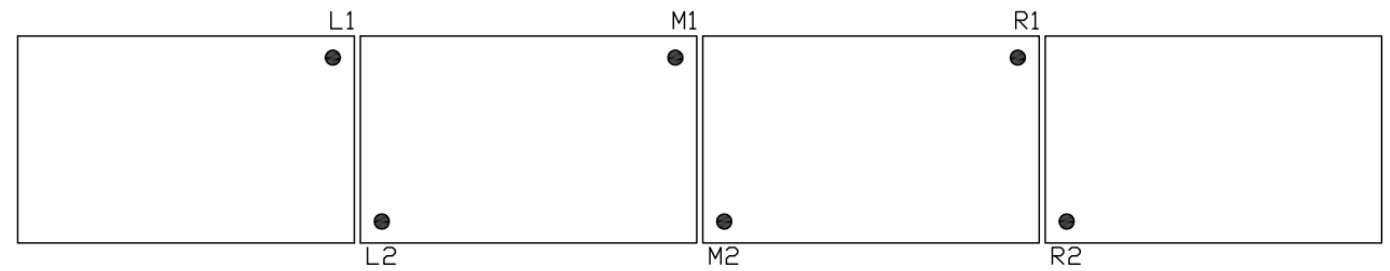

Figure 4-14: LVDT Recording Stations on Model Bridge

For two vehicle tests, the inter-vehicle spacers used to separate the two vehicles were made of rigid aluminum strips. This did not only ensure that the two vehicles were always at the specified distance apart, but also serves as a connection by which the leading vehicle pulled the following vehicle across the bridge. Table 4-3 presents the inter-vehicle spacing tested.

Table 4-3: Inter-vehicle Spacing

\begin{tabular}{|l|l|}
\hline Prototype Vehicle Spacing (m) & $\mathbf{1 / 2 5}$ Model Vehicle Spacing (m) \\
\hline 20 & 0.8 \\
\hline 25 & 1.0 \\
\hline $30 *$ & 1.2 \\
\hline 40 & 1.6 \\
\hline
\end{tabular}

* Current MLC recommended minimum spacing

\subsection{Calibration of Experimental Equipment}

The turnkey output voltage was directly proportional to the degree of rotation of the turnkey pulley from a reference position. Both the turnkey potentiometer and LVDTs were calibrated to determine the appropriate calibration factors for the DAQ system. 


\subsubsection{Calibration of Turnkey Potentiometer and Driving Motor}

The turnkey potentiometer measures the travelling speed of the cars. To obtain the distance - voltage relationship of the turn-key, fixed lengths were marked on the string that passes round the pulley groove connected to the turnkey potentiometer. The nonflexible string was advanced for known distances and the resulting voltage recorded. The calibration graph for the turnkey potentiometer is shown in Figure 4-15.

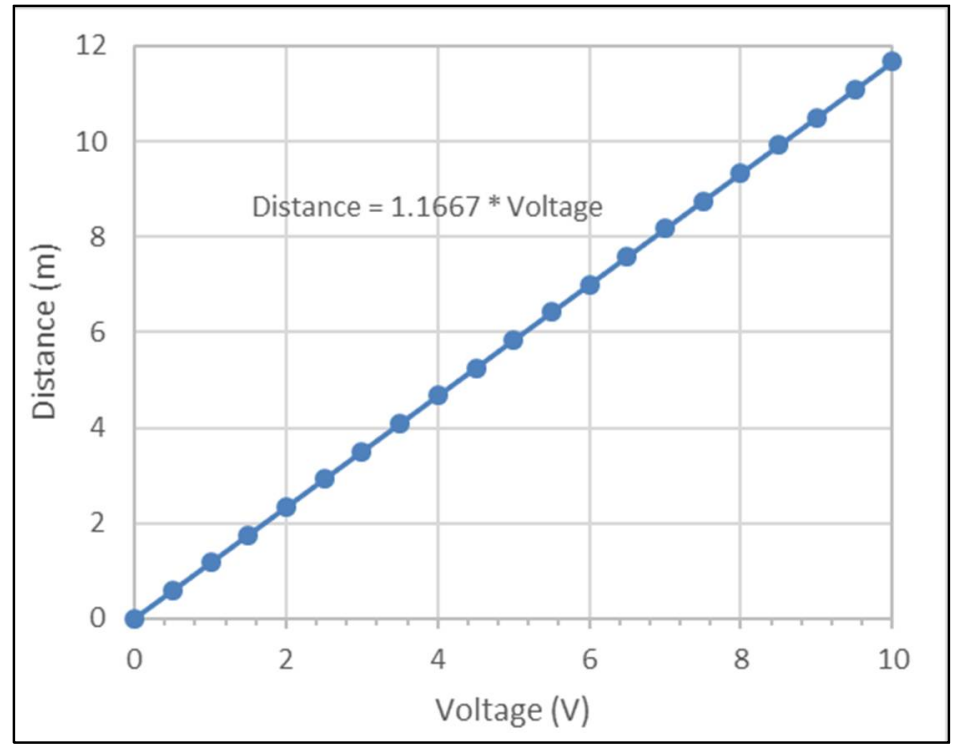

Figure 4-15: Turnkey Potentiometer Calibration Graph

The manually calibrated turnkey potentiometer in terms of meters per Volts was then used to calibrate the driving motor with regards to the voltage required to produce a desired vehicle velocity (Volts $/(\mathrm{m} / \mathrm{s}))$ for a specific vehicle weight. To calibrate the driving motor, different voltages were supplied to the Ametek Motor, and resulting velocities recorded with the calibrated turnkey potentiometer. The relationship of travelling speed with respect to input voltage was established for the three vehicle test 
weights $(2.56 \mathrm{~kg}, 2.88 \mathrm{~m} \mathrm{~kg}$ and $3.20 \mathrm{~kg})$. These calibration charts are shown respectively in Figure 4-16, Figure 4-17 and Figure 4-18.

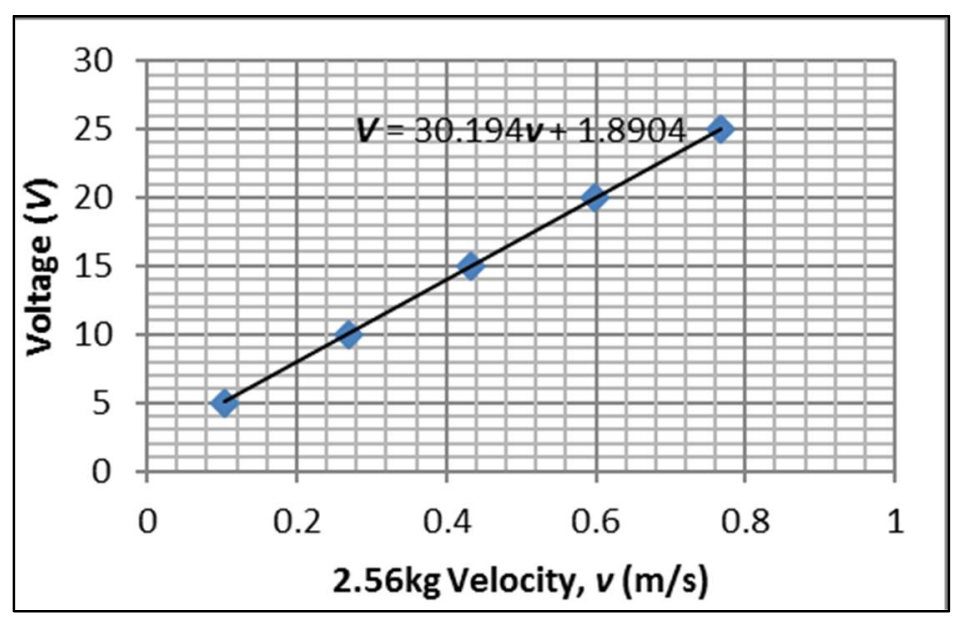

Figure 4-16: Velocity-Voltage Calibration for $2.56 \mathrm{~kg}$

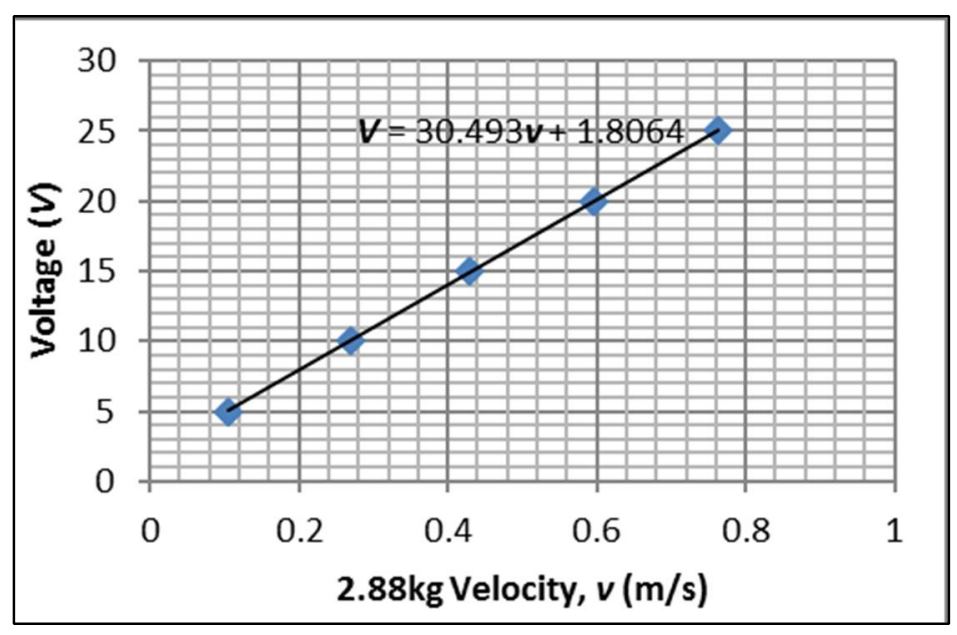

Figure 4-17: Velocity-Voltage Calibration for $2.88 \mathrm{~kg}$ 


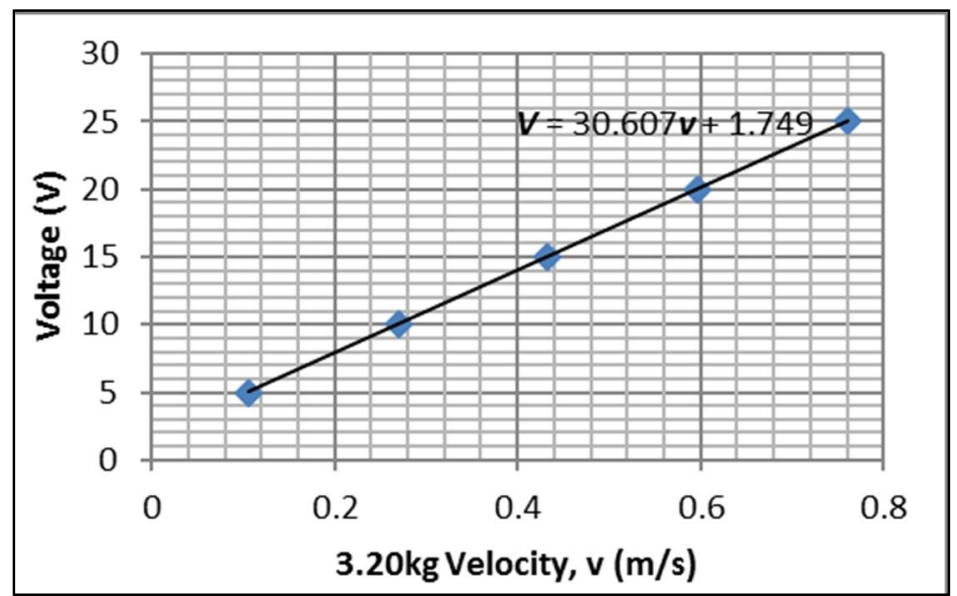

Figure 4-18: Velocity-Voltage Calibration for 3.20kg

Using the calibration charts, and additional fine-tuning tests, the final calibration factors for the different test weights were established as shown in Table 4-4.

Table 4-4: Final Velocity-Voltage Calibration Factors for different Test Weights

\begin{tabular}{|l|l|l|l|}
\hline \multirow{2}{*}{ Model Vehicle Velocity (m/s) } & \multicolumn{4}{|l|}{ Driving Motor Voltage (Volts) } \\
\cline { 2 - 4 } & $\mathbf{2 . 5 6} \mathbf{~ k g}$ & $\mathbf{2 . 8 8} \mathbf{~ k g}$ & $\mathbf{3 . 2 0} \mathbf{~ k g}$ \\
\hline 0.278 & 10.31 & 10.44 & 10.45 \\
\hline 0.444 & 15.32 & 15.35 & 15.36 \\
\hline 0.666 & 22.00 & 22.11 & 22.12 \\
\hline
\end{tabular}

\subsubsection{Calibration of Linear Variable Displacement Transducers}

The LVDTs used in the experiments had a maximum physical stroke length of $80 \mathrm{~mm}$ which represents the maximum absolute range of vertical displacement of pontoon joints that could be accommodated by the LVDTs.

To measure the bridge vertical displacements, the LVDTs were calibrated to establish the displacement-voltage relationship. Each LVDT was supplied with an input voltage of 
$10 \mathrm{~V}$ from the HP Power Supply System. The LVDT output Voltage ranged from 0 to 10 V depending on the extension length of the LVDT shaft, which moved freely so that no significant force was transferred to the bridge. Calibration of LVDTs was carried out by using steel calibration blocks. The slope of the distance versus voltage plot (Figure 4-19) was inputted into the DAQ as the calibration factor.

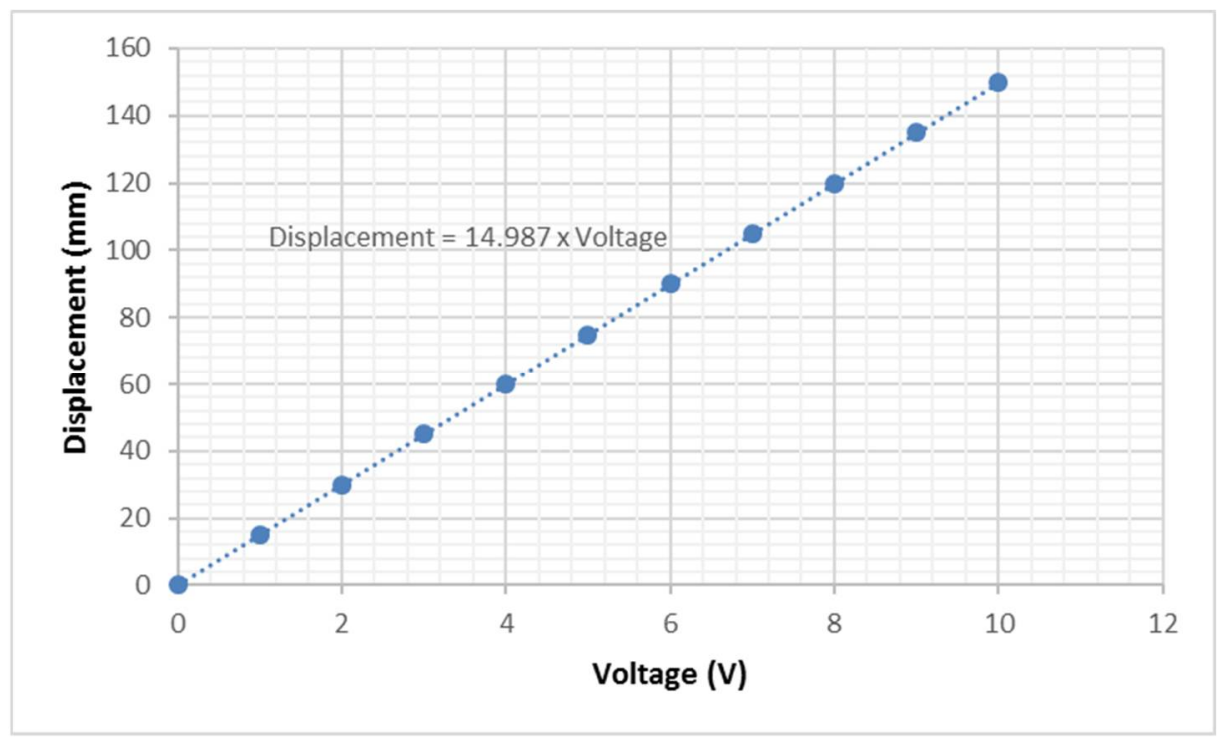

Figure 4-19: LVDT Calibration Graph

\subsection{Experimental Test Procedure}

The Experimental Test Program consisted of 56 tests on two $2.56 \mathrm{~kg}$ vehicles, 12 tests on two $2.88 \mathrm{~kg}$ vehicles, and 12 tests on two $3.20 \mathrm{~kg}$ vehicles. To investigate the relationship between vehicle speed and spacing, and bridge midpoint displacement, additional tests were carried out on the $2.56 \mathrm{~kg}$ vehicles. Discrete displacement data in millimeters from the LVDT and meters from the Turnkey potentiometer were collected at a rate of 100 readings per second. The full experimental program can be found in Appendix A. The procedure involved in a test run is outlined as follows: 
1. Specify test voltage Drive Motor (Ametek 30V Motor) on Agilent Power Supply (Figure 4-20) according to Voltage-Speed Calibration Factor for the specific vehicle weight.

2. Specify DAQ recording window to capture both vehicles passing on the bridge. This varies with the speed and spacing of the vehicles.

3. Switch on Driving Motor and simultaneously activate DAQ system

4. Turn off motor after both vehicles have crossed the bridge

5. Export Data to Excel for processing

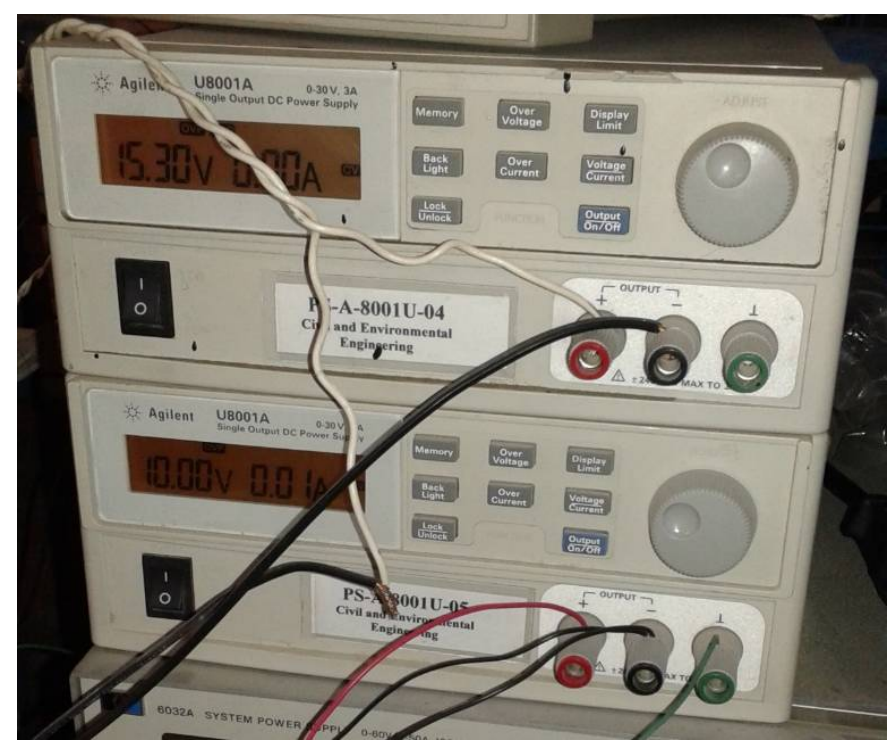

Figure 4-20: Agilent Power Supplies for 30V Ametek Motor (Top) and LVDTs (Bottom)

The overall testing program was carried out without issue. The only occasional problem was LVDT vertical slippage. As shown in Figure 4-14, the LVDTs are slightly offset horizontally from the hinge connection gap. Sometimes during relative rotation of bridge pontoons, the LVDT shaft slips vertically through the connection gap, resulting in misreading of bridge vertical displacements. This is noticed as a sharp increase in 
downward displacement on the displacement history. In such a case, the offending LVDT is repositioned and the test repeated. 


\section{Chapter: Results and Discussion of Experimental and Numerical}

\section{Study}

This chapter consists of two parts. First, a preliminary experimental study is conducted to establish the essential parameters affecting the midpoint displacement response of a 1/25 scale hinge-connected ribbon pontoon floating bridge. The experimental results are used to validate the Matlab numerical finite element program. The second part of the chapter investigates the capacity of a full-scale hinge-connected ribbon pontoon floating bridge in order to optimize its vehicle transport capacity.

\subsection{Results and Discussion of Experimental Test Program and Validation of Finite}

\section{Element Program}

Table 5-1 presents the properties of the model floating bridge constructed and used in the experimental program.

Table 5-1: Model Ribbon Pontoon Bridge Properties

\begin{tabular}{|l|l|l|l|}
\hline Property & Value & Property & Value \\
\hline Pontoon length & $0.54 \mathrm{~m}$ & $\begin{array}{l}\text { Bridge mass per unit } \\
\text { length }\end{array}$ & $1.716 \mathrm{~kg} / \mathrm{m}$ \\
\hline Number of pontoons & 4 & Water density & $1000 \mathrm{~kg} / \mathrm{m}^{3}$ \\
\hline $\begin{array}{l}\text { Number of elements per } \\
\text { pontoon }\end{array}$ & 1 & Modal damping ratio & 0.02 \\
\hline Bridge width & $0.345 \mathrm{~m}$ & Vehicle axle spacing & $0.11 \mathrm{~m}$ \\
\hline Bridge depth & $0.05 \mathrm{~m}$ & & \\
\hline $\begin{array}{l}\text { High Density } \\
\text { Polystyrene Elastic } \\
\text { Modulus }\end{array}$ & $3.6 G P a$ & & \\
\hline Moment of inertia & $6.62\left(10^{-7}\right) \mathrm{m}^{4}$ & & \\
\hline
\end{tabular}

Figure 5-1 shows the analytical model of the 4-pontoon model floating bridge tested in the laboratory where $x_{1}$ and $x_{2}$ are the spatial coordinates of the front axles of the leading 
and rear vehicles respectively. $v$ and $S_{v}$ are the velocity and inter-vehicle spacing of the vehicles respectively and $d=\{N\}\{u\}$ is vertical displacement at a point on a beam element where $\{N\}$ is the shape function evaluated at the point of interest and $\{u\}$ is the nodal displacement vector of the particular beam element.

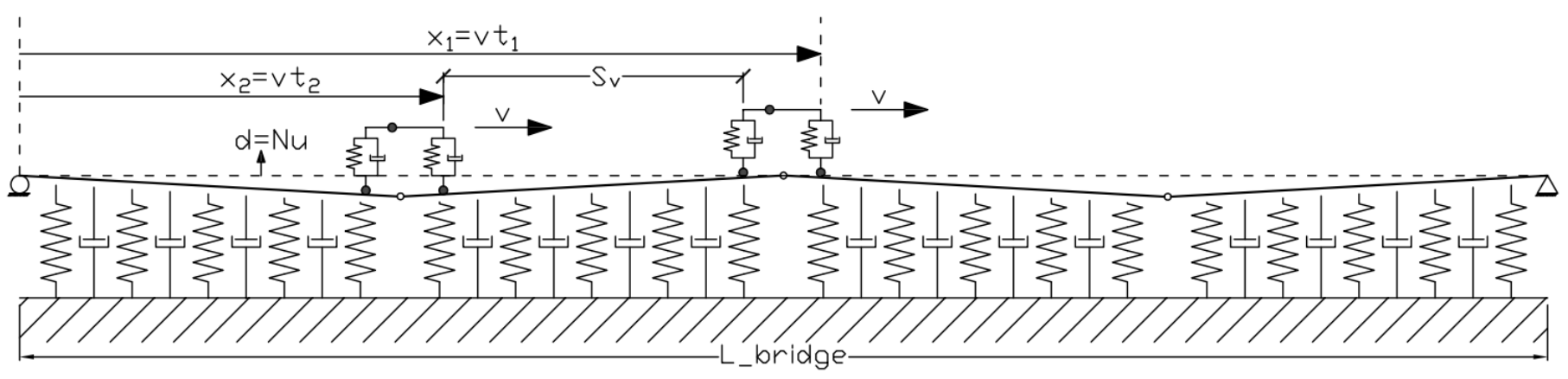

Figure 5-1: Analysis Model Two Vehicles on Hinge-Connected Bridge

Bridge displacements during vehicle crossings at various points are measured relative to bridge displaced shape under its self-weight. The maximum displacement (of the displaced shape) of the hinge-connected ribbon pontoon floating bridge under self-weight was determined to be $4 \mathrm{~mm}$ and occurred at the midpoint of the bridge. According to (Hornbeck et al., 2005) for safe operation of a floating bridge, the maximum pontoon displacement must not exceed $80 \%$ of the pontoon depth (Hornbeck et al., 2005). This leaves $20 \%$ of the bridge depth as free board under maximum displacement. Maximum displacement of the floating bridge exceeding the 
pontoon depth can lead to overtopping of the ribbon pontoon floating bridge.

The depth of the model pontoon is $50 \mathrm{~mm}$; considering a bridge self-weight displacement of $4 \mathrm{~mm}$, the maximum allowable pontoon displacement is equal to $36 \mathrm{~mm}$ leaving a free board of $10 \mathrm{~mm}$ ( $20 \%$ of the depth of $50 \mathrm{~mm})$. Figure 5-2 shows sample experimental results from three tests involving two $2.56-\mathrm{kg}$ test vehicles at $0.667 \mathrm{~m} / \mathrm{s}$ for $0.8 \mathrm{~m}, 1.2 \mathrm{~m}$ and $1.6 \mathrm{~m}$ inter-vehicle spacing. Two distinct downward peaks in the midpoint displacement profiles are denoted Peak 1 and Peak 2. The peaks correspond to the front axles of the leading vehicle and rear vehicle arriving at the bridge midpoint position; 1.08 $\mathrm{m}$ from the left support of the bridge.

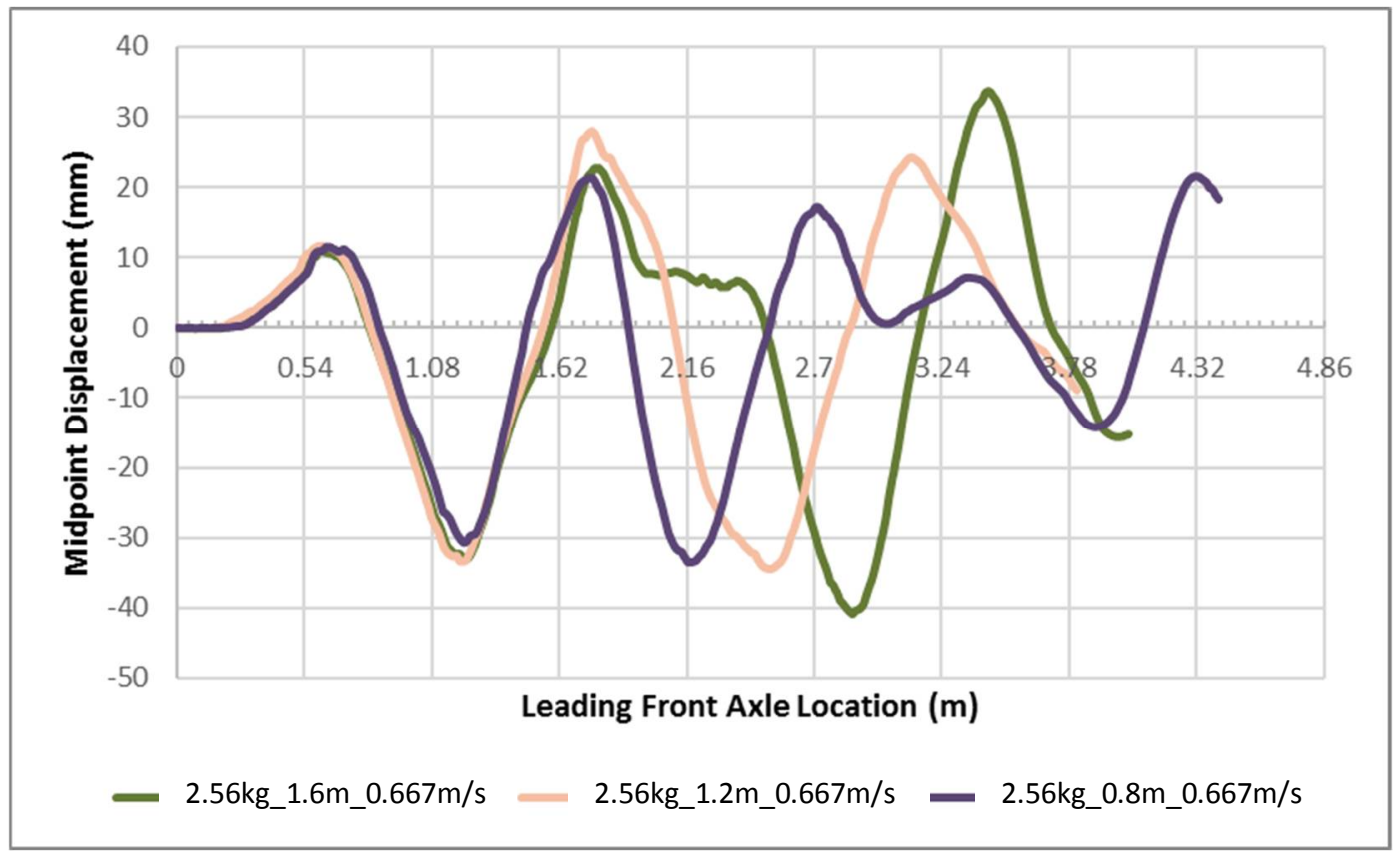

Figure 5-2: Midpoint displacements of model floating bridge under two $2.56-\mathrm{kg}$ vehicles at $0.667 \mathrm{~m} / \mathrm{s}$ for different inter-vehicle spacing

In general, very little difference was observed in the magnitude and time of the first peak. The second peak however, was observed to depend on the inter-vehicle spacing 
with the second peak occurring earlier for the shorter inter-vehicle spacing in comparison to the longer. Also, the vehicle with the longer inter-vehicle spacing yielded higher midpoint displacement corresponding to the second vehicle arrival at the midpoint.

For comparison, the ratio of single vehicle maximum induced midpoint displacement to that caused by two vehicles was defined as the Amplification Factor and represented by Equation 5-1.

$$
\beta_{n}=\frac{\bar{u}_{S v}}{\bar{u}_{v}}
$$

where :

$\bar{u}_{S v}$ is the maximum midpoint displacement due to two or more vehicles of a given weight and speed.

$\bar{u}_{v}$ is the maximum midpoint displacement due to a single vehicle of the same weight and speed

\subsubsection{Effect of Vehicle Weight on Midpoint Displacements}

In previous studies El-Desouky (2011) and Viecili et al. (2013, 2014), the midpoint displacements were reported to increase with vehicle weight. Midpoint displacement histories for $2.56-\mathrm{kg}, 2.88-\mathrm{kg}$ and $3.20-\mathrm{kg}$ and speed $0.278 \mathrm{~m} / \mathrm{s}$ which correspond to prototype weights of 40-ton, 45 -ton and 50 -ton and speed $25 \mathrm{~km} / \mathrm{hr}$, are presented in Figure 5-3 and shows increased peak midpoint deflection with increased vehicle weight. The relationship between vehicle weight $(W)$ and maximum midpoint displacement $\left(u_{v}\right)$ is plotted for different vehicle speeds and presented in Figure 5-4. The experimental 
results show a linear relationship between maximum midpoint displacement and vehicle weight with higher displacement recorded for the faster vehicles.

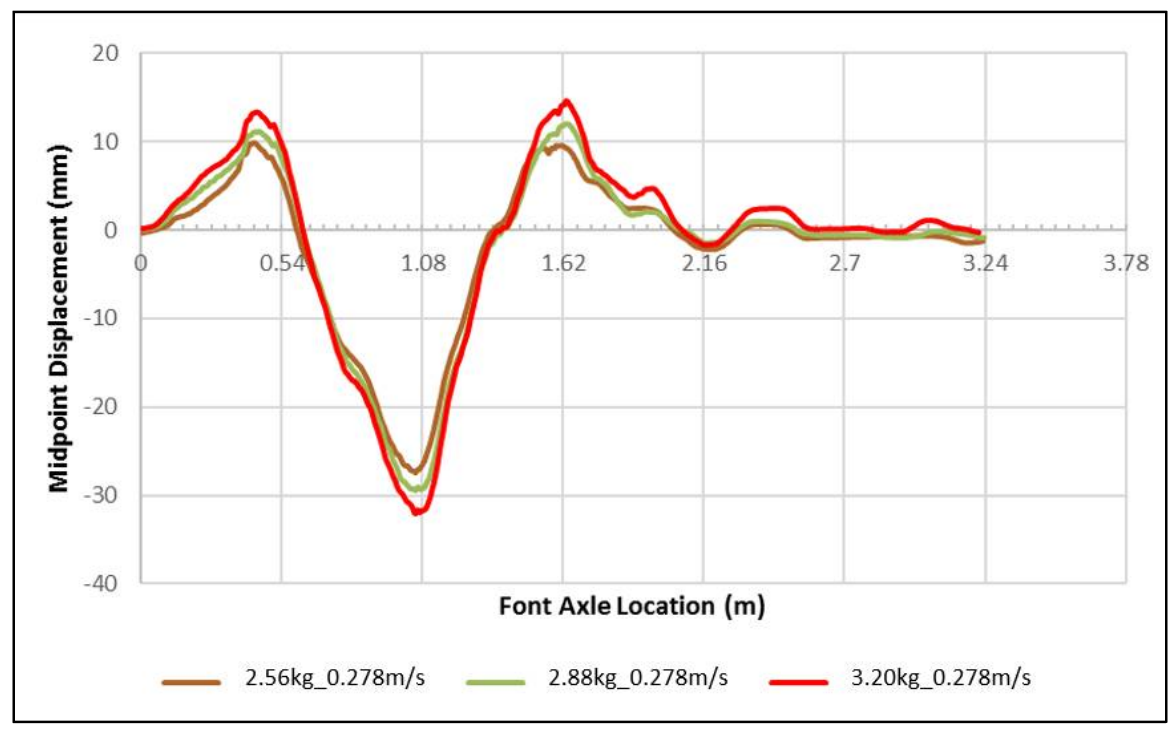

Figure 5-3: Experimental Midpoint Displacements Profiles under Single Vehicle Crossing at $25 \mathrm{~km} / \mathrm{hr}$

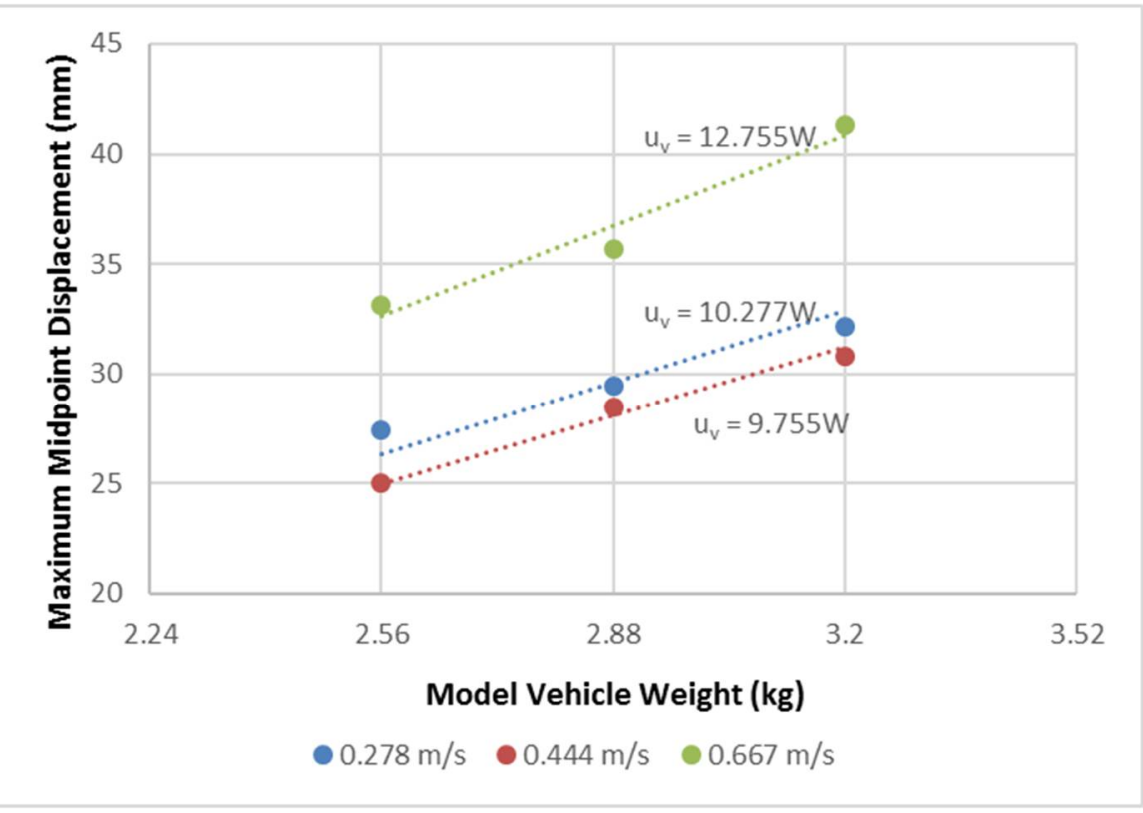

Figure 5-4: Effect of Vehicle Weight on Experimental Maximum Midpoint Displacement 


\subsubsection{Effect of Speed and Spacing of 2.56-kg Vehicle on Midpoint Displacements}

To study the effects of vehicle speed and spacing on vertical midpoint displacement of ribbon pontoon floating bridges, two $2.56-\mathrm{kg}$ vehicles at varying speeds and inter-vehicle spacing were examined. The results are presented in Table 5-2 through Table 5-8. Results for $2.88 \mathrm{~kg}$ and $3.20 \mathrm{~kg}$ vehicles at inter-vehicle spacing ranging from $0.8 \mathrm{~m}$ to $1.6 \mathrm{~m}$ and speeds $0.278 \mathrm{~m} / \mathrm{s}, 0.444 \mathrm{~m} / \mathrm{s}$ and $0.666 \mathrm{~m} / \mathrm{s}$ are given in Appendix C.

Table 5-2: Maximum Midpoint Displacements for 2.56-kg Vehicles spaced at $1.6 \mathrm{~m}$

\begin{tabular}{|l|l|l|l|l|l|l|c|}
\hline $\begin{array}{l}\text { Vehicle } \\
\text { Weight } \\
(\mathrm{kg})\end{array}$ & $\begin{array}{l}\text { Inter- } \\
\text { Vehicle } \\
\text { Spacing } \\
(\mathrm{m})\end{array}$ & $\begin{array}{l}\text { Vehicle } \\
\text { Speed } \\
(\mathrm{m} / \mathrm{s})\end{array}$ & $\begin{array}{l}\text { Peak 1 } \\
\text { Deflection } \\
(\mathrm{mm})\end{array}$ & $\begin{array}{l}\text { Peak 2 } \\
\text { Deflection } \\
(\mathrm{mm})\end{array}$ & $\begin{array}{l}\text { Single } \\
\text { Vehicle } \\
\text { Peak } \\
(\mathrm{mm})\end{array}$ & $\beta_{1}$ & $\beta_{2}$ \\
\hline 2.56 & 1.6 & 0.278 & -26.43 & -26.80 & -27.40 & 0.97 & 0.98 \\
\hline 2.56 & 1.6 & 0.333 & -24.55 & -27.46 & -24.91 & 0.99 & 1.10 \\
\hline 2.56 & 1.6 & 0.389 & -25.43 & -25.61 & -24.97 & 1.02 & 1.03 \\
\hline 2.56 & 1.6 & 0.444 & -25.50 & -22.76 & -25.00 & 1.02 & 0.91 \\
\hline 2.56 & 1.6 & 0.500 & -26.81 & -20.56 & -26.97 & 0.99 & 0.76 \\
\hline 2.56 & 1.6 & 0.556 & -29.35 & -27.25 & -30.08 & 0.98 & 0.91 \\
\hline 2.56 & 1.6 & 0.611 & -32.35 & -37.02 & -32.75 & 0.99 & 1.13 \\
\hline 2.56 & 1.6 & 0.667 & -33.00 & -40.89 & -33.13 & 1.00 & 1.23 \\
\hline
\end{tabular}

Table 5-3: Maximum Midpoint Displacements for 2.56-kg Vehicles spaced at $1.4 \mathrm{~m}$

\begin{tabular}{|l|l|l|l|l|l|l|l|}
\hline $\begin{array}{l}\text { Vehicle } \\
(\mathrm{kg})\end{array}$ & $\begin{array}{l}\text { Inter- } \\
\text { Vehicle } \\
\text { Spacing } \\
(\mathrm{m})\end{array}$ & $\begin{array}{l}\text { Vehicle } \\
\text { Speed } \\
(\mathrm{m} / \mathrm{s})\end{array}$ & $\begin{array}{l}\text { Peak 1 } \\
\text { Deflection } \\
(\mathrm{mm})\end{array}$ & $\begin{array}{l}\text { Peak 2 } \\
\text { Deflection } \\
(\mathrm{mm})\end{array}$ & $\begin{array}{l}\text { Single } \\
\text { Vehicle } \\
\text { Peak } \\
(\mathrm{mm})\end{array}$ & $\beta_{1}$ & $\beta_{2}$ \\
\hline 2.56 & 1.4 & 0.278 & -27.38 & -28.25 & -27.40 & 1.00 & 1.03 \\
\hline 2.56 & 1.4 & 0.333 & -25.31 & -26.83 & -24.91 & 1.02 & 1.08 \\
\hline 2.56 & 1.4 & 0.389 & -26.24 & -24.59 & -24.97 & 1.05 & 0.99 \\
\hline 2.56 & 1.4 & 0.444 & -25.32 & -21.44 & -25.00 & 1.01 & 0.86 \\
\hline 2.56 & 1.4 & 0.500 & -26.95 & -27.85 & -26.97 & 1.00 & 1.03 \\
\hline 2.56 & 1.4 & 0.556 & -29.80 & -36.80 & -30.08 & 0.99 & 1.22 \\
\hline 2.56 & 1.4 & 0.611 & -32.45 & -40.71 & -32.75 & 0.99 & 1.24 \\
\hline 2.56 & 1.4 & 0.667 & -34.38 & -44.46 & -33.13 & 1.04 & 1.34 \\
\hline
\end{tabular}


Table 5-4: Maximum Midpoint Displacements for 2.56-kg Vehicles spaced at $1.4 \mathrm{~m}$

\begin{tabular}{|l|l|l|l|l|l|l|l|}
\hline $\begin{array}{l}\text { Vehicle } \\
(\mathrm{kg})\end{array}$ & $\begin{array}{l}\text { Inter- } \\
\text { Vehicle } \\
\text { Spacing } \\
(\mathrm{m})\end{array}$ & $\begin{array}{l}\text { Vehicle } \\
\text { Speed } \\
(\mathrm{m} / \mathrm{s})\end{array}$ & $\begin{array}{l}\text { Peak 1 } \\
\text { Deflection } \\
(\mathrm{mm})\end{array}$ & $\begin{array}{l}\text { Peak 2 } \\
\text { Deflection } \\
(\mathrm{mm})\end{array}$ & $\begin{array}{l}\text { Single } \\
\text { Vehicle } \\
\text { Peak } \\
(\mathrm{mm})\end{array}$ & $\beta_{1}$ & $\beta_{2}$ \\
\hline 2.56 & 1.2 & 0.278 & -27.30 & -25.37 & -27.40 & 1.00 & 0.93 \\
\hline 2.56 & 1.2 & 0.333 & -25.69 & -24.05 & -24.91 & 1.03 & 0.97 \\
\hline 2.56 & 1.2 & 0.389 & -25.65 & -21.97 & -24.97 & 1.03 & 0.88 \\
\hline 2.56 & 1.2 & 0.444 & -25.32 & -29.04 & -25.00 & 1.01 & 1.16 \\
\hline 2.56 & 1.2 & 0.500 & -27.49 & -37.96 & -26.97 & 1.02 & 1.41 \\
\hline 2.56 & 1.2 & 0.556 & -30.79 & -39.44 & -30.08 & 1.02 & 1.31 \\
\hline 2.56 & 1.2 & 0.611 & -32.86 & -39.42 & -32.75 & 1.00 & 1.20 \\
\hline 2.56 & 1.2 & 0.667 & -33.31 & -34.38 & -33.13 & 1.01 & 1.04 \\
\hline
\end{tabular}

Table 5-5: Maximum Midpoint Displacements for 2.56-kg Vehicles spaced at $1.0 \mathrm{~m}$

\begin{tabular}{|l|l|l|l|l|l|l|c|}
\hline $\begin{array}{l}\text { Vehicle } \\
(\mathrm{kg})\end{array}$ & $\begin{array}{l}\text { Inter- } \\
\text { Vehicle } \\
\text { Spacing } \\
(\mathrm{m})\end{array}$ & $\begin{array}{l}\text { Vehicle } \\
\text { Speed } \\
(\mathrm{m} / \mathrm{s})\end{array}$ & $\begin{array}{l}\text { Peak 1 } \\
\text { Deflection } \\
(\mathrm{mm})\end{array}$ & $\begin{array}{l}\text { Peak 2 } \\
\text { Deflection } \\
(\mathrm{mm})\end{array}$ & $\begin{array}{l}\text { Single } \\
\text { Vehicle } \\
\text { Peak } \\
(\mathrm{mm})\end{array}$ & $\beta_{1}$ & $\beta_{2}$ \\
\hline 2.56 & 1.0 & 0.278 & -26.18 & -29.41 & -27.40 & 0.96 & 1.07 \\
\hline 2.56 & 1.0 & 0.333 & -25.43 & -24.26 & -24.91 & 1.02 & 0.97 \\
\hline 2.56 & 1.0 & 0.389 & -25.81 & -27.45 & -24.97 & 1.03 & 1.10 \\
\hline 2.56 & 1.0 & 0.444 & -23.30 & -27.04 & -25.00 & 0.93 & 1.08 \\
\hline 2.56 & 1.0 & 0.500 & -28.48 & -34.80 & -26.97 & 1.06 & 1.29 \\
\hline 2.56 & 1.0 & 0.556 & -30.62 & -32.01 & -30.08 & 1.02 & 1.06 \\
\hline 2.56 & 1.0 & 0.611 & -32.71 & -30.48 & -32.75 & 1.00 & 0.93 \\
\hline 2.56 & 1.0 & 0.667 & -34.54 & -38.73 & -33.13 & 1.04 & 1.17 \\
\hline
\end{tabular}

Table 5-6: Maximum Midpoint Displacements for 2.56-kg Vehicles spaced at $0.8 \mathrm{~m}$

\begin{tabular}{|l|l|l|l|l|l|l|l|}
\hline $\begin{array}{l}\text { Vehicle } \\
(\mathrm{kg})\end{array}$ & $\begin{array}{l}\text { Inter- } \\
\text { Vehicle } \\
\text { Spacing } \\
(\mathrm{m})\end{array}$ & $\begin{array}{l}\text { Vehicle } \\
\text { Speed } \\
(\mathrm{m} / \mathrm{s})\end{array}$ & $\begin{array}{l}\text { Peak 1 } \\
\text { Deflection } \\
(\mathrm{mm})\end{array}$ & $\begin{array}{l}\text { Peak 2 } \\
\text { Deflection } \\
(\mathrm{mm})\end{array}$ & $\begin{array}{l}\text { Single } \\
\text { Vehicle } \\
\text { Peak } \\
(\mathrm{mm})\end{array}$ & $\beta_{1}$ & $\beta_{2}$ \\
\hline 2.56 & 0.8 & 0.278 & -23.29 & -23.71 & -27.40 & 0.85 & 0.87 \\
\hline 2.56 & 0.8 & 0.333 & -23.55 & -23.32 & -24.91 & 0.95 & 0.94 \\
\hline 2.56 & 0.8 & 0.389 & -23.12 & -27.81 & -24.97 & 0.93 & 1.11 \\
\hline 2.56 & 0.8 & 0.444 & -23.19 & -27.35 & -25.00 & 0.93 & 1.09 \\
\hline 2.56 & 0.8 & 0.500 & -25.36 & -24.85 & -26.97 & 0.94 & 0.92 \\
\hline 2.56 & 0.8 & 0.556 & -28.44 & -27.93 & -30.08 & 0.95 & 0.93 \\
\hline 2.56 & 0.8 & 0.611 & -29.65 & -33.12 & -32.75 & 0.91 & 1.01 \\
\hline 2.56 & 0.8 & 0.667 & -30.80 & -33.59 & -33.13 & 0.93 & 1.01 \\
\hline
\end{tabular}


Table 5-7: Maximum Midpoint Displacements for 2.56-kg Vehicles spaced at $0.6 \mathrm{~m}$

\begin{tabular}{|l|l|l|l|l|l|l|l|}
\hline $\begin{array}{l}\text { Vehicle } \\
(\mathrm{kg})\end{array}$ & $\begin{array}{l}\text { Inter- } \\
\text { Vehicle } \\
\text { Spacing } \\
(\mathrm{m})\end{array}$ & $\begin{array}{l}\text { Vehicle } \\
\text { Speed } \\
(\mathrm{m} / \mathrm{s})\end{array}$ & $\begin{array}{l}\text { Peak 1 } \\
\text { Deflection } \\
(\mathrm{mm})\end{array}$ & $\begin{array}{l}\text { Peak 2 } \\
\text { Deflection } \\
(\mathrm{mm})\end{array}$ & $\begin{array}{l}\text { Single } \\
\text { Vehicle } \\
\text { Peak } \\
(\mathrm{mm})\end{array}$ & $\beta_{1}$ & $\beta_{2}$ \\
\hline 2.56 & 0.6 & 0.278 & -19.80 & -22.95 & -27.40 & 0.72 & 0.84 \\
\hline 2.56 & 0.6 & 0.333 & -18.05 & -20.49 & -24.91 & 0.73 & 0.82 \\
\hline 2.56 & 0.6 & 0.389 & -16.09 & -19.03 & -24.97 & 0.64 & 0.76 \\
\hline 2.56 & 0.6 & 0.444 & -18.43 & -17.31 & -25.00 & 0.74 & 0.69 \\
\hline 2.56 & 0.6 & 0.500 & -20.73 & -17.83 & -26.97 & 0.77 & 0.66 \\
\hline 2.56 & 0.6 & 0.556 & -21.79 & -23.10 & -30.08 & 0.72 & 0.77 \\
\hline 2.56 & 0.6 & 0.611 & -23.67 & -24.58 & -32.75 & 0.72 & 0.75 \\
\hline 2.56 & 0.6 & 0.667 & -24.45 & -26.58 & -33.13 & 0.74 & 0.80 \\
\hline
\end{tabular}

Table 5-8: Maximum Midpoint Displacements for 2.56-kg Vehicles spaced at $0.4 \mathrm{~m}$

\begin{tabular}{|l|l|l|l|l|l|l|l|}
\hline $\begin{array}{l}\text { Vehicle } \\
(\mathrm{kg})\end{array}$ & $\begin{array}{l}\text { Inter- } \\
\text { Vehicle } \\
\text { Spacing } \\
(\mathrm{m})\end{array}$ & $\begin{array}{l}\text { Vehicle } \\
\text { Speed } \\
(\mathrm{m} / \mathrm{s})\end{array}$ & $\begin{array}{l}\text { Peak 1 } \\
\text { Deflection } \\
(\mathrm{mm})\end{array}$ & $\begin{array}{l}\text { Peak 2 } \\
\text { Deflection } \\
(\mathrm{mm})\end{array}$ & $\begin{array}{l}\text { Single } \\
\text { Vehicle } \\
\text { Peak } \\
(\mathrm{mm})\end{array}$ & $\beta_{1}$ & $\beta_{2}$ \\
\hline 2.56 & 0.4 & 0.278 & -20.774 & -21.182 & -27.40 & 0.76 & 0.77 \\
\hline 2.56 & 0.4 & 0.333 & -20.744 & -18.593 & -24.91 & 0.83 & 0.75 \\
\hline 2.56 & 0.4 & 0.389 & -15.199 & -21.761 & -24.97 & 0.61 & 0.87 \\
\hline 2.56 & 0.4 & 0.444 & -17.346 & -22.122 & -25.00 & 0.69 & 0.89 \\
\hline 2.56 & 0.4 & 0.500 & -19.818 & -21.336 & -26.97 & 0.74 & 0.79 \\
\hline 2.56 & 0.4 & 0.556 & -19.801 & -20.785 & -30.08 & 0.66 & 0.69 \\
\hline 2.56 & 0.4 & 0.611 & -21.453 & -21.289 & -32.75 & 0.66 & 0.65 \\
\hline 2.56 & 0.4 & 0.667 & -23.474 & -21.369 & -33.13 & 0.71 & 0.65 \\
\hline
\end{tabular}

Two trends are worthy of note: first, the Peak 1 amplification factor $\left(\beta_{1}\right)$ remains near 1 at large inter-vehicle spacing $(1.4 \mathrm{~m}$ to $1.0 \mathrm{~m})$ and decreases for smaller spacing $(0.8 \mathrm{~m}$ and less). When the second vehicle is off the bridge when the leading vehicle arrives at the midpoint, the Peak 1 displacement is similar to the midpoint displacement due to an equivalent single vehicle. When the second vehicle is closer than one and a half pontoon lengths, however, Peak 1 is influenced by the second vehicle (Figure 5-6). 
The second observation is that Peak 2 amplification factor $\left(\beta_{2}\right)$ deviates from 1 for most inter-vehicle spacing since the Peak 2 displacement is influenced by bridge displacements in the wake of the leading vehicle.

\subsubsection{Analysis of Experimental Displacement Trends}

The value of Peak 1 is approximately equal to that produced by a single vehicle of the same weight and speed parameters, provided the second vehicle is still off the bridge when the first vehicle reaches the midpoint of the bridge. Thus, the corresponding minimum inter-vehicle spacing where the rear vehicle does not affect the peak midpoint displacement due to passage of the lead vehicle can be denoted as $\gamma$, calculated as:

$$
\gamma=\frac{L_{\text {bridge }}}{2}-S
$$

where $L_{\text {bridge }}$ is the length of the pontoon bridge $(2.16 \mathrm{~m})$ and $S$ is the vehicle inter-axle spacing $(0.11 \mathrm{~m})$.

$$
\gamma=\frac{2.16}{2}-0.11=0.97 m
$$

Figure 5-5 shows the maximum midpoint displacements with respect to inter-vehicle spacing for $2.56 \mathrm{~kg}$ vehicle weight. It can be observed that maximum bridge midpoint displacements for inter-vehicle spacing greater than $0.97 \mathrm{~m}$ generally converge to a value which is the same as that caused by a single vehicle of the same parameters.ie weight and speed (Table 5-9). This is further illustrated in Figure 5-6. For the sake of clarity, only results for $0.333 \mathrm{~m} / \mathrm{s}, 0.500 \mathrm{~m} / \mathrm{s}, 0.556 \mathrm{~m} / \mathrm{s}$ and $0.661 \mathrm{~m} / \mathrm{s}$ are shown. All values of Peak1 displacement influenced by the $2^{\text {nd }}$ vehicle (inter-vehicle spacing less than $0.97 \mathrm{~m}$ ) are 
less than an equivalent single vehicle displacement. Apart from $0.333 \mathrm{~m} / \mathrm{s}(30 \mathrm{~km} / \mathrm{hr})$, all other vehicle speeds follow the expected trend.

Figure 5-5 also shows that Peak 1 displacements do not necessarily increase with vehicle speed. This was also observed by El-Desouky(2011) and Viecili et al.(2014). The two vehicles travelling at $0.278 \mathrm{~m} / \mathrm{s}$ produce higher Peak 1 displacements than $0.389 \mathrm{~m} / \mathrm{s}$, $0.333 \mathrm{~m} / \mathrm{s}$ and $0.444 \mathrm{~m} / \mathrm{s}$ which is counterintuitive, as one would expect bridge displacements to increase with increasing vehicle speed. This phenomenon can however be explained by considering the resonance of vehicle velocities with the bridge frequency of vibration. This is explored further in the chapter.

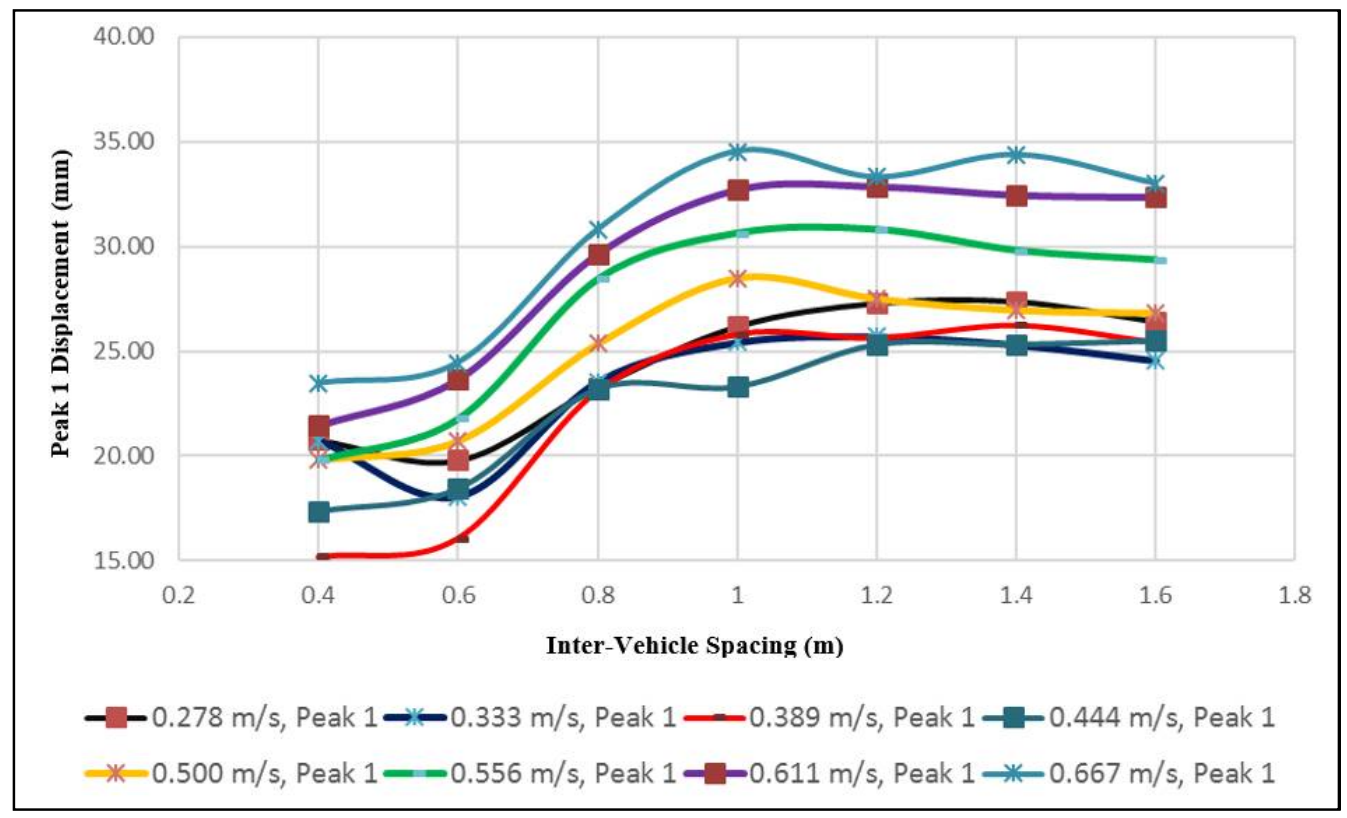

Figure 5-5: Peak 1 Displacement vs Inter-Vehicle Spacing (2.56 kg) 


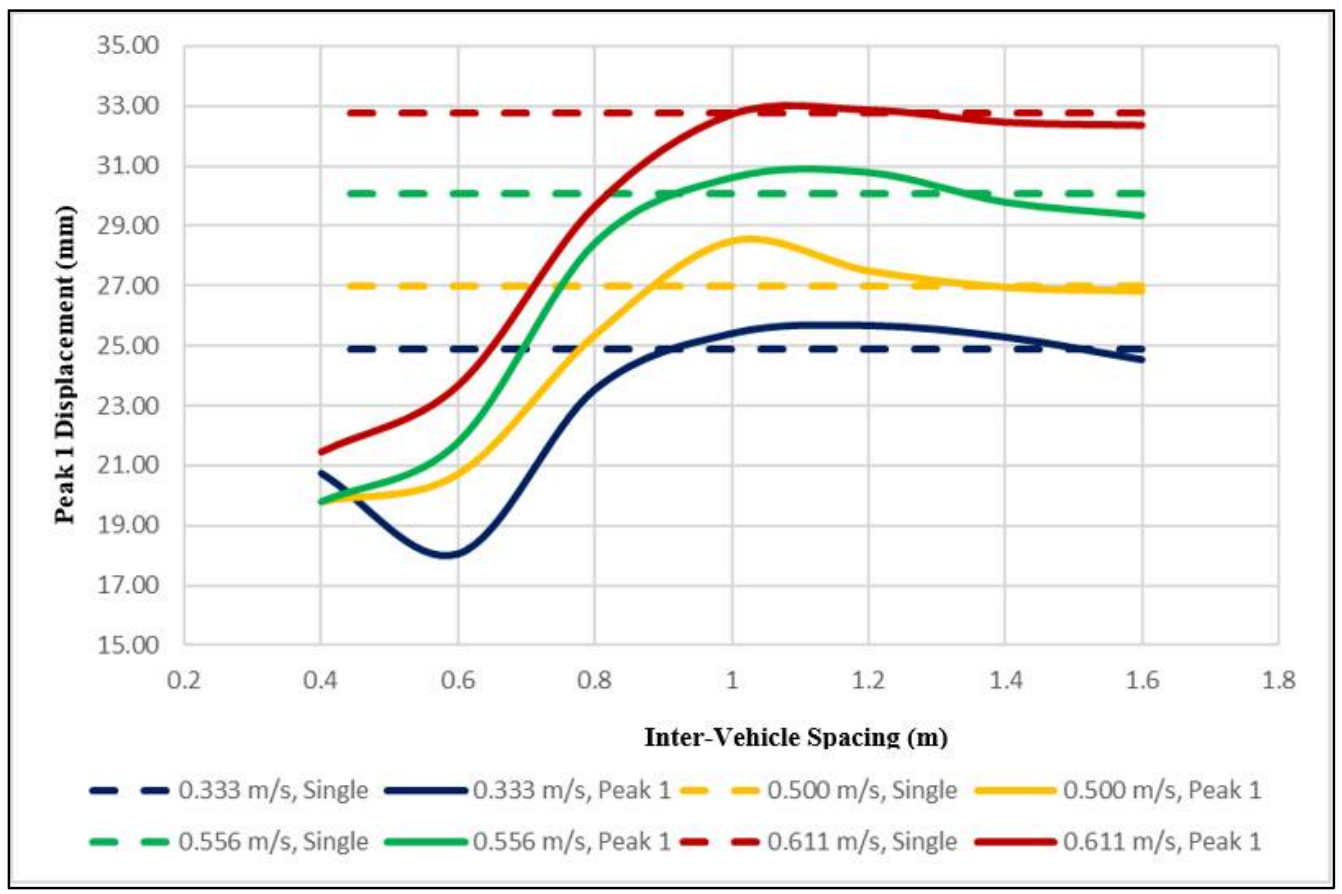

Figure 5-6: Convergence of Peak 1 Displacement to Single Vehicle Equivalent

Table 5-9: Maximum Single Vehicle Displacements $(2.56 \mathrm{~kg})$

\begin{tabular}{|l|l|}
\hline $\begin{array}{l}\text { Single Vehicle } \\
\text { Speed }(\mathbf{m} / \mathbf{s})\end{array}$ & $\begin{array}{l}\text { Maximum Midpoint } \\
\text { Displacement }(\mathbf{m m})\end{array}$ \\
\hline 0.278 & 27.40 \\
\hline 0.333 & 24.91 \\
\hline 0.389 & 24.97 \\
\hline 0.444 & 25.00 \\
\hline 0.500 & 26.97 \\
\hline 0.556 & 30.08 \\
\hline 0.611 & 32.75 \\
\hline 0.667 & 33.13 \\
\hline
\end{tabular}

Figure 5-7 shows the experimental midpoint displacements due to a single $2.56-\mathrm{kg}$ vehicle at $0.278 \mathrm{~m} / \mathrm{s}$ (40-ton, $25 \mathrm{~km} / \mathrm{hr}$ for prototype). The two vertical lines indicate the vertical displacements that would be superimposed under the front axle of a rear vehicle 
lagging behind the front vehicle at inter-vehicle distance ranging from $0.4 \mathrm{~m}$ to $1.6 \mathrm{~m}$. The extent to which the magnitude of Peak 2 is amplified or reduced depends mainly on inter-vehicle spacing. Figure 5-8 to Figure 5-15 show:

- Peak 2 displacements with respect to inter-vehicle spacing (horizontal axis)

- displacement experienced by the front axle of the rear vehicle in the wake of (post) the first vehicle for that inter-vehicle spacing (horizontal axis).

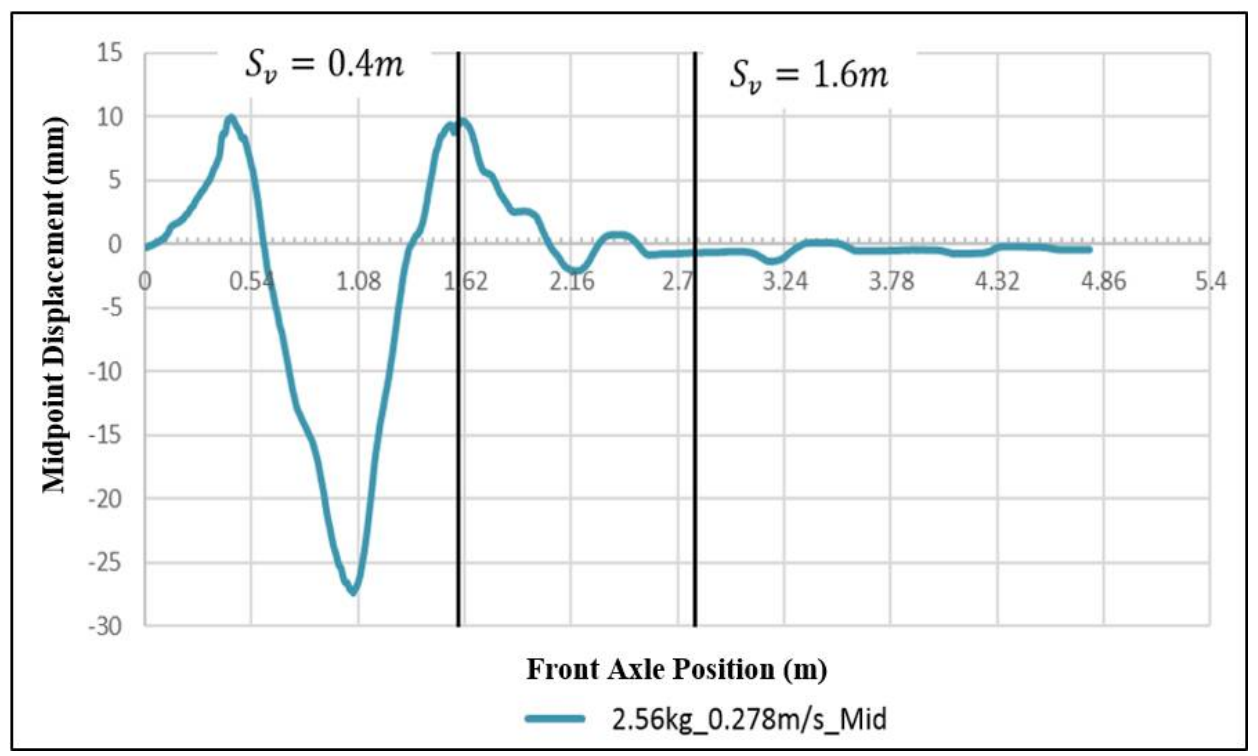

Figure 5-7: Midpoint Displacements for single 2.56-kg vehicle at $0.278 \mathrm{~m} / \mathrm{s}$

At lower velocity $(0.278 \mathrm{~m} / \mathrm{s}$ to $0.444 \mathrm{~m} / \mathrm{s})$, there is a strong correlation between Peak 2 values and corresponding single vehicle displacement, with appreciable deviation at higher velocities possibly due to time lag effects. Peak 2 Amplification will be discussed further in the latter part of Chapter 5. 


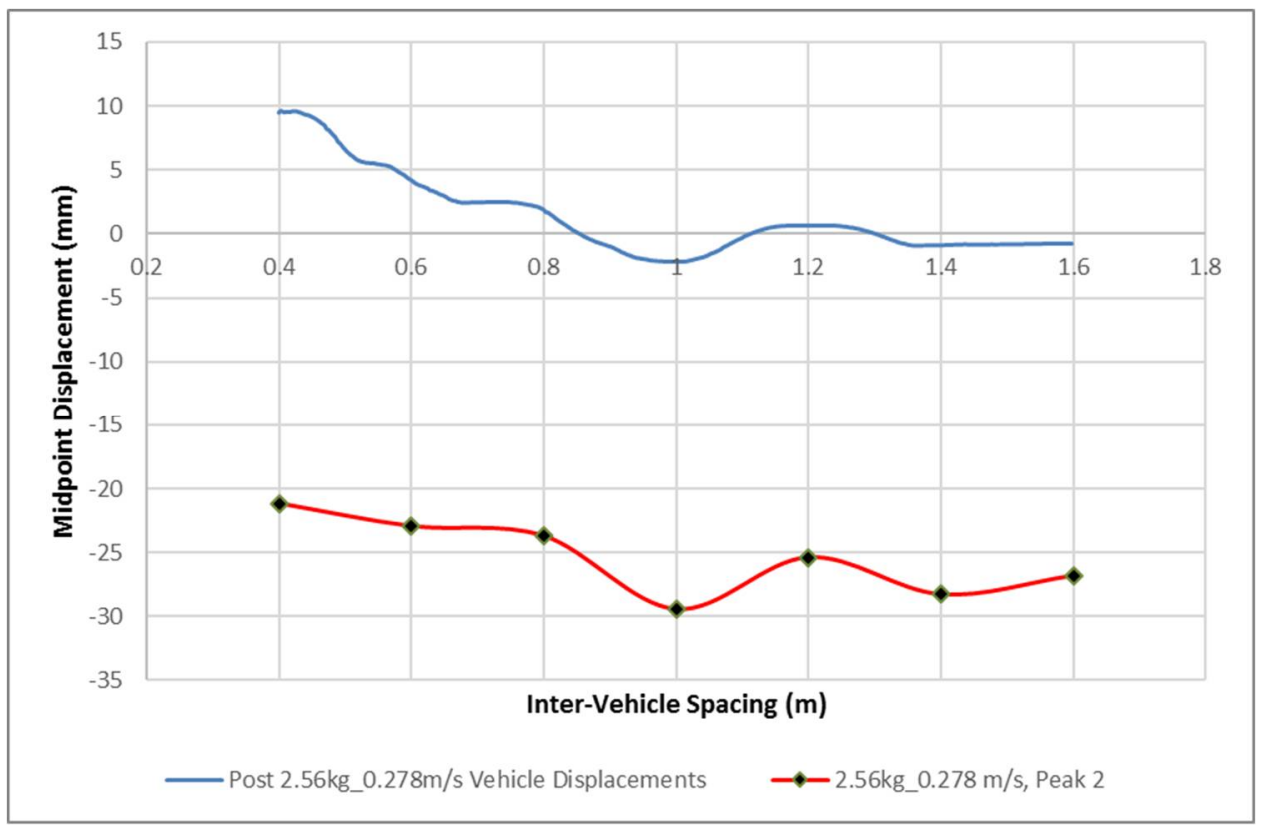

Figure 5-8: Influence of Leading Vehicle-Induced Displacements on Peak $2(0.278 \mathrm{~m} / \mathrm{s})$

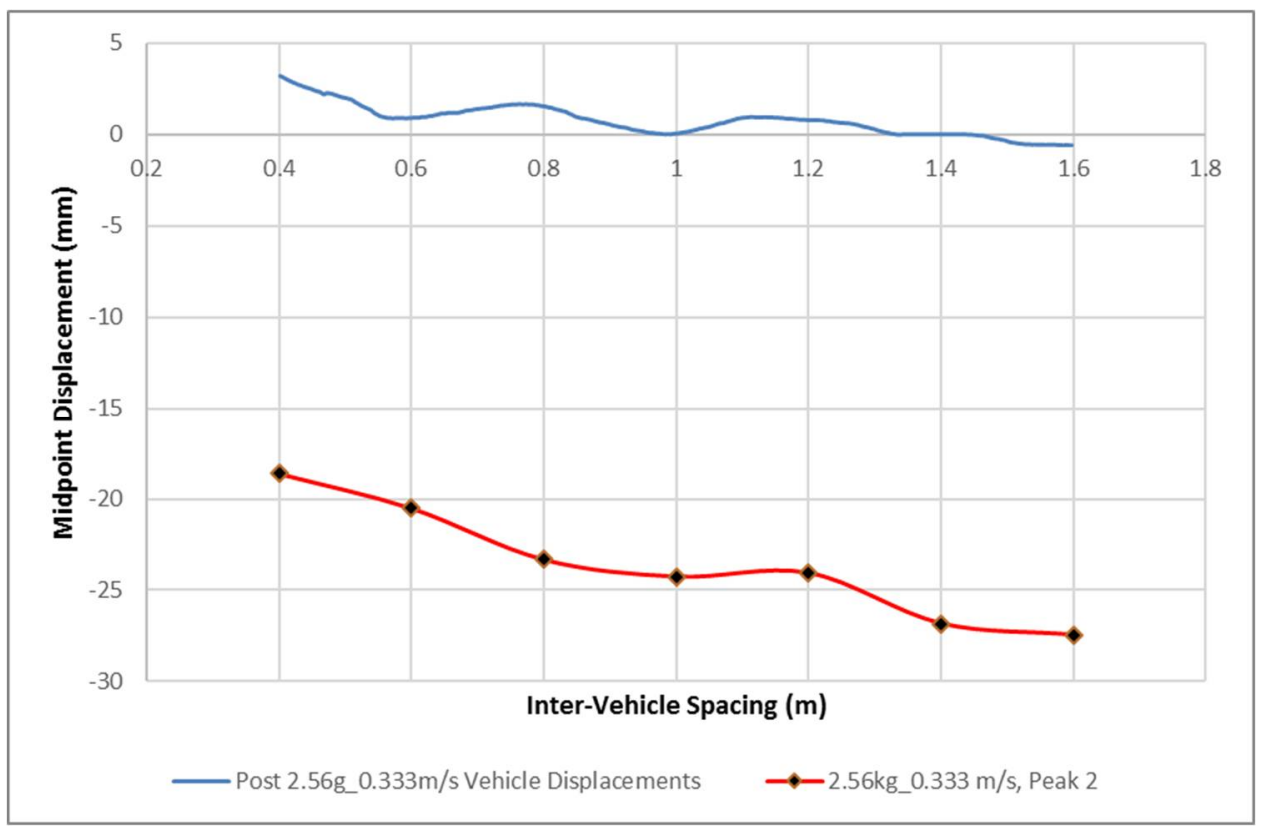

Figure 5-9: Influence of Leading Vehicle- Induced Displacements on Peak $2(0.333 \mathrm{~m} / \mathrm{s})$ 


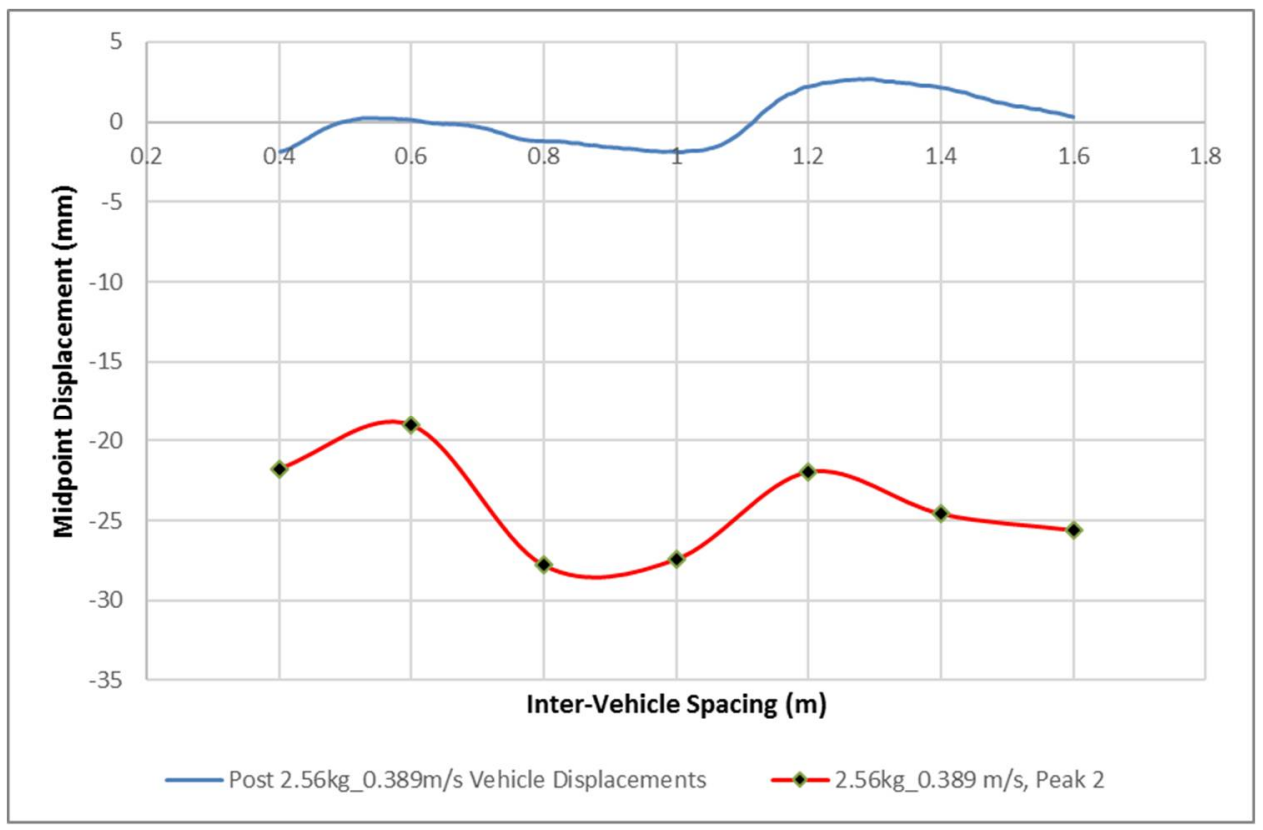

Figure 5-10: Influence of Leading Vehicle- Induced Displacements on Peak $2(0.389 \mathrm{~m} / \mathrm{s})$

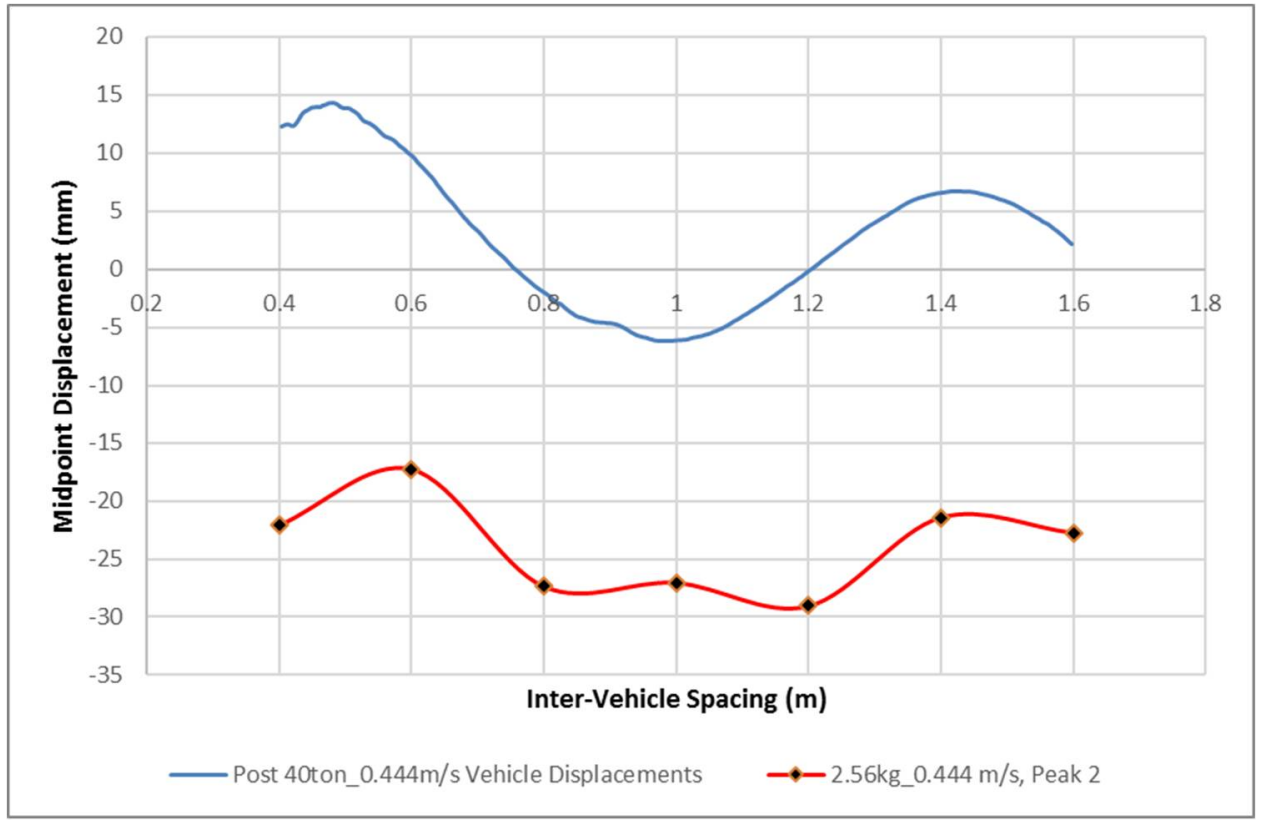

Figure 5-11: Influence of Leading Vehicle- Induced Displacements on Peak $2(0.444 \mathrm{~m} / \mathrm{s})$ 


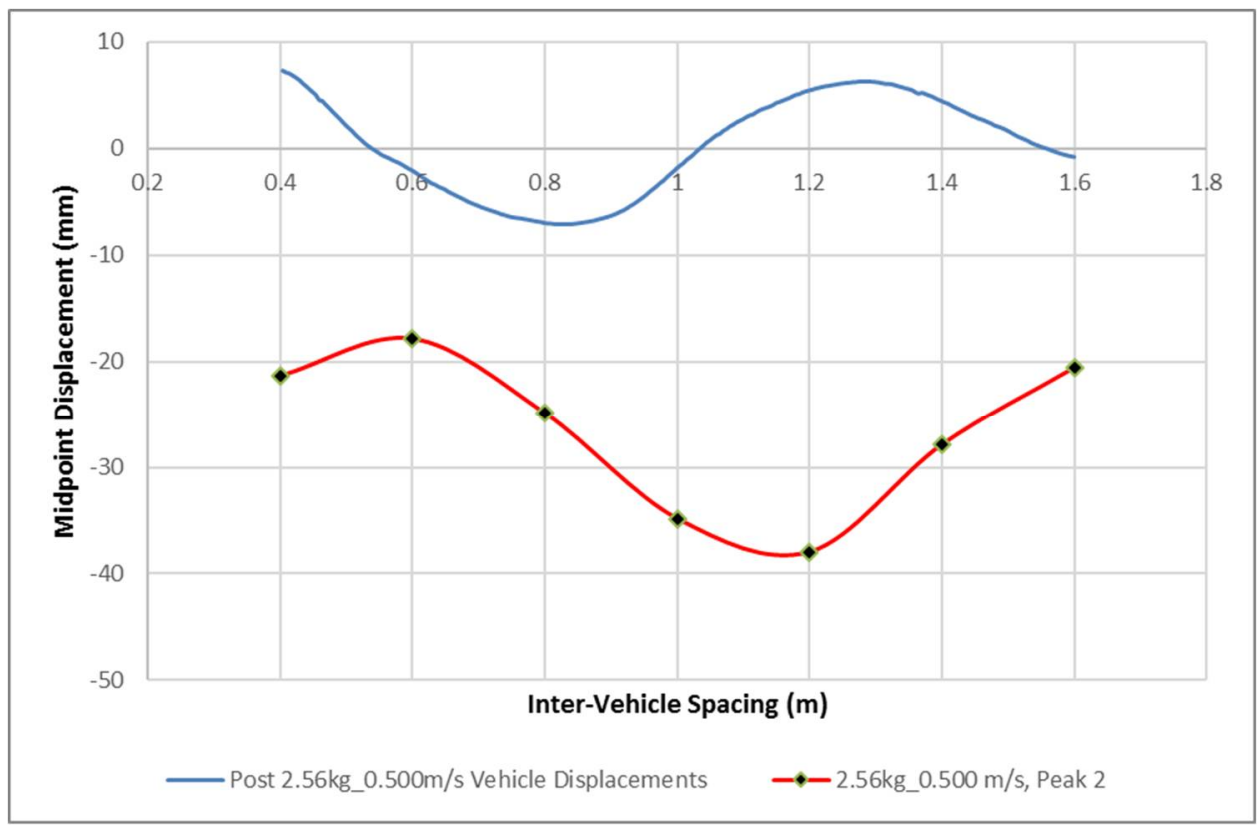

Figure 5-12: Influence of Leading Vehicle- Induced Displacements on Peak $2(0.500 \mathrm{~m} / \mathrm{s})$

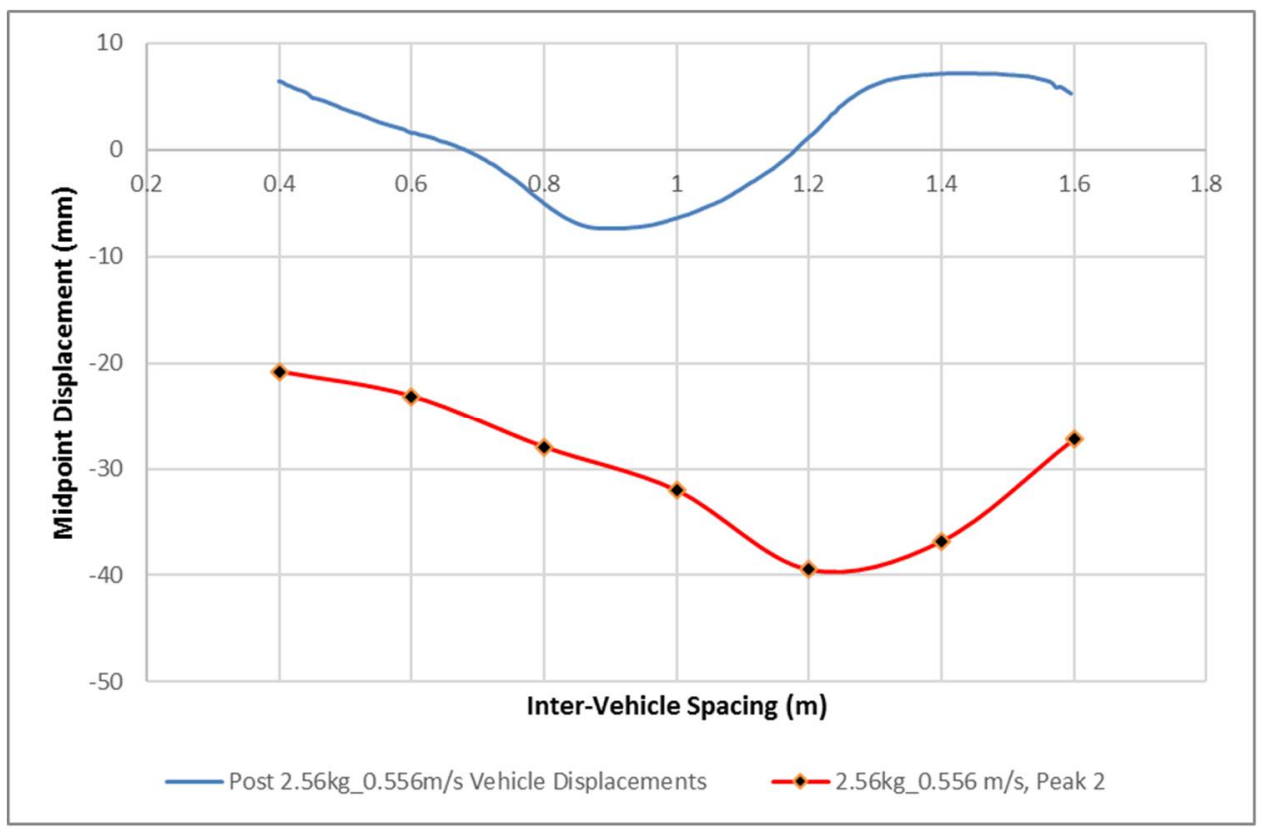

Figure 5-13: Influence of Leading Vehicle- Induced Displacements on Peak $2(0.556 \mathrm{~m} / \mathrm{s})$ 


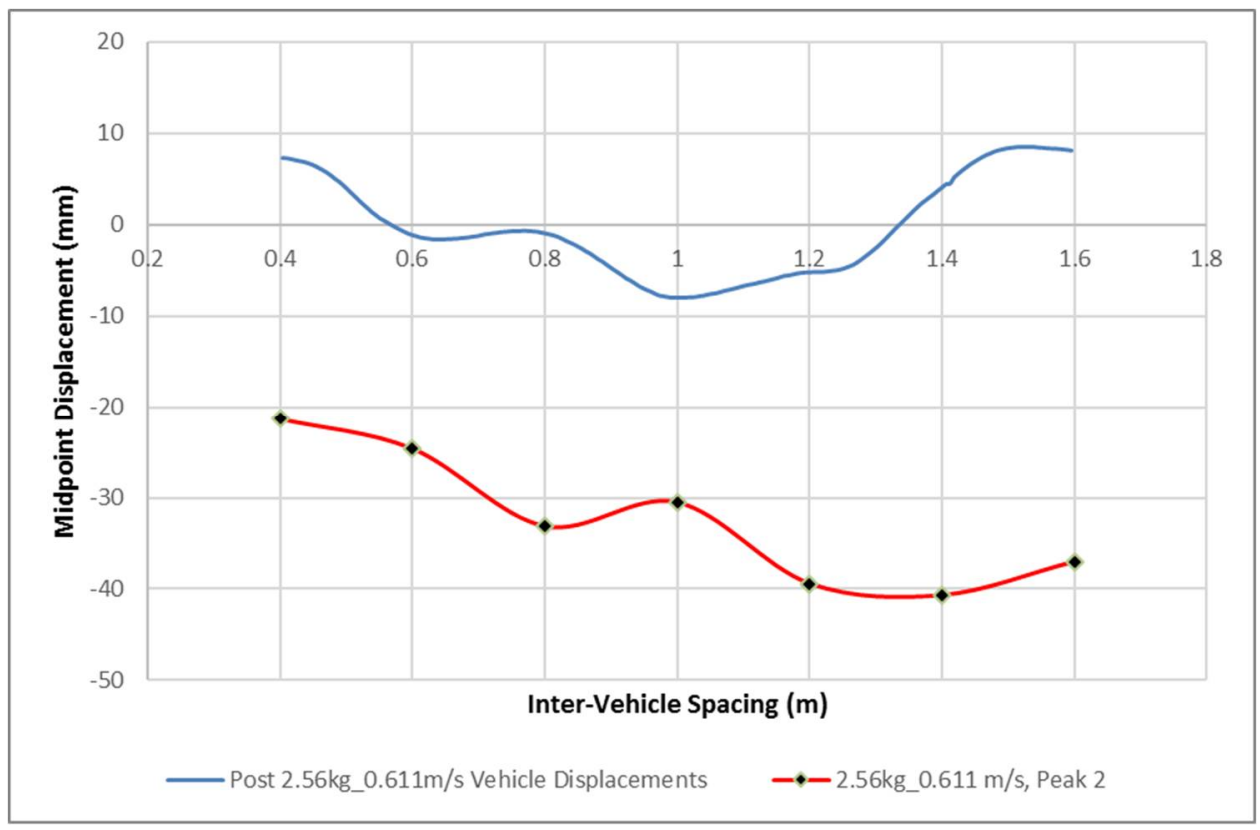

Figure 5-14: Influence of Leading Vehicle- Induced Displacements on Peak $2(0.611 \mathrm{~m} / \mathrm{s})$

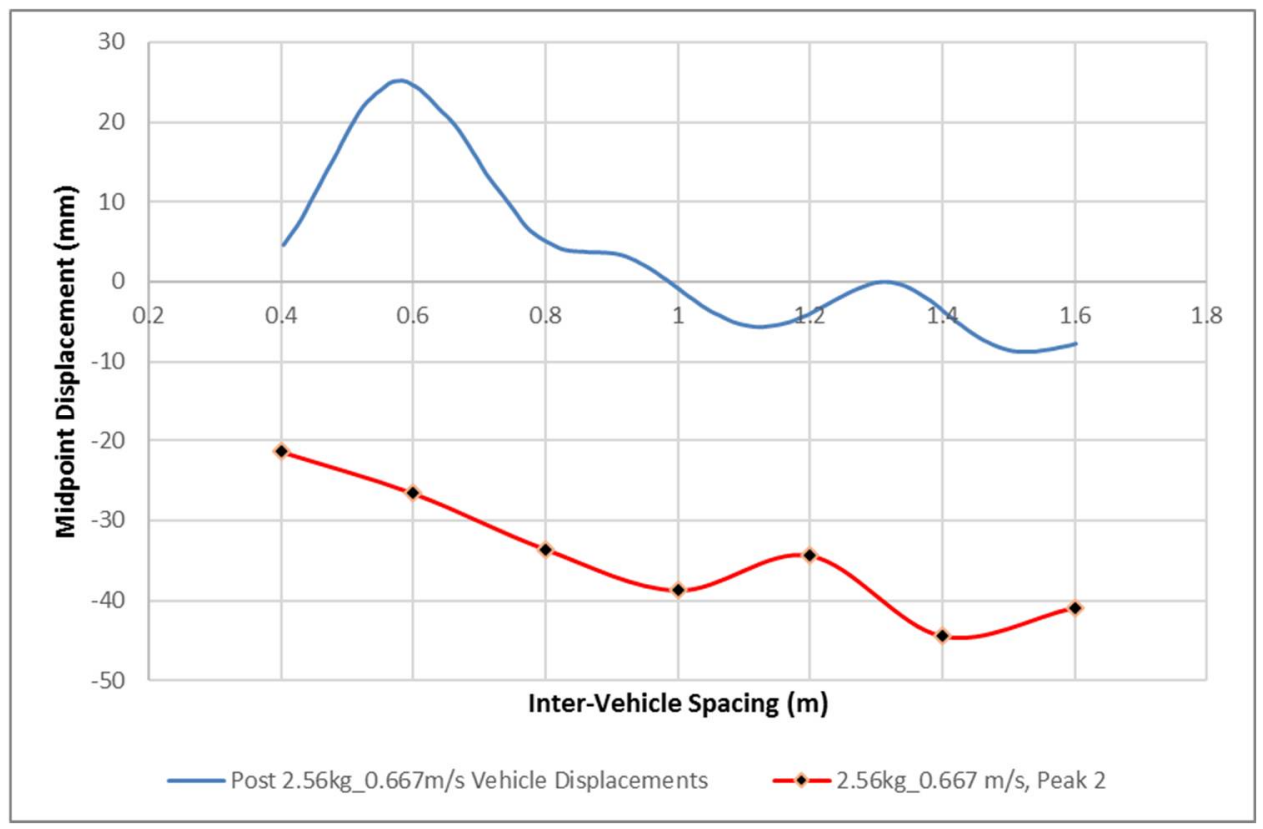

Figure 5-15: Influence of Leading Vehicle- Induced Displacements on Peak $2(0.667 \mathrm{~m} / \mathrm{s})$ 


\subsubsection{Validation of MatLab Finite Element Program}

Figure 5-16 to Figure 5-19 show a comparison of numerical and experimental midpoint displacements, with the percentage errors between Numerical and Experimental displacements listed in Table 5-9 for two $2.56-\mathrm{kg}$ vehicles. The percentage error between experimental and numerical results is high at vehicle velocity of $0.278 \mathrm{~m} / \mathrm{s}$ and generally decreases with increase in velocity. Results for $2.88 \mathrm{~kg}$ and $3.20 \mathrm{~kg}$ vehicles are presented in Appendix C.

In general, good agreement is achieved between the experimental and numerical midpoint deflection profiles with the numerical displacement yielding lower values for both Peak 1 and Peak 2 displacements.

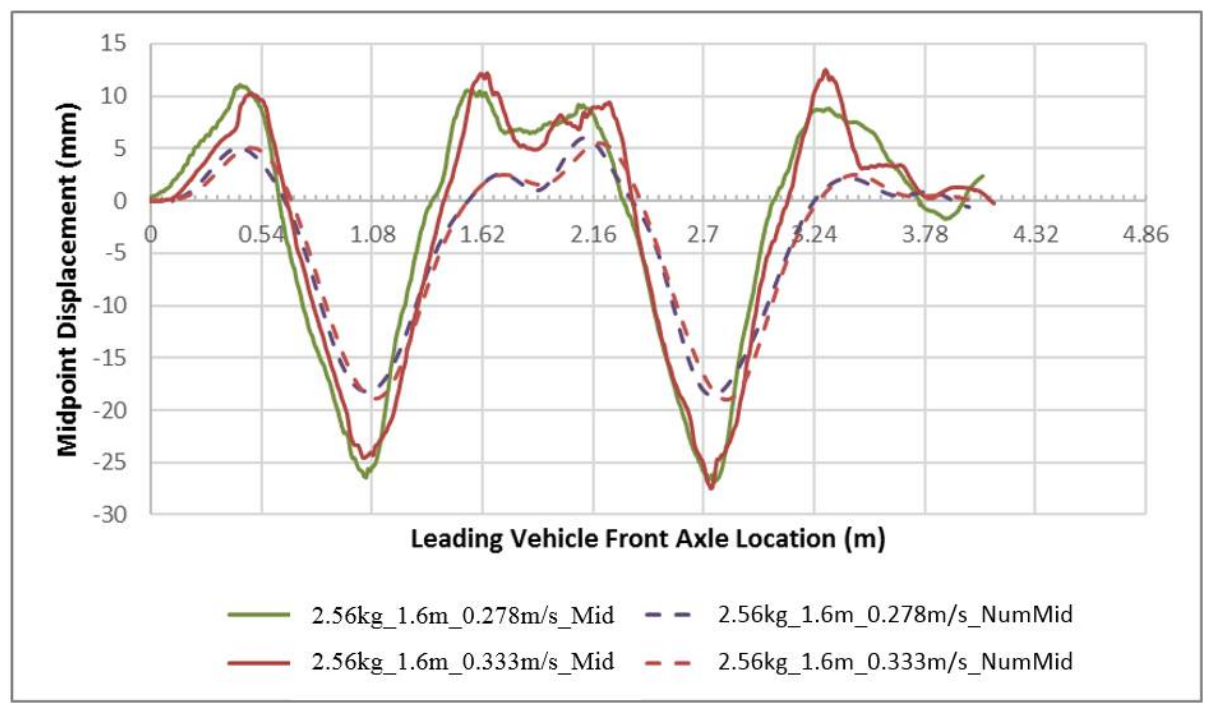

Figure 5-16: Numerical vs Experimental Results for $0.278 \mathrm{~m} / \mathrm{s}$ and $0.333 \mathrm{~m} / \mathrm{s}$ 


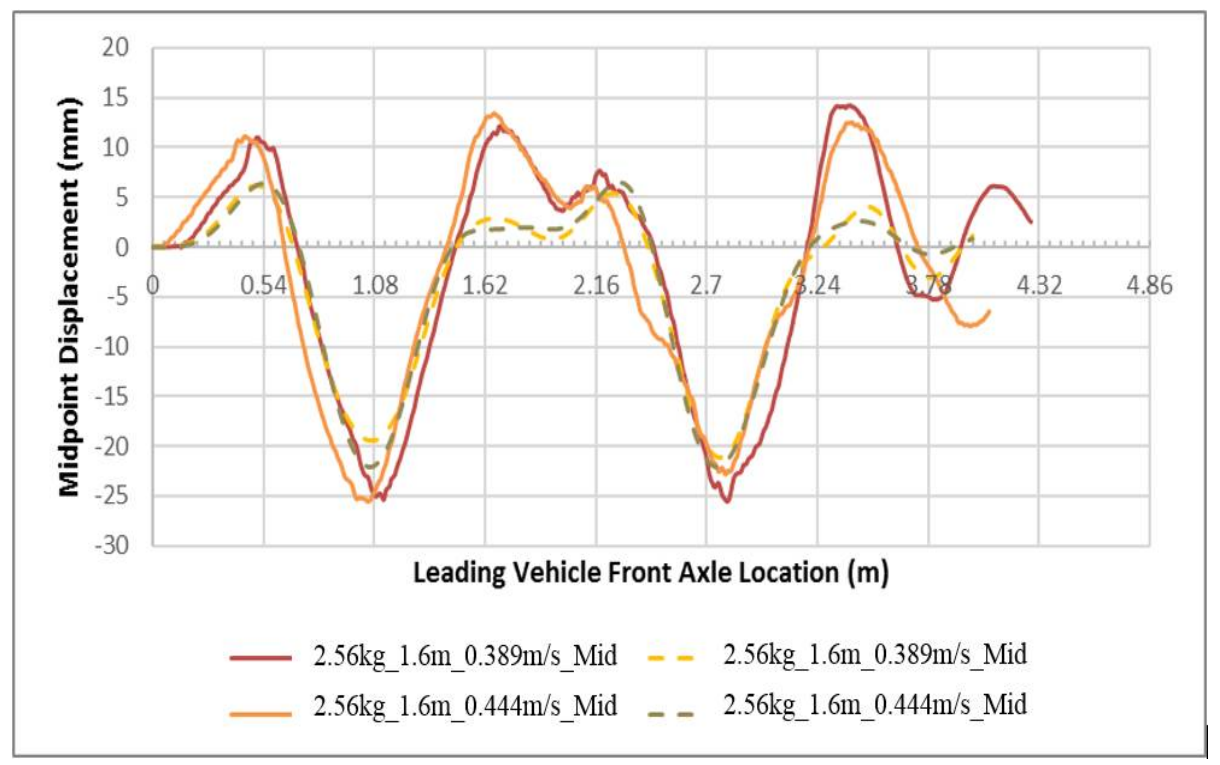

Figure 5-17: Numerical vs Experimental Midpoint Displacement for $0.389 \mathrm{~m} / \mathrm{s}$ and 0.444 $\mathrm{m} / \mathrm{s}$

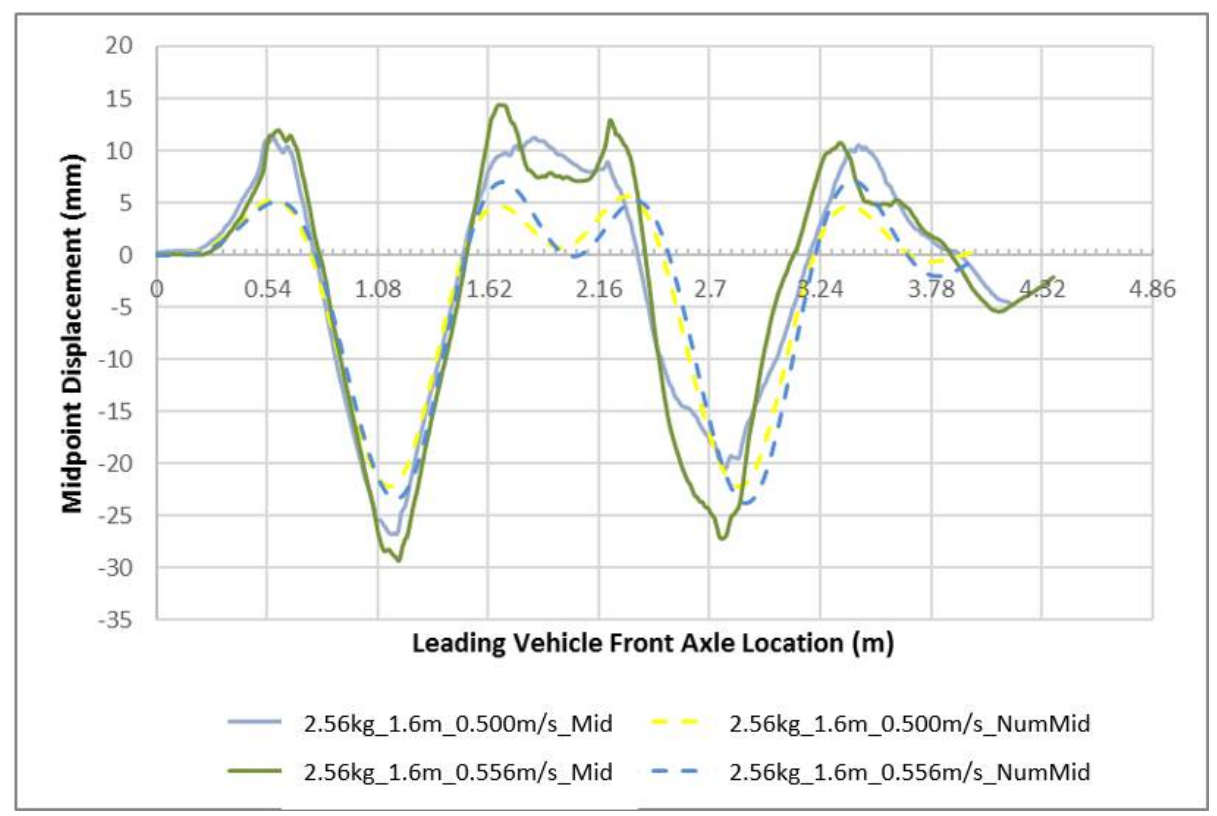

Figure 5-18: Numerical vs Experimental Midpoint Displacement for $0.500 \mathrm{~m} / \mathrm{s}$ and 0.556 $\mathrm{m} / \mathrm{s}$ 


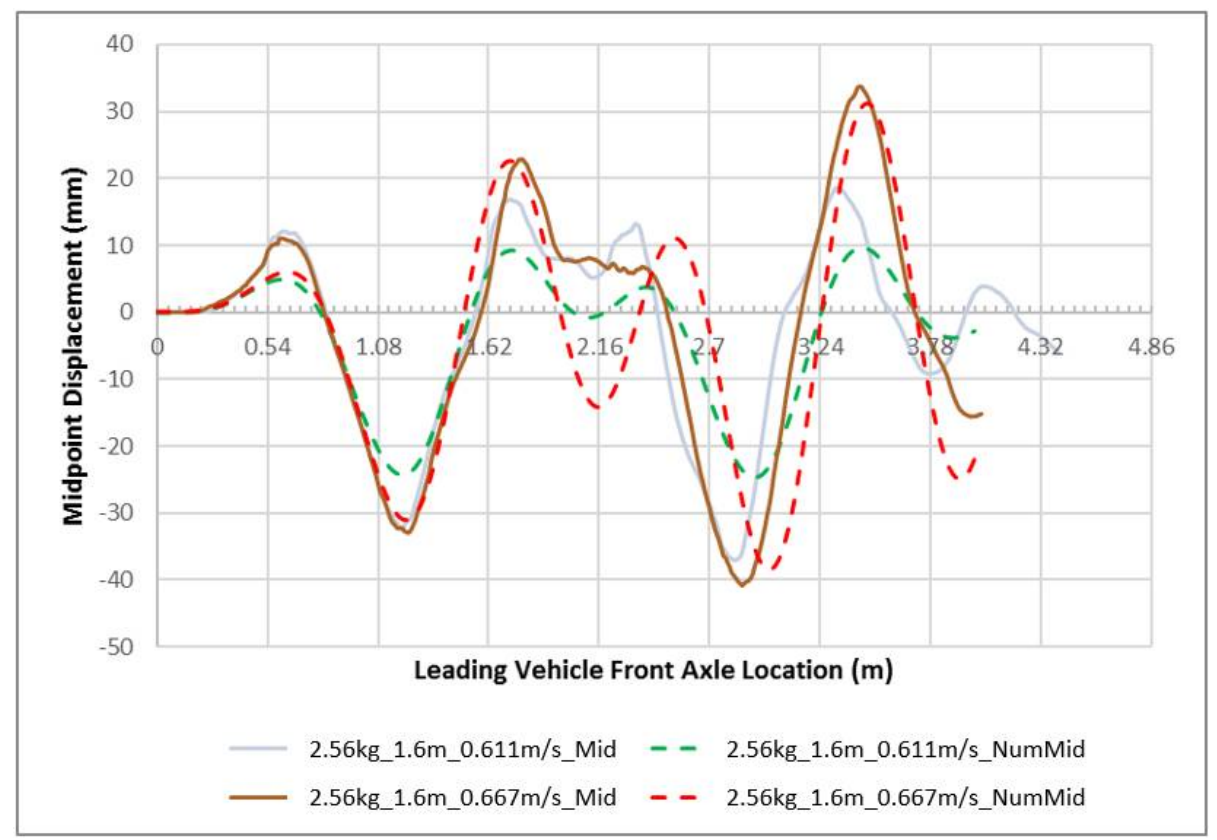

Figure 5-19: Numerical vs Experimental Midpoint Displacement for $0.611 \mathrm{~m} / \mathrm{s}$ and 0.667 $\mathrm{m} / \mathrm{s}$

Table 5-10: Numerical vs Experimental Results for $2.56 \mathrm{~kg}$

\begin{tabular}{|c|c|c|c|c|c|c|}
\hline Velocity $(\mathrm{m} / \mathrm{s})$ & \multicolumn{2}{|c|}{ Experimental } & \multirow{2}{*}{\multicolumn{2}{|c|}{ Numerical }} & \multirow{2}{*}{\multicolumn{2}{|c|}{$\begin{array}{c}\text { Percentage } \\
\text { Difference }(\%)\end{array}$}} \\
\hline \multicolumn{3}{|c|}{$2.56-\mathrm{kg}, 1.4 \mathrm{~m}$} & & & & \\
\hline & Peak 1 & Peak 2 & Peak 1 & Peak 2 & Peak 1 & Peak 2 \\
\hline 0.278 & -26.43 & -26.80 & -18.31 & -17.65 & -30.74 & -34.14 \\
\hline 0.444 & -25.50 & -22.76 & -22.17 & -24.79 & -13.08 & 8.90 \\
\hline 0.667 & -33.00 & -40.89 & -31.13 & -33.78 & -5.66 & -17.39 \\
\hline \multicolumn{5}{|c|}{$2.56-\mathrm{kg}, 1.2 \mathrm{~m}$} & & \\
\hline 0.278 & -27.30 & -25.37 & -18.31 & -17.96 & -32.93 & -29.20 \\
\hline 0.444 & -25.32 & -29.04 & -22.17 & -22.11 & -12.44 & -23.86 \\
\hline 0.667 & -33.31 & -34.38 & -31.13 & -31.59 & -6.52 & -8.12 \\
\hline \multicolumn{5}{|c|}{$2.56-\mathrm{kg}, 1.0 \mathrm{~m}$} & & \\
\hline 0.278 & -26.18 & -29.41 & -18.31 & -18.68 & -30.08 & -36.47 \\
\hline 0.444 & -23.30 & -27.04 & -22.17 & -24.71 & -4.87 & -8.63 \\
\hline 0.667 & -34.54 & -38.73 & -31.12 & -46.35 & -9.91 & 19.69 \\
\hline \multicolumn{5}{|c|}{$2.56-\mathrm{kg}, 0.8 \mathrm{~m}$} & & \\
\hline 0.278 & -23.29 & -23.71 & -18.02 & -18.97 & -22.63 & -20.00 \\
\hline 0.444 & -23.19 & -27.35 & -22.05 & -22.23 & -4.92 & -18.74 \\
\hline 0.667 & -30.80 & -33.59 & -30.43 & -47.62 & -1.21 & 41.78 \\
\hline \multicolumn{5}{|c|}{ Absolute Average Percentage Difference (\%) } & 14.58 & 22.24 \\
\hline
\end{tabular}


The percentage difference between numerical and experimental displacements were calculated as:

$$
\frac{\text { ExpPeak-NumPeak }}{\text { ExpPeak }} \times 100
$$

Where ExpPeak and NumPeak are the maximum experimental and numerical maximum displacements respectively. The minimum percentage difference of $1.21 \%$ occurs for Peak 1 displacement for the case of two $2.56 \mathrm{~kg}$ vehicles at $0.667 \mathrm{~m} / \mathrm{s}$ and 0.8 $\mathrm{m}$ spacing. The differences between numerical and experimental displacements can be mainly attributed to waves generated during bridge oscillations, which travelled along the bridge and were not accounted for in the numerical model.

Waves are generated during bridge vibrations and are reflected against the walls of the tank longitudinally. For slower vehicle speeds e.g. $0.278 \mathrm{~m} / \mathrm{s}$, the window of time in which the generated waves affect bridge displacements is longer, resulting in larger error at lower speeds. These waves are not considered in the numerical model because in the field, there would be more room on the river or lake for generated waves to dissipate and thus have negligible impact on bridge displacements.

Another source of error is the idealisation of the bowl-shaped experimental pontoons as a rectangular cross section. This introduces some error in both the buoyant stiffness estimation and the added mass of water accelerated during bridge vibrations. 


\subsection{Numerical Parametric Studies for the Dynamic Response of a Hinge- Connected Full-Scale Floating Bridge to Two or More Vehicles}

In this section, the Matlab program is used to simulate a full-scale crossing of an $84 \mathrm{~m}$ long hinge-connected floating bridge. Three rigidly connected, $7 \mathrm{~m}$ long pontoon bays are used to form a longer 21-m long hinge connected bridge pontoon. Please refer to Appendix B for interior and exterior pontoon bay details. 'Pontoon' from here onwards refer to the 21-m long bridge section.

Varying vehicle weights (MLC25 to MLC75), speeds (5 km/hr to $45 \mathrm{~km} / \mathrm{hr}$ ), and intervehicle spacing (10m to $40 \mathrm{~m})$ are tested to establish the controlling parameters that influence maximum bridge displacements. Finally, the midpoint displacements are studied when the bridge is subjected to multiple consecutive vehicles.

For each numerical run, a time-step is automatically selected by the program which is equal to $1 / 10$ of the fundamental period of vibration of the floating bridge. This ensures acceptable accuracy of the numerical procedure. The properties of the tested floating bridge are shown in Table 5-11.

The damping of a dynamic system is difficult to determine (J. Humar, 2002). The experimental model was thus used to estimate appropriate damping coefficient for the numerical simulation by measuring the response of the bridge to various types of excitation. Vertical displacements were applied to the hinge-connection points of the bridge consecutively and the model vehicle was passed over the bridge at test velocities. In all cases, the damping coefficient was approximately determined as $5 \%$ by logarithmic decrement. 
The dynamic vertical bridge deflection presented are measured in reference to the maximum deflection under self-weight $(-0.127 \mathrm{~m})$. For safe operation of ribbon floating bridges, the maximum vertical deflection is limited to $80 \%$ of the bridge depth, to reserve $20 \%$ of the depth as free board (Hornbeck et al., 2005). The hinge-connected floating bridge studied in this chapter has a total depth of $1.12 \mathrm{~m}$. Considering the self-weight deflection, the additional deflection under vehicle loads must not exceed $0.769 \mathrm{~m}$.

Table 5-11: Input Properties of Ribbon Floating Bridge for Full Scale Parametric Study

\begin{tabular}{|l|l|l|l|}
\hline Property & Value & Property & Value \\
\hline Pontoon length & $21 \mathrm{~m}$ & Bridge mass per unit length & $812 \mathrm{~kg}$ \\
\hline Number of pontoons & 4 & Water density & $1000 \mathrm{~kg} / \mathrm{m}^{3}$ \\
\hline $\begin{array}{l}\text { Number of elements per } \\
\text { pontoon }\end{array}$ & $3^{*}$ & Damping coefficient & $5 \%$ \\
\hline Bridge width & $8.13 \mathrm{~m}$ & Vehicle axle spacing & $6 \mathrm{~m}$ \\
\hline Bridge depth & $1.12 \mathrm{~m}$ & & \\
\hline Steel young modulus & $2.0 \mathrm{E} 11 \mathrm{~Pa}$ & & \\
\hline Moment of inertia & $0.015 \mathrm{~m}^{4}$ & & \\
\hline
\end{tabular}

* According to numerical tests, 3 elements per pontoon is adequate.

\subsubsection{Modal Analysis}

In dynamic problems where the mass, stiffness and damping matrices of the system do not change, a modal analysis is required to ensure that the loading frequency does not approach that of the dynamic system. In the current problem, the system properties change at each time-step of analysis. It is still important to examine the vibration modes as they may still have sufficient influence on the bridge vibration.

The first twelve natural frequencies and periods of vibration of the hinge-connected floating bridge are shown in Table 5-12. It was determined that the first three rigid modes 
of vibration contribute $96 \%$ of the effective mass of the floating bridge dynamic system. Thee rigid modes of vibration are more easily excited as compared to higher modes which involve elastic deformations of the pontoon bridge. Figure 5-20 shows the first three rigid modes of vibration.

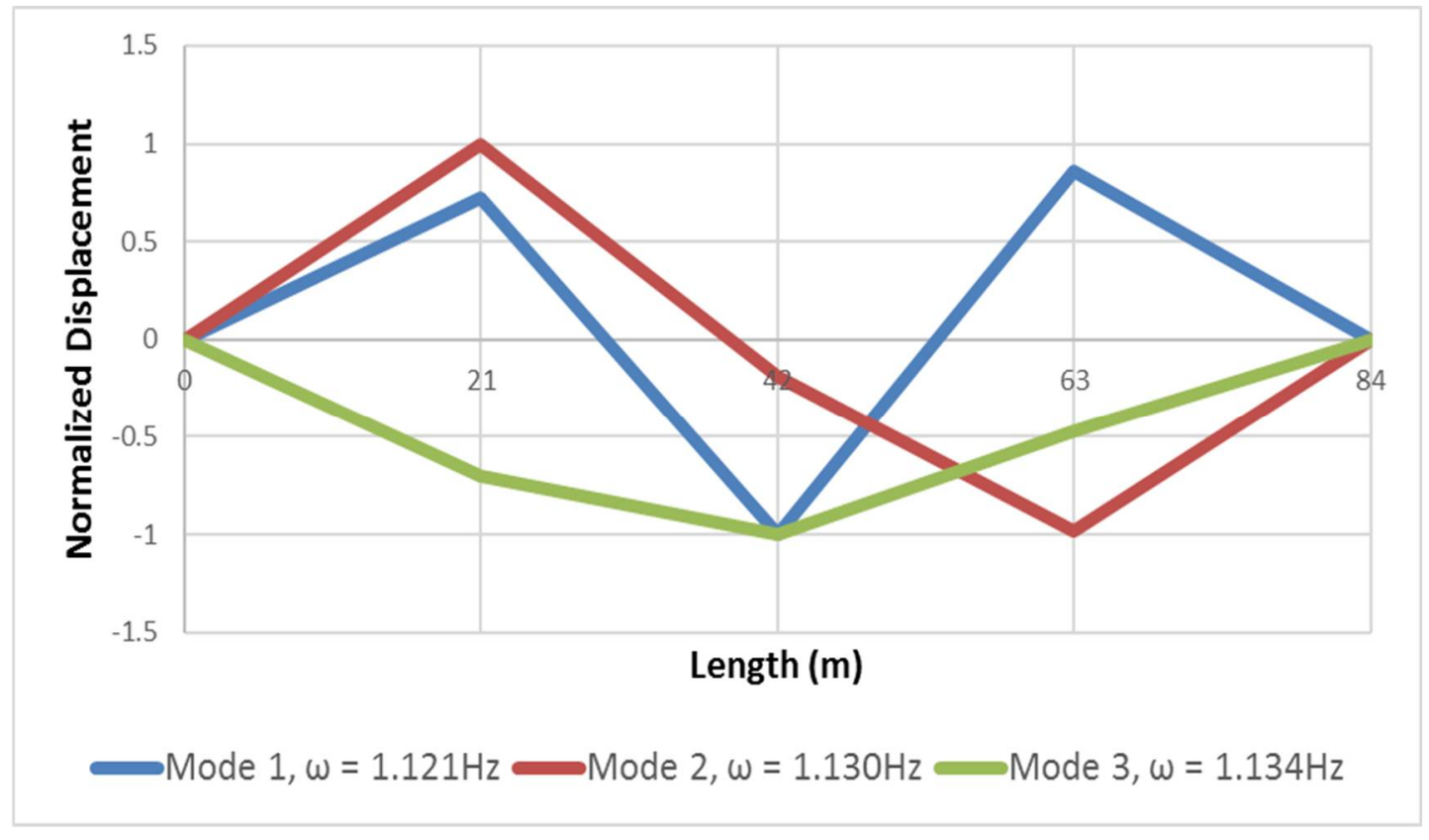

Figure 5-20: First Three Flexural Mode Shapes of Floating Bridge

Table 5-12: Floating Bridge Vibration Frequencies

\begin{tabular}{|c|c|c|}
\hline Mode & Natural Frequency (Hz) & Vibration Period (s) \\
\hline 1 & 1.121 & 5.605 \\
\hline 2 & 1.130 & 5.560 \\
\hline 3 & 1.134 & 5.541 \\
\hline 4 & 5.046 & 1.245 \\
\hline 5 & 5.594 & 1.123 \\
\hline 6 & 6.846 & 0.918 \\
\hline 7 & 8.071 & 0.778 \\
\hline 8 & 9.911 & 0.634 \\
\hline 9 & 19.100 & 0.329 \\
\hline 10 & 19.456 & 0.323 \\
\hline 11 & 20.215 & 0.311 \\
\hline 12 & 20.882 & 0.301 \\
\hline
\end{tabular}




\subsubsection{Effect of Single Vehicle Speed and Weight on Bridge Displacements}

Single vehicles at various speeds were modelled numerically to determine the effect of vehicle speed on maximum midpoint displacement. It was assumed that certain vehicle speeds would induce resonant displacements in the bridge. For studying the vehicle speed effect, the vehicle Speed Ratio is defined as:

$$
\chi=\frac{2 T v}{L_{\text {bridge }}}
$$

Where $T$ is the period of vibration of the bridge, $v$ is the vehicle travel velocity $(\mathrm{m} / \mathrm{s})$ and $L_{\text {bridge }}$ is the bridge length $(84 \mathrm{~m})$. The Speed Ratio gives an indication of the relationship between the frequency of vehicle-induced axle loads along the bridge, and the bridge frequency of vibration. The first three modes of vibration are assumed to dominate bridge response. The variation bridge vibration period is negligible for different vehicle speeds and can be taken as the fundamental period of vibration (5.60 s)

Figure 5-21 shows the relationship between vehicle speed ratio and maximum midpoint displacement for various vehicle weights. It is observed that maximum displacement occurs for all vehicle weights when $\chi$ is close to 1 , which corresponds to a vehicle travelling speed of $26.06 \mathrm{~km} / \mathrm{hr}$. 


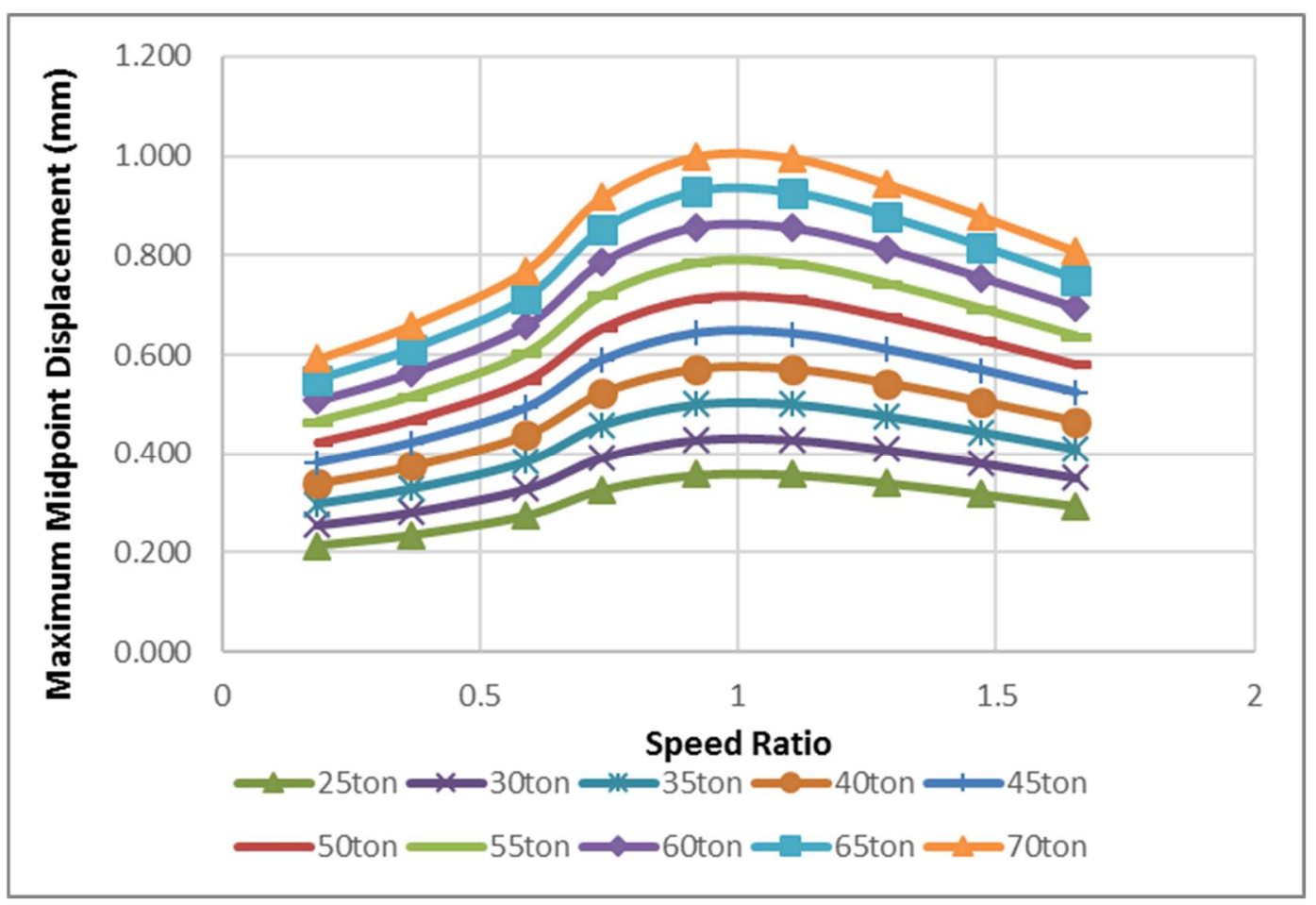

Figure 5-21: Speed Ratio vs Maximum Midpoint Displacement for a Single Vehicle

The equally spaced, parallel plots for different vehicle weights in Figure 5-21 also imply a linear relationship between vehicle weight and maximum induced bridge displacement at all Speed Ratios. This is further illustrated in Figure 5-22, where it can be observed that the rate at which maximum displacements increase with vehicle weight is proportional to the proximity of the Speed Ratio to 1 . This can be expressed in equation form as:

$$
\frac{d\left(U_{\max }\right)}{d(W)}=C \cdot f(\chi)
$$

Where $U_{\max }$ is the maximum midpoint displacement (m), $W$ is the single vehicle weight in tonnes, and $C$ is a constant of proportionality. $f(\chi)$ was obtained by curve fitting the Maximum Displacement to Speed Ratio curve for a vehicle with the arbitrary weight of 75-ton and is given as: 
$f(\chi)=1.021 \sin (0.861 \chi+0.548)+0.076 \sin (5.385 \chi+2.532)$

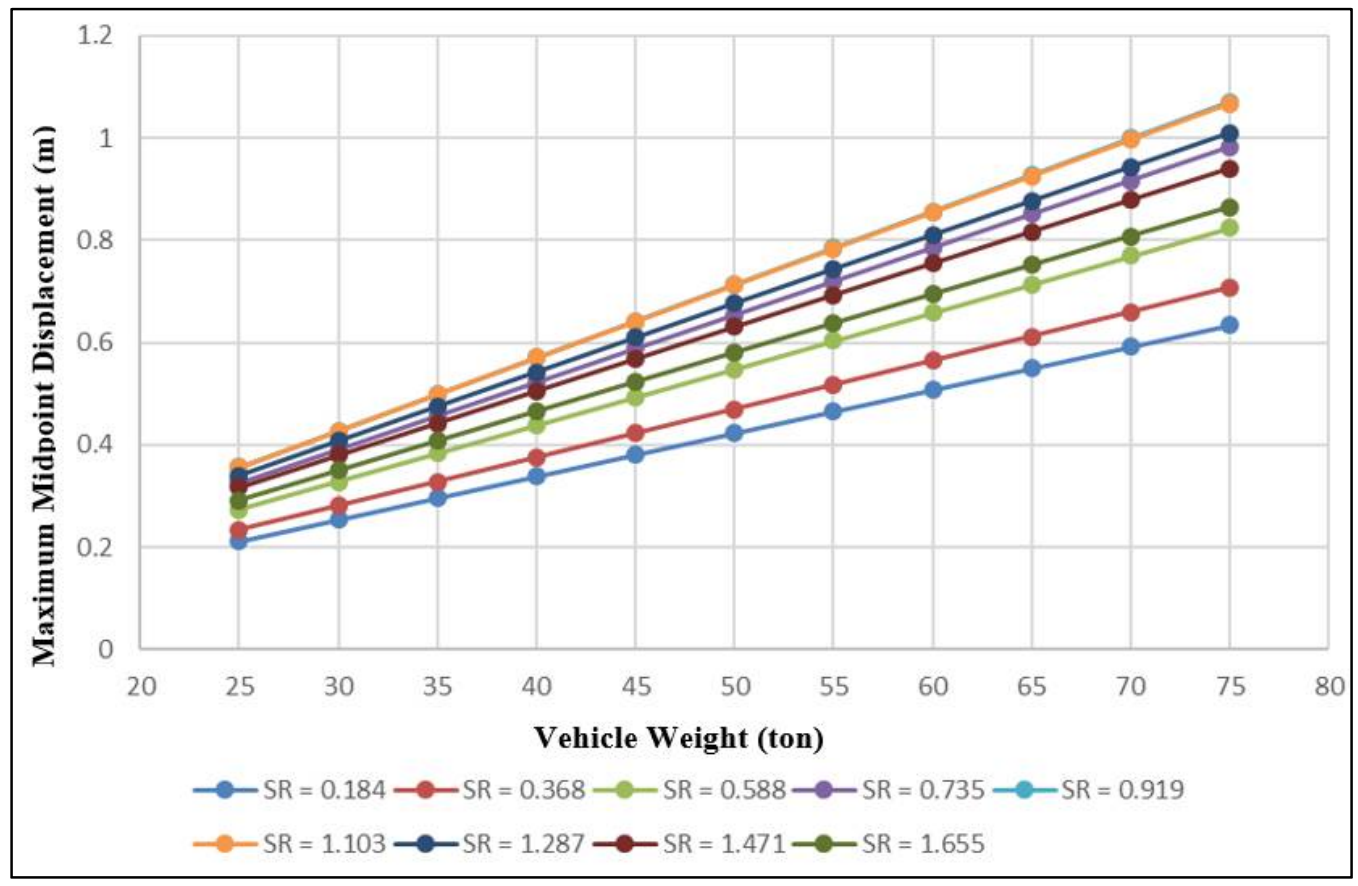

Figure 5-22: Effect of Vehicle Weight on Maximum Midpoint Displacement for Different Speed Ratios

Figure 5-23 shows a comparison of $f(\chi)$ with numerical maximum displacements for the 75-ton vehicle. Substituting for known values of displacement-weight gradient and $f(\chi)$, from Table 5-13, the constant of proportionality $C$ is obtained as $13.138 \mathrm{~m} /$ ton for the 75-ton vehicle. Thus:

$$
\frac{d\left(U_{\max }\right)}{d(W)}=13.138 \cdot f(\chi)
$$




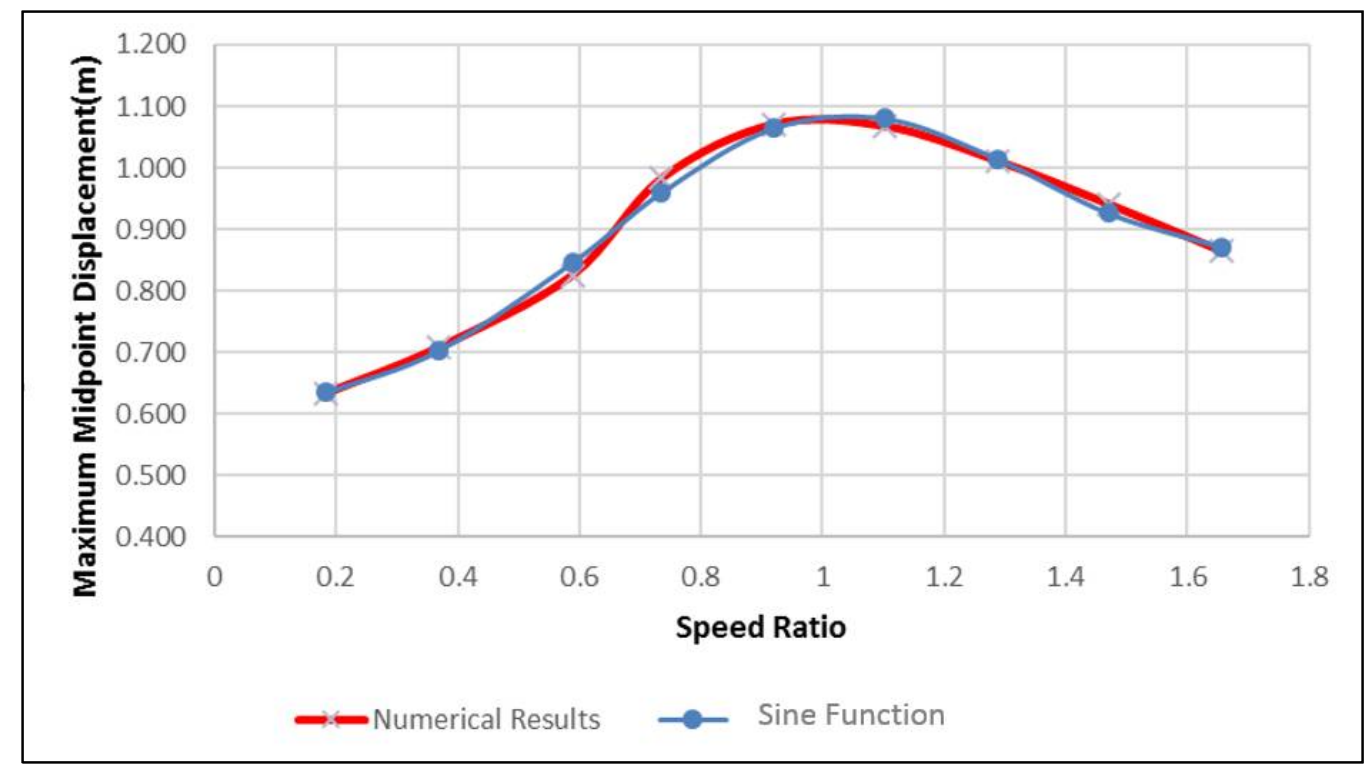

Figure 5-23: Comparison of Numerical Results and Sine Function

Table 5-13: Maximum Displacement to Weight Gradient at various Speed Ratios

\begin{tabular}{|l|l|l|}
\hline $\begin{array}{l}\text { Vehicle Speed } \\
(\mathbf{k m} / \mathbf{h r})\end{array}$ & Speed Ratio $(\boldsymbol{\chi})$ & $\begin{array}{l}\text { Gradient of Max } \\
\text { Displacement to } \\
\text { Vehicle Weight (m/ton) }\end{array}$ \\
\hline 5 & 0.184 & 0.00846 \\
\hline 10 & 0.368 & 0.00936 \\
\hline 16 & 0.588 & 0.01128 \\
\hline 20 & 0.735 & 0.01280 \\
\hline 25 & 0.919 & 0.01419 \\
\hline 30 & 1.103 & 0.01440 \\
\hline 35 & 1.287 & 0.01353 \\
\hline 40 & 1.471 & 0.01234 \\
\hline 45 & 1.655 & 0.01162 \\
\hline
\end{tabular}

For an arbitrary vehicle weight $(W)$, the right-hand side of Equation (5-6) is multiplied by $W / 75$ to obtain:

$$
\frac{d\left(U_{\max }\right)}{d(W)}=\frac{W}{5.71} f(\chi)
$$

For a particular Speed Ratio and vehicle weight in tonnes, Equation (5-7) can be used to analytically determine the rate at which maximum bridge displacement would increase 
with an increase in vehicle weight. As an example, if we know the maximum displacement $U_{\max , 1}$ caused by a vehicle of weigh $W_{1}$ and Speed Ratio $\chi$, we can calculate the maximum midpoint displacement $U_{\max , 2}$ caused by another vehicle of weight $W_{2}$ having the same Speed Ratio $\chi$ as:

$$
U_{\max , 2}=U_{\max , 1}+\left(\frac{d U_{\max }}{d W}\right)_{a v}\left(W_{2}-W_{1}\right)
$$

Where $\left(\frac{d U_{\max }}{d W}\right)_{a v}$ is the average maximum displacement to vehicle weight gradient at and can be taken as:

$$
\left(\frac{d U_{\max }}{d W}\right)_{a v}=\frac{1}{2}\left(\frac{d U_{\max , 1}}{d W_{1}}+\frac{d U_{\max , 2}}{d W_{2}}\right)
$$

\subsubsection{Effect of Vehicle Speed and Spacing of Two or More Vehicles on Midpoint}

\section{Displacement}

Since the relationship between midpoint displacement and vehicle weight is linear, focus will be placed on an arbitrary vehicle weight of 50-ton to investigate the effect of speed and spacing. The relationship between vehicle speed and maximum bridge displacement was presented in Section 5.2.2. Vehicles with Speed Ratio close to 1 produced the largest displacements in the ribbon pontoon hinge-connected floating bridge.

Moreover, the minimum inter-vehicle spacing beyond which successive vehicles have no effect on the midpoint displacement of the hinge-connected ribbon pontoon floating bridge, denoted $\gamma$, was given by Equation (5-2) and equal to $36 \mathrm{~m}$ for a bridge length of $84 \mathrm{~m}$ and vehicle axle spacing of $6 \mathrm{~m}$. 
At inter-vehicle spacing greater than $\gamma$, Peak 1 displacements are approximately equal to the maximum produced by a single vehicle of similar properties. More importantly, Peak 1 displacements decrease for inter-vehicle spacing less than $\gamma$, down to a minimum value of displacement as shown in Figure 5-24. Thus, the presence of a second vehicle decreases the first peak displacement, up to a minimum inter-vehicle spacing which differs depending on vehicle crossing velocity (Figure 5-24) the speed ratio.

The speed of vehicles and their inter-vehicle spacing have a more significant effect on Peak 2 displacements as compared to Peak 1 displacements. Figure 5-25 shows the high variability in Peak 2 displacement with respect to inter-vehicle spacing as compared to Peak 1 displacement. For the sake of clarity, only $16 \mathrm{~km} / \mathrm{hr}$ and $25 \mathrm{~km} / \mathrm{hr}$ results are shown, which are a good representation of the general trend for Peak 2 displacements with respect to inter-vehicle spacing.

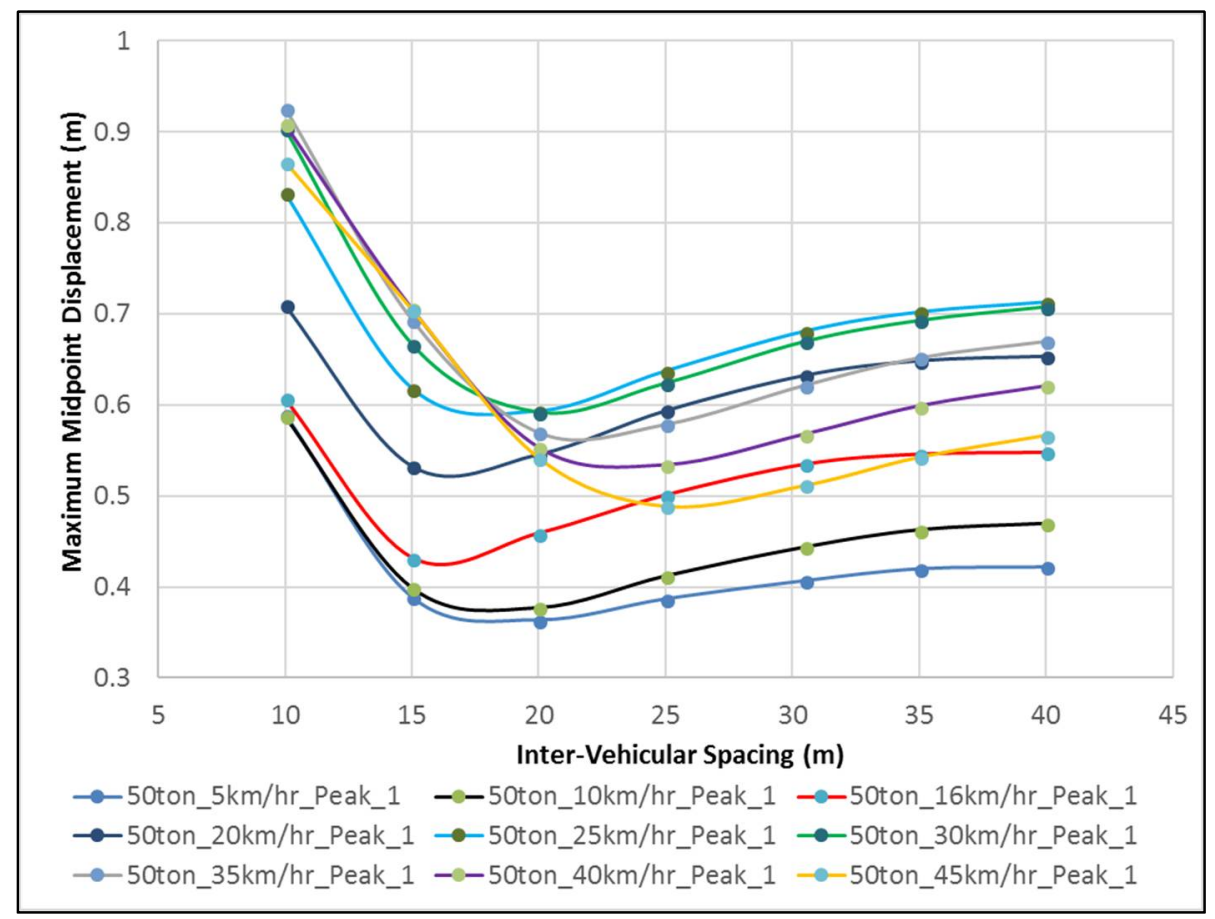

Figure 5-24: Influence of Inter-Vehicle Spacing on Peak 1 Displacements for different Speeds 


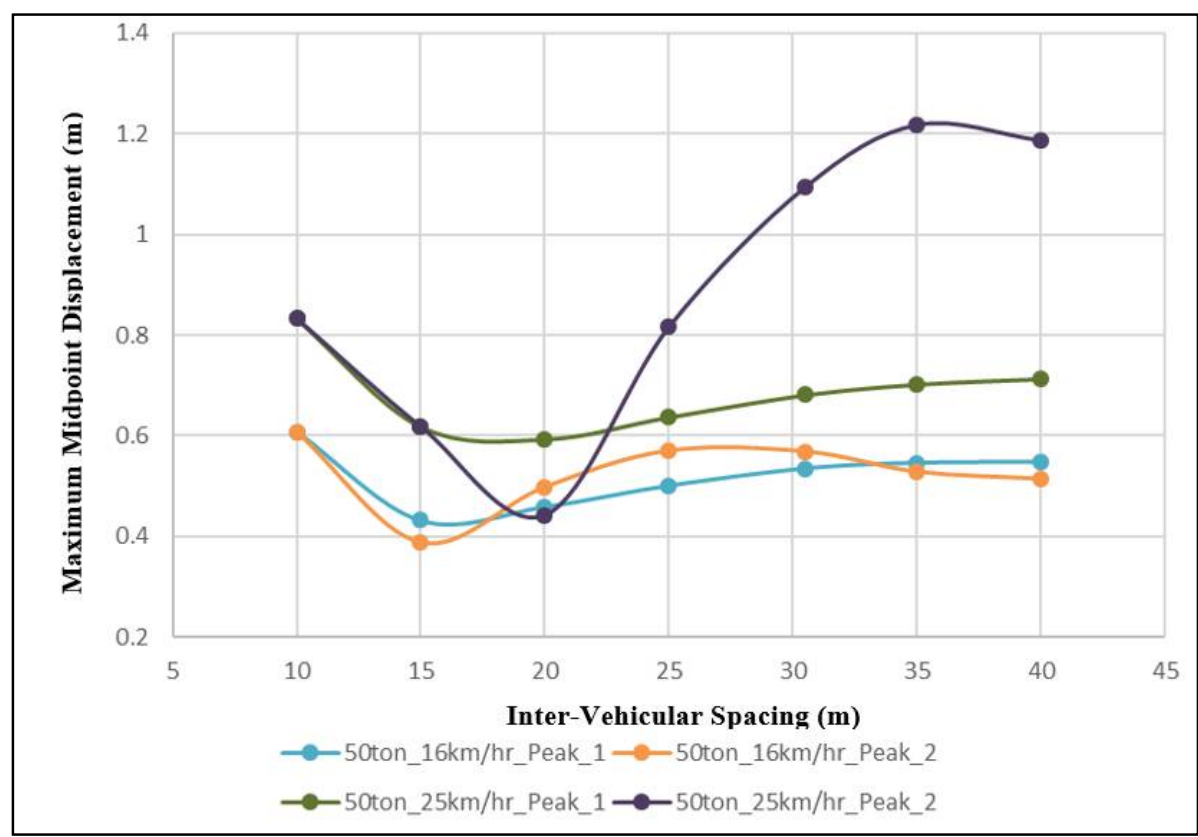

Figure 5-25: Peak 1 and Peak 2 Displacements for different Inter-Vehicle Spacings at $16 \mathrm{~km} / \mathrm{hr}$ and $25 \mathrm{~km} / \mathrm{hr}$

It can be observed from Figure 5-25 that the inter-vehicle spacing which yields minimum Peak 2 displacement is higher for $25 \mathrm{~km} / \mathrm{hr}$ than for $16 \mathrm{~km} / \mathrm{hr}$. This trend (Figure 5-26) is observed in general for all vehicle speeds whereby higher speeds require larger intervehicle speed to yield the minimum Peak 2 displacement.

The magnitude of Peak 2 is affected by the vibration of the bridge after the first vehicle has passed the midpoint. The Peak 2 displacements can be increased or reduced based on superposition of displacements induced by the first vehicle with that caused by the second vehicle, as discussed previously in Section 5.1.2. 


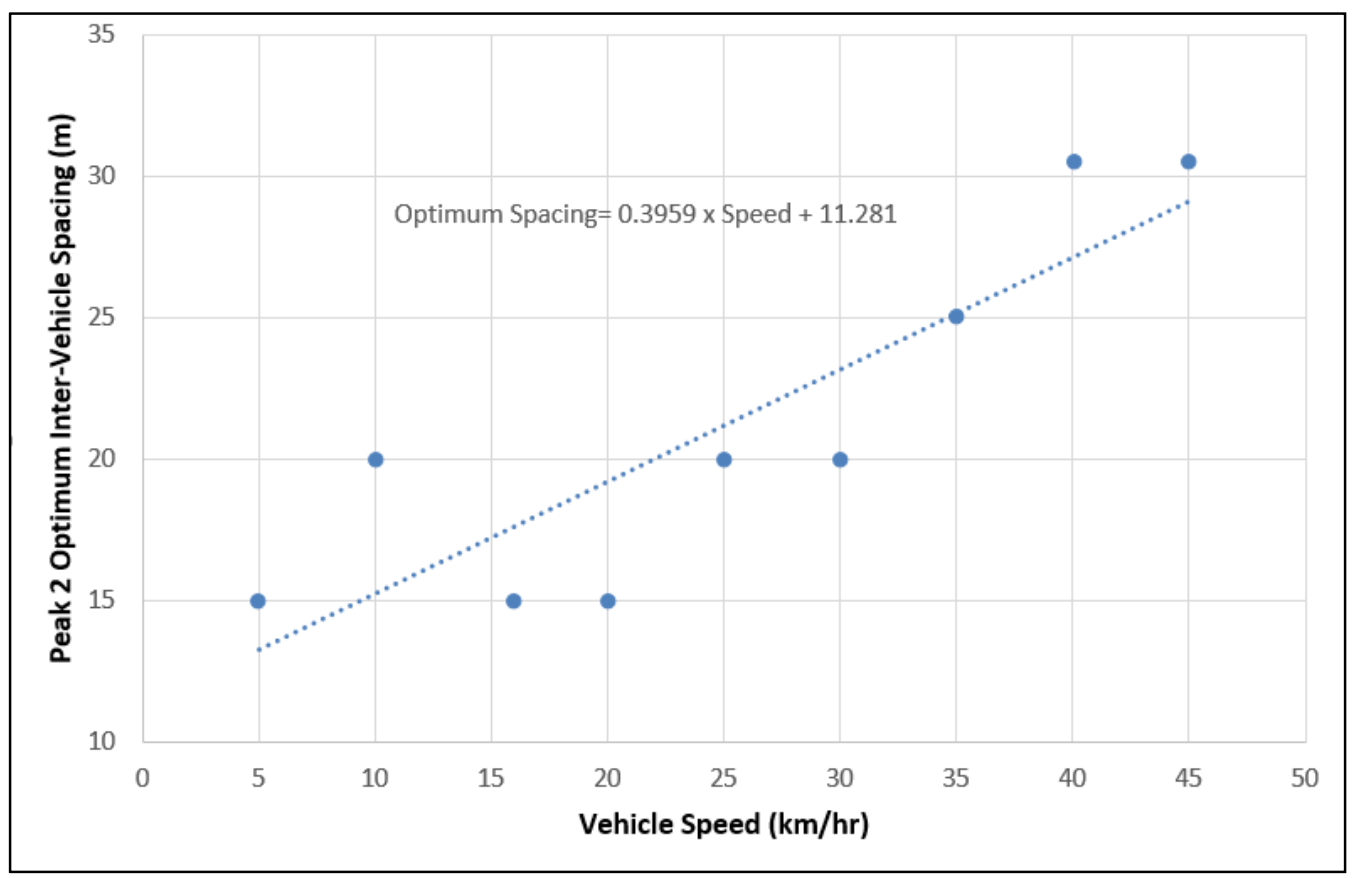

Figure 5-26: Peak 2 Optimum Inter-Vehicle Spacing vs Vehicle Speed

When the second vehicle arrives at the midpoint of the bridge while the ribbon pontoon floating bridge is in a rebound (upward) position the magnitude of the Peak 2

displacement is reduced. When the vehicle arrives during the inbound (downward) displacement, however, the magnitude of the Peak 2 displacement is amplified. The arrival of successive vehicles is linked to the velocity and inter-vehicle spacing, hence the higher variation of the maximum midpoint displacement versus inter-vehicle spacing plot for Peak 2 as compared to Peak 1 in Figure 5-25. Figure 5-27 shows the Midpoint displacement time history during the passage of a single 50 -ton vehicle at $16 \mathrm{~km} / \mathrm{hr}$. The frequency of vibration of the bridge after the vehicle passes the midpoint (i.e. from $15.07 \mathrm{~s}$ onwards) is approximately equal to the fundamental period of vibration (5.6s). 


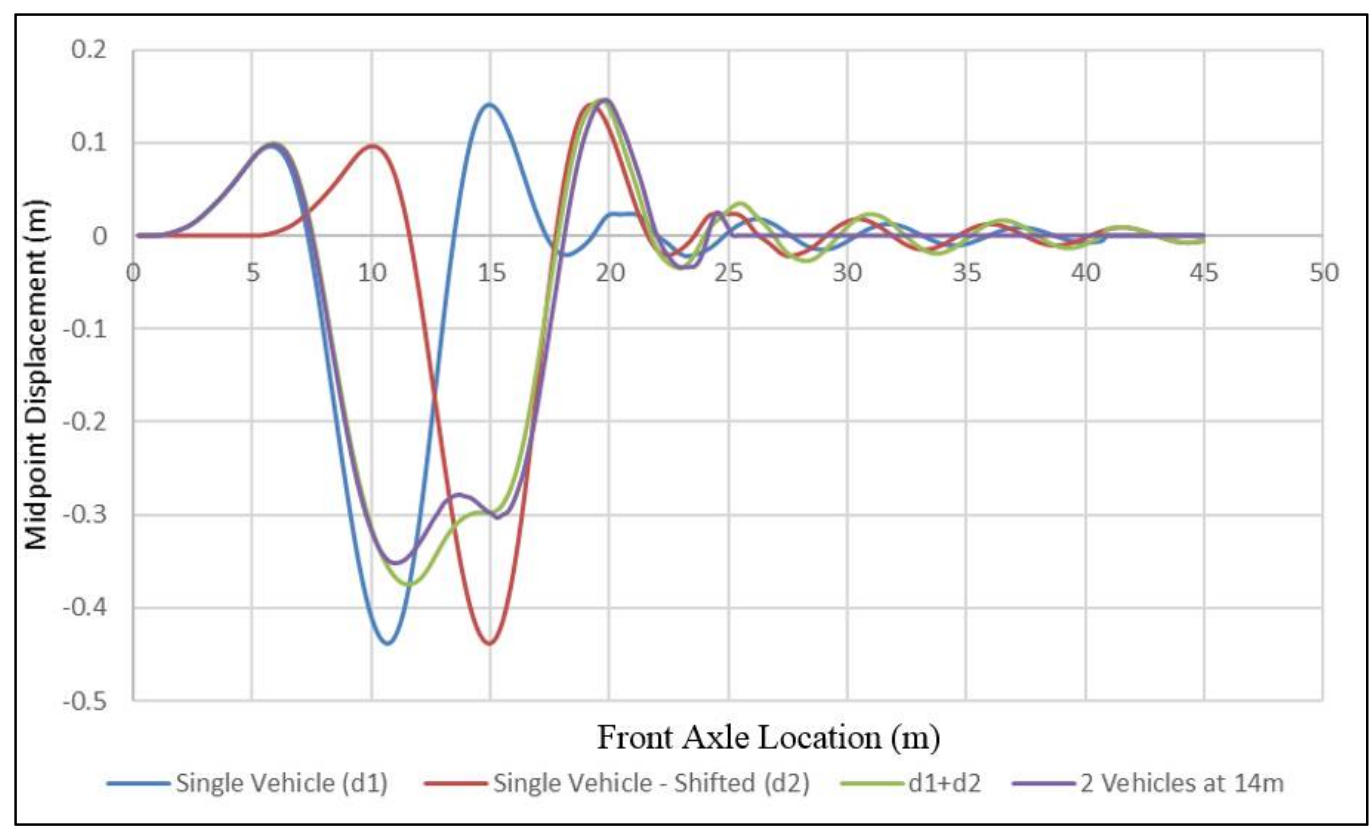

Figure 5-27: Superposition of Midpoint Displacements for 50ton Vehicle at $16 \mathrm{~km} / \mathrm{hr}$

If we assume a second single vehicle with an appropriate inter-vehicle spacing arrives at the bridge midpoint at $15.07 \mathrm{~s}(\mathrm{~d} 2)$, it coincides with the free vibration mode of the bridge under the action of the first vehicle (d1). The summation of these two displacements gives the displacement the ribbon pontoon floating bridge under the second vehicle loading; resulting in attenuated Peak 2 of the displacement of the bridge. Considering a single vehicle, the time difference between the maximum downward displacement and the next subsequent upward displacement is equal to:

$$
15.07 s-10.82 s=4.26 s
$$

Accounting for an axle spacing of $6 \mathrm{~m}$ and vehicle speed of $16 \mathrm{~km} / \mathrm{hr}$, the above time difference corresponds to an inter-vehicle spacing calculated as:

$$
4.26 s \times\left(\frac{16}{3.6} m / s\right)-6 m=12.91 m
$$


This inter-vehicle spacing would produce the maximum reduction in the magnitude of Peak 2.

According to the same superposition procedure, the inter-vehicle spacing which produces maximum downward displacement is calculated by considering the time lag between the single vehicle maximum displacement and the next occurring displacement trough which occurs at $18 \mathrm{~s}$. The corresponding inter-vehicle spacing is equal to $27 \mathrm{~m}$, which yields the maximum Peak 2 displacement for $16 \mathrm{~km} / \mathrm{hr}$ (Figure 5-25). From the period of free vibration, it can be concluded that consecutive vehicles with inter-vehicle spacing that yield minimum or maximum peak 2 displacements are separated by an equivalent time difference of $5.6 \mathrm{~s}$.

Apart from producing reduced Peak 2 displacements, the optimum inter-vehicle spacing listed in Table 5-14 also had the effect of reducing Peak 1 displacement in comparison to Peak 1 displacement corresponding to the maximum downward midpoint displacement caused by a single vehicle.

\subsubsection{Bridge Midpoint Displacements for 10 Consecutive 50-ton Vehicles}

Using the superposition procedure described in the previous section, optimum intervehicle spacing for two 50-ton vehicles were developed for different vehicle speeds (Table 5-14). The optimum inter-vehicle spacing was used for ten vehicles crossing the floating bridge to determine the effect on midpoint displacement.

Figure 5-28 to Figure 5-34 show the midpoint displacement time history for ten consecutive 50 ton vehicles travelling at speeds of $16 \mathrm{~km} / \mathrm{hr}$ to $45 \mathrm{~km} / \mathrm{hr}$ and spaced at optimum inter-vehicle spacing. It can be observed that in all cases, bridge oscillations 
eventually reach an equilibrium state whereby displacements are less than the first Peak displacement. However, very high upward ribbon pontoon floating bridge midpoint displacement was observed upon passage of the last vehicle. All resulting midpoint displacements were less than the maximum allowable displacement of $0.769 \mathrm{~m}$.

Table 5-14: Optimum Inter-Vehicle Spacing

\begin{tabular}{|l|l|l|}
\hline $\begin{array}{l}\text { Velocity } \\
(\mathbf{k m} / \mathbf{h r})\end{array}$ & $\begin{array}{l}\text { Optimum Inter- } \\
\text { Vehicle Spacing }(\mathbf{m})\end{array}$ & $\begin{array}{l}\text { Bridge Capacity } \\
\text { (Vehicles/hr) }\end{array}$ \\
\hline 16 & 12.9 & 720 \\
\hline 20 & 13.6 & 780 \\
\hline 25 & 16.0 & 960 \\
\hline 30 & 18.6 & 1080 \\
\hline 35 & 21.1 & 1260 \\
\hline 40 & 24.5 & 1440 \\
\hline 45 & 27.2 & 1620 \\
\hline
\end{tabular}

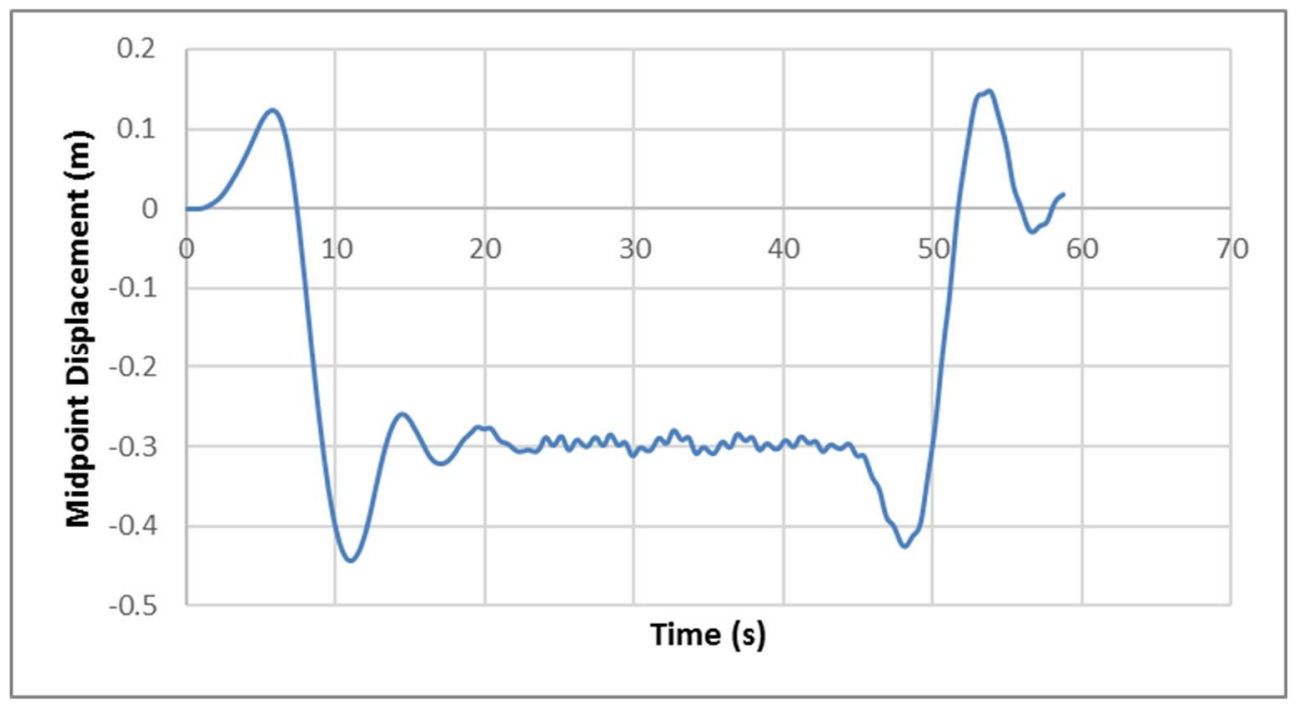

Figure 5-28: Bridge Midpoint displacement for 10 consecutive 50-ton vehicles at 16 $\mathrm{km} / \mathrm{hr}$ spaced at $12.9 \mathrm{~m}$ 


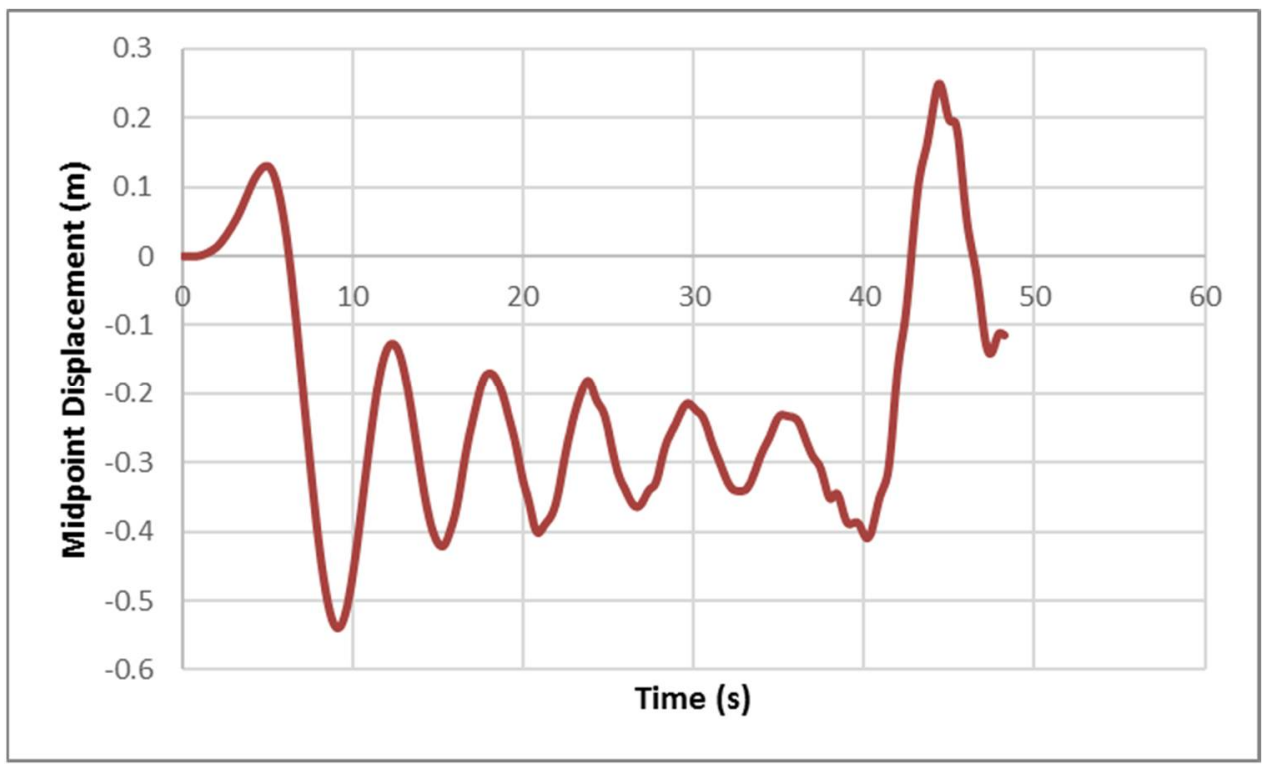

Figure 5-29: Bridge Midpoint displacement for 10 consecutive 50-ton vehicles at 20 $\mathrm{km} / \mathrm{hr}$ spaced at $13.6 \mathrm{~m}$

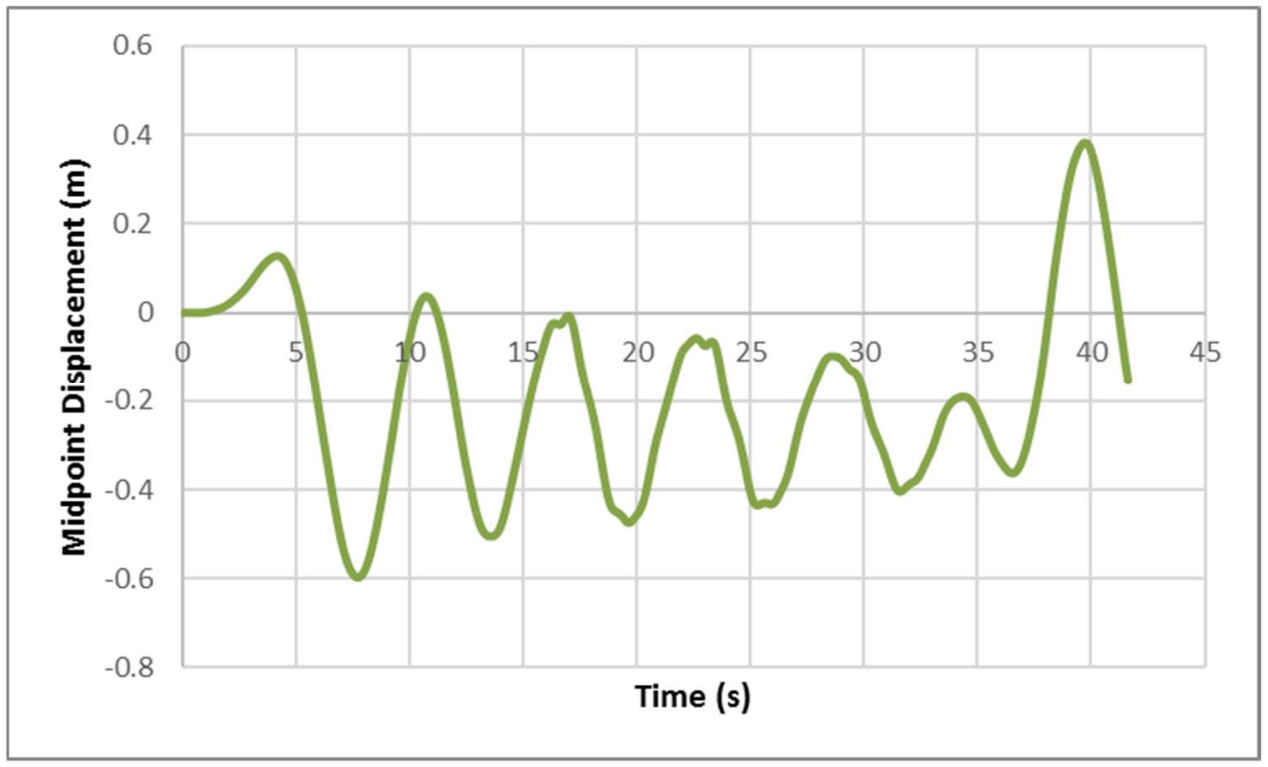

Figure 5-30: Bridge Midpoint displacement for 10 consecutive 50-ton vehicles at 25 $\mathrm{km} / \mathrm{hr}$ spaced at $16.0 \mathrm{~m}$ 


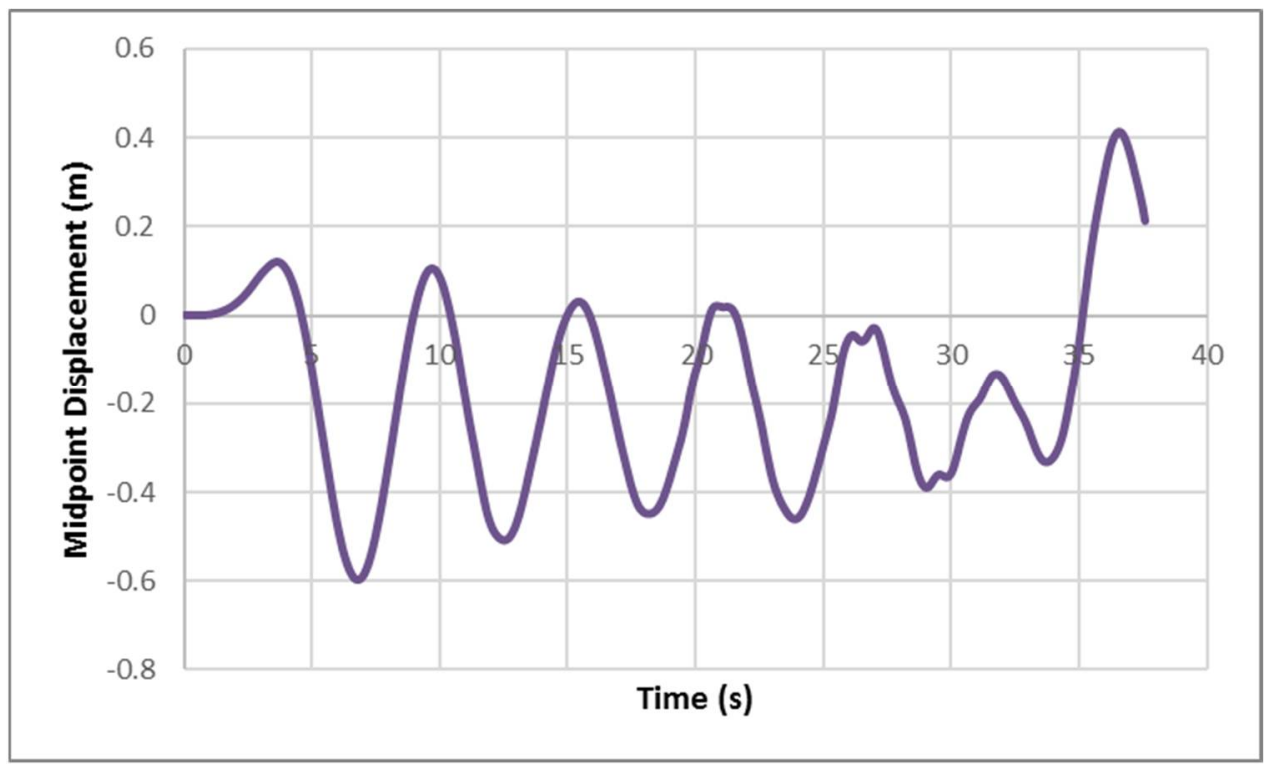

Figure 5-31: Bridge Midpoint displacement for 10 consecutive 50-ton vehicles at 30 $\mathrm{km} / \mathrm{hr}$ spaced at $18.6 \mathrm{~m}$

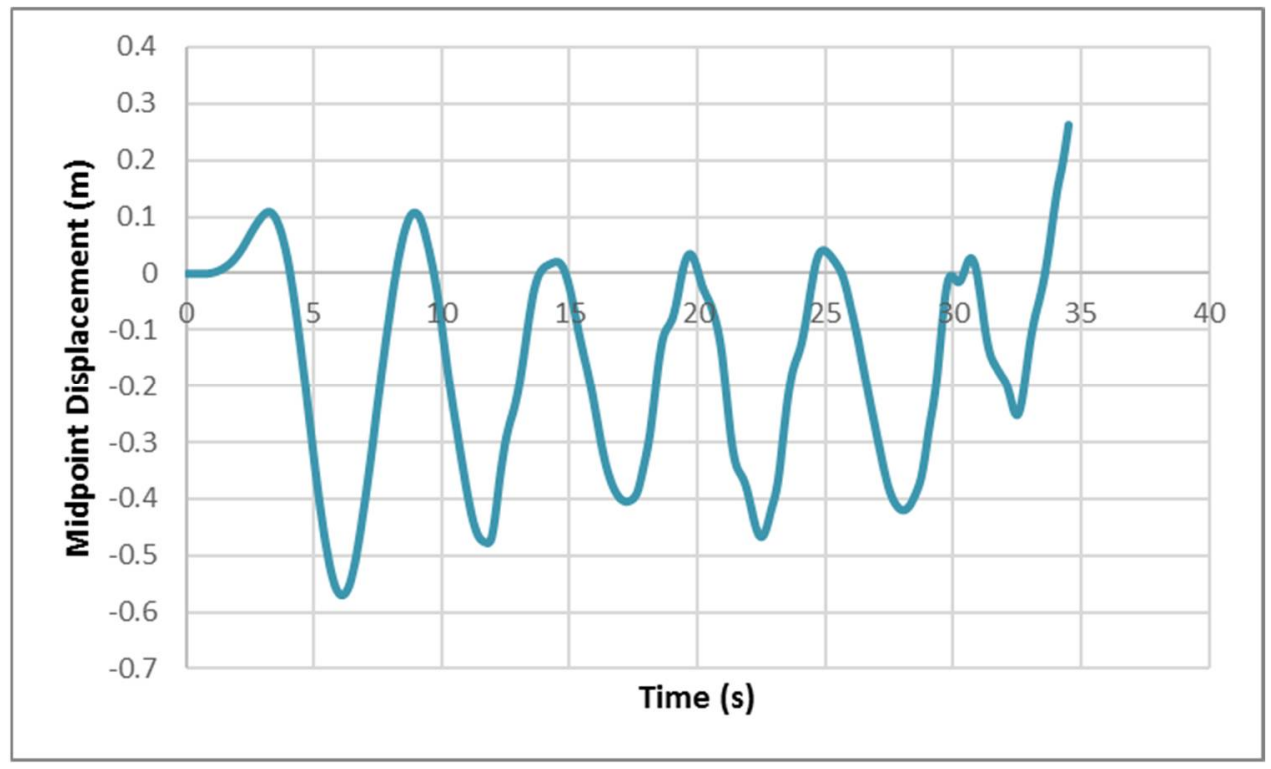

Figure 5-32: Bridge Midpoint displacement for 10 consecutive 50-ton vehicles at 35 $\mathrm{km} / \mathrm{hr}$ spaced at $21.1 \mathrm{~m}$ 


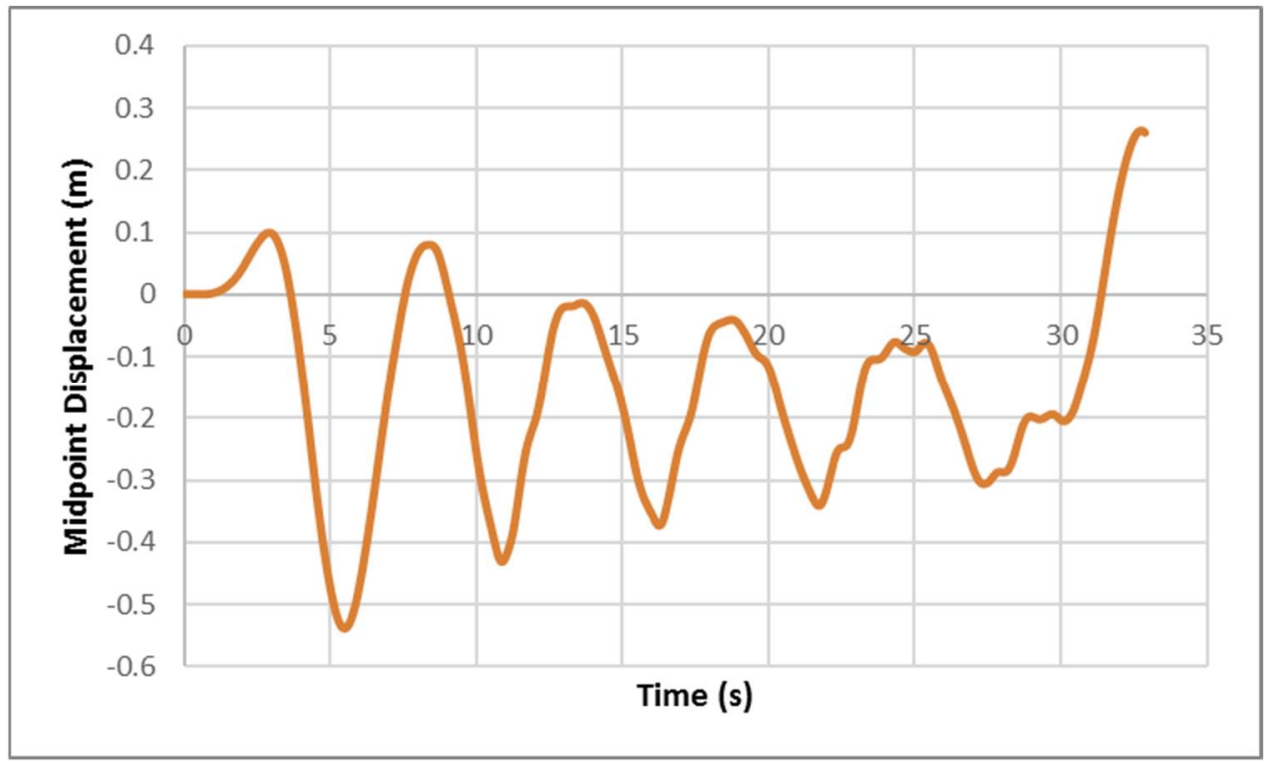

Figure 5-33: Bridge Midpoint displacement for 10 consecutive 50-ton vehicles at 40 $\mathrm{km} / \mathrm{hr}$ spaced at $24.5 \mathrm{~m}$

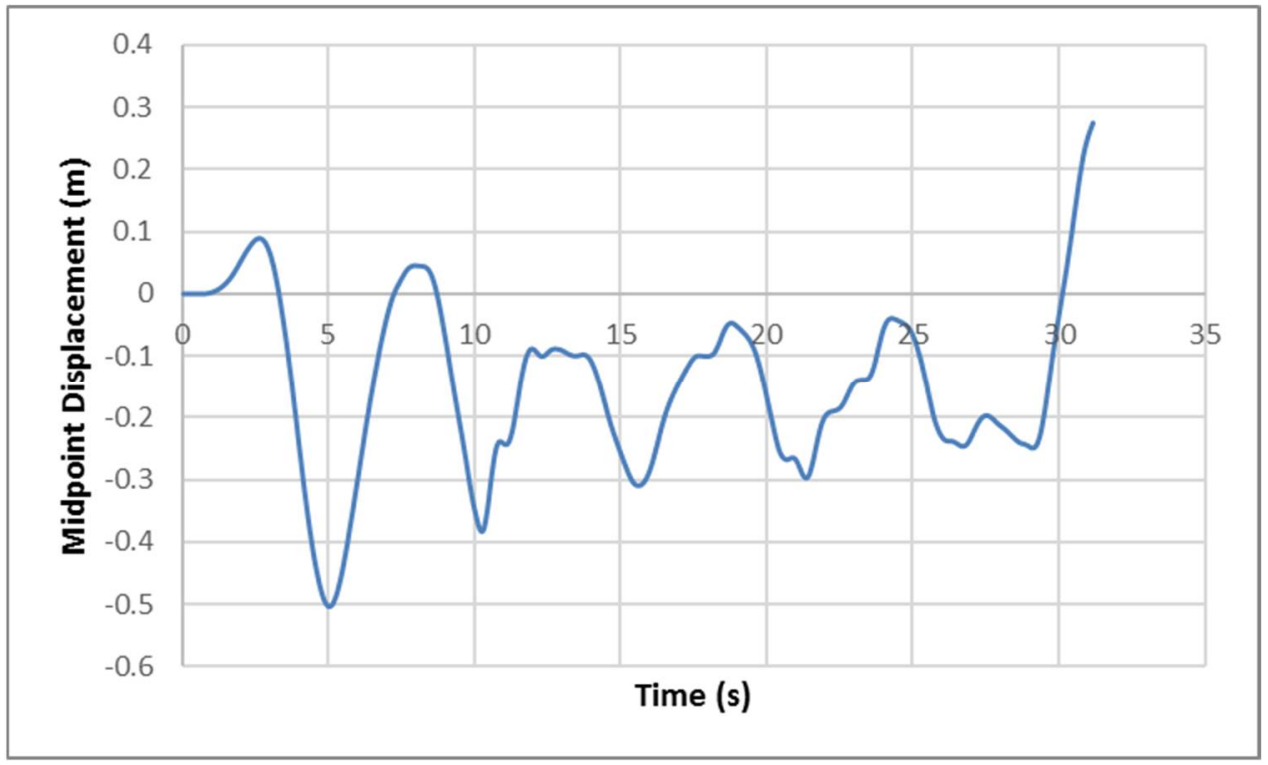

Figure 5-34: Bridge Midpoint displacement for 10 consecutive 50-ton vehicles at 45 $\mathrm{km} / \mathrm{hr}$ spaced at $27.2 \mathrm{~m}$ 


\section{Chapter: Conclusions and Recommendations for Future Work}

The thesis investigated the behaviour of hinge-connected ribbon pontoon floating bridges under two- and multi-vehicle crossing. The research work was follow on to the investigation by El-Desouky (2011) to numerically model the response of ribbon pontoon floating bridges under single- and double-axle vehicles and the experimental work of Viecili et al. $(2013,2014)$ to validate the numerical works by El-Desouky (2011). This current work included the modification and extension of a finite element analysis program developed by El-Desouky (2011) to include multi-vehicle crossing and the vehicle dynamics in terms of vehicle suspension characteristics and to extend the capability of the experimental works of Viecili et al. (2014) to test two-vehicle crossing of the ribbon pontoon floating bridges. The research investigation was also to optimize the inter-vehicle spacing in order to maximize the vehicle crossing capacity of the bridge.

\subsection{Conclusions}

The following are the main conclusions drawn from the preceding investigation.

- The bridge response under two-vehicle crossing shows two distinct maxima/ peaks in the vertical displacement versus time plots corresponding to the passage of each vehicle. The first peak in vertical displacement was found to be the same as that of a single vehicle if the inter-vehicle spacing is greater than about onehalf the bridge span. For smaller values of inter-vehicle spacing, the magnitude of the first peak displacement was reduced in comparison with the maximum displacement caused by a single vehicle. 
- The second peak in vertical displacement response of the floating bridge was dependent on the inter-vehicle spacing and vehicle speed, and its magnitude was affected by the bridge free vibration resulting from passage of the lead vehicle.

- The developed finite element program was used to simulate the effect of vehicles on a 4-pontoon, $84 \mathrm{~m}$ ribbon floating bridge. However, any length of bridge and number of vehicles can also be tested with the program.

- For the tested ribbon floating bridge of length $84 \mathrm{~m}$, the maximum vehicle weight was been increased to 86 ton at $15 \mathrm{~km} / \mathrm{hr}$ and 64 ton at $25 \mathrm{~km} / \mathrm{hr}$. Compared to the minimum prescribed inter-vehicle spacing of $30.5 \mathrm{~m}$ in the Trilateral Design and Test Code for Military Bridging and Gap-Crossing Equipment (2005), the reduced optimum inter-vehicle spacings of $12.9 \mathrm{~m}$ at $15 \mathrm{~km} / \mathrm{r}$ and $16 \mathrm{~m}$ at $25 \mathrm{~km} / \mathrm{h}$ represent massive increments in bridge vehicle-passing capacity of $236 \%$ and $90 \%$ respectively.

- The maximum midpoint displacement of the hinge-connected ribbon floating bridge varies linearly with vehicle weight, with the rate of increase being dependent on the speed ratio of the vehicle. Also, an analytical method was proposed for calculating the increase in maximum midpoint displacement with vehicle weight increase.

- Optimum inter-vehicle spacing is proposed for various vehicle speeds to maximize bridge vehicle passing capacity. Using the prescribed spacings, the maximum vehicle weights of 30 -ton have been increased to 64-ton and 76-ton at $25 \mathrm{~km} / \mathrm{hr}$ and $40 \mathrm{~km} / \mathrm{hr}$ respectively. 


\subsection{Recommendations for Future Work}

The experimental and numerical work undertaken in this thesis provides a basis for solving the displacements of ribbon pontoon floating bridges. However, the scope of the research was limited. The following recommendations for future work have been identified:

- In the current research, emphasis was placed on hinge-connected ribbon floating bridges. Rigid connections are also commonly used in ribbon floating bridges, which result in less bridge displacement. It is important to model these connections in the future to determine their effect on bridge response.

- The developed numerical program is limited to single-lane bridge traffic. The vehicles must travel at constant speed with no acceleration on the bridge. Two lane traffic and variable vehicle speed on the bridge should be investigated in the future.

- A major source of error between numerical and experimental results was the presence of significant water waves in the confined experimental tank, A larger experimental tank should be considered to ensure the dissipation of waves generated during bridge vibrations. 


\section{Appendices}

\section{Appendix A Experimental Results}

Table A1a: Experimental Program for $2.56 \mathrm{~kg}$

\begin{tabular}{|c|c|c|c|c|}
\hline $\begin{array}{c}\text { Vehicle } \\
\text { Weights } \\
\text { (tons)/(kg) } \\
\end{array}$ & $\begin{array}{l}\text { Vehicle } \\
\text { Spacing } \\
(\mathrm{m}) /(\mathrm{m})\end{array}$ & $\begin{array}{c}\text { Vehicle } \\
\text { Velocity } \\
(\mathrm{km} / \mathrm{hr}) /(\mathrm{m} / \mathrm{s})\end{array}$ & $\begin{array}{c}\text { Peak } 1 \\
\text { Displacement }(\mathrm{mm})\end{array}$ & $\begin{array}{c}\text { Peak } 2 \\
\text { Displacement }(\mathrm{mm})\end{array}$ \\
\hline \multirow{24}{*}{$40 / 2.56$} & \multirow{8}{*}{$40 / 1.6$} & $25 / 0.278$ & -26.43 & -26.80 \\
\hline & & $30 / 0.333$ & -24.55 & -27.46 \\
\hline & & 35/0.389 & -25.43 & -25.61 \\
\hline & & $40 / 0.444$ & -25.50 & -22.76 \\
\hline & & $45 / 0.500$ & -26.81 & -20.56 \\
\hline & & $50 / 0.556$ & -29.35 & -27.25 \\
\hline & & $55 / 0.611$ & -32.35 & -37.02 \\
\hline & & $60 / 0.667$ & -33.00 & -40.89 \\
\hline & \multirow{8}{*}{$35 / 1.4$} & $25 / 0.278$ & -27.38 & -28.25 \\
\hline & & $30 / 0.333$ & -25.31 & -26.83 \\
\hline & & $35 / 0.389$ & -26.24 & -24.59 \\
\hline & & $40 / 0.444$ & -25.32 & -21.44 \\
\hline & & $45 / 0.500$ & -26.95 & -27.85 \\
\hline & & $50 / 0.556$ & -29.80 & -36.80 \\
\hline & & $55 / 0.611$ & -32.45 & -40.71 \\
\hline & & $60 / 0.667$ & -34.38 & -44.46 \\
\hline & \multirow{8}{*}{$30 / 1.2$} & $25 / 0.278$ & -27.30 & -25.37 \\
\hline & & $30 / 0.333$ & -25.69 & -24.05 \\
\hline & & $35 / 0.389$ & -25.65 & -21.97 \\
\hline & & $40 / 0.444$ & -25.32 & -29.04 \\
\hline & & $45 / 0.500$ & -27.49 & -37.96 \\
\hline & & $50 / 0.556$ & -30.79 & -39.44 \\
\hline & & $55 / 0.611$ & -32.86 & -39.42 \\
\hline & & $60 / 0.667$ & -33.31 & -34.38 \\
\hline
\end{tabular}


Table A1b: Experimental Program for $2.56 \mathrm{~kg}$ (cont.)

\begin{tabular}{|c|c|c|c|c|}
\hline $\begin{array}{c}\text { Vehicle } \\
\text { Weights } \\
\text { (tons)/(kg) }\end{array}$ & $\begin{array}{l}\text { Vehicle } \\
\text { Spacing } \\
(\mathrm{m}) /(\mathrm{m})\end{array}$ & $\begin{array}{c}\text { Vehicle } \\
\text { Velocity } \\
(\mathrm{km} / \mathrm{hr}) /(\mathrm{m} / \mathrm{s})\end{array}$ & $\begin{array}{c}\text { Peak } 1 \\
\text { Displacement }(\mathrm{mm})\end{array}$ & $\begin{array}{c}\text { Peak } 2 \\
\text { Displacement }(\mathrm{mm})\end{array}$ \\
\hline \multirow{32}{*}{$40 / 2.56$} & \multirow{8}{*}{$25 / 1.0$} & $25 / 0.278$ & -26.18 & -29.41 \\
\hline & & $30 / 0.333$ & -25.43 & -24.26 \\
\hline & & $35 / 0.389$ & -25.81 & -27.45 \\
\hline & & $40 / 0.444$ & -23.30 & -27.04 \\
\hline & & $45 / 0.500$ & -28.48 & -34.80 \\
\hline & & $50 / 0.556$ & -30.62 & -32.01 \\
\hline & & $55 / 0.611$ & -32.71 & -30.48 \\
\hline & & $60 / 0.667$ & -34.54 & -38.73 \\
\hline & \multirow{8}{*}{$20 / 0.8$} & $25 / 0.278$ & -23.29 & -23.71 \\
\hline & & $30 / 0.333$ & -23.55 & -23.32 \\
\hline & & $35 / 0.389$ & -23.12 & -27.81 \\
\hline & & $40 / 0.444$ & -23.19 & -27.35 \\
\hline & & $45 / 0.500$ & -25.36 & -24.85 \\
\hline & & $50 / 0.556$ & -28.44 & -27.93 \\
\hline & & $55 / 0.611$ & -29.65 & -33.12 \\
\hline & & $60 / 0.667$ & -30.80 & -33.59 \\
\hline & \multirow{8}{*}{$15 / 0.6$} & $25 / 0.278$ & -19.80 & -22.95 \\
\hline & & $30 / 0.333$ & -18.05 & -20.49 \\
\hline & & $35 / 0.389$ & -16.09 & -19.03 \\
\hline & & $40 / 0.444$ & -18.43 & -17.31 \\
\hline & & $45 / 0.500$ & -20.73 & -17.83 \\
\hline & & $50 / 0.556$ & -21.79 & -23.10 \\
\hline & & $55 / 0.611$ & -23.67 & -24.58 \\
\hline & & $60 / 0.667$ & -24.45 & -26.58 \\
\hline & \multirow{8}{*}{$10 / 0.4$} & $25 / 0.278$ & -20.77 & -21.18 \\
\hline & & $30 / 0.333$ & -20.74 & -18.59 \\
\hline & & $35 / 0.389$ & -15.20 & -21.76 \\
\hline & & $40 / 0.444$ & -17.35 & -22.12 \\
\hline & & $45 / 0.500$ & -19.82 & -21.34 \\
\hline & & $50 / 0.556$ & -19.80 & -20.78 \\
\hline & & $55 / 0.611$ & -21.45 & -21.29 \\
\hline & & $60 / 0.667$ & -23.47 & -21.37 \\
\hline
\end{tabular}


Table A2: Experimental Program for $2.88 \mathrm{~kg}$ and $3.20 \mathrm{~kg}$

\begin{tabular}{|c|c|c|c|c|}
\hline $\begin{array}{c}\text { Vehicle } \\
\text { Weights } \\
\text { (tons)/(kg) } \\
\end{array}$ & $\begin{array}{l}\text { Vehicle } \\
\text { Spacing } \\
(\mathrm{m}) /(\mathrm{m})\end{array}$ & $\begin{array}{c}\text { Vehicle } \\
\text { Velocity } \\
(\mathrm{km} / \mathrm{hr}) /(\mathrm{m} / \mathrm{s}) \\
\end{array}$ & $\begin{array}{c}\text { Peak } 1 \\
\text { Displacement (mm) }\end{array}$ & $\begin{array}{c}\text { Peak } 2 \\
\text { Displacement }(\mathrm{mm})\end{array}$ \\
\hline \multirow{12}{*}{$45 / 2.88$} & \multirow{3}{*}{$40 / 1.6$} & $25 / 0.278$ & -29.56 & -31.01 \\
\hline & & $40 / 0.444$ & -29.93 & -26.34 \\
\hline & & $60 / 0.666$ & -37.38 & -43.86 \\
\hline & \multirow{3}{*}{$30 / 1.2$} & $25 / 0.278$ & -29.35 & -28.12 \\
\hline & & $40 / 0.444$ & -29.09 & -35.72 \\
\hline & & $60 / 0.666$ & -39.14 & -41.23 \\
\hline & \multirow{3}{*}{$25 / 1.0$} & $25 / 0.278$ & -28.87 & -32.89 \\
\hline & & $40 / 0.444$ & -29.44 & -37.03 \\
\hline & & $60 / 0.666$ & -38.92 & -42.37 \\
\hline & \multirow{3}{*}{$20 / 0.8$} & $25 / 0.278$ & -25.27 & -27.14 \\
\hline & & $40 / 0.444$ & -25.65 & -29.57 \\
\hline & & $60 / 0.666$ & -33.16 & -37.12 \\
\hline \multirow{12}{*}{$50 / 3.20$} & \multirow{3}{*}{$40 / 1.6$} & $25 / 0.278$ & -33.61 & -34.97 \\
\hline & & $40 / 0.444$ & -31.39 & -27.40 \\
\hline & & $60 / 0.666$ & -38.35 & -54.45 \\
\hline & \multirow{3}{*}{$30 / 1.2$} & $25 / 0.278$ & -33.04 & -30.52 \\
\hline & & $40 / 0.444$ & -30.43 & -36.71 \\
\hline & & $60 / 0.666$ & -42.31 & -43.33 \\
\hline & \multirow{3}{*}{$25 / 1.0$} & $25 / 0.278$ & -32.73 & -36.64 \\
\hline & & $40 / 0.444$ & -31.71 & -44.33 \\
\hline & & $60 / 0.666$ & -40.60 & -49.28 \\
\hline & \multirow{3}{*}{$20 / 0.8$} & $25 / 0.278$ & -28.07 & -29.56 \\
\hline & & $40 / 0.444$ & -30.28 & -34.36 \\
\hline & & $60 / 0.666$ & -37.29 & -38.77 \\
\hline
\end{tabular}


Table A2: Maximum Midpoint Displacements for two 2.88-kg Vehicles spaced at $1.6 \mathrm{~m}$, $1.2 \mathrm{~m}, 1.0 \mathrm{~m}, 0.8 \mathrm{~m}$

\begin{tabular}{|c|c|c|c|c|c|}
\hline $\begin{array}{c}\text { Vehicle } \\
\text { Speed }(\mathrm{m} / \mathrm{s})\end{array}$ & $\begin{array}{c}\text { Peak } 1 \\
\text { Deflection }(\mathrm{mm})\end{array}$ & $\begin{array}{c}\text { Peak } 2 \\
\text { Deflection }(\mathrm{mm})\end{array}$ & $\begin{array}{l}\text { Single Vehicle } \\
\text { Peak (mm) }\end{array}$ & \multirow[t]{2}{*}{$\beta_{1}$} & \multirow[t]{2}{*}{$\beta_{2}$} \\
\hline \multicolumn{4}{|c|}{$2.88-\mathrm{kg}, 1.6 \mathrm{~m}$} & & \\
\hline 0.278 & -29.56 & -31.01 & -29.48 & 1.00 & 1.05 \\
\hline 0.444 & -29.93 & -26.34 & -28.51 & 1.05 & 0.92 \\
\hline 0.666 & -37.38 & -43.86 & -35.95 & 1.04 & 1.22 \\
\hline \multicolumn{4}{|c|}{ 2.88-kg, $1.2 \mathrm{~m}$} & & \\
\hline 0.278 & -29.35 & -28.12 & -29.48 & 1.00 & 0.95 \\
\hline 0.444 & -29.09 & -35.72 & -28.51 & 1.02 & 1.25 \\
\hline 0.666 & -39.14 & -41.23 & -35.95 & 1.09 & 1.15 \\
\hline \multicolumn{4}{|c|}{ 2.88-kg, $1.0 \mathrm{~m}$} & & \\
\hline 0.278 & -28.87 & -32.89 & -29.48 & 0.98 & 1.12 \\
\hline 0.444 & -29.44 & -37.03 & -28.51 & 1.03 & 1.30 \\
\hline 0.666 & -38.92 & -42.37 & -35.95 & 1.08 & 1.18 \\
\hline \multicolumn{4}{|c|}{ 2.88-kg, $0.8 \mathrm{~m}$} & & \\
\hline 0.278 & -25.27 & -27.14 & -29.48 & 0.86 & 0.92 \\
\hline 0.444 & -25.65 & -29.57 & -28.51 & 0.90 & 1.04 \\
\hline 0.666 & -33.16 & -37.12 & -35.95 & 0.92 & 1.03 \\
\hline
\end{tabular}


Table A3: Maximum Midpoint Displacements for two 3.20-kg Vehicles spaced at $1.6 \mathrm{~m}$, $1.2 \mathrm{~m}, 1.0 \mathrm{~m}, 0.8 \mathrm{~m}$

\begin{tabular}{|c|c|c|c|c|c|}
\hline $\begin{array}{c}\text { Vehicle } \\
\operatorname{Speed}(\mathrm{m} / \mathrm{s})\end{array}$ & $\begin{array}{c}\text { Peak } 1 \\
\text { Deflection }(\mathbf{m m})\end{array}$ & $\begin{array}{c}\text { Peak } 2 \\
\text { Deflection }(\mathrm{mm})\end{array}$ & $\begin{array}{c}\text { Single Vehicle } \\
\text { Peak }(\mathrm{mm})\end{array}$ & & \\
\hline \multicolumn{4}{|c|}{$3.20-\mathrm{kg}, 1.6 \mathrm{~m}$} & & \\
\hline 0.278 & -33.61 & -34.97 & -32.13 & 1.05 & 1.09 \\
\hline 0.444 & -31.39 & -27.40 & -30.96 & 1.01 & 0.88 \\
\hline 0.666 & -38.35 & -54.45 & -41.40 & 0.93 & 1.32 \\
\hline \multicolumn{4}{|c|}{$3.20-\mathrm{kg}, 1.2 \mathrm{~m}$} & & \\
\hline 0.278 & -33.04 & -30.52 & -32.13 & 1.03 & 0.95 \\
\hline 0.444 & -30.43 & -36.71 & -30.96 & 0.98 & 1.19 \\
\hline 0.666 & -42.31 & -43.33 & -41.40 & 1.02 & 1.05 \\
\hline \multicolumn{4}{|c|}{$3.20-\mathrm{kg}, 1.0 \mathrm{~m}$} & & \\
\hline 0.278 & -32.73 & -36.64 & -32.13 & 1.02 & 1.14 \\
\hline 0.444 & -31.71 & -44.33 & -30.96 & 1.02 & 1.43 \\
\hline 0.666 & -40.60 & -49.28 & -41.40 & 0.98 & 1.19 \\
\hline \multicolumn{4}{|c|}{$3.20-\mathrm{kg}, 0.8 \mathrm{~m}$} & & \\
\hline 0.278 & -28.07 & -29.56 & -32.13 & 0.87 & 0.92 \\
\hline 0.444 & -30.28 & -34.36 & -30.96 & 0.98 & 1.11 \\
\hline 0.666 & -37.29 & -38.77 & -41.40 & 0.90 & 0.94 \\
\hline
\end{tabular}


Appendix B Bridge Prototype Details

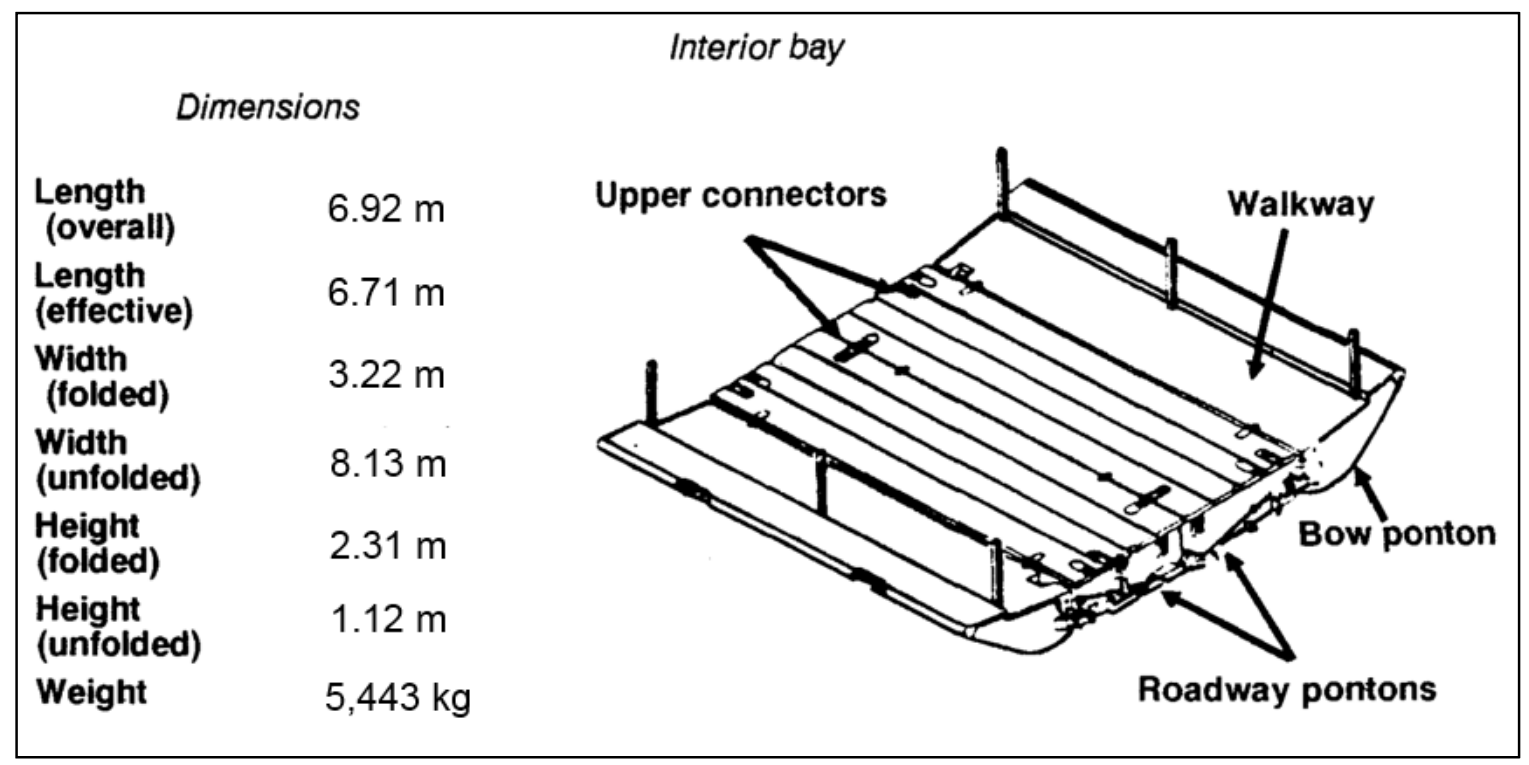

Figure B1: Interior Bay Pontoon

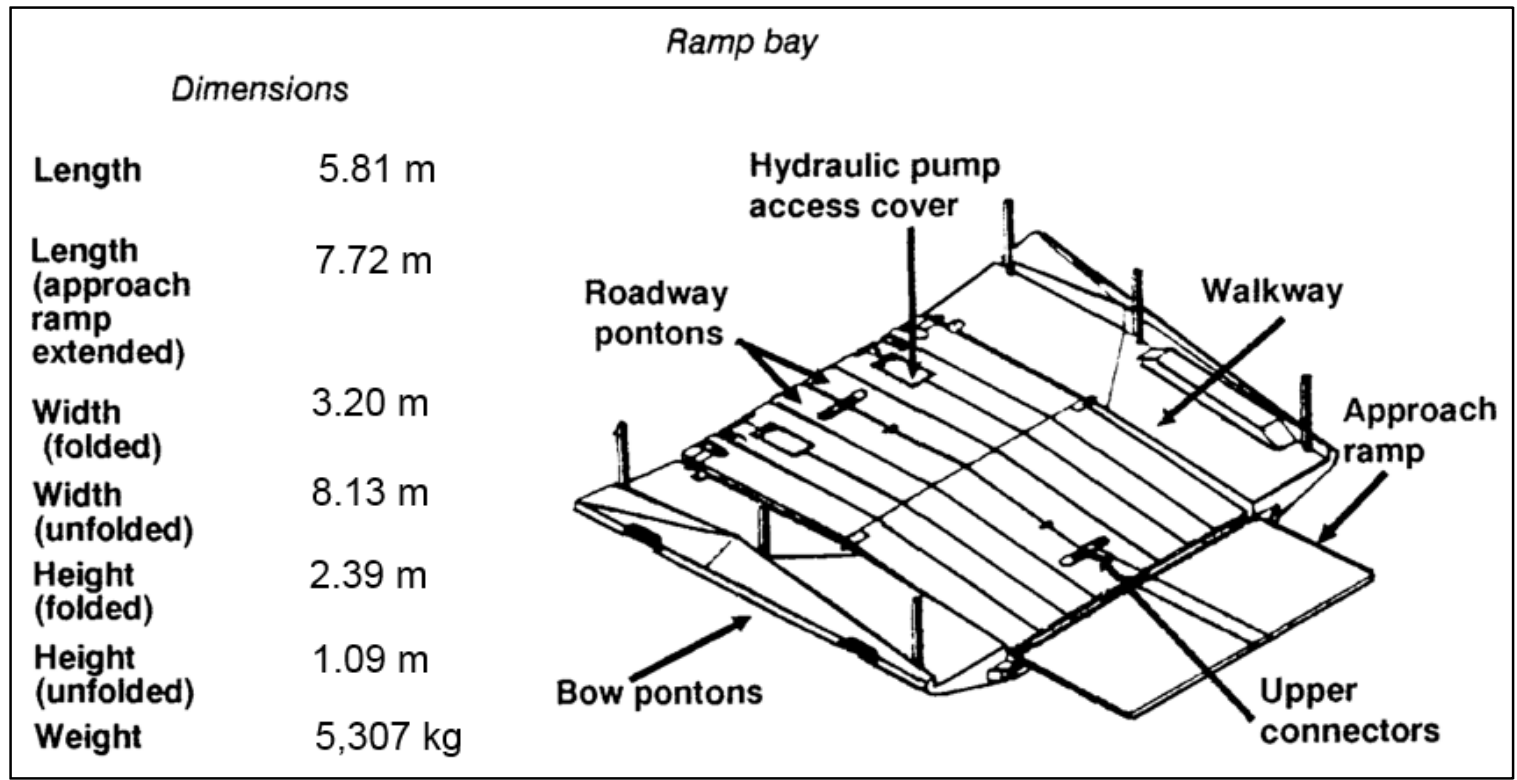

Figure B2: Ramp Bay Pontoon 


\section{Appendix C Numerical vs Experimental Results for $2.88 \mathrm{~kg}$ and $3.20 \mathrm{~kg}$}

Table C1: Numerical vs Experimental Results for 2.88-kg

\begin{tabular}{|c|c|c|c|c|c|c|}
\hline Velocity (m/s) & \multicolumn{2}{|c|}{ Experimental } & \multicolumn{2}{|c|}{ Numerical } & \multirow{2}{*}{\multicolumn{2}{|c|}{$\begin{array}{c}\text { Percentage } \\
\text { Difference (\%) }\end{array}$}} \\
\hline \multicolumn{5}{|c|}{$2.88-\mathrm{kg}, 1.4 \mathrm{~m}$} & & \\
\hline & Peak 1 & Peak 2 & Peak 1 & Peak 2 & Peak 1 & Peak 2 \\
\hline 0.278 & -29.56 & -31.01 & -20.61 & -19.88 & -30.26 & -35.89 \\
\hline 0.444 & -29.93 & -26.34 & -24.97 & -28.01 & -16.55 & 6.35 \\
\hline 0.667 & -37.38 & -43.86 & -35.04 & -38.07 & -6.28 & -13.21 \\
\hline \multicolumn{7}{|c|}{$2.88-\mathrm{kg}, 1.2 \mathrm{~m}$} \\
\hline 0.278 & -29.35 & -28.12 & -20.61 & -20.23 & -29.79 & -28.04 \\
\hline 0.444 & -29.09 & -35.72 & -24.97 & -24.94 & -14.15 & -30.19 \\
\hline 0.667 & -39.14 & -41.23 & -35.04 & -35.60 & -10.49 & -13.67 \\
\hline \multicolumn{7}{|c|}{$2.88-\mathrm{kg}, 1.0 \mathrm{~m}$} \\
\hline 0.278 & -28.87 & -32.89 & -20.61 & -21.03 & -28.59 & -36.06 \\
\hline 0.444 & -29.44 & -37.03 & -24.97 & -27.95 & -15.17 & -24.53 \\
\hline 0.667 & -38.92 & -42.37 & -35.02 & -52.26 & -10.04 & 23.32 \\
\hline \multicolumn{7}{|c|}{$2.88-k g, 0.8 \mathrm{~m}$} \\
\hline 0.278 & -25.27 & -27.14 & -20.29 & -21.38 & -19.69 & -21.24 \\
\hline 0.444 & -25.65 & -29.57 & -24.84 & -24.99 & -3.14 & -15.48 \\
\hline 0.667 & -33.16 & -37.12 & -34.47 & -53.80 & 3.96 & 44.93 \\
\hline \multicolumn{5}{|c|}{ Absolute Average Percentage Difference (\%) } & 15.68 & 24.41 \\
\hline
\end{tabular}


Table C2: Numerical vs Experimental Results for $3.20-\mathrm{kg}$

\begin{tabular}{|c|c|c|c|c|c|c|}
\hline Velocity $(\mathrm{m} / \mathrm{s})$ & Experim & ntal & Numerical & & \multirow{2}{*}{\multicolumn{2}{|c|}{$\begin{array}{c}\text { Percentage } \\
\text { Difference (\%) }\end{array}$}} \\
\hline \multicolumn{5}{|c|}{$3.20-\mathrm{kg}, 1.4 \mathrm{~m}$} & & \\
\hline & Peak 1 & Peak 2 & Peak 1 & Peak 2 & Peak 1 & Peak 2 \\
\hline 0.278 & -33.61 & -34.97 & -22.93 & -22.12 & -31.79 & -36.76 \\
\hline 0.444 & -31.39 & -27.40 & -27.79 & -31.26 & -11.48 & 14.10 \\
\hline 0.667 & -38.35 & -54.45 & -38.94 & -42.37 & 1.53 & -22.19 \\
\hline \multicolumn{7}{|c|}{$3.2-\mathrm{kg}, 1.2 \mathrm{~m}$} \\
\hline 0.278 & -33.04 & -30.52 & -22.93 & -22.52 & -30.59 & -26.23 \\
\hline 0.444 & -30.43 & -36.71 & -27.79 & -27.79 & -8.69 & -24.30 \\
\hline 0.667 & -42.31 & -43.33 & -38.94 & -39.62 & -7.98 & -8.58 \\
\hline \multicolumn{7}{|c|}{$3.2-\mathrm{kg}, 1.0 \mathrm{~m}$} \\
\hline 0.278 & -32.73 & -36.64 & -22.93 & -23.37 & -29.95 & -36.21 \\
\hline 0.444 & -31.71 & -44.33 & -27.79 & -31.22 & -12.37 & -29.57 \\
\hline 0.667 & -40.60 & -49.28 & -38.92 & -58.19 & -4.15 & 18.07 \\
\hline \multicolumn{7}{|c|}{$3.2-\mathrm{kg}, 0.8 \mathrm{~kg}$} \\
\hline 0.278 & -28.07 & -29.56 & -22.57 & -23.80 & -19.60 & -19.47 \\
\hline 0.444 & -30.28 & -34.36 & -27.64 & -27.76 & -8.72 & -19.20 \\
\hline 0.667 & -37.29 & -38.77 & -38.56 & -60.01 & 3.42 & 54.79 \\
\hline \multicolumn{5}{|c|}{ Absolute Average Percentage Difference (\%) } & 14.19 & 25.79 \\
\hline
\end{tabular}




\section{References}

Anderson, R. (2000). US Army in World War II, Engineers and Logistics. Retrieved from http://www.militaryhistoryonline.com/wwii/usarmy/engineers.aspx

Bailkey, N., \& Richard, L. (1992). Readings in Ancient History. D.C. Heath and Co.

Barker, R. M., \& Puckett, J. A. (2013). Design of Highway Bridges: An LRFD Approach: Third Edition. Design of Highway Bridges: An LRFD Approach: Third Edition. https://doi.org/10.1002/9781118411124

Chen, S. S., \& Chung, H. (1976). Design Guide for Calculating Hydrodynamic Mass. Part I. Circular Cylindrical Structures.

Department, U. S. W. (1942). Handbook on the British Army.

El-Desouky, O. (2011). Dynamic Behaviour of Short-Term Floating Bridges. Carleton University.

Ertekin, R. C., Riggs, H. R., Kim, J. W., \& Demirbilek, Z. (2001). Hydroelastic Analysis of Floating Bridges in Current. Conference on Ocean, Offshore \& Arctic Engineering.

Fleischer, D., \& Park, S. K. (2004). Plane hydroelastic beam vibrations due to uniformly moving one axle vehicle. Journal of Sound and Vibration, 273(3), 585-606. https://doi.org/10.1016/S0022-460X(03)00518-2

Fu, S., \& Cui, W. (2012). Dynamic responses of a ribbon floating bridge under moving loads. Marine Structures, 29(1), 246-256. https://doi.org/10.1016/j.marstruc.2012.06.004

Georgiadis, C. (1985). Finite Element Modeling of the Response of Long Floating Structures Under Harmonic Excitation. Journal of Energy Resources Technology, 
107(1), 48. https://doi.org/10.1115/1.3231162

Green, M. F., Cebon, D., \& Cole, D. J. (1995). Effects of Vehicle Suspension Design on Dynamics of Highway Bridges. Journal of Structural Engineering, 121(2), 272-282. https://doi.org/10.1061/(ASCE)0733-9445(1995)121:2(272)

Harre, W. (2002). Experimental Realisation of a Pretentious Testing Task on the Field of Pioneer Bridge Structures. Otto-Graf-Journal, 13.

, B., Kluck, J., \& Connor, R. Trilateral Design and Test Code for Military Bridging and Gap-Crossing Equipment (2005).

Humar, J. (2002). Dynamics of Structures (2nd ed.).

Humar, J. L., \& Kashif, A. M. (1993). Dynamic response of bridges under travelling loads. Canadian Journal of Civil Engineering, 20(2), 287-298. https://doi.org/10.1139/193-033

Logan, D. L., Veitch, E., Carson, C., Burrell, K. R., Gould, V., Wagner, E., ... Wagner, E. (2007). A First Course in the Finite Element Method Fourth Edition. Transport (Vol. 147). https://doi.org/10.1016/0022-460X(91)90505-E

Needham, J. (1994). The Shorter Science and Civilisation in China. Cambridge University Press (Vol. 4). https://doi.org/10.1179/030801880789767585

Neves, S. G. M., Azevedo, A. F. M., \& Calçada, R. (2012). A direct method for analyzing the vertical vehicle-structure interaction. Engineering Structures, 34, 414420. https://doi.org/10.1016/j.engstruct.2011.10.010

Nguyen, T. P., \& Pham, D. T. (2016). A contact element for dynamic analysis of beams to a moving oscillator on tensionless elastic foundation. International Journal of Advanced Structural Engineering, 8(4), 351-361. https://doi.org/10.1007/s40091- 
016-0135-8

Raftoyiannis, I. G., Avraam, T. P., \& Michaltsos, G. T. (2014). Analytical models of floating bridges under moving loads. Engineering Structures, 68, 144-154. https://doi.org/10.1016/j.engstruct.2014.03.002

Seif, M., \& Inoue, Y. (1998). Dynamic analysis of floating bridges. Marine Structures, 11(1-2 /2), 29-46. https://doi.org/http://dx.doi.org/10.1016/S0951-8339(97)00012-9

Seif, M. S., \& Koulaei, R. T. P. (2005). Floating Bridge Modeling and Analysis. Scientia Iranica.

Study Group of World Cities. (1998).

Thambiratnam, D., \& Zhuge, Y. (1996). Dynamic Analysis of Beams on an Elastic Foundation Subjected To Moving Loads. Journal of Sound and Vibration, 198(2), 149-169. https://doi.org/10.1006/jsvi.1996.0562

Viecili, G., Braimah, A., Abd El Halim, A., \& El-Desouky, O. (2013). Dynamic Behavior of Ribbon Floating Bridges. Transportation Research Record: Journal of the Transportation Research Board, 2331, 35-44. https://doi.org/10.3141/2331-04

Viecili, G., El Halim, A. E. H. O. A., Braimah, A., \& El-Desouky, O. (2014). Transportation optimization of ribbon floating bridges: Analytical and experimental investigation. Open Civil Engineering Journal, 8(1). https://doi.org/10.2174/1874149501408010042

Watanabe, E., \& Utsunomiya, T. (2003). Analysis and design of floating bridges. Progress in Structural Engineering and Materials, 5(3), 127-144. https://doi.org/10.1002/pse.151 Wu, J.-S., \& Sheu, J.-J. (1996). An exact solution for a simplified model of the heave and 
pitch motions of a ship hull due to a moving load and a comparison with some experimental results. Journal of Sound and Vibration, 192(2), 495-520.

https://doi.org/10.1006/jsvi.1996.0200

Wu, J.-S., \& Shih, P.-Y. (1998). Moving-load-induced vibrations of a moored floating bridge. Computers \& Structures, 66(4), 435-461.

https://doi.org/http://dx.doi.org/10.1016/S0045-7949(97)00072-2

Yener, M., \& Chompooming, K. (1994). Numerical method of lines for analysis of vehicle-bridge dynamic interaction. Computers and Structures, 53(3), 709-726. https://doi.org/10.1016/0045-7949(94)90113-9

Zhang, J., Liu, J., Xiao-lu, N., Li, W., \& Mu, R. (2010). Dynamic Model of a DiscretePontoon Floating Bridge subjected to Moving Loads. Applied Mechanics and Materials.

Zhang, J., Miao, G. ping, Liu, J. xun, \& Sun, W. jun. (2008). Analytical Models of Floating Bridges Subjected by Moving Loads for Different Water Depths. Journal of Hydrodynamics, 20(5), 537-546. https://doi.org/10.1016/S1001-6058(08)60092-X 